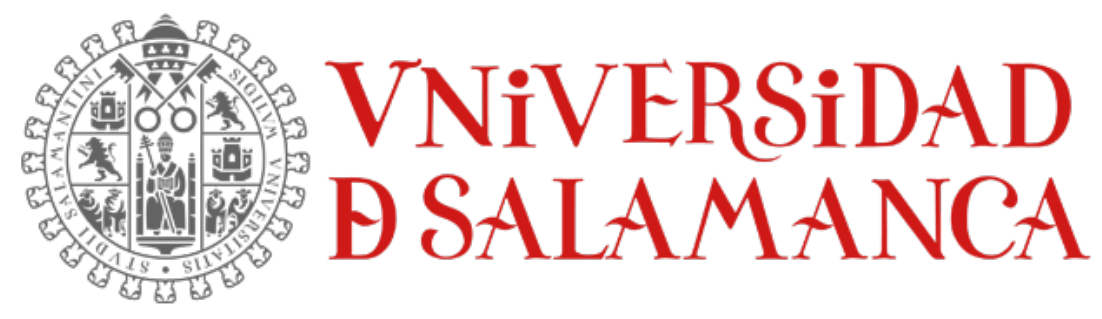

Doctoral Dissertation

Discourse Analysis and ADHD in the English as a Second Language teaching context.

Sandra Moro Ramos

Departamento de Filología Inglesa 


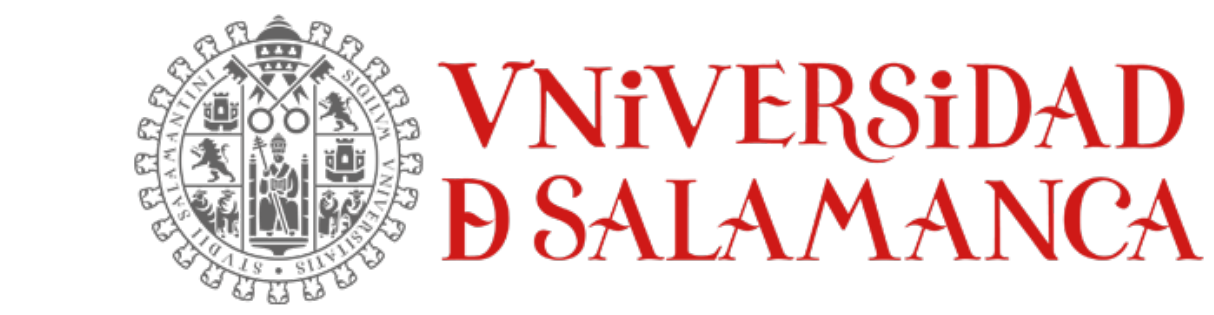

Discourse Analysis and ADHD in the English as a Second Language teaching context

This thesis is submitted in partial fulfillment of the requirements for the degree of PhD in Advanced English Studies: Languages and Cultures in Contact 



\section{Acknowledgements and justification}

This thesis is the outcome of many years of teaching, studying and investigating. I decided to turn the difficulties I encountered during my experience as a teacher into a challenging and open-source project for other teachers. ADD/ADHD (Attention Deficit Disorder) is a very popular disorder at present, but a few years ago it was very difficult to find articles related to ADHD and language acquisition. Interestingly, the majority of the available research concerned behavioural and social problems, and few studies regarding methods or activities to deal with academic difficulties correlated to ADHD could be found. And most of the posted papers about ADHD and teaching or learning were about literacy or Maths skills. Therefore, I started to read and investigate with the only purpose to help my students. As I could only find a handful resources about teaching a foreign language to ADHD pupils, I decided to compile the drafts of my investigation and teaching practice.

These drafts include notes about discourse analysis, as teaching is based and aims for communication; language acquisition and ESL (English as a Second Language) as my field of work is teaching English as a second language; ADHD, as when I started to inquire about this project ADHD was an emerging concept in the schools in Spain and precious few studies about it were available; and a collection of games and activities I have performed during my English lessons over the years and find helpful to teach ESL to ADHD children in inclusive classrooms, where a wide range of students are supposed to learn a second language, no matter the number of students or the personal characteristics they may have or encounter in their way.

The only purpose of this thesis is to examine and improve my knowledge and my teaching methodologies and practice. It is not offered as a model of good teaching, but as an analysis of my own pedagogy.

Nevertheless, I thank all my past and years to come students, for they are my motor and inspiration. Being a teacher is a challenging and rewarding profession. One of the most important lessons I have learned as a teacher is that children are also great teachers, for they teach adults many lessons too. They cheer us up and see rainbows when adults sometimes just see cloudy skies. There is not only one way of teaching. There is not only one proper answer. And as Ignacio Estrada once quoted, "if a child cannot learn the way we teach, maybe we should teach the way they learn”.

I wish to thank the school where I work, for giving me the opportunity to enjoy my job. 
I would particularly like to thank Pilar Alonso, my mentor and $\mathrm{PhD}$ director, for her scientific and methodologic rigour, and for offering me her strong support, guidance and praiseworthy help. Her admirable patience, and her kind and loving words and manners have eased me during difficult moments and enhanced me to keep working. I am very much indebted to her.

Finally and especial thanks are to my family, in particular to my son, who gave me the strength and confidence to finish this project.

And last, but not least, I want to dedicate this project to all those children with ADHD, and to their parents. When difficulties arise, just remember Gandhi's words: "Strength does not come from physical capacity, it comes from an indomitable will”. 



\begin{abstract}
This thesis analyses the teaching practice of an English as a second language teacher in a Primary School. The aim of this inquiry is to revise the pedagogy used during the teaching practice regarding attention to diversity, more specifically about ADHD, and the elaboration of a proper plan to teach English to ADHD as a foreign language in inclusive classes. The study shows how to address the needs of ADHD children while they learn English as a second language under a discourse analysis scope. A large proportion of published material about the matter of study shows how to cope with the difficulties of ADHD individuals in the basic areas, literacy and Mathematics. The majority of these studies and research literature are based on the teaching of subjects in the L1 of students, that is, using their mother tongue. Teaching a second language to ADHD students is starting to gain importance in the field of language acquisition. The present thesis is a compilation of strategies, games and activities to make language learning possible and fun for hyperkinetic children.
\end{abstract}

Under a desk research scope, discourse analysis, language acquisition and ESL (English as a Second Language), as well as ADHD have been studied and discussed to outline a realistic model in the paradigm of teaching and learning English as a second language with ADHD students in inclusive classrooms. These issues have been tackled over several sections. The teaching of second languages and an approximation of the definition of discourse analysis conform the theoretical framework on section four. A deeper investigation about discourse analysis can be found in section five, as a basis to the teaching of languages. An approach to the concept of ADHD is submitted in section six, while further explanations about the matter and considerations for teachers are to be found in section seven. Besides that, section eight shows a compilation of different techniques, implementations and activities suggested to teach ESL with ADHD students in inclusive classes. Finally, a case intervention is presented in section nine. Additionally, this thesis also presents two cognitive training self-instruction models for children, with and without ADHD, for oral and written activities in ESL. 



\section{Index}

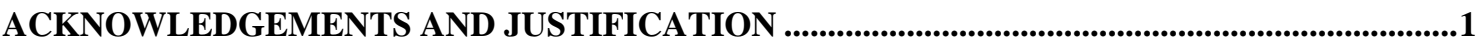

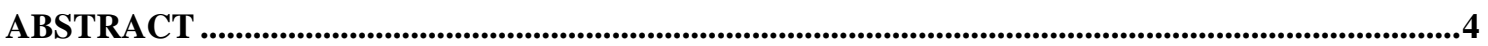

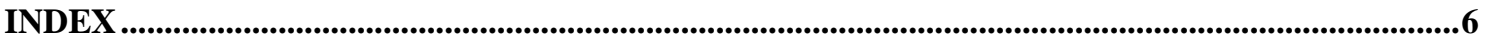

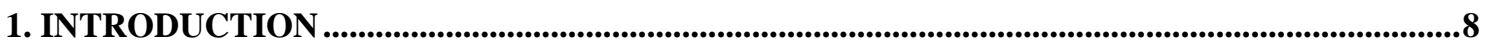

2. WORK HYPOTHESIS AND MAIN OBJECTIVES TO ACHIEVE ...............................................13

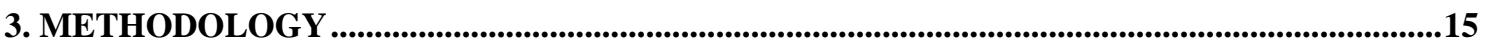

4. THEORETICAL FRAMEWORK..........................................................................................................17

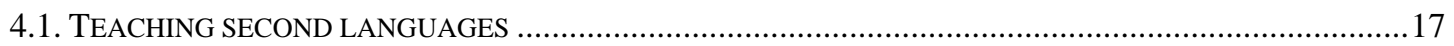

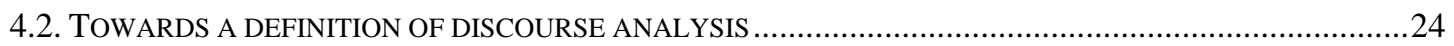

5. A DISCOURSE ANALYSIS BASED APPROACH TO THE TEACHING OF LANGUAGES...32

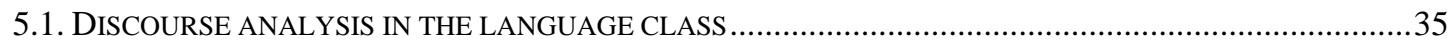

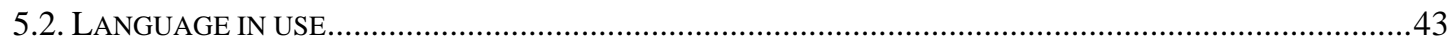

5.3. ESL ACTIVITIES IN WHICH DISCOURSE ANALYSIS IS EXERCISED ..........................................................5

5.3.1. Activities related to written comprehension..............................................................................53

5.3.2. Activities related to oral comprehension ................................................................................6

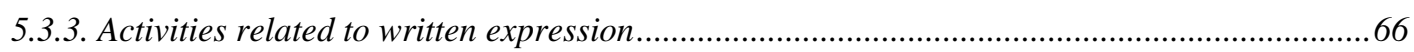

5.3.4. Activities related to oral expression ………………............................................................

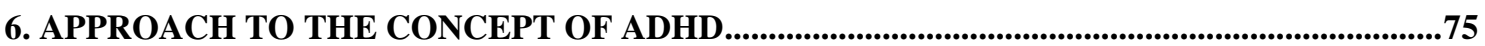

6.1. ASSESSMENT AND DIAGNOSIS ………………………………………………………………....79

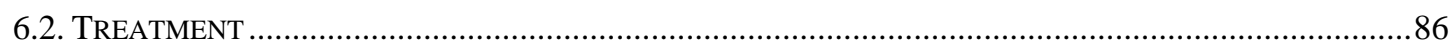

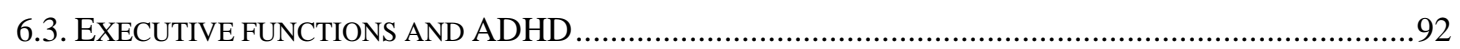

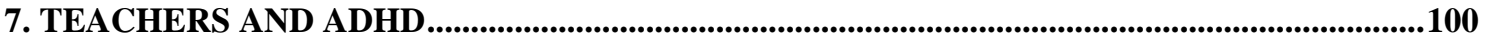

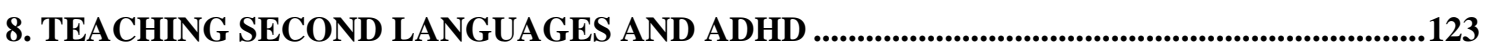

8.1. GENERAL CONSIDERATIONS ..................................................................................................124

8.2. ESL ACTIVITIES TO WORK WITH STUDENTS WITH ADHD .............................................................130

8.2.1. Activities related to written comprehension......................................................................131

8.2.2. Activities related to oral comprehension ............................................................................ 143

8.2.3. Activities related to written expression ................................................................................161

8.2.4. Activities related to oral expression ..................................................................................182

8.3. FURTHER ACTIVITIES AND CONSIDERATIONS................................................................................204

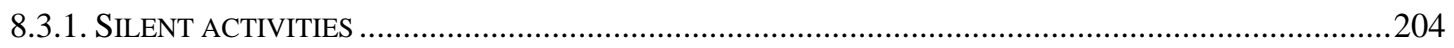




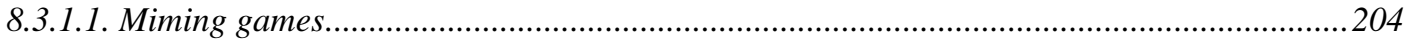

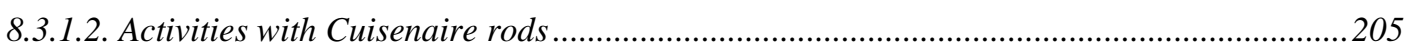

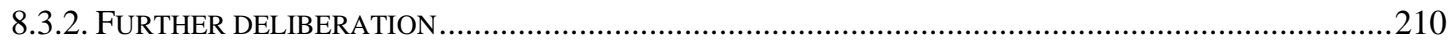

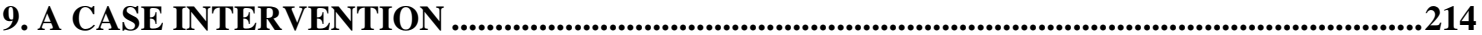

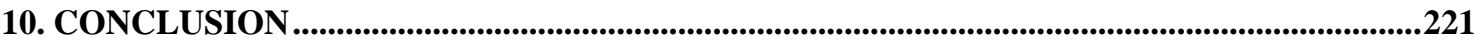

11. WORKS CITED 


\section{Introduction}

Attention Deficit Disorder with or without Hyperactivity (ADHD) is a psychiatric disorder that affects 3-7\% of children, which is equivalent to, at least, two children per classroom (Quintero \& García, 2019).

ADHD is a neurobiological disorder which manifests itself in inappropriate hyperactivity, impulsivity and self-control, as well as difficulties in maintaining attention (Barkley, 2013, page 19). Therefore, it presents alterations in attention and control of impulses, as well as an excess of motor activity.

This disorder of executive functions is divided into three types, according to the predominant symptoms of DSM-V (American Psychiatric Association, 2013):

- Inattentive type of ADHD: Predominance of attention deficit.

- Hyperactive/impulsive type of ADHD: Predominance of hyperactivityimpulsivity.

- Combined type: presentation of symptoms of two previous types.

Also, ADHD is a disorder with a degree of comorbidity with other disorders (learning anxiety, conduct disorder, oppositional-defiant disorder, anxiety, emotional disorders, tics, etc.).

Many cases of ADHD are not diagnosed. Nor can we ignore that a high percentage of these students have low school performance and / or behavioural problems, which is the object of rejection by peers or even reason for dropping out of school.

Consider the following quotes, drawn from some general provisions established in the LOMCE (Ministerio de Educación, Cultura y Deporte de España, 2013):

- El alumnado es el centro y la razón de ser de la educación (...). Solo un sistema educativo de calidad, inclusivo, integrador y exigente, garantiza la igualdad de 
oportunidades y hace efectiva la posibilidad de que cada alumno o alumna desarrolle el máximo de sus potencialidades (...).

- (...) Equidad y calidad son dos caras de una misma moneda. No es imaginable un sistema educativo de calidad en el que no sea una prioridad eliminar cualquier atisbo de desigualdad.

- (...) El dominio de una segunda o, incluso, una tercera lengua extranjeras se ha convertido en una prioridad en la educación como consecuencia del proceso de globalización en que vivimos (...).

Let's also examine one of the Principles that appear in Chapter 1 of the LOMCE (Ministerio de Educación, Cultura y Deporte de España, 2013):

\section{Artículo 1. Principios:}

b) La equidad, que garantice la igualdad de oportunidades para el pleno desarrollo de la personalidad a través de la educación, la inclusión educativa, la igualdad de derechos y oportunidades que ayuden a superar cualquier discriminación y la accesibilidad universal a la educación, y que actúe como elemento compensador de las desigualdades personales, culturales, económicas y sociales, con especial atención a las que se deriven de cualquier tipo de discapacidad.

If you evaluate what is stipulated by law and compare it with the educational results, we come to the consideration that we must improve our work with students with ADHD, who have the same opportunities and successes as other students. As Irene Brower says in her handbook Foreign Languages for everyone, students with learning difficulties may be proficient in the use and learning of foreign languages, the only essential thing is that teachers adapt teaching strategies to the needs of all students. To do this, we must be aware of the types of learners that are in the classroom and determine what their needs are (Brower, 2011).

Earlier we talked about the types of ADHD. Depending on the predominance of symptoms, learners will have more or less difficulties in different areas.

- Inattentive type of ADHD: the academic difficulties related to inattention are mainly in: 
- Reading: they often have difficulty following the readings; it is difficult for them to focus their attention on the text, especially if it is long or difficult; they often forget what they have read.

- Writing: They have difficulty planning and organizing tasks; they often make mistakes caused by carelessness in their homework; they do not usually finish tasks or do them in a scant way; they do not perform the work with precision; they make mistakes in spelling, punctuation and mechanics, because they are too bored to pay attention to the details.

- Mathematics: they make mistakes in the operations due to lack of attention, they have trouble in solving problems.

- Hyperactive/impulsive type of ADHD: the academic difficulties related to inattention are mainly the following:

- They often get up when they should not; they cannot stop: they run, jump, play with objects or make noise when it is not appropriate; they talk excessively and have problems to respect shifts; they respond before the questions are finished; they have a hard time being quiet, they need to move their hands and / or their feet excessively; they have difficulties to respect class rules; they interrupt or annoy companions; they get bored easily; they are impatient; they have difficulties to perform tasks or participate in games in a quiet and/or silent way.

Taking into account these characteristics (Rief, 2005, pp. 6-8), and regardless of the treatment to which these students are subject, if they follow any treatment, we must make methodological changes when working with them. If, in addition, we talk about teaching English as a second language, the difficulty that these students will have is greater than in L1, in this case, the Spanish language.

The main objective of this research is to teach English as a foreign language to students with and without ADHD. Bearing in mind that the language, in this case the English language, is the vehicle of the English classes and, starting from the base that a language is acquired to communicate and relate, as a social activity, so we will also talk about Discourse Analysis. Talking about Discourse is not just about the language used as the medium of instruction or the study of grammar, but it also has an important effect on people, linguistically and personally speaking. Linguistic choices as the examples 
used in class, the linguistic register, the intonation, even the gestures teachers and students use play an important role during the lessons, as Discourse does to teaching.

In order to achieve the objective successfully, we must know the disorder and consider what kind of problems we must take into account in order to work specifically on the aspects that present difficulties, firstly in L1 and, extensively, in L2 and, in this way, get to use English to communicate and socialize, to see it as something more than a subject, to feel it as a tool that will allow us to make friends, travel anywhere on the planet, among other interesting activities.

Not all students with ADHD have problems with language, although many of them do. These problems can be of all kinds:

- Syntax: problems with the use and/or understanding of the components of the sentence.

- Semantics: problems with the organization and meaning of words. Comprehension problems (both oral language and written language). Poverty of vocabulary.

- Pragmatic-discursive: problems of expression and relationships. They talk in excess, but they have trouble maintaining an orderly and coherent conversation and/or expressing feelings.

- Metalinguistics: Problems with idioms and the figurative sense of the language.

Throughout the development period of this thesis, we will work with students with ADHD and give them tools and strategies to alleviate these problems. In the section of notes and reflections on the educational practice we will propose specific activities to deal with them.

But we must not only take into account the disorder, the personal characteristics of the student and the problems that this has. In order to achieve our goal, we must also take into account the different learning styles. Therefore, we will also talk about the teaching of second languages and the relationship that this has with the Discourse Analysis methodological approach. The aim of using Discourse Analysis during instruction is to comprehend the individual communicative repertory, unique of every 
single student, from all the students in class, to ease and promote conversations and inclusive learning (Rymes, 2016).

What is clear is that students with ADHD can perfectly master a second language, all that is needed is for teachers to know what their needs are to help them achieve their goal. 


\section{Work hypothesis and main objectives to achieve}

Can ADHD children succeed in learning languages? Children with ADHD are more likely to have language problems and difficulties with the executive functions. That means that different activities and techniques will be needed when teaching ADHD children. Peer interactions may also be affected, which stands for assorted activities and grouping (individual tasks, pair-work or group).Therefore, unpredicted situations will take place during instruction and teachers need, firstly, to prevent some situations and, secondly, to be prepared to change activities, methodologies or just cope with the unexpected moments or, in other words, “challenging moments”. We discuss the following working hypotheses to answer this question:

Work hypothesis (Barkley, 2015; Brouwer, 2011;Rief, 2005;Rymes, 2016):

- $\mathrm{ADHD}$ is not just an academic problem, it affects family relationships, social and child health.

- ADHD has a high degree of co-morbidity.

- ADHD is not synonymous with failure.

- $\mathrm{ADHD}$ is a disorder that can affect the executive functions, which entails the possibility of having problems with any of the five executive skills: inhibition, non-verbal work memory, verbal work memory, emotional memory and motivational self-control, planning and problem resolution.

- A large number of students with ADHD require special help in schools.

- A high percentage of students with ADHD have problems with language.

- All students deserve to learn a second language.

- We must adapt the pedagogy and methodology to work with students with ADHD in ordinary classrooms.

- Motivation is crucial in teaching.

- In the language classes we work on discourse analysis.

- Learning a second language can be fun, despite being difficult for certain students with ADHD.

The aim of this thesis is to outline a realistic model in the paradigm of teaching and learning English as a second language, adjusting the intervention procedures to 
ensure that all pupils, with or without ADHD, learn ESL. Relying on this study, the present project has the following purposes:

General purpose:

- Teach English as a foreign language to students with ADHD applying a discourse analysis based approach as theoretical framework.

Specific purposes:

- Study different methods and techniques of work to cultivate a second language with students with ADHD.

- Analyse ESL activities in which discourse analysis is exercised and put them into practice with students with ADHD.

- Study the educational practice.

- Make a record of activities carried out with children with ADHD. 


\section{Methodology}

This is a hypothetical-deductive investigation of children with ADHD in its three subtypes:

- Inattentive type

- Hyperactive / impulsive type.

- Combined type.

The study follows an Action Research methodology. That is, this project aims to capture the study of our educational practice. For this, we will focus on the aspects of our research and our teaching to improve the educational practice. As ESL teachers (English Second Language) in several classrooms of Primary Education, the activities that we carried out were English activities aimed at all students, taking into account ADHD. We sought activities that benefit ADHD, to be able to teach English as a second language with all the students in the classroom.

The research approaches are:

- Descriptive: it has the purpose of describing events, focusing the aspects of our teaching to improve the educational practice. Class activities are aimed at all students, taking into account students who have ADHD, looking for activities that benefit them, to work teaching and learning the English language with all students in the classroom.

- Experimental: we intend to improve ESL teaching with students with ADHD by making methodological modifications and working specifically with them.

- Participatory: Activities and methods of working with children with ADHD will be put into practice to find solutions and improve the quality of ESL teaching with this type of students.

Regarding the methodology used to teach ESL, we must say that, unlike the old techniques of memorization and repetition, there are now many techniques and methodologies with more fun and attractive approaches.

First of all, we must emphasize that the present project will put into practice various techniques to teach ESL in a centre where all students work and learn together. 
This will have an influence when carrying out activities, because there are many individuals to take into account, each with needs and peculiarities. The students with whom we work, the contents, the activities, the material resources and the situations that are given when putting them into practice will make us use one methodology or another and carry out certain activities. At all times we will use the methodology that is most propitious for all students to achieve the proposed objectives, taking into account the different types of learners that come together in the classrooms. It is important that students put their knowledge and linguistic skills into practice and obtain meaningful learning.

In the second language teaching section we will explain different methodologies and in the second language teaching and ADHD section we will explain the activities and various methodologies that have been used throughout the present investigation. 


\section{Theoretical framework}

\subsection{Teaching second languages}

Language teaching has changed a lot over time. At present, there are many types of methods to teach languages. Here are some of the methodologies used to teach English as a second language:

\section{Classical method or Grammar-translation method}

This method emerges at the end of the sixteenth century and it is based on the teaching of classical languages. The study of the language is based on the memorization of rules and vocabulary and has a deductive approach, going from the rule to the example (Hernández, 2000). It focuses on written production. The student's role is passive, because it is a mere receiver of knowledge. Although it is the oldest method of teaching languages, sometimes it is still used following a similar procedure in some activities, such in oral reading-translating exercises, where the text is read in the foreign language and translated into the mother tongue. It must be emphasized that in the original method there was a scarce attention to pronunciation and the role of students was passive, which is fortunately inconceivable nowadays.

\section{Direct method}

Among the natural methods, the direct method is the most widespread. Very popular during the beginning of the twentieth century, it emerges as a response of the grammar-translation method. It is an intuitive and eminently oral method, considering that the students have to acquire the L2 intuitively, just as a native speaker would. To be really fast and effective students must be in continuous contact with the L2. Its name is Direct method because it attends to establish a direct connection between the language the students are learning and reality (objects, actions, etc.). Mother tongue is dismissed and translations are removed from the procedures. It focuses on the four abilities (speaking, listening, reading and writing), being speaking the fundamental skill. In this method mistakes are avoided, considering that they create an incorrect pattern (Hernández, 2000). In the present this method is still used, placing the focus on the four abilities of a language, but mistakes are welcome in modern times. In this project there are several activities that have been played under this scope, as it is the case of the games "Memory game" or "Find it!", where the flashcards representing the vocabulary of the L2 and the pupils' recognition and production of the words elude the mother 
tongue. Children assimilate the new words with a direct connection between the image and its oral representation and practice it by drilling and playing games. As Elbert Hubbard said, "the greatest mistake a man or a woman can ever make is to be afraid of making one”. Errors make people think about other possibilities and are part of the learning process.

\section{Audio-lingual method}

Dating from World War II, this method is based on linguistic theory and behavioural psychology. Correct answers get a positive response and wrong answers get a negative one. It is fundamentally oral (oral expression and hearing). Students learn the new language by associating spoken words with visual images. It uses repetition and mechanical exercises, using recorders and other technological means, as well as a guide where all the possible situations the students may need are included(Richards and Rodgers, 2003).It is used up to now with some variations in some activities, such as "role-plays" or "theatre plays", where probable and familiar situations are rehearsed, the focus is set on pronunciation and intonation and grammar and vocabulary are practiced in context. The difference is that, as we have commented before, errors are part of the learning process. There is a Spanish proverb that comes to say that "only those who never speak, never misspeak”.

\section{Communicative Language Teaching}

More than a method, it is an approach that understands language learning as a process in which communicative intention is essential. Its origins date from the sixties due to the changes on the language teaching methodologies in Great Britain. Among its principals, the approach pursues the acquisition of a language in the ordinary course of communication (Richards and Rodgers, 2003). Fluency is contemplated as a very important part of the act of communication and various linguistic abilities are required. This is a trial and error system to learn creatively a language. This approach is used to this days and has influenced other methodologies. The fact that learners are welcome to make assumptions and mistakes was a great improvement in the language teaching and it is a very important part of the modern teaching methods, where a wide variety of methodologies and approaches conform the lesson plans of the languages classes, but errors and communication are the foundations. 


\section{Total Physical Response (TPR)}

It is a methodology developed by James Asher in the seventies that combines speech with action (Richards and Rodgers, 2003). The contents are presented in a context of commands and actions, emphasizing listening comprehension. It aims to teach the second language through physical activity, listening and comprehension, the same way children learn their first language. It is currently used and it is very popular among young children and, it must be said, among infants with some dysfunctions, such as is the case of ADHD students. Maybe that is because, as Asher considered, stress interferes in the languages learning, so stress and pressures may be released when learning a language (Richards and Rodgers, 2003). With the TPR method the focus is set on acquiring meaning through movement, not on the linguistic aspects, which may reduce pressure and stress. And last but not least, many activities under this method are active games, making learning funnier than doing writing exercises or just applying grammar rules (Langel and Kuzcala, 2010). In the present project several activities have been executed using this procedure, to give a few examples: "Emperor, how far may I travel?” or "Simon says".

\section{Silent method}

The Silent method is a methodology dating from the seventies. The basis of this method is that the teacher should keep as much silent as possible, thus encouraging the students to intervene. As a result, students learning arises from discovery, using materials and solving problems with these items (Richards and Rodgers, 2003). The most relevant articles to teach silent way are Cuisenaire rods and Fidel's spelling charts. It is still used in the present day and Cuisenaire rods are not only used to teach Maths, they can also be used to teach languages. In the present project some examples will be given in the activities' section.

\section{Suggestopedia}

This method from the seventies is based on several psychotherapeutic disciplines, focusing on the students and their mental states. Suggestopedia believes in the great power of the mind and uses suggestion and relaxation techniques to retain knowledge (Richards and Rodgers, 2003). It has variants such as hypnopedia, rhytmpedia, relaxopedia, etc. Nowadays some language academies are using this method so far. In the present project relaxation techniques have been used, not to 
acquire the language, but to create a calmed, relaxed atmosphere before starting the lessons, during breaks or just after a disagreement or misunderstanding during the lessons, incidents that occur sometimes when teaching young children and, if there are children with a special condition, such as ADHD infants, there is a greater chance to happen.

\section{Natural approach}

Developed in the early eighties, communication is the most important function of this approach. It raises the learning of the second language through its use, considering vocabulary, input and practice a must to acquire the new language (Richards and Rodgers, 2003). It is based on the use of the new language in communicative situations without using the mother tongue. The activities this approach proposes are based on activities from other methods, such as the Direct Method or TPR (Total Physical Response). Therefore, it is currently used to teach second languages.

\section{Cognitive academic language learning approach (CALLA)}

The Cognitive academic language learning approach is a method developed in the eighties and designed to learn English through course content. This program places its focus on the content of the subject (Maths, Science, etc.), focusing the learning strategies on the needs of the student (Chamot, 1995). Learners take part of the process and are mentally active, relating former knowledge with the new one, looking for information and adjusting their own learning. In this way, significant acquisition takes place. It is an actual English teaching method, very popular in the United States of America, as it is Content Based Instruction (CBI), and Content and Language Integrated Learning (CLIL), its European counterpart, all of them content-oriented methodologies.

Content Based Instruction focus on the topic or subject matter, and is used in language classes that are designed around topics of interest or need, being very popular in ESL and EFL settings (Snow, 2017, p. 160). In Europe CLIL is right now a wellestablished content-oriented methodology. The term Content and Language Integrated Learning refers to educational settings where a second language is used as a medium of instruction. It is believed that internationalization and globalization are pressuring the education systems to provide students with language skills to accomplish their goals in international contexts. (Dalton-Puffer, 2007, p. 1). 


\section{Task-based instruction}

This approach appeared in the eighties, although it is connected with the prior Bangalore Project. Students analyse and put into practice the language by performing tasks or activities, such as going shopping, opening an account in a bank, etc. Students use the language in today's society, within their daily routines. This instruction prioritises the project over the product, in the sense that students learn a language meaningfully through the project interaction. Task-based instruction considers that a second language acquisition is based on communication, using the spoken language, that is why its general guidelines is to make apprentices use their linguistic and communicative skills through the tasks they are required (Richards and Rodgers, 2003). It is used in the present days and it really is a very interesting methodology to use, among others, in the ESL instruction and even more when working with children with disabilities or very different levels or, in the case of this thesis, ADHD students. The reason is very simple, when working in a group, those who are ashamed of participating in front of the whole class, have the opportunity to work in a small group, reducing the stress facing a lot of people or making mistakes in front of the whole class might cause them. When grouping the class, teachers may take into account the needs and the benefits some classroom mates have or can offer, so pupils with a good second language level or good social skills can help those who have needs (language needs, social needs or any other necessity). That grouping technique was practiced in several task-based instruction activities explained in this study, for example in an exercise where children had to invent a menu for a restaurant or in a story-telling proposal where students had to write a story or a tale to tell the pre-schoolers.

\section{Game-Based Learning (GBL)}

Game Based Learning is used to engage students in learning while playing, making the learning process more interesting and fun (Al-Azawi, Al-Faliti and AlBlushi, 2016, p. 134). Playing is a ubiquitous experience in childhood. Therefore, apart from the motivation that games may bring to the instructional process, there are other beneficial developmental implications, such as collaboration, competition and other social factors (Greipl, Moeller and Ninaus, 2020). We use game-based learning in our daily basis teaching practice. We include games in our lesson plans, blending listening, 
reading, speaking and writing exercises with some more playful activities. Children love it and help many of them to learn ESL.

\section{Gamification}

Gamification can be defined as the "use of game design elements within nongame contexts”. It is a term that was originated in the digital media industry in 2008 (Deterding, Dixon, Khaled \& Nacke, 2011, p. 1). Gamification does not necessarily imply electronic devices or video games, but introduces the working or learning process in the form of a game (Liu, Ahmed and Gazizova, 2020, p. 2). Although there has been much controversy about the benefits of the use of technology in foreign language teaching, some studies show the improvements they can bring to students' language skills, apart from the strategies learners get to work on their own (Guaqueta and Yicely, 2018). We have used gamification as part of our methodology during our teaching practice, as we have used games as a behaviour management system ("group response cost”) in class, motivating and incentivizing our students with this gaming technique. We also have played games, some of them online, to learn or review vocabulary and grammar with our pupils (e.g. "Jenga”), turning the learning process into a game.

Society has changed and so do us, as teachers need to vary and adapt their methodologies and teaching strategies to their student's needs, who are influenced by society. Although we do not consider that technology should replace other materials, it is important to include it in language instruction, always preparing students to learn in the online environment, as Davis (2006) states.

\section{Multisensory instruction in language teaching}

With multisensory instruction students use more than one sense at a time. It combines the methods: auditory, visual and kinaesthetic. Multi-modal learning can help children remember the new knowledge. Manipulating materials, watching videos or pictures, listening to music or stories, smelling, tasting, making crafts, singing songs, moving around... All those activities can help kids concentrating, learning and remembering concepts. Movement helps interconnection with the brain, which enriches the learning process. This method is very interesting, but can be very noisy and, in small classes with lots of students it can be difficult to practice. Space, materials and a students' ratio inferior to 30:1 are a must in this project where children can acquire significant learning. Throughout the activities' section of this paper, several activities 
are conducted under this methodology, such as watching closed-captioned video with subtitles. James L. Rowland (2007) states that closed-captioned video with subtitles helps ESL acquisition with spelling, reading, writing and word recognition, because they blend audio, meaning, thought and speech. During this research it was noted that reading the dialogue in English while they listen and watch the video helps them with pronunciation and word recognition. The same video without subtitles or with Spanish subtitles did not have the same results. No subtitles produced no assistance at all and many pupils were lost, and Spanish subtitles led children to read the Spanish lines, without listening or paying attention to the English dialogues. Therefore, closed-caption videos with subtitles helped students learning ESL as far as the writing lines matched the audio language.

\section{Present and Future expectations}

Along this section we have been looking for similarities between the methods and approaches and current ways of teaching languages, specifically ESL, but the truth is that when emerging, methods, as Richards and Rodgers assume, imposed teachers what to teach and how to do it (Richards and Rodgers, 2003). Not only present, but future expectations in teaching a second language entail the domain of a wide variety of methodologies and approaches, where the teachers choose which one is better to use, depending on the part of the language they pretend to foster, the students, the needs of the children or the school, the materials they have or even the timing. Moving from one methodology to another should be an easy and creative task, providing teachers a wide range of possibilities to achieve their goals and challenge pupils to learn a second language and enjoy doing so. Yet another interesting statement is related to selfevaluation and regulation. Hernández declares that students should control and adjust their learning in the future, leaving the teacher to supervise and assess them (Hernández, 2000). We can guess that such teaching is feasible with adults, but children need more guidance and help, particularly those who have a dysfunction or, in the specific case of this thesis, ADHD students. Nevertheless, it is vital that teachers show pupils how to learn a language, providing them with the skills they need to gradually become more independent in the process. Therefore, studying techniques and self-evaluation tutoring are part of the present and future teaching of second languages. The younger the children, the most difficult is the process of self-evaluation. That is why we should start to see it as a game and always give them positive feedback to, progressively, give them 
the skills and resources they need to be more autonomous. Learning is challenging in many ways, and so is teaching. There are no shortcuts or magic tricks to become a fluent speaker in a foreign language or a multilingual person, but sure there is a lot of magic in the process. It is the job of all teachers to help small children to learn and enjoy in the process of assimilating a language, for their future is determined by their first experiences. Kids can love a language or just get stressed or frustrated every time they have a language lesson, it is up to us teachers to show that learning languages can be fun, but most important, learning a language can be a way of life, not just a subject they need to study to complete a test or graduate.

\subsection{Towards a definition of discourse analysis}

Discourse analysis is a discipline that studies the language in communication, that is, it studies the language and the contexts in which it is used. To put it in other words, we can cite a well-known definition in the field of discourse analysis. Brown and Yule disclosed in their publication of Discourse Analysis that "the analysis of discourse is, necessarily, the analysis of language in use” (Brown and Yule, 1983, p.1). Born in the 60s and influenced and influencing other disciplines such as psychology, anthropology or sociology, among others (Coulthard, 1985), it analyses the subjective range of language (oral, written, gestures, etc.) and its connection with society. That diverseness and the fact that discourse analysis is a combination of different approaches to the study of language in context, leads to some people to differentiate between the meanings of "discourse" and "discourse analysis". For some of them, "discourse" is defined by anything beyond the sentence, while for others the inquiry of discourse is the study of language use (Schiffrin, Tannen and Hamilton, 2001, p. 1).

Zellig Harris was the first person to introduce the concept of discourse analysis in the scientific community, defining it as "a method of analysis connected to speech (or writing)" (Harris, 1952, p. 1). He submitted a paper where he proposed to go beyond the boundaries of a sentence and to consider the association between the sentences and social situations.

Another definition to highlight is that offered by Van Dijk, a groundbreaking discourse analysis' critic, who believes that discourse should not only be studied as 
form, meaning and mental process, but also as a set of complex structures and hierarchies of interaction and social practice. The author affirms that the connection between discourse and society is more complicated than the mere assertion that discourse is a form of action and interaction, deducing consequently that discourse is social. Therefore, discourse analysis studies the concepts of action, context and power. Van Dijk defines discourse as action because it is controlled, it is an activity with a human purpose. He considers that social discourse analyses discourse in context. "The term context refers to the information we need to know in order to understand the discourse itself. To analyse the term of power we must take into account that both the action and the context are part of the people, as members of social groups, with power being a weapon of social control. This power is a tool that allows us to exert a power over the reader or listener through the persuasive power of discourse. Discourse is, therefore, a resource and a recourse of persuasion” (Van Dijk, 1997).

As Cook states (Cook, 1989), discourse analysis is an expanding field that puts pronunciation, grammar and vocabulary into action to achieve efficient communication. Speech analysts study the language in use, examining written texts, conversations and other institutionalized forms of speech. Discourse analysis has become a heterogeneous discipline that analyses language, taking into account the social and cultural contexts that affect, impact and form part of the language in use. From Harris to the present, there have been several authors and schools that have dedicated themselves to carrying out this analysis. Alonso provides a review through the theories and precursors of discourse analysis in her book A Multi-dimensional Approach to Discourse Coherence. From Standardness to creativity (2014). She offers us a walk that begins in the 70s, in which several authors develop their grammar texts based on the fields of linguistics and cognitive psychology, such as Halliday and Hasan or Quirk, who goes further in his book Words at Work and takes into account communicative studies, combining text and discourse and affirming that what we do in texts is to communicate (as cited in Alonso, 2014, p. 25).

Alonso (2014, pp. 32-34) distinguishes between two approaches: oral discourse and written texts. In the oral discourse approaches the London school stands out as one of the most distinguished approaches that precede the analysis of discourse. His initiator, Firth, introduced Malinowski's idea of context to his theory, linking the 
meaning of words to their context, associating the meaning of words with the linguistic context in which they occurred. These ideas contributed to other theories, such as Lyons' linguistic semantic theory or systemic functional linguistic theory, in which the author unites the study of the language system with the study of discourse.

Focusing on written discourses, she mentions several authors, highlighting the contributions of Wienold, who studies the production of meaning in literary texts, anticipating the main components of text linguistics and discourse analysis (Alonso, 2014, pp. 35, 36).

Within the framework of discourse, it is assumed that language will be precisely analysed. But, what is needed or essential for the understanding of discourse? Are all utterances acceptable? Many utterances are meaningful and linguistically appropriate in a connected discourse, but not isolated. The accurate grammar of a sentence is not enough to have coherence in the pragmatic level of speech or of a whole text. Hence, coherence relations, cohesive means and contextual information will determine the acceptability of the sum of its parts, to wit, a stretch of language, a linguistic message, an entire passage... a piece of discourse or, as Halliday and Hasan would say, a text. For text is used in linguistics to denote any written or spoken extract, despite its length, forming a unified whole (Halliday and Hasan, 1993, p.1).

There are several concepts of supreme importance in discourse analysis. Based on the notion of text from Halliday and Hasan, in which text is a unit of language in use (ibid, p. 1), there are some properties texts must have. We are referring to coherence and cohesion. Coherence, on the grounds that it gives meaning and unifies the discourse and, with regard to cohesion, defined as the series of linguistic resources to create texture in the grammatical sense. Despite the starting position of the notion of text, this study shares with Alonso the idea that both features, coherence and cohesion, collaborate on the construction of a macrostructure, called either text or discourse (ibid, p. 52).

As has been previously highlighted, coherence relations, cohesive means and contextual information will give unity to a text, will conform the discourse. This implies that we cannot show grounds for discourse without contemplating the context, in other words, the details outside the language: people embroiled, the implicit and explicit 
knowledge they have, the place and situation where it takes place, when does it take place... Ergo apart from coherence and cohesion, context is vital for discourse analysis too.

Cook contends that there are two ways to address language, the "contextual" approach, which refers to the details outside the language, and the "formal” approach, which refers to the analysis of language itself, to the features of language and the links between the sentences and utterances (Cook, 1989, p. 14). To assess formal links within a piece of discourse it is not up for debate to consider the traditional categorization of cohesive ties from Halliday and Hasan. The authors consider that "ties” permit the analysis of a text with regard to its cohesive properties, considering the following cohesive ties: reference, substitution, ellipsis, conjunction, and lexical cohesion (Halliday and Hasan, 1993, p.4). For reference, the linguists point to items that make reference to something else for their interpretation (ibid, p.31). Substitution is defined as a replacement of one item by another and ellipsis as the omission of an item (ibid, p. 88). Conjunction ties are controversial, because they are cohesive not in themselves but indirectly, by virtue of their specific meanings. Therefore, they can be defined as items that logically connect two independent sentences (ibid, pp. 226-231). Lexical cohesion stands for the selection of mutually relevant vocabulary, which form an interconnected frame of meaning and where general nouns depend on their presence in the context (ibid, pp. 274-282).

Although Halliday and Hasan already introduced five main subclasses of cohesion, we will mention the types of cohesion proposed by Bae in the article Cohesion and Coherence in Children's Written English: Immersion and English-only Classes, in favour of clarity and simplification (Bae, 2001). The study shows a table that summarizes the work of several distinguished linguists: Cook, Halliday and Hasan, McCarthy and Renkema. That table classifies the types of cohesion in four groups, like the above mentioned distribution, the differences are found within the subdivisions. Bae avers four types of reference cohesion: pronominal, proper nouns, demonstratives and comparatives. The author specifies four conjunction cohesive categories: additive, adversative, causal and temporal. She also declares that there are three possible classes of ellipsis: noun ellipsis, verbal ellipsis and clausal ellipsis; and two varieties of substitution: noun substitution and verb substitution. Bae concludes the table with six 
different lexical ties: collocation, repetition, synonym, antonym, hyponymy and meronymy.

To continue with the formal assessment within a piece of discourse we need to address the definition of coherence. Alonso contends that coherence makes the discourse relevant to the goals of the producer, the response of the receiver and the circumstances when and where it takes place, defining how the circumstances affect and determine the meaning and function of discourse, and highlights that coherence is an expected characteristic of discourse (Alonso, 2014, p. 11).Undoubtedly an absence of coherence may lead to misunderstandings and lack of comprehension to the receivers. We can examine a single sentence and determine if it is grammatically correct or not, regardless of whether it is meaningful or not. We can continue examining the next sentence of a text and analyse it grammatically and conclude if it is right or not, and if it is coherent with the previous one or if it is not. Even being both sentences part of the same text, we can foresee different possible scenarios depending not only on the context or the users' goals but also on the expectations determined by the selected discourse genre, the register associated with it and the social function it conventionally performs (Bhatia, 2002) . To give some examples of the diverse possibilities we can find, we are going to use some lines from some famous English nursery rhymes from the book $M y$ Treasury of Nursery Rhymes (Igloo, 2008). They could be both grammatically correct and coherent:

Little Jack Horner sat in the corner,

Eating a Christmas pie.

(Little Jack Horner, Igloo, 2008)

In this sample, both sentences are grammatically correct and coherent. But we can also find an example of two sentences grammatically correct and incoherent. As it is the case that follows:

Eat an apple going to bed,

Knock the doctor on the head.

(An Apple a Day, Igloo, 2008) 
Both sentences are syntactically right, but they do not make sense as a whole. What does it mean "knock the doctor on the head"? Who has to knock him? What does it have to do with eating apples? It is obvious that these two isolated lines are incoherent, but the text, the complete nursery rhyme, is coherent, because it is a children's rhyme. Another possibility is to have two sentences grammatically wrong, and still being coherent:

Pretty maid, pretty maid,

*What gave she you?

(Pretty Maid, Igloo, 2008)

The asterisk is a linguistic convention for denoting ungrammatical sequences. In this example, the second line “what gave she you?” is syntactically incorrect, yet we can understand the message it is trying to convey: "pretty maid, pretty maid, what did she give you?". We do not know who is the pretty maid, who is making the questions or the context of the situation, but we can foresee multiple scenarios in which these two lines could fit perfectly. In consequence, we can contend that they are coherent. To complete this point, we have a fourth and last possibility, an illustration of two sentences grammatically incorrect and incoherent:

\section{*Georgie Porgie pudding and pie,}

Kissed the girls and made them cry.

(Georgie Porgie, Igloo, 2008)

The sentence "Georgie Porgie pudding and pie" is syntactically incorrect considering that it does not follow the SVO (subject-verb-object) pattern that English language normally follows. It is a declarative clause and requires a verb at its centre. The absence of verb not only makes it grammatically wrong, but it makes it also incoherent, on the grounds that is completely misleading. What is Georgie Porgie doing with the pudding and pie? Is he smelling, cooking or eating them? He could also be stealing them... We cannot figure out the context or what is happening, therefore, we do not understand what the addresser is trying to say, there is no proper reception of the message. 
We can sum this segment up by stating that coherence is inevitably linked to the context and the specific purposes of the communicative event. Having different sentences grammatically correct does not mean the text is coherent. Conversely, we can have some syntactical mistakes and yet have a coherent discourse.

To address the contextual approach it is crucial to start from the previously mentioned aim of discourse analysis, that is, the notion of language in use. People use language to communicate and in this act, there are different elements that influence the communicative process. Language permits the exchange of information. In order to do so, we have to consider two features: the elements of communication and the language functions. Cook considers the following elements of communication, based on the linguists Roman Jakobson and Dell Hymes (Cook, 1989, p. 25):

Addresser: The person who produces the message.

Addressee: The person who receives the message.

Channel: Is the via through which the message is addressed.

Message form: The specific use of language of the message.

Topic: The information produced by the addresser.

Code: The language or dialect in use.

Setting: The context in which it takes place.

Cook contends that the language functions are correlated to the elements of communication and identifies the following language functions (ibid, pp. 25, 26):

Emotive function: Language is used to communicate the emotions of the addresser.

Directive function: Language is used to affect the behaviour of the addressee. Phatic function: Language issued to keep, extend or stop the communication or just to check on the channel.

Poetic function: The specific use of language used is the essence of the message.

Referential function: It refers to the act of carrying information.

Metalinguistic function: It emphasizes the code itself.

Contextual function: It creates a specific kind of communication. 
To finish with the contextual approach, it is important to mention that sharing Jakobson and Hymes' ideas entails breaking every function down into more specific micro-functions.

Continuing with the contributions of Cook, and to finish the definition of discourse analysis in relation to language teaching, we must highlight the similarities with his contemporary McCarthy (McCarthy, 1991). Both authors highlight the multiple disciplines that make up discourse analysis, and the interest of language in use. Both consider that it is essential to take into account the language that people use in their day to day when we are teaching languages, as well as cultural differences that exist, affect and influence the understanding and development of the speech. Neither of them considers discourse analysis as a teaching method, but both consider that it is fundamental in describing and understanding how language works and show us practical examples of its relevance in language teaching. Concretely, Cook considers that "the foreign language class is one of the best observation sources for discourse analysis and the most rigorous area to analyse this theory” (Cook, 1989, IX). 


\section{A discourse analysis based approach to the teaching of languages}

The need to communicate emerges along with the need for social organization. Therefore, discourse is understood as part of that social organization, and discourse analysis is seenas the study of language in use, making reference to all kinds of acts, relationships, media, symbols that allude to a concept, without limiting ourselves to talk about spoken or written language (Buenfil, 1991). Humans beings need to communicate. This communicative need that we have implies the study of language in use, the linguistic aspects, the research within discourse analysis, as well as other disciplines of study, such as psychology, anthropology, sociology or philosophy. But why do we need different scopes? The answer is not as simple as it sounds. Humans do not always mean what they say, we use our utterances to state something, but also to have an effect on the interlocutor, to mould the communication. To do so, we need to analyse the whole context, in which we do not always find true statements or signals. We can find a great variety of language resources, pitch variations or even misleading gestures than can alter completely the original message of the speaker. That is why interpretations and context play such an important role. That is why we need to teach languages based on the discourse analysis approach. Teaching grammar, vocabulary and phonetics is necessary, but we cannot forget to teach pragmatics too in order to be communicatively competent. We do not study a language to pass a test, we learn a language to speak, to communicate, to interact with others. The following example from Henry Widdowson will manifest the importance of pragmatics. Noting that Harris (1952) went beyond the sentence to explain discourse analysis, it may seem deluding to state that a sign or a legend is a text. Nevertheless, Widdowson contends that the "ladies” signs on the door from public lavatories are texts (as cited in Cameron, 2001, p.12) on account of context. The familiarity with the world, the context, will influence the texts. It is not the same being familiar or not with the word "ladies" as a lavatories synonym, considering that it is not a world-wide term to name a "restroom”. If an English speaker is unfamiliar with the expression, the word itself may be misleading, therefore the context will determine the understanding of the sign. A similar explanation is given by Alonso, when she contends that ungrammatical utterances such as "Picture coming soon” make sense in some real situations, according to the contextual elements (Alonso, 2014, p. 28). Given the circumstances, Cameron regards that "language in use" is a better definition of discourse analysis (Cameron, 2001, p.13). 
If we take Saussure's linguistics as a reference, which only took into account the signifier and meaning of spoken language, the concept of discourse is closer to the analysis of language as a social process. Conversely, Cook distinguishes a twofold type of language to study: one extracted to show how the rules of the language work, and a second one which is used to communicate and is expected to be coherent. The last mentioned, which he calls "language in use", corresponds to the notion of "discourse", and the author contends that the quest for what gives discourse coherence is "discourse analysis” (Cook, 1989, p. 6).

Discourse analysis focuses on the use of language in communication. For this reason, it is something that especially concerns language teachers, since not only do they use language as a vehicle for transmission, but their objective is focused on the teaching of language itself. To achieve this, there are many factors to take into account, such as the materials that will be used to teach, reinforce or assess the language, what happens in each classroom, at each moment of teaching, students and their personal characteristics, their language level, their gestures, or their way of communicating. But this should not lead us to erroneous conclusions, discourse analysis is not a method of teaching languages, nor a mere study of languages. As Austin acknowledged in his theory of speech acts, language is action, showing that utterances not only have meaning, but they have force too, creating diverse situations. Thereupon, utterances could be contemplated as: their locutionary meaning (what they are about), their illocutionary force (what the speaker does with them), and their perlocutionary force (their effects on the hearer) (as cited in Wood and Kroger, 2000, pp. 4-5). And what does it have to do with teaching ESL? There are infinite possible scenarios in a language class. Sixty minutes that can lead to multiple and unforeseeable moments, where not always the learning of a language is the centre of the class. If people are unpredictable, imagine children. For example, if a kid states a simple "I don’t understand”, the utterance can be interpreted in many ways. First of all, it depends on whom he or she is addressing. It can be a response to a teacher explanation. In that case scenario the teacher will probably repeat the explanation or try to illustrate his or her words in a more comprehensible way, maybe using some examples. But it can also bring another possibility, maybe the teacher can ask another pupil, attempting to verify if the rest of the class did understand and giving the chance to the children to express themselves and explain their classmate what he or she explained before. Students 
paraphrasing teachers are great help to those pupils who need further explanations and that also permit teachers to check if their students correctly grasped the concepts. But what happens if a student tells another student "I do not understand"? Well, in that case we can predict different reactions. We can witness a simple repetition from the questioned children or, it is possible to perceive a sad response, or even an annoying one, depending on the personal characteristics of the questioned kid, the intonation used by the interrogator, his or her face or gestures, the response of the class when interrogating, the age of the children, if any of the two of them have a disability... If we have an ADHD kid making the question, as happens in this study, several responses can be seen. If he or she is a child with severe behavioural problems, his or her classmates can be tired of his or her attitude and can have a mean answer, unleashing a dispute or causing the crying of the ADHD kid. But we can also witness a kind and proper response, helping the ADHD child not only with his or her doubt, but also with his or her self-esteem. Just like Austin said, language is action and has force. We can play with the locutionary and illocutionary forces of the language, but there will always be uncertainty with the perlocutionary one.

The field related to the analysis of discourse is very broad, but as regards the teaching of languages Celce-Murcia and Olshtain consider that a discourse-based curriculum should consist of four types of content: thematic content, linguistic content, cultural content, and subject-matter content (Celce-Murcia and Olshtain, 2000, p. 194).These authors consider that the teaching of languages has gone from being oriented to the teaching-learning of grammar to being oriented to discourse, with the final objective of using language to communicate. To do so, it stands to reason to use texts and discourse types that are interesting and useful for students. Therefore, we need to know our pupil's interests and their difficulties to be able to build a tantalizing and functional curriculum that really teaches them a practical foreign language that will permit them to understand and communicate in the foreign language. In other words, we teachers need to create a curriculum that engages and enhances students to learn and to become competent in a foreign language.

It is crucial that teachers know the language they are teaching, not only concerning grammar or vocabulary, they are also supposed to possess the pragmatic skills and the cultural awareness they need to enlighten their students, they need to be 
aware of the social and linguistic aspects. Instructors need to know the prosody of the foreign language, the pre-established patterns, the intonation, they need to be aware of the speech patterns, the functions of the language and its structures. Teachers need to be familiar with the features and elements that make a text coherent and cohesive. They need to recognize the details related to discourse analysis.

When teaching languages it is of concern the concept "shared knowledge". As Olshtain and Celce-Murcia contend, it always affects communication, for better or worse. Shared knowledge is the understanding of the world of the participants in the communicative event and the sociocultural awareness associated to the learning language (Olshtain and Celce-Murcia, 2005, p. 710). The authors also argue that it is significant to distinguish between adult learners or children. Adults are influenced by their cultural knowledge and children are affected by their maturational development and world's knowledge (ibid, p. 711). All those notes must be taken into account when planning the curricula and the lessons in order to establish feasible objectives and to know the possible difficulties that may rise during the language classes.

But it is not all about teachers or teaching tactics, language learning strategies are fundamental too. First and foremost learners need to know their learning style, and their strengths and weaknesses when learning the target language. That is barely impossible when teaching children, but it is extremely useful with adults, helping them to make the most out of their time and effort. For children the aim is to let them learn while having fun. No matter what age learners are, they all are active participants in the language classrooms. As Benjamin Franklin claimed "Tell me and I forget, teach me and I remember, involve me and I learn”.

\subsection{Discourse analysis in the language class}

When we search for order and regularity in language, we can distinguish between two different approaches (Cook, 1989, p. 12): sentence linguistic data and discourse analysis data. 
Sentence linguistic data

Isolated sentences

Grammatically well-formed

Without context

Invented or idealized
Discourse analysis data

Any stretch of language felt to be unified

Achieving meaning

In context

Observed

Both approaches are mutually important and contributing to communication, although throughout this thesis we will be analysing texts with the Discourse analysis data approach, as it is the approach adopted here. Grammar rules are obviously needed, as the texts and instances from other books or internet that have been used during this thesis, but making up examples from situations that happened in the classrooms or involving children in the process, in terms of considering important or social information at the time and the personal characteristics of children, or asking them to create an example, are also considerably significant.

In broad terms, Discourse analysis may be said to comprehend six approaches: speech act theory, interactional sociolinguistics, ethnography of communication, pragmatics, conversation analysis, and variation analysis (Schiffrin, as cited in CelceMurcia and Olshtain, 2000, p. 184).Therefore, a discourse-oriented curriculum encompasses three domains: context, text types or discourse genres, and communicative goals. Celce-Murcia and Olshtain assert that the difference between a discourse-oriented curriculum and a linguistically oriented one is the inclusion of the contextual features on the first one (ibid, p. 185).

To create a curriculum the first inquiry to attend is about the addressees. Curriculums are official papers created by a central educational authority to guide teachers, therefore, teachers and students are the addressees. So, in order to develop a good curriculum, we need to consider both teachers and students (ibid, p. 186). When creating a discourse-analysis curriculum, apart from the general guidelines, such as the educational philosophy, or the linguistic, cultural and social goals, it is also important to focus on the learners' communicative needs and interests. The topical content should be relevant, authentic (or as natural as it can be), it should also arouse interest to students, and be useful for their future communicative exchanges. Regarding to the learning goals, these might be reachable and challenging for learners and must cover all learners' 
needs, including people with disabilities or special needs and be adjusted to their age level, school grade and classroom and personal resources. The same could be applied to the activities or the process of learning. Tasks should involve students and help them practice and assimilate the target language and culture with natural, or as natural as possible activities, embracing their needs and abilities and their difficulties too.

Available materials are also relevant, and it is important to mention that materials differ greatly from one school to another. Fortunately there are millions of documents at present that can be used to teach the ESL lessons following a discourse analysis perspective. It is now an era where technology brings us closer to almost anything: a countless number of papers, articles, news, magazines, books, audios, videos... A simple English comment on Instagram (to name randomly a popular social network or mobile application) can be analysed within the scope of discourse analysis and be useful for learning a language.

Content in a discourse based curriculum must consider the natural use and application of a language. Even during grammar learning and practice, the content in which is presented, the examples and the practice and activities should make use of realia. Learners should listen, read and practise the language native speakers use in genuine acts of communication. That is possible even with very beginners or even with small children. The clue lies in the way it is presented. Illustrations, mimics, games, videos and role-plays can help the least proficient ones. For example, after presenting the vocabulary with image-illustrated flashcards, we can play "Simon Says” with the smallest pupils and teach them some verbs by playing with the corresponding actions. "Simon Says" is a game in which the teacher or one of the players takes the role of "Simon" and gives instructions to the other players. The instructions are physical actions that must only be rehearsed if the sentence "Simon says" precedes the inquired action. Thereafter we can practice some sentence construction using:

a) subject + action verb: E.g.: I run.

b) subject + like/s + action verb: E.g.: I like jumping.

Turn-taking patterns are significant and of great concern in discourse-oriented curriculums too. In traditional classrooms teachers' intervention is frequent, which entails constant interruptions to students, either to correct them or to give them some 
extra information. This turn-taking sequence follows the IRE (Initiation, Response, and Evaluation) pattern that Rymes describes in his manual. As the author contends, IRE patterns can reinforce basic skills and information, but when these sequences govern the classroom, its purpose fails and the class is ruled by a teacher-centred pattern. Inclusive learning where teachers and students ask and answers questions, where students' knowledge and experiences are included, bring pupils to think critically under a discourse analysis dimension (Rymes, 2016).

Classroom observation is also fundamentally important. It not only gives teachers some hints on the extent of students' involvement, but also about their understanding. Adult learners normally ask without hesitation, especially those people who join a language course by own choice. Nevertheless, questions and participation not only depends on teachers. It is true that instructors must prompt learners to participate and arouse questions, but sometimes it also depends on students' personality and the management of the classroom, among other factors. Miller contends that there are nine factors that influence language learning for children (Miller, n.d.). Motivation is the first considering element. It is not the same to be forced to learn a language than to be interested in doing so. The same applies to the importance and significance they give to the new language; if children think that it is useful and see or foresee that they are going to use it or may need to use it, their motivation will be much higher than that of those who study a new language because it is mandatory at school or their parents just want them to acquire it. Related to the previous one stands the second factor, support at home. Support in a twofold way, on the one hand, as the help to provide the children to exposure to the target language and, on the other hand, to have parents or tutors that understand and value the target language and support the children and the teacher/s. Another important issue is the prior linguistic knowledge. Having acquired previously another language helps learning a different one, due to the ability to translate skills from one language to another. The learning environment is another basic, yet relevant factor to consider. It is important to have a relaxed and positive environment in the classrooms, otherwise learning will be adversely affected. Teaching strategies are also a fundamental element to regard. The strategies a teacher uses, the methodologies, the skills, the gestures, even his or her tone of voice affects children's learning. Comprehensible input is the sixth aspect the author argues. The language input a children receives must be comprehensible and feasible, otherwise they will not 
understand and will have troubles understanding the lessons. That is a very important issue regarding to this study. Many ADHD children have problems to follow the same pace than others when learning a second language, although it is important to give every child the input and feedback they need. In inclusive classes, having one or two ADHD children represents a lot of additional work for the teacher, particularly when we face inclusive classes with more than 25 children and just one teacher. Teaching a language under that circumstances is especially challenging, as it is the case under study here, but it can also be quite stressing, because it is a huge responsibility for just one person to have all children working at the same time, whatever their personal or academic abilities, and helping them all at the same time. We cannot forget that teachers want all of their students to succeed in the target language they are teaching. Regarding the next feature, age, it is important to take into account that people over 10 years old find more difficulties to learn a language, although it does not apply to everyone. Miller also talks about comfort in their country of residence, which applies to those people who changed their residence, either moving from one country to another or it can also be considered when moving from one state or city to another. Big changes need time to be assimilated, even more time if we talk about some children. Therefore it is important to welcome them and help them feel comfortable and happy in their new place of residence. The last feature regards thestudent's personality. There are several studies that examine how being introverted or extroverted can affect the acquisition of a language. According to some researchers, having an outgoing personality leads to greater results in language learning. That may be due to the fact that extroverted people are more optimistic and interact more frequently during the lessons than introverted ones. Howsoever, the success in learning a language does not depend only on our personal characteristics, cognitive, affective and motivational factors play an important role too (Azadipour, 2019).

Classroom observation is also part of pupils’ assessment. The capacity learners have to understand language and to make themselves comprehended cannot be appraised directly through grammar or vocabulary tests (Celce-Murcia and Olshtain, 2000, p. 201). Therefore teachers have to assess some goals through test and some other via classroom observation, questions, projects, portfolios, role-plays and individual talks, among other gradable activities. Once again, the age and the language level of students will determine the goals and the procedures to test them. We cannot expect 
second school Spanish graders to write an essay in English, to give an example. They are starting to write simple writing tasks in their first language, consequently it would be out of place to ask them the same task using a second language they are starting to acquire. The same example can be applied to intonation, it would be absurd to expect that those little kids may intonate a discourse perfectly. We can ask them to pronounce some words or small chunks or sentences we have been drilling and practicing frequently, such “Today the weather is sunny and it is hot”, but we cannot expect them to produce a perfectly, natural intonated discourse. Concerning adults, we have to differentiate between beginners and intermediate or advanced ones. With beginners we could apply the same rationale we have argued for small children, although they have a better general knowledge and they are mature, literate grown-ups. Nevertheless we cannot expect them to produce a natural discourse or to establish a perfect serious conversation. Once again, the goals or aims must be established according to their language level too. That does not mean that intonation or oral interaction should not be evaluated, because they should. What we are saying is that we have to adjust the goals carefully in order to have feasible, yet challenging assessing objectives. Apart from intonation or the capacity to establish an oral conversation, the ability to produce several grammatical and lexical manifestations, the ability to make inferences while listening or the capability to place stress on the proper elements according to the prior context in oral interactions are other testable discourse features (ibid, p. 210). It is undeniable that with younger or older, beginners or advanced learners, discourse is part of the communicative competence and must be assessed.

Nowadays the functions of teachers, students and materials variate endlessly. Teachers and learners are active pieces in the teaching- learning process. Back in time, students used to be passive elements when we were talking about language acquisition. Teachers were the doers, the speakers, the investigators, the language analysts, the examiners and the conductors of the lessons. In these days instructors and apprentices play an active role in the process, conditioned by the dynamic states, environments, social circumstances, technology, networks and the changing and developing resources.

Previously, students were expected to listen and study. Right now the demands they are asked to face include a wide assortment of activities, such as being more independent, self-evaluate themselves, give speeches, research or even improve their 
own learning and language skills. Anything that makes you an autonomous learner is expected from you. Teachers, on the other hand, have become mentors, reflective instructors that show the different approaches of the area of study, giving feed-back at any time and prompting students to become better and more efficient learners.

Therefore, language apprentices must acquire the grammar in the context of discourse, which provides the frame for the study of grammar and cohesive devices. Not doing so would lead us to form incompetent learners, only capable of analysing decontextualized and unrelated sentences (Celce-Murcia andOlshtain, 2000, p. 61). Celce-Murcia and Olshtain establish six features that are the basis for creating the context for language learners. According to the authors, being a group of language learners, sharing a common purpose, as it is learning a language within a classroom, makes us a discourse community, characterised by: the promotion of the students; the mechanisms of intercommunication among its members; the mechanisms to provide feedback; the genres explored in the language classrooms, with so many features in common and yet so different depending on the class topic or activity; the specific lexis; and the degree of relevant content and discoursal expertise (Olshtain and Celce-Murcia, 2005). In effect, teachers' main goal is for their pupils to learn and acquire the foreign language, as efficiently as possible. To do so, teachers and pupils communicate with each other, that is, teachers with pupils, students with teachers and students among themselves. There are several ways to intercommunicate, not just orally, tasks, individual and group activities, projects, e-mails, lectures or meetings are effective methods of communication too. Age and fluency in the target language will play an important role in the communicative process in the classroom. It is not the same to teach adults than children. Adults' credits vary from those of young learners. In the normal run of things, adults can easily speak, they have a wider understanding of the world, the knowledge of studying techniques and the ability to focus during longer periods of time (as a general rule, although ADHD adults would lack that premise), to mention some flairs. Children, on the other hand, tend to be friendlier and are not afraid of making mistakes when learning a language, although some of them are extremely shy, but it is not the general rule. Infants are less likely to have bad habits when learning languages and find it easier to acquire a new language. The younger they are, the more enthusiasm to learn they have and the better pronunciation and stress patterns they produce. 
It stands to reason that communicative methods are important, yet feedback is equally essential and influential. Every student needs and deserves feedback, but some pupils need more positive feedback than others, as is the case under study in this paper, i.e. ADHD children, among other disabled infants. It is surprising somewhat how many ADHD children have low self-esteem and think that they are not capable of completing a task or achieving a goal. The lack of concentration or ability to sustain their concentration during an exercise, the difficulties some of them find when completing an activity, the absence of patience and information about the disability which some people they have faced had, makes many of those diagnosed children to diminish themselves and to blame themselves for their mistakes, in the sense that they feel they are not worthy or they are never going to be able to learn the target language. What they do not know is that, in many occasions, they make the same mistakes than their mates, the only difference is the way they feel or someone made them feel about themselves. That is why positive feedback is so important, especially with some people. Not less important is the fourth feature, regarding genres of language classrooms. As Olshtain and CelceMurcia claim there is a common genre to all language classrooms, although every classroom has its particular genre. For that matter, sometimes even with the same classrooms and the same pupils, in a different school year the genre changes. That is very common when teaching children, where a year course implies a lot of maturational changes in them and new acquisitions of the world, leading to new individuals after all, therefore to a new whole class genre. Closely linked to classroom genres stands the idea of specific lexis. Every classroom, even sometimes every teacher-pupil relationship has its own lexis. Teachers speak in a very particular way and, sometimes, the lexis used to refer to some children, due to special characteristics (sometimes it is a disability, some others a particular or difficult moment in their lives, sometimes it is just the personality or the sense of humour of a particular person) is distinct. Finally, we can recall at the end of each school year that the initial "new learners" are not beginners. Eventually, all students improve in the target language, therefore, we are a discourse community that makes progress every term and every school year.

It is clear that teaching ESL in context through discourse is essential to produce real learning. The most intricate task is to practice discourse in the language class with toddlers or beginners. In both scenarios we face an absence of grammatical structures, vocabulary and comprehension of the new target language. Activities that just entail 
listening or drilling may result boring and frustrating for the new learners. Giving them vocabulary related to the topic before starting and using games and TPR activities can enhance and comfort them despite the difficulties they may encounter. We must aim to make our classes funny and creative. Jokes or amusing illustrations help children understand some explanations or are a good example to follow; games, theatre plays and role plays are the best way to practice grammar; and crafts or watching videos are a wonderful strategy to teach culture.

Intermediate and advanced learners are easier to deal with. Stories, poems, passages from books, lectures, theatre plays, movie sketches, YouTube videos or picking just a topic bring us hundreds of possibilities.

In the subsequent sections we will present a variety of activities where discourse analysis and ADHD are exercised in the English as a second language teaching context in several inclusive primary education classes.

\subsection{Language in use}

Cook contends that discourse analysis delves into how stretches of language develop into significant texts for their users (Cook, 1989, p. IX). In his book Discourse, he offers convenient definitions related to discourse and shows how to practice theory with language learners, prompting teachers to experiment with techniques. In like manner, in Discourse Analysis for Language Teachers, McCarthy presents familiar definitions and tasks to put discourse analysis into practice in the language class. Both authors demonstrate in an applicable way how to teach languages under the scope of discourse analysis. They present diverse activities to learn the target language perfectly affordable even for those teachers with little experience with discourse. Both of them build their activities and examples upon the language in use. Another common element they share is that the two authors encourage teachers to explore and try different methods. They consider that discourse analysis is essential for the understanding of how language is used, but there are many possibilities in teaching languages based on the language in use, as many as teachers are, as McCarthy states (McCarthy, 1991, p.2). 
Discourse analysis has many uses in some areas, such as phonology, grammar and vocabulary (Olshtain and Celce-Murcia, 2005, p. 714). The teaching of phonology contributes to the acquisition of rhythm and intonation, an essential matter, considering that rhythm and intonation are vital in oral communicative interactions. Some people are more willing than others to open up when trying to understand a foreign speaker. I recall my first trip to England, I was at a restaurant and asked for some vinegar to a waiter. I asked for it three times and yet he did not understand me, because instead of placing the accent on the first syllable "/'viniger/” I placed it on the second one, pronouncing “/vi'nigər/”. I finally found a bottle of vinegar by myself and told the waiter "That was what I was asking for”, looking for the proper word in response, and he replayed “Oh, I see. You wanted some “/'vinıgər/” ”. I was obviously making a mistake, but I did not think it was such a big one to not to be understood after all. Nonetheless I learned how important pronunciation was. Pragmatic rules are also considerably important in grammar discourse-oriented approaches, that may seem odd, but context and pragmatics are part of discourse analysis, and therefore we cannot forget them when making the grammatical choices when analysing the whole text to comprise a coherent discourse.

When analysing the relationship between grammar and discourse we can differentiate between the macropragmatic approach and the microanalytic approach. As the word itself implies, the macropragmatic approach begins with a written or oral event, using a pertinent corpus to describe the macrostructure, to later relate its features with microstructure textual elements. By contrast, the microanalytic approach starts with the analysis of forms or constructions such as tense-aspect forms or discourse markers, based on a corpus (ibid, pp. 54, 55).Regarding grammar, we need to differentiate the study of grammar in formal linguistics and a discourse-oriented approach to grammar. In formal linguistics the analysis of grammar is normally limited to the sentence level, while in a discourse oriented approach the grammatical choices the interlocutors make depend on context. Celce-Murcia and Olshtain consider that some choices involving rules of English grammar are sensitive to discourse and context, as it is the case of the following rules (Celce-Murcia and Olshtain, 2000, p. 52):

- use of passive versus active voice

- indirect object alternation

- pronominalization (across clauses) 
- Article/determiner choice

- position of adverbials (phrases, clauses) in sentences

- use of existential "there" versus its non-use

- tense-aspect-modality choice

- right/left dislocation of constituents

- choice of logical connector

- use versus non-use of "it” clefts and "wh-“ clefts

The teaching of vocabulary under a discourse scope, on the other hand, presents no doubt when relating it to context. It seems pretty clear that, for the correct comprehension of vocabulary within discourse, a substantial part of the text is required. We could read "He is so soft on his sons”. Unless we can continue reading or analysing the preceding parts of the text, "soft on” can be interpreted in different ways, from meaning that he is not strict with his sons, to just declaring that he is fond of his sons. "Soft", as a single word is also polysemic, its meaning varies depending on the context. In the sentence "the light at the restaurant is soft", the word "soft" has a different meaning than in "the mattress is too soft". Therefore, "soft" can have multiple readings, depending on the context. To address more effectively the concept we are discussing, we must emphasize that vocabulary is not always literal, it can also be figurative, as is the case of idioms, metaphors or oxymoron, among others. This is where many language learners get lost. Figurative language not only entails the domain of the vocabulary, but also the formulaic language and sometimes, some cultural knowledge too. For instance, the English idiom "miss the boat" means "it is too late”. In Spanish there is a very similar one, "perder el tren”, therefore a Spanish person who is learning the English language could understand the idiom “miss the boat” by association. But there is not a chance that the same could happen with the idioms "under the weather" or “on the ball”, to give some examples. Some people despair when facing figurative language. We cannot say that it is not rocket science, but definitely you can't make an omelette without breaking some eggs.

Although the approach of study determines if the non-native vocabulary is supposed to be either taught or learnt without tuition, McCarthy (1991, p.64) considers 
that vocabulary encompasses a very wide language section when learning a foreign language, and not to teach it under a discourse dimension would be irresponsible.

Depending on where linguists place their centre of attention, Celce-Murcia and Olshtain (2000, p. 75) present two different processes to cultivate vocabulary and language:

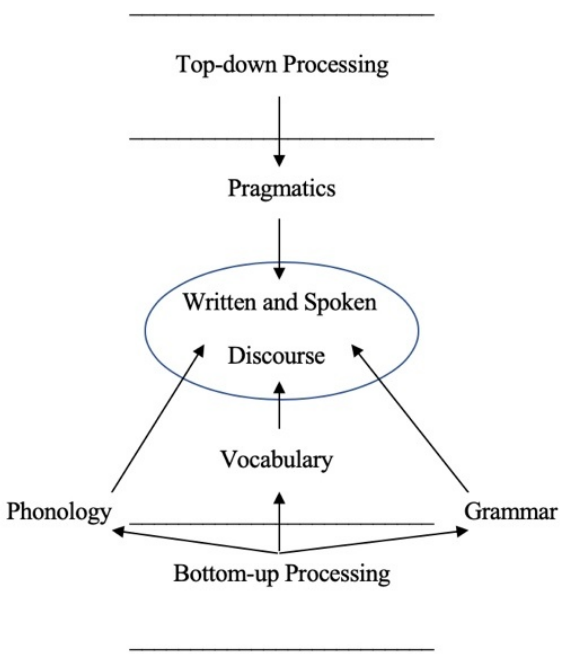

Image 1. Processes to cultivate vocabulary and language (Celce-Murcia and Olshtain, 2000, p. 75)

Top-down strategies are pragmatically orientated and involve the speaker's background knowledge of the matter or speech circumstances and the shared knowledge with the hearer/s. Words tend to be assorted around topics or, as Halliday and Hasan call them, "lexical collocations”. Being familiar with vocabulary or phrases of a certain topic are really helpful to understand and/or speak in a foreign language. On the other hand, bottom-up strategies are suitable when lexis is unknown and speakers or writers need to use someone’s help or a dictionary aid for assistance (Celce-Murcia and Olshtain, 2000, p. 74).

Notwithstanding the methodology, we cannot forget that vocabulary variates and renovates endlessly. How can this happen? Society changes rapidly, leading us to prompt new words. Some of them are used in just one occasion, meanwhile others are assimilated and established for regular usage. Vocabulary appropriation from other 
languages, television influences or industry copies are manifested in the word formation process.

Despite the fact that nowadays people can create one-time coinages in any language, some of them furthered by mass media, there are several types of word formation processes in English(Celce-Murcia and Olshtain, 2000, p. 81):

a) Compounding: A noun is formed from two or more previous ones, creating a new word with a different meaning. Ex.: heartbeat.

b) Affixation: An affix is added to the stem of a word, creating derivative words. We can add prefixes in front of a word (ex.: subtitle, the prefix sub- means under) or suffixes, added to the back of the word (ex.: softly, the suffix -ly is related to quality).

c) Conversion: Is a word formation procedure where a word changes its grammatical form without changing the spelling or the pronunciation. For example the noun "email”, can be converted into a verb "to email”. A very clear example for children and youngster is the conversion from noun to verb of the word "google". "Google" is a search engine and the verb "google” means to seek information from the mentioned search engine.

Regarding cohesion, here can be no doubt of the importance of cohesion through grammatical words in language teaching. Discourses, either written or spoken, show ties between their sentences. These grammatical connections can be classified into several categories, according to Halliday and Hasan (1993): reference, ellipsis, substitution, and conjunction, as previously mentioned in section 4.2.

a) Reference: Items that make reference to something else for their interpretation. According to the authors, in English these items are personals, demonstratives and comparatives (Halliday and Hasan, 1993, p.31).

Reference items enable the retrieval of information.

Doctor Foster went to Gloucester, In a shower of rain.

He stepped in a puddle, 
Right up to his middle,

And never went there again.

(Doctor Foster, Igloo, 2008)

In this example "he" replaces Doctor Foster and "there" replenishes

Gloucester. Both refer to previous words in the text and form cohesive ties in the text. The importance of context can also be fully appreciated in this example. If we read the sentence "He stepped in a puddle" we can predict different possibilities, but unless we know the text-activated context or, in this case, the nursery rhyme, we will not probablythink about Doctor Foster. We could think about a child playing under the rain, about a man accidentally stepping in the puddle, but not about Doctor Foster specifically. Ambiguity arises when full-text context is unknown.

b) Ellipsis: Omission of elements, which are usually needed. Ellipsis are omissions that difficult the comprehension of some learners and entails a certain language proficiency and practice to use it properly. There are three types of ellipsis: nominal, verbal and clausal.

Birds of a feather flock together, And so do pigs and swine.

Rats and mice will have their choice,

And so will I have mine.

(Birds of a Feather, Igloo, 2008)

Here "choice” is omitted in the last sentence, “And so will I have mine”.

c) Substitution: Is the replacement of one item by another (Halliday and Hasan, 1993, p. 88). In English the replacement can function as a noun, as a verb or as a clause, whence the three types of substitution: nominal (one, ones; same), verbal (do) and clausal (so, not).

All the leaves are falling down, Orange, yellow, red and brown.

Falling softly as they do,

Over me and over you. 
All the leaves are falling down,

Orange, yellow, red and brown.

(Falling leaves, Igloo, 2008)

In this sample, “do” displaces “falling down”. Halliday and Hasan contend that many substitutions are learnt idiomatically (e.g. “I think so”) and primary rules are easy to apply, despite the difficulties more advanced levels entail (ibid, p. 91).

d) Conjunction: Conjunction presuppose a relationship between segments of discourse. The simplest form of conjunction is "and". Although there is not a unique way of typifying conjunctions, Halliday and Hasan (ibid, pp. 242, 243) classify them into:

- Additive (e.g.: and, nor, or, besides, that is, thus, likewise).

- Adversative (e.g.: yet, though, but, however, in fact, on the other hand, instead, rather, at least, anyhow).

- Causal (e.g.: so, then, therefore, hence, consequently, as a result, for, because, otherwise, in this regard).

- Temporal (e.g.: then, next, at the same time, previously, finally, at last, first... then, soon, next time, meanwhile, an hour later, in conclusion, finally, from now on, briefly).

I wriggle my fingers,

I wriggle my toes.

I wriggle my shoulders,

I wriggle my nose.

No more wriggles are left in me,

So I will be as still as can be.

(I Wriggle My Fingers, Igloo, 2008)

Here "so" is a causal conjunction that gives cohesion to the text, showing what happens after all the wriggling. The causal relation between the two events, the first one is related to all the wriggling and, the second one, is a causal relation product of the cessation of wriggles. 
It is curious, to say the least, to note the differences in the use of grammatical connections according to cultural differences. A very remarkable example is seen in the use of cohesive conjunctions, where there is a big difference between native speakers and language learners, much more apparent when teaching children. McCarthy claims that "because" is a very regular word in spoken English, not just as a causal cohesion, but it is also used to express the reason relationship, and as a speech marker expressing "this is why I am saying this” (McCarthy, 1993, p. 49).During the fifteen years I have been teaching ESL, I could confirm that "so" is also a very common word among Spanish children learning English, the difference is that they only use it to show the causal relation. It is also striking the exclusive use of "then" as a temporal conjunction. I tried to work some intrasentential subordinating conjunctions (e.g. "because”, “although”, “if”, “before”) and some intersentential cohesive conjunctions (e.g. “then”, “so”, "finally”) with sixth graders and I even left some posters on the walls with useful ones, but few really included them in their writing. On account of that, it is important to respect every child's pace when learning a language. Although some conjunctions seem affordable for young learners, the proper use of these cohesive devices is much more complicated that it seems. Consequently I decided to extend the knowledge of these connections for those children who needed some extra work.

When reading essays from beginner learners of a language it is very common to find a great amount of mistakes, not only because of the lack of awareness of many grammar rules or their difficulties when applying connectors. Many errors come from the unfamiliarity to write essays in a second language, that is, to create a discourse. It is not the same to use written English, to name a language, to answer some questions, where initial students may use short answers or a single sentence, than to write an essay or generate longer texts or pieces of discourse. Cook studies cohesion and contends that, focusing on the sentences which construct the discourse, we can recognise three kinds of sentences which are considered incorrect, apart from those with writing mistakes of spelling and punctuation (Cook, 1989, p.8):

a) Morphological errors: Word endings, or other parts of the word, are incorrect. Ex.: *He are a nice person.

b) Syntactic errors: The word order is incorrect. Ex.: *He person is a nice. 
c) Semantic errors: The meaning is incorrect.

Ex.: *He is a nice potato.

In order to have a cohesive and meaningful discourse, there is no doubt that we need some grammar rules. But shared knowledge is as important as the understanding of grammar rules. When we refer to shared knowledge we are referring not only to facts about the world, but also to awareness of cooperative interaction rules. When producing or interacting in a spoken discourse, there are several components to consider: speed, intonation, pitch, pauses, filler words, gestures, giggles, assumptions, social conventional features and rules that vary depending on the cultural signals that differ from one culture or country to another.

Referring to coherence, when we try to understand a discourse, we have to interpret every utterance enclosed in it, but we also need to know how these utterances or sentences are related to one another. Interlocutors make assumptions and inferences to understand texts or discourses, which could make us think that coherence is basic to our understanding ability (Kehler, 2001, p. 3). Hobbs (1982) starts his definition of coherence by showing us what coherence is not. He stands that coherence is not the same as cohesion, the use of explicit connectives, prescriptive rhetoric, or mere comprehensibility. He distinguishes between three types of coherence: global coherence, local coherence, and thematic coherence. We will see the coherence of another interlocutor's utterance insofar if we see it as an action on our plan. Therefore, the global coherence of an utterance is its relation to the speakers' overall plan (Hobbs, 1982, pp. 226, 227).Eventually in the development of a discourse, the speaker or the writer is going to feel the responsibility of covering the needs of the text above all. That is called local coherence, the relation to adjacent segments in the discourse (ibid, p. 227). On the other hand, thematic coherence is characterized within long texts where certain "themes" (words, facts, schemas...) are repeated. It also stands for different texts in a corpus built on top of the same beliefs (ibid, p. 228).

As Hobbs contends, it is very difficult to find an incoherent discourse, and when we discover a piece of discourse that lacks of coherence, we try to find the hidden coherence within it. 
In relation to effective communicative processes, it is important to claim that they depend on culture-specific rules and turn-taking processes. Therefore, we need to allude to politeness. Politeness involves perceptions, expectations, and customary realizations of communicative approaches that contribute to mutual understanding between individuals and groups. People acquire these politeness rules when learning their first language, as part of their pragmatic competence, but when learning a second language the conventional rules of the culture need to be learned (Celce-Murcia and Olshtain, 2000, pp. 25, 26).To give an example, there are several differences between Spanish and English cultures. The eating schedule is very different, as well as the meals, punctuality is not very common between Spaniards, and British people are known for their formality and politeness. But one of the most remarkable contrasts regards to personal space. As a teacher I always tell children to be very respectful with personal space. Spanish people use to be much more proximate physically to others than other cultures. That does not apply to all Spanish people, but it is a general Spanish aspect. Shaking hands is expected between men and kissing in both cheeks or hugging is expected among women or men-women in Spain. Conversely, shaking hands is a common greeting in Great Britain among men and women, but kisses or hugs are left for very close ones. Therefore, some people may be disturbed or upset if they feel their personal space is being invaded. It is very important to teach cultural aspects too, not only grammar rules, vocabulary or phonetics, the main idea is to focus on language usage in communicative situations.

Culture-specific rules and turn-taking processes are extremely difficult for foreign learners, as Cook asserts (Cook, 1989, p. 57). What is correct in one culture may appear rude in another. Changing a topic might be a way to elude an uncomfortable question, just a strategy to avoid a topic we are not familiar with or a way to hide the lack of vocabulary or fluency in a specific matter. It is not the reason that matters though, but the means we use to do so without being inappropriate. Sometimes young learners or beginners need more time to think about the words they want to use and that interferes or ends a conversation or a spoken interaction too. For some others, that very same reason not only hinders, but impedes the interaction. Occasionally children also answer "out of turn” in class. That's why many discourse analysts have led the attention of their study towards how people behave and manage cooperatively the discourse. 
How can we teach how to participate in a conversation if that communicative action is supposed to be free and spontaneous? Some involved features are very difficult to teach, however some quirks are affordable for all learners, such as idiomatic expressions. In the next section some general activities related to oral expression will be shown, and in section 8 the tasks will be focused on children, including ADHD students.

\subsection{ESL activities in which discourse analysis is exercised}

"What is the difference between being a teacher and being a teacher-who-doesclassroom-discourse-analysis?"

Betsy Rymes

Rymes poses the query "What is the difference between being a teacher and being a teacher-who-does-classroom-discourse-analysis?” (Rymes, 2016, p. 212). Throughout the section Discourse analysis in the language class and language in use we have provided the readers with some clues to know what an instructor can do to be a discourse analysis oriented teacher. The author highlights the importance of including discourse analysis in classrooms as a recursive procedure. That would give students more opportunities to learn and participate, fostering communication and meaningful learning during the classroom interactions (Rymes, 2016).

Throughout this section different activities are proposed, based on several author's activities. The ESL activities in which discourse analysis is exercised are divided in turn into four categories: activities related to written comprehension, activities related to oral comprehension, activities related to written expression, and activities related to oral expression.

\subsubsection{Activities related to written comprehension}

Serjev Ivanov (2009) explains some of the recommendations that Lezberg and Hilferty (as cited in Ivanov, 2009) offer to teachers who work with reading in the classroom. Among them, "scanning" and "skimming" activities are noteworthy, activities prior to reading, during and after reading. 
The activities of "skimming" consist of doing a quick reading, looking for ideas or phrases. They aim to quickly recognize the main ideas of a text. On the contrary, "scanning" activities are based on finding specific information. Its objective is to make an exploratory reading, more attentive. As for the activities prior to reading, we will take into account the previous knowledge and experiences of the readers, which will be used to predict the content of the reading. For this they could pay attention to the title and the illustrations if there were any. Throughout the reading you can perform activities that confirm that the readers are understanding the content, that is, activities of reading comprehension. Once the reading is finished, we can propose activities to deepen understanding, in which students make inferences and can critically expose what they have perceived. As we shall see in section 8, “Teaching Second Languages and ADHD” these activities can be carried out in very different levels, adjusting the texts and the questions to the L2 level students have. We will explain in detail how they have been implemented in inclusive Primary Education classes. Another example is detailed below:

TEXT:

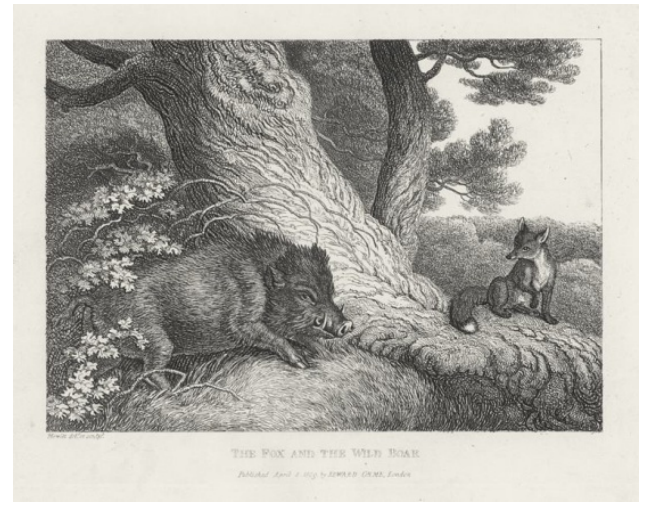

Image 2. Howitt, S. (1810). The Fox and the Wild Boar.

\section{The Wild Boar}

A wild boar was whetting his tusks against a tree when a fox came passing by. Curious, the fox asked why the boar did sharpen his tusks so. "Why do you spend your time like this? There is neither a hunter nor a hound in sight, nor any danger that I can see at hand," said the fox.

“True,” replied the boar. "But when the danger does arise, I shall have something else to do than to sharpen my weapons.” 
It is too late to whet the sword when the trumpet sounds to draw it.-AESOP

(Allison, 1998, p.16)

The scarce length of the text makes it suitable for children or beginner's language apprentices. The first activity aims to analyse the knowledge of the readers related to the text and the language. To do so, the following pre-reading activities are suggested:

ACTIVITY 1: What does the title suggest to you? What do you think the reading is going to be about?

Depending on the age of the readers we could make a different question or simply add it to the previous one, in case we want to extend the pre-reading activities:

ACTIVITY 2: Where can we find wild boars? Give an elaborated response.

A skimming activity could follow the previous ones. We could ask the readers the following:

ACTIVITY 3: Read the text quickly.

ACTIVITY 4: What is the text about? Does it match the previous idea you had? We suggest to read the text aloud, so we can make some questions to confirm that the learners are understanding the text:

ACTIVITY 5: Throughout the reading questions:

1. Can anyone think of another animal with tusks?

2. Do you have anything in your case to whet?

3. Who can describe a hound?

A scanning activity is perfectly suitable to continue with the proposal. The aim is to look for specific information. Once we know that the readers understand the text, we can delve into the content:

ACTIVITY 6: Find these words in the text:

1. Sharpen. 
2. Fang.

3. Taking a great interest in other's affairs.

4. A breed of dog trained to pursue game either by sight or by scent.

(Definitions by Wordreference Dictionary).

To complete the after-reading activities, deepening understanding activitieslike the one that follows are a good suggestion:

ACTIVITY 7:Answer the following questions:

1. What does the moral of the fable mean?

2. If you were the boar, what would have you answered to the fox?

3. Can you imagine a different answer for a different moral or just a different ending? Give a detailed answer.

Another author who offers an interesting methodology for teaching languages is Catherine Wallace, through the activities she proposes for critical reading, she claims that what the reader brings to the text is as important as what he or she gains from it (Wallace, 2003, p. 15).She has given many critical reading courses, using practical critical discourse analysis, in which "classroom" is considered a critical community (ibid, p. 92). Among her courses' principals, she states that no text are ideologically neutral (ibid, p. 102) and uses everyday life texts to teach. She examines several authors and proposes different texts in which her students practice critical reading analysis. The next text and activity 8 are examined using one of her activities, which in turn is based on Halliday’s framework of analysis (ibid, p. 113).

\section{TEXT:}

\section{Aesop and the Donkey}

“The next time you write a fable about me”, said the donkey to Aesop, “why not have me say something wise and sensible? I am tired of being the clown in all of your tales.”

"Something sensible about you?" exclaimed Aesop. "What would the world think? People would call you the moralist, and me the donkey!”.

(Allison, 1998, p.35) 
ACTIVITY 8: Read the text and answer the following questions:

1. Note any use of:

- Personal pronouns or ways the main participants are referred to.

- Declarative or indicative, interrogative, imperative and subjunctive mood.

- Language items, such as adjectives, which reflect the writer's attitude.

2. Note the verbs that collocate with the participants.

3. Note what kind of text this is.

ACTIVITY 9: Answer the following questions about the text:

1. What does the text mean?

2. To whom is the text addressed?

3. What other ways of sending the message could have used "donkey”?

4. Write a different ending for the text and ask your partners to debate about it.

Josep Cots proposes activities to carry out a critical analysis of discourse through reading, with activities similar to those proposed by Catherine Wallace. Cots exposes how to work critical analysis of discourse through two activities. The first activity is based on a text by Oxenden et al. (as cited in Cots, 2006). He addresses social analysis by explaining the shortcomings offered in the proposed activities. To do this, Cots suggests complementary fill in the gap activities. These activities analyse three levels: social practice, practical discourse and textual practice. In these activities, not only the readers analyse the social factor, but the author also proposes a reflection of the society and the emotions and ideas that this provokes. Additionally, he delves into the analysis of the text from inferences. The same happens with the activities in which he performs the textual practice, performing a discourse analysis while analysing whether the ideas presented are paradoxical or contradictory in terms of the connectors, the vocabulary and the way in which the ideas are exposed. In his second proposal, Cots reveals how through two versions of the same text, critical analysis of the discourse can be implemented in the classrooms following Willis' proposal (1996, as cited in Cots, 2006) of tasks: activities to be done before, during and after the task. Further details about how to implement them in a Primary Education lesson and an example will be given in section 8, together with the skimming and scanning proposal (Portfolio-Oxford reading). An example about how to implement discourse as a result of social, discursive 
and textual practice is presented below. Three activities will address the purpose of discourse analysis through a text about Inuits from the National Geographic:

\section{TEXT:}

In the spring, when animals migrate north and the sun never sets, Inuit children join their families on weeks-long camping trips across Canada’s Arctic. They're taught hunting skills and cultural values passed down for more than 5,000 years. In the past three decades, multiyear ice, the thickest (and oldest) type that supports the Arctic marine ecosystem, has declined by 95 percent. Elders no longer can predict safe travel routes on thinning ice, and animal migration patterns are changing. The future of the ice-and those who live on it-is uncertain (Johnson, A., 2019).

ACTIVITY 10: Answer the following questions:

1. Are the Inuits a typical community? Name some of the differences with your own community.

2. Do you think global warming is affecting them?

3. Would you like to be an Inuit? Why?

In this activity we are practicing the social point of view, not only by analysing an unusual community, but also exploring about what the readers know about an ongoing issue like global warming and using that exploration to raise awareness about the importance of doing something to really minimize the effects of such an important worldwide problem. The next activity focuses on the discursive practice.

ACTIVITY 11: Answer the following questions:

1. Where can you find this text? What is the genre of the text?

2. What are the main ideas of the text?

3. What do you remember of the Inuits after reading the text?

4. Do you think Inuits are a typical community? Why?

In this activity we have analysed the discourse type of the text and the readers' previous knowledge about the topic. We will complete the proposal with a sample activity about textual practice, focusing on the formal and semantic features of the text: 
ACTIVITY 12: Answer the following questions:

1. What linking words connect the following ideas in the text?

Animals migration, . Camping trips

Routes prediction, . Migration patterns

2. How did the author link the two main ideas of the text?

3. Write two independent sentences from the text joined by a connector.

Another author that also prompts us to use discourse analysis during the ESL lessons, or, as children love to hear, to "play with the language" is Cook. We are referring to Cook’s “flouting co-operative principle” (Cook, 1989, p. 31), where the disregard of the co-operative principle plays an important part on the communicative process. When the addresser pretends the addressee to notice "the intentional infractions"-that is the use of metaphors, hyperboles, irony or sarcasm- the correct interpretation of the message will depend upon the previous knowledge the addressee has, otherwise the message will be misunderstood. Therefore, Grice’s four maxims of communication -quantity, quality, relevance and manner- can be flouted. As the author contends, children and language apprentices are probably lacking the knowledge they need to understand the message properly. It is therefore quite challenging to use that principle to teach ESL to kids, it is for that reason that we have used the term "play with the language”. Two activities will be shown hereunder, the first one is addressed to grown up learners and the second one to children:

ACTIVITY 13: Which maxims of the co-operative principle are being flouted?

1. DO NOT feed the monkeys.

2. Dude just chill out!

3. -How do you like that book?

- I think it’s terrific!

ACTIVITY 14: Can you guess what the following messages are really trying to tell us?

1. Her eyes were fireflies.

2. My teacher is a dragon.

3. The kids were monkeys on the jungle gym. 
The examples in these activities come from two websites, although they could be part of a conversation in real life. The sentences in activity 13 come from Google and from the book “May you live in interesting times” (Glük, 1995, p. 131), and the ones in activity 14 are by Elisabeth Baxter (2014).

Some of the activities described in this subsection could be drawn under a double typology, written and spoken. The only difference between both is based on the means of production and reception. Written activities depend on hands and eyes, meanwhile spoken ones rely on the use of mouth and ears (Cook, 1989, p. 50). Hence some of the activities could have been answered orally, such as task 11 . The teacher can ask them written or orally, letting the students discuss the answers aloud, bringing out a debate. Interpretations of texts can also be variable, as they depend on every person, therefore the results can be subjective sometimes, as it can be the case in activity 13 . For example, for the sentence “Dude just chill out!” there will probably be more than one possible scenario between the students, despite they agree on the cooperativeprinciple being flouted.

When reading a text in a foreign language we need to approach different concepts. Yet on the basis of a coherent and cohesive text, readers may encounter difficulties. In the process of comprehending a written text the reader needs to complete three tasks: decoding the message, interpreting the message and understanding the author's intentions (Celce-Murcia and Olshtain, 2000, p. 119). Even native speakers can misconceive the author's ideas, what leave foreign learners in a hazardous position when beginning to acquire the target language. That is why previous and cultural knowledge are determining to decode and understand texts properly.

\subsubsection{Activities related to oral comprehension}

Olshtain and Celce-Murcia claim that it is fundamental to associate discourseoriented activities where phonological features signal awareness, as pause and intonation; lexico-grammatical features signal consciousness, such as discourse markers and word order; and content organization knowledge signals contextual details that are performed. The authors discuss a very interesting activity in which all the previous 
characteristics are integrated. This activity is actually suggested by Geddes and Sturtridge (1979, as cited in Olshtain and Celce-Murcia, 2005, p. 717) and is based on the idea of a "listening jigsaw". In the course of the task, small groups of students will listen to nonidentical parts of a piece of discourse (e.g. a story, a TV or radio broadcast, etc.) and will take notes of the relevant details. Each group will share their information with the rest of the groups, so they can build up the whole discourse. Celce-Murcia and Olshtain also contend that language apprentices require to acquire some strategies that help listeners when they are facing difficulties during interactive listening (ibid, p. 716). The best way to develop the compensatory strategies they can need is practicing. Hence, Celce-Murcia and Olshtain propose some tasks to develop this skill, activity 15incorporates some noise, but is reinforced by body language and activity 17 is a telephone conversation, where the absence of face-to-face interaction may difficult the right comprehension of the whole discourse. Students need to listen to, interpret and practice the stereotyped expressions of telephone conversations.

ACTIVITY 15: Explain a partner a piece of news you have heard recently. During the explanation some music will be played, feel free to use body language if you need it to convey your message despite the noise. (Note to teachers: play some loud, noisy music during the activity).

Once the students have finished activity 15 , we can ask them a few questions about it.

ACTIVITY 16: Answer the following questions:

1. Did your classmate understand the piece of news you tried to explain him/her?

2. Was it easy to convey the message with such noise?

3. Did you use body language? Do you recall making face gestures?

4. Did the listener use any discourse markers during the intervention? If so, which ones?

ACTIVITY 17: Find a partner. Then, one or the other will leave the class. You need to have an English phone conversation about bushfires. 
The topic can be adapted to the language level of students. Beginners may talk about routines, holidays or a familiar topic, meanwhile advanced learners should be able to discuss any subject. For advanced students we can also use walkie-talkie instead of phones, adding some extra difficulty to the activity with a worse quality of sound, noise and buzzing. This activity can also be done with children using walkie-talkies, although kids with a beginner language level may encounter too many problems to understand the message. Once again, we will ask the students some questions after concluding the phone call conversation.

ACTIVITY 18: Answer the following questions:

1. Did you understand your classmate? Did he/she understand you?

2. Did you find any difficulty to maintain the conversation? In case of an affirmative answer, explain which ones.

One of the discourse-teaching features we have emphasised along this paper is the use of real data, as well as the use of students' background information. Nowadays almost every adult has a mobile phone and preparing students for telephone calls with customer services will be a great help for them in the future. That is why we suggest the following activity:

ACTIVITY 19: Listen to the phone conversation in the following link. Then answer the questions:

\section{https://www.youtube.com/watch?v=h3XfI8rNGdE}

1. What is the problem of the customer? Give a detailed answer.

2. Does the company offer him a solution? Give reasons to your answer.

3. After a second listening, write down words and phrases used to open or close the interventions during the conversation.

We have already used a video from YouTube to hear and examine a telephone conversation. Information and communication technologies (ICTs) can be applied in discourse analysis oriented language teaching. Internet is a very useful tool that not only 
allows us to find millions of resources that fifteen years ago were beyond the means of teachers, but also permits us to use real and interactive materials that attract students very much. Fernández (2014) considers that ICTs should be included in any course in discourse analysis and, by doing so, essential theoretical concepts and tools for the analysis of texts will be provided, and texts can also be considered an instrument of social action, which might encourage students to undertake critical assessments on texts following coherent reasoning (Fernández, 2014, p. 72). The author approaches the teaching of discourse analysis through several activities using ICTs. One of the exercises she displays is about asking for a critical position through the analysis of a speech from a film. Based on that very idea, we suggest the following activity:

ACTIVITY 20: Watch “Wonder”, the film. Then watch and listen carefully to the following sketch from the movie, and answer the following questions:

https://www.youtube.com/watch?v=JBnh8BuUxHo\&feature=emb_logo

1. How would you define the term "bullying"?

2. Describe some "antibullying" actions that are shown in the film.

3. Mr. Tushman cites a quote from Henry Ward Beecher. Part of that quote says: “Greatness lies, not in being strong, but in the right using of strength". What does it mean to you?

4. Who was Henry Ward? Do you think the quote he stated in the nineteenth century is still needed to be pronounced in today's society? Why?

5. Today's society has evolved considerably in the last centuries. Technological inventions and developments have helped people considerably. But what about social values? Have we really evolved that much?

6. Mr. Tushman gives the Henry Ward Beecher medal to "Auggie”, because he considers that "his quiet strength has carried up the most hearts". Can you name some of the moments he showed up that "quiet strength"?

A very similar activity with the same film, adapted to children, is submitted in section 8. Critical thinking as part of discourse analysis or language teaching is as important as the contents we are expected to teach. We could have used many other films to suggest a critical thinking activity, but showing how to use the same material to 
teach different language learners is also interesting and significant from a pedagogical point of view.

Fernández also studies discourse as a social tool, showing how discourse and context interact and can be used as an instrument of power and ideological control. Based on other authors works, she states that the relation between discourse and social context is bidirectional, in a way that discourse is affected by social conditions and context is influenced by discourse too(ibid, p. 74). We can see this correlation in the following activity, in which the lyrics and the images depict a clear protest against a terrorist attack.

ACTIVITY 21: Listen to the song displayed in the following video and answer the following questions:

https://www.youtube.com/watch?v=cWfZjV4i2Nk

1. What is the video about?

2. Why are there some scenes where children are dressed up as angels?

3. What do you know about IRA? Find information about IRA if you do not know anything about it.

4. What do you think about terrorist attacks?

5. What do you think the music band thinks about terrorist attacks? What makes you think that?

Richards (2008) is another author who copes with spoken and written discourse and deals with oral comprehension. The author focuses on the two approaches involved in understanding spoken discourse: the bottom-up and top-down approaches. As mentioned above, in bottom-up processes comprehension is viewed as a process of decoding, examining the oral discourse and using grammar to assemble the received elements (Richards, 2008, p.4). According to Richards, exercises such as dictation, cloze listening, multiple-choice activities after a listening, and activities that require specific identification and processing of the data, develop bottom-up processing and help students to: keep data while processing, identify words and sentence divisions, identify transitions in a discourse, identify grammatical relationships, identify sentence 
functions through stress and intonation (ibid, p. 5). The next activity is based on one of Richards' examples and aims to develop the ability to identify key words after listening to the text. The passage is from a free English resources website (www.rongchang.com/reading.htm), although there are numerous websites that offer short and long texts to use for all levels.

TEXT

Sara Smith, a Pasadena resident, went shopping. She is 30, and has lived at 3037 N. Foothill Street since 1992. Sara has been married to John for seven years. They have two children; Bob is five years old and Nancy is three. Sara owns a 1995 four-door blue Toyota. At 9 a.m., Sara got into her car and drove to Barget, a department store a mile away.Barget was having a holiday sale. Sara bought a four-slice toaster for $\$ 29.95$ plus tax. The regular price was $\$ 39.95$. She paid by check. On her way home, Sara stopped at MilkPlus to buy a gallon of nonfat milk. The milk was $\$ 3.50$. Sara got 50 cents back in change. Sara arrived home at 10 a.m., John and the kids were still sleeping. She woke them up and then made a hot and nutritious breakfast for everyone.

ACTIVITY 22: Which of these words did you hear? Number them in the order you hear them.

$\begin{array}{lll}\text { Breakfast } & \text { holiday sale } & \text { shopping } \\ \text { married } & \text { nonfat milk } & \text { department store }\end{array}$

The same activity can be adapted to the level of students. For beginner learners instead of asking them to number the given words in the order they hear them, we can give them some words from the text and some words that do not appear in the text and ask them to circle the words they have heard. We show how to do it in the next activity.

ACTIVITY 23: Which of these words did you hear? Circle the words you hear.

$\begin{array}{lll}\text { owns } & \text { cash } & \text { gallon } \\ \text { Carnaby Street } & \text { four-slice toaster } & \text { cold }\end{array}$


In top-down processes Richards comprehension relies on the use of background knowledge. The information we have about the world is the data we apply when using top-down processes to understand an utterance or a discourse. Correspondingly, topdown procedures help students to develop abilities to: use the main words to create the gist of discourse, deduce the context of a text, deduce the characters' features and their aims, deduce causes or effects, deduce implied details, and predict details of the situations (ibid, p. 9). If we turn over task 23, giving the words before letting students hear the text, we will be working under a top-down approach. The same idea can exercise different aspects, depending on the way we plan it and where we place the focus.

ACTIVITY 24: Read the following words, then listen to the text:

$\begin{array}{lll}\text { children } & \text { girl } & \text { bread } \\ \text { resident } & \text { department store } & \text { nutritious }\end{array}$

(After hearing the text) Which of the words you previously read are mentioned in the listening?

Teaching listening strategies can just develop learners' listening abilities such as comprehension or it can also imply language development. For this latter to happen students have to use them in oral production to include them as part of their active vocabulary. There are thousands of activities to practice listening as comprehension, listening as acquisition, and even activities that combine bottom-up and top-down processes. Richards offers a variety of examples to cover them all in his book Teaching Listening and Speaking. From theory to practice (2008).

\subsubsection{Activities related to written expression}

Celce-Murcia and Olshtain assert that writing has much in common with reading and speaking when viewed as a language skill used for communication. Writing is the use of the written text, but it is mostly often expected to be read. Hence, to perform a communicative act we need someone to write the text, but we also need someone to read it, therefore the relation is quite clear. Regarding to speaking, it has been said that writing is very different from speaking, but it has also been compared and stated that writing and speaking are similar. The similarity lies in considering speaking and writing 
productive skills, because in both actions the writer and the speaker are producing a discourse, written or oral (Celce-Murcia and Olshtain, 2000, p. 143).Anyway, writing with a communicative intention needs some mental organization and some linguistic knowledge in order to produce a cohesive and coherent text. Teachers should help students to write coherent texts and to take into account not only the background knowledge of the readers, but the intratextual characteristics too. Celce-Murcia and Olshtain submit several activities to make students aware of the importance of coherence and to practice. Based on these ideas, we present the next activity.

ACTIVITY 25: Fill in the blanks with one to three words:

The owner of a (1) cat is asking for help. "My baby has been missing for (2) a month now, and I want him back so (3) ," said Mrs. Brown, a 56year-old woman. Mrs. Brown lives by herself (4) a trailer park near Clovis. She said that Clyde, her 7-year-old cat, didn't (5) home for dinner more than a month ago. The next (6) he didn't (7) for breakfast either. After Clyde missed an extra-special (8) , she called the police.

With this text from the website www.rong-chang.com, we can show you how sometimes several possibilities are feasible. Giving closed answers do not permit students to use their background knowledge properly, and may end in more errors than the ones they could have, which may disappoint and discourage them. Therefore, it is widely recommended to accept any possible proper answer, as long as the text makes sense. Besides, each space will constrain the others, and here is where lexicogrammatical knowledge and intratextual features domain will need to be used and shown.

Another good activity to practice written discourse analysis is taken from Widdowson' example explained above, where a simple word as "Ladies” on a door can be considered a text in some context. Accordingly, we suggest an activity in which the students have to think about single words that can be considered texts in particular contexts and write down possible scenarios that can take place when reading it. 
ACTIVITY26: Here is a sign: "Silence”. Supply a context in which it would make sense, so it could conform a text. Give another example of text with one word.

McCarthy also contends that writing is not very different from speech. He offers several examples of how letter-writing activities are affected by cross-cultural features, which can generate problems in some kind of letters, specifically with business letters (McCarthy, 1991, p. 152).Writing formal letters may present difficulties, so it stands to reason to submit several activities in which students can practice and get feedback about a proper way to write a business letter.

ACTIVITY 27: Imagine you are working for Google at the publishing section. Write a letter to schedule a meeting.

ACTIVITY 28: Imagine you are at the post office and you want to write a complaint letter to the office regarding something that happened to you there. Write the letter.

ACTIVITY 29: Imagine you have just graduated from college and you want to apply for a job position at a company and you are sending them your CV and an application letter. Submit an application letter for a job.

McCarthy also presents an interactive activity in which students need to recreate a text, paying attention to word order, cohesion and sequences of tenses in discourse. The activity aims to recreate a text that students have previously read. When the content is familiar, the author offers the possibility to use the idea of "jigsaws", where the class is split in two and one of the group gets the even paragraphs and the other one gets the odd paragraphs. Both groups have to complete the missing paragraphs with their own words, conforming a coherent and cohesive text (ibid, p. 153). That interesting activity can also be adapted when the text is unknown or for known stories for children or beginner learners. We submit and adapted activity based on McCarthy's proposal. The next text is divided into different paragraphs. Students will be given the paragraphs in a wrong order. The title of the story is “Brave Dan” (Allison, 1998, p. 21). 
1. The whole family had gone out for the evening, leaving Dan, the new pup, all alone.

2. Dan was overjoyed because he had always wanted to be master of the house.

3. Dan had never been the master of anything before, and he liked the idea of being in charge.

4. He trotted proudly through the halls and poked his nose into every room, looking for burglars and other bad guys.

5. All was quiet until Dan heard a noise.

6. It seemed to come from his master's room: “Tick...tick...tick...”.

7. Oh dear! Someone was in the house! Who could it be?

8. Dan wasn't so sure he liked being all alone.

9. Suddenly he heard a loud gong as the clock on the mantlepiece struck one.

10. Brave Dan scampered off as fast as his legs could carry him.

11. And that was Dan's big night as master of the house.

ACTIVITY 30: Put the paragraphs into the correct order. Clue: Read all the paragraphs before deciding on the correct order.

The same story, “Brave Dan” can be used to work on clause relations and cohesion. We can ask students to invent a different ending, using different cohesive ties, such as conjunctions, reference, substitution, ellipsis, and lexical cohesion.

ACTIVITY 31: Read the story “Brave Dan” and invent a different ending.

Some activities could be categorized in several categories because they develop different skills. That is the case of “dictations”. Dictations are exercises that can be aimed as oral or written comprehension activities. If the teacher reads a passage and students write it, it is obviously a written comprehension activity, a productive activity where listening comprehension is also practiced. But if we ask students to pair up and ask one of them to read and the other one to write and then we ask them to switch roles, both students will be practicing reading, oral, listening and written comprehension with just one activity. 
A good way to collect written works is the use of "portfolios". Portfolios are a popular method for students and teachers at the moment. They consist in a compilation of written works and assignments that permit students to collect their works and teachers to assess them. They permit not only evaluate every single task or activity, but to see the evolution and language improvement of every student. Some teachers allow students to select a specific number of writing activities in order to evaluate them using their most representative works (Celce-Murcia and Olshtain, 2000, p. 159). There are some specific portfolios for children. We have used the European Language Portfolio with students in primary classes. The official portfolio not only pretends to keep the writing assignments, but any activity or item related to the learning of languages. Pictures, audio-recordings, even toys are welcomed to be part of the portfolio. Its main aim is to promote language acquisition and cultural awareness. Further details will be given subsequently.

\subsubsection{Activities related to oral expression}

As has already been stated, sometimes the only difference between writing and speech is based on production and receptions means. As mentioned above, written activities depend on hands and eyes, meanwhile spoken ones rely on the use of mouth and ears (Cook, 1989, p. 50). But there is a considerable difference between both, speech is produced in a specific moment and there is no way to turn back or possible retreat. Of all four linguistic skills, speaking is, as a general rule, the most difficult one for non-native speakers. When we read we understand much more vocabulary and grammar structures than the ones we are able to produce. Passive vocabulary is always larger than our active vocabulary. The same happens with listening, we often understand much more discourse than the one we are able to produce. Although sometimes listening comprehension is far lower than it should be due to local accent variations, slurring, speech rhythm, rapid rate (speaking too fast), mood shifts, hesitation markers, unknown idiomatic expressions, misperception of irony, sarcasm or any other non-literal language, or even due to external noise. When we write we can read several times our writing and change the written matter. But when we speak we do not have extra time to think about what we want to say or how we can say something we have in mind. There is also no manner to delete something that we have already 
blurted out. Speaking is, therefore, a skill that not only entails grammar and vocabulary knowledge or proficiency, but it also requires quick thinking and prosody domain. Nonetheless, few times oral discourse can be prepared, as it is the case of lectures or meetings.

Teaching conversation is rather challenging, to say the least. As Cook contends, between the features of conversation we find spontaneity, freedom or equality among participants, but it also involves holding, pliant in turn-taking, the agreement of meaning, topic's adjustment, the voice quality, and face and body gestures (ibid, p.117).

When we speak we should use assimilations and elisions naturally, as McCarthy professes, but even some good advanced students keep articulating the citation-form phonemes of English words in connected speech (McCarthy, 1991, p. 89). Given this circumstance, the teaching of pronunciation is an important part of the teaching of oral expression. According to McCarthy, three areas should be confronted: segmental features, voice-setting features and prosodic features. The author also states that every language has a rhythm when we listen to a stretch of discourse, a fluctuation of strong and weak beats (ibid, p. 90). Following McCarthy's statements and sample activities, we submit a rhythm practice in the next activity:

ACTIVITY 32: Imagine contexts for these utterances and mark them with / for stressed beats and - for unstressed beats:

1. How are you doing?

2. I've been there a while ago.

3. He is really doing a great job, isn't he?

4. This chilli is extremely hot and spicy.

Pawley and Syder study the communicative process too. They contend that there are numerous routines for conversations, wordings to express the beginning or ending of a conversation, idioms to refill discussions, patterns to change from one topic to another and other fixed expressions that a language learner have to acquire to sound natural in his or her speech (Pawley and Syder, 1983, as cited in Richards, 2008, p. 20). Therefore, we can suggest several activities to practice some of those conversation routines. The first one aims to practice chunks to buy thinking time. Depending on the 
level of the learners we can add or suppress chunks. Another way to adapt the activity to the language level is with timing, it can be a good idea to establish a minute of interactive conversation for beginners.

ACTIVITY 33: Practice the following chunks to buy thinking time in a conversation explaining a need with a partner:

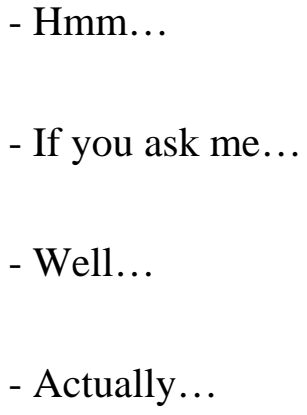

The next activity involves speaking without seeing the other person, which makes communication more difficult due to the lack of face and body gestures.

ACTIVITY 34: Pretend you are making a phone call to change your mobile company with a partner, who will try to persuade you to hire his or her firm. To make it more natural, put your backs together, so you cannot see each other.

Richards also claims that different speech styles reflect perceptions of social roles (Richards, 2008, p. 21). Different speech styles can also show the relation between speech participants, roles, age, sex or even their status. The next activities seek to practice different speech styles.

ACTIVITY 35: Consider four different ways to ask someone the time. Practice with them with your classmates.

ACTIVITY 36: Choose one style from the different ones suggested below and speak with a partner in the selected style. Your partner has to guess the speech style you are using. Then, change roles. Your partner will be the speaker and you have to recognise the speech style he or she is using. Some examples will be given. Feel free to use them and add some new words and expressions to your discourse. 


Speech styles
“whasssup?”, “dude”, “watchagonna
do?”
“Well, that is up to you”, “can you
please...?”, “I just...”
"He/she likes you”, “I’m so proud of you
sweatheart”, “Cold” (instead of “it is
cold”)

Olshtain and Celce-Murcia affirm that when we use a language with a communicative purpose, we are immersed in two processes: the production and the interpretation of discourse. The former one is used in speaking and writing, whereas the last one, interpretation, entails listening or reading strategies. When we use spoken language in a conversation, we need to appeal to compensatory skills to overcome the lack of language means to maintain the communicative process, otherwise misunderstanding will arise (Olshtain and Celce-Murcia, 2005, p. 716). The same appeals to appropriateness and cultural and social norms, language learners must improve the mastery of these strategies in order to become good speakers, making themselves understood and perfectly interpreted by their hearers or the audience (ibid, p. 720).

Finally we should mention that language teachers are trained to teach grammar, phonetics, reading, writing, listening and speaking, but there is still a lack of pedagogical discourse analysis training between primary educators. Cultural communication is important to be acquired too, being a good teacher requires far more domain of skills than just the linguistic ones.

Teachers need to be aware of the different types of texts and to be familiar with speech and writing skills, they need to receive a good training in phonetics and in lexico-grammar and learn how to blend it and bring it to the discourse level in the classroom. Educators also need to be aware of the shared knowledge of the students and take into account their personal capabilities, needs and background. Discourse is about language and context, and students' contexts also count, for all discourse is interactive in some way. 
Discourse feed-back is crucial too, as we have mentioned above. And so is assessment. According to the age of the students discourse evaluation will vary, trying to raise the students' learning awareness and stimulate self-correction. Likewise selfanalysis is fundamental. Celce-Murcia and Olshtain argue that reflective language teachers, who are concerned on students' needs and development, classroom events and their own actions, can conceive personal and professional principles that will guide their work in the future (Celce-Murcia and Olshtain, 2000, p. 223).

We concur with Celce-Murcia and Olshtain that the language classroom should be a discourse community in which teachers and learners are both an interactive part of the teaching-language process. Classes should not be teacher centred, and apprentices should be active and independent learners. Materials should be comprised of actual information, activities should be planned and exercised under a discourse analysis scope, and students should develop critical lexico-grammar knowledge. 


\section{Approach to the concept of ADHD}

From the many definitions of the concept, we spotlight two definitions from Barkley:

"ADHD is a development disorder of self-control, consisting of problems with attention span, impulse control, and activity level.” (Barkley, 2013, p. 19).

"ADHD is not only a disorder related to physical impulsivity or inattention, it is an impairment that also affects the ability to control the passage of time, or the consequences of their own actions.” (Barkley, 2013, p.25).

Dykman offers us a glimpse through the early history until recent years of ADHD. From "brain damage syndrome" to ADHD several names have been used to refer to the same dysfunction. In fact he was one of the first ones to propose to use an attentional definition instead of the term “minimal brain dysfunction” (MBD) in 1971. He highlights Bloomingdale and Sergeant's proposal of strict research diagnosis criteria and draws attention to several authors' works, such as Barkley, among others, who questioned the concept of attention deficit as the determining characteristic for $\mathrm{ADD} / \mathrm{ADHD}$ and contends that Barkley's theory of Response Inhibition is one of the most popular ones (Gozal and Molfese, 2005).

We define ADHD as a neurodevelopmental disorder, typified by inattention and hyperactivity. There are five brain regions connected to it: the prefrontal cortex, the anterior cingulate cortex, the frontal section of the corpus callosum, the striatum, and the cerebellum. These areas seem to be about 15-30\% smaller than they should be in ADHD people (Barkley, 2016, p. 12). It is also an inherited condition, there is a $35-54 \%$ chance to inherit the dysfunction when one of the parents is typified under this term. Therefore ADHD can be a neurogenetic disorder (Barkley, 2016, p. 11). The aetiology of ADHD is varied. The main factors that contribute to ADHD are genetic and neurological factors, being heredity one of the most confirmed ones. Children with ADHD are likely to have a parent, sibling, grandparent or another relative associated to the disorder. Gene abnormalities, such as veliocardiofacial syndrome, may also raise the risk for evolving ADHD (Barkley, 2015, p. 357). Sometimes ADHD is caused by nongenetic factors, such as fetal alcohol and/or smoking exposure, prenatal or birth complications, low birth weight (less than 2500 grams) or even mother stress during 
pregnancy. Cocaine mother consumption during pregnancy may also lead to ADHD signs, although further research is needed to conclude it (Barkley, 2013). Another factor related to the development of the disorder's symptoms is postnatally exposure to some environmental toxins, such as lead or pesticide. ADHD may also be caused by traumatic brain injuries. In fact, several studies have found similarities between ADHD symptoms and the injuries produced in the prefrontal cortex of the brain too, such as inattention and problems with inhibition and regulation of emotions and motivation (Barkley, 2015). It is also believed that ADHD’s neurotransmitters may be impaired or imbalanced, affecting certain regions related with the disorder. Medication facilitate the release of the neurotransmitters and inhibit their reuptake, increasing dopamine levels, and improving subject's attention as a result. It is also believed that environmental factors such as the lack of structures or routines or the handling of techniques and situations, affect children with ADHD, being able to improve or worsen the symptoms (Rief, 2005, p. 18).

This syndrome is commonly equally used with the acronyms ADD (Attention Deficit Disorder) or ADHD (Attention Deficit/Hyperactivity Disorder). Emphasizing that $\mathrm{ADHD}$, also written as $\mathrm{AD} / \mathrm{HD}$, stands for the three categories of the dysfunction. Barkley clarifies that ADD-H was removed as a subtype and redefined as category. He also stands that ADHD it is now categorized with two other behavioural dysfunctions, ODD (Oppositional Defiant Disorder), and CD (Conduct Disorder). The three mentioned disorders are catalogued under the term "disruptive behaviour disorders" (Barkley, 2015, p.22).

In its early history, society would have thought that attention deficit and hyperactivity disorder did not exist, ascribing this behaviours to a bad raising practice from parents. At present, many people still think that ADHD children do not have a disability, considering that these children simply need more punishment, more correction and less pampering. Unfortunately, that may lead to leave a child undiagnosed and untreated, which may end in a consistent chain of failures in a person's life, not only in his career, but in his personal life too. On the other hand, ADHD is starting to be a very familiar and popular disorder, and many children drop under this category just because they are very active or “uncontrolled”. Sometimes infants are just physically active, and there is no disability involved. Occasionally some of them are 
suffering from other problems, at other times they are just trying to get adults' attention, or in some other scenarios they are being raised under an excess of screen time (Miller, 2007). As a result, we have some children catalogued and medicated erroneously. To top it all, the drastic growth of people diagnosed with ADHD has led to speculations about whether or not we are facing a disorder or just a syndrome (García and Carral, 2012). None of this arguments facilitate the diagnose of the disorder.

Amidst the whirl of ideas, several studies have tried to proof whether television viewing and excessive use of screens (TV, smartphones, tablets, computers and video games) are associated or lead to ADHD. Although further studies are needed to support some data, outcomes submit several results where it is shown how attention and comprehension have been compromised when screen time exceeds the recommendations, as well as it is linked with behavioural and emotional problems (Tamana, Ezeugwu, Chikuma, Lefebvre, Azad, Moraes, et al., 2019). The American Academy of Paediatrics advises "no screens under 2”, only for video chat (https://pediatrics.aappublications.org/content/pediatrics/138/5/e20162591.full.pdf).

Aforementioned, additional considerations need to be analysed. In these times of ever-increasing use of screens, where TV is no longer the only distracting device at home, but computers, video games, tablets and smartphones can also take people's mind off everyday life, it is very difficult to ward off children or adolescents from them, and the more behavioural difficulties they have, the worse. But it is not fair to stress all the guilt over children. In a world where jobs do not end in our workplace and workdays are longer than expected, TVs and other electronic equipment sometimes are the quick way some parents have to take a break and, not to mention those ones who find it normal or even "cool”. It truly is funny to see a toddler playing with no problem with a mobile phone, for instance, when he or she barely emits words. But it is not funny we seek, but to prevent further problems. It is also remarkable how some studies show that ADHD individuals watch more television and account that they enjoy it more often than those ones without ADHD (Acevedo-Polakovich, Pugzles Lorch and Milich, 2007). Nonetheless, we are not here to judge or teach parenting to anyone, we just wanted to point out some other scopes that also need to be examined. The same applies to screentime exposure at schools. Does it benefit or is it going to be detrimental for students? 
Little is known about the effects produced by the introduction of technology in the classroom.

Although ADHD is the most diagnosed childhood disorder, affecting around 3\%-7\% of school-age children, there are still ubiquitous misconceptions about it at present and a lot of questions about how to cope with the undesired behaviours that take place in the classrooms. There are thousands of papers about ADHD, but this troubling disorder is still one of the major cause of teachers' distress (Cook, Tankersley, and Landrum, 2012, p. XIII). To provide children with a proper intervention teachers must have the required knowledge about the topic and show a positive attitude towards the disorder, leaving prejudged expectations aside. Despite the fact that there are general behaviour characteristics about ADHD, not every person acts the same or has the very same attributes. Stereotyping must be avoided in order to offer a proper prevention and intervention program.

It begins in early childhood and it often persists with variable severity into puberty or even adulthood in up to $65 \%$ of all cases diagnosed. It is predominantly diagnosed during pre-school or early school years and boys are two to nine times more often affected than girls (Wehmeier, Schacht, and Barkley, 2010, p. 209). They are likely to have difficulties at school and in their private life, including disrupting behaviour, social problems, low self-esteem, depression, or even delinquency in the hyperkinetic type (Taylor et al., 2004, p. 8). ADHD children are believed to be emotionally dysfunctional, they tend to have poor self-regulation skills, which includes the regulation of their emotions and the management of their frustration. These impairments together with their poor social and communication skills, leads them to have difficulties in their relationships, both with friends and family, getting worse when they also have some comorbid impairments such as oppositional defiant disorder (ODD) or conduct disorder (CD), which occurs about $60 \%$ of the time. All these factors make ADHD individuals prone to have low self-esteem (Wehmeier, Schacht, and Barkley, 2010, p. 210). Further to this, some health problems are associated with the dysfunction, such as eating pathologies and sleeping problems. Likewise they are prone to internet addictions, risky behaviours and they also have a high rate of physical accidents. To top it all, ADHD adolescents and adults appear to be associated with 
substance dependence or abuse disorder (Barkley, 2015). Hence the importance of having an accurate prevention and intervention program.

\subsection{Assessment and diagnosis}

There are different degrees of ADHD with a diversity of characteristics. Each individual manifests and copes with the disorder in their own way. Nobody has all of the symptoms or experiences the same personal events. Each individual's features are also believed to change as children grow up, disappearing during adulthood in some cases, despite the fact that $65 \%$ of ADHD children will continue to have the disorder during their adult life, as we have stated above.

Although ADHD has been acknowledged by clinical science since 1902, the formal criteria for diagnosing ADHD were published by the APA (American Psychiatric Association) in 1994 on the DSM (Diagnostic and Statistical Manual of Mental Disorders). The prevailing diagnostic for ADHD is described in the fifth edition of the DSM (DSM-V) and in the tenth edition of the International Classification of Diseases (ICD-10) (Barkley, 2016, p. 53). Both schemes present very similar behaviours, they differ in terms of the ways that the symptoms are weighted and combined into categories (Taylor et al., 2004, p. 9). DSM-V is widely used in the United States of America and, although ICD-10 is commonly used in Europe, many clinicians prefer to use the DSM-V too. Despite the European guidelines, practice vary between countries and centres (ibid, p.8). According to our experience and practice, we are familiar with the DSM-V. Therefore, given the nature of this paper, we are reviewing the diagnosed criteria described in the DSM-V.

The diagnostic criteria for DSM-V requires the presence of six or more manifested symptoms persisting for at least six months. The diagnosis is given only when the manifested symptoms are pervasive and do not match their developmental degree, causing impairment in at least two areas (family, school, social, work), and interfering with social, academic, or occupational functioning. The symptoms causing the impairment must be present before seven years of age, or twelve years of age for adolescents and adults (American Psychiatric Association, 2013). The diagnosed criteria for ADHD according the DSM-V are reported below. 


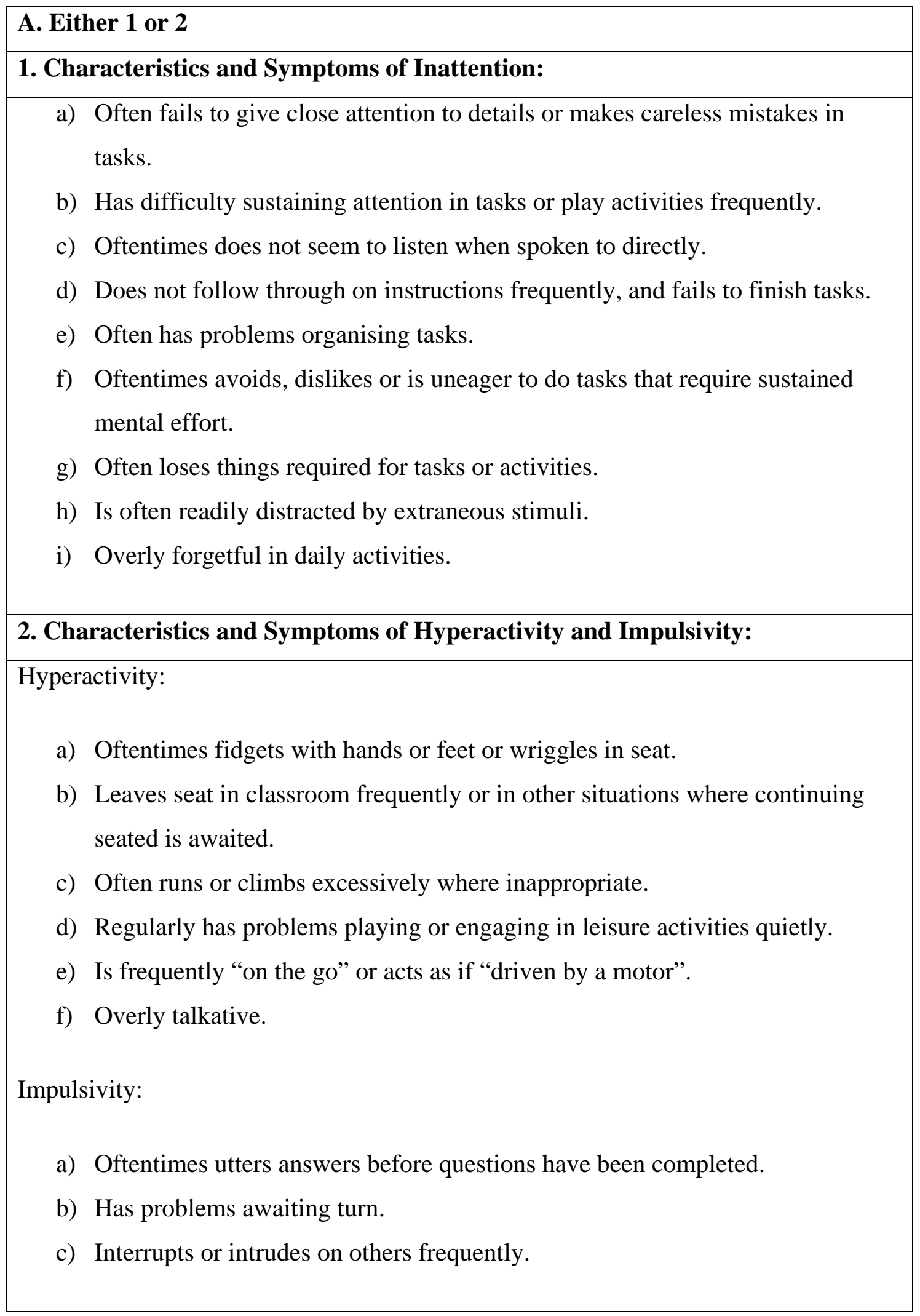

Table 1. Behaviours that are listed in the DSM-V (American Psychiatric Association, 2013) 
Based on these criteria, ADHD is typified under three categories:

- Predominantly Inattentive Type: if criteria 1 is met but criteria 2 is not met for the past 6 months.

- Predominantly Hyperactive-Impulsive Type: if Criteria 2 is met but criteria 1 is not met for the past 6 months.

- Combined Type: if both criteria 1 and 2 are met for the past 6 months.

According to the American Psychiatric Association (2013), there should be a specification about the possible partial remission of the dysfunction or the severity of the symptoms. The severity of the symptoms is in turn divided into three categories: mild, moderate and severe.

These are the official behaviours rated to evaluate the disorder according to the DSM-V. But there are some other common characteristics in children and adolescents with ADHD. In her book How to Reach and Teach Children with ADD/ADHD, Rief contends that they have a high degree of emotionality, get frustrated with ease, are extremely reactive and suffer distress with transitions and changes in routine. She alleges that in many cases they are belligerent too, have difficulties working for longterm goals and have poor handwriting. They are also likely to struggle with learning, many of them have school difficulties and language and communication problems (Rief, 2005, p. 8).

There are lots of manuals and articles about ADHD, and most of them address the negative characteristics from the individuals having the dysfunction, but not many of them spotlight the positive attributes they have. Once again we are quoting Rief, who emphasises the positive faculties from ADHD children, and enhances parents and teachers to appreciate them and use them to build up their self-esteem. She claims that these infants are highly energetic, verbal and spontaneous, she points out how creative, resourceful and innovative they are, highlighting their persistence. She affirms that they are also compassionate and very sensitive to others’ needs. They do make and create fun, are enthusiastic and outgoing, and they are always ready for action, but most importantly, they are passionate (ibid, p. 9). Some of these features may seem negative 
in some cases, but it is important to change our minds and transform the negative into positive, to see a virtue instead of an imperfection and to use these qualities to challenge their learning and to boost their self-esteem.

Another remarkable characteristic correlated with some ADHD children is the delay in the use of the executive functions. In case of an existing delay, the deviations and grooves of the patterns differ considerably from one subject to another. Due to their importance, further details will be discussed later.

Some other features have been attributed to ADHD children throughout the years, but not everything that has been said is a true statement. An instance of that declaration is referred to the filtering of information. Barkley's research shows that ADHD children do not have problems filtering information, they just face difficulties with the durability of the effort they have to make. They cannot maintain their effort as much as children without ADHD (Barkley, 2013, p. 38). The incompetence to endure a task which they find boring or the struggle for waiting may be confused with having a problem with filtering information, which is not related to ADHD.

Knowing the symptoms, how do we start the process or the evaluation? When a family considers that their child has ADHD, or the school has noticed some symptoms about any infant and informs their family about it, an accurate assessment and diagnosis of children is needed on the first place at the level of primary care. The first commitment is to detect the ADHD symptoms, where parental and teachers rating scales are needed, as well as a physical examination. If the symptoms or behaviours are causing social impairment, a child mental health service should be consulted. At the level of secondary care interviews with parents, teachers and children must be conducted (Taylor et al., 2004, p. 11). Interviews with parents pursue seeking for information about the child and family history about ADHD or other dysfunction symptoms, as well as about pregnancy, birth history and early development of the infant. Behavioural observation during interviews with children are very useful, and an adaptation of the questions to the child's developmental level is always required. Collateral interviews with teachers or other people who are involved with the child's nursing are recommended to expand the exploration. One of the main aims of that evaluation is to ascertain if there is a psychiatric disorder and to differentiate between 
an ADHD diagnosis or any other psychiatric disorders. Finding comorbid dysfunctions is also part of the assessment, as is to begin outlining the types of interventions to confront the disorder (Barkley, 2015, p. 455).

Diagnosis entails having clear evidence of important dysfunction in social, academic, or occupational areas. There are multiple rating scales to conduct the assessment. Although there are no psychological tests to exclusively diagnose ADHD, the DSM-V symptom list for ADHD has been selected in the form of a behaviour rating scale (Barkley, 2015, p. 465). Taylor suggests the Children’s Global Assessment Scale (CGAS) to evaluate infants' impairment (Taylor et al., 2004, p. 9). Regarding child behaviour rating scales for parents and teachers, it is important to highlight that they are an essential tool in the assessment and diagnosis process. So much so that several scales have been incorporated into the assessment protocol, as is the case of the ones that Barkley recommends (2015, p. 462). He suggests the use of the scales BASC-2, Behavior Assessment System for Children (Reynolds and Kamphaus, 2004); and CBCL, Child Behavior Checklist (Achenbach, 2001). On the other hand, some of the suggested scales by the European guidelines for hyperkinetic disorder are the following:

a) Questionnaires:

- CBCL: Child Behavior Checklist (Achenbach, 1991)

- CPRS: Conners’ Parent Rating Scale (Conners, 1989)

- CTRS: Conners’ Teacher Rating Scale (Conners, 1989)

- Home Situations Questionnaire (Barkley, 1991)

- SNAP-IV-Rating Scale (Swanson, 1992)

b) Neuropsychological assessment, including tests of executive functions:

- CPT: Continuous Performance Test (Cooners, 1985)

- Stroop (Cohen and Servan-Schreiber, 1992)

- WCST: Wisconsin Card Sort Test (Grant and Berg, 1948)

- WISC-R: Vocabulary, Arithmetic, Block Design and Picture Arrangement (Groth-Marnat, 1990)

Taking into account the analysis of this study, it is considered that rating scales used in Spain should be pointed out. García and González (2016, p. 4) consider that the 
most used scales to assess ADHD children and adolescents in Spain are the following: ADHD Rating Scale-IV, Conners’ Rating Scales, Escala Magallanes, EDAH (Evaluación del trastorno por Déficit de Atención con Hiperactividad) and SNAP-IV.

All the aforementioned scales quantify the opinion of parents, teachers and children, and the results of the neuropsychological evaluation. A clinician will analyse those data, collected altogether with the results from the interviews and the physical examination, to report the family about the diagnosis. The existence or absence of ADHD symptoms and other comorbidity disorders, the severity of them and the age of the infant, will determine the treatment.

As mentioned above, ADHD is not only an academic problem, it affects family relationships too. Some studies show a correlation between children with ADHD and parental stress and problems. It is believed that contextual variables play an important part on this matter. The difficult upbringing which the dysfunction implies affect directly in the rising of stress levels within the families. But it also appears that family's social life is also considerably influential on mother's stress, even more than marital disagreements (Muñoz-Silva, Lago-Urbano, Sánchez-García, and Carmona-Márquez, 2017).

Comorbidity is, without doubt, another hurdle to confront when dealing with ADHD children. It is considered that between $67 \%$ and $80 \%$ of clinic-referred children have at least another disorder (Barkley, 2015, p. 140). The main comorbidities found with ADHD are the following:

- ODD and CD: Oppositional Defiant and Conduct Disorders. The Multimodal Treatment Study of ADHD (MTA) found that $40 \%$ of children with ADHD met criteria for ODD, and 14.3\% met criteria for CD (Swanson et al., 2008, as cited in Barkley, 2015, p. 141). Yet, it appears that even those ADHD children with a pure pattern of hyperactivity in school are at risk of developing conduct disorders over time (Taylor et al., 2004, p. 10).

- Anxiety disorder: The co-existence of an anxiety disorder in children with ADHD is about $25 \%-50 \%$. Sleeping disorders are also more likely to appear when ADHD and anxiety converge (Barkley, 2015, p. 152). 
- Depression: The incidence of depression in ADHD varies across studies. Rates of comorbid depression vary from $45 \%$ to $0 \%$ in epidemiological studies. Therefore, further studies must be conducted (Oxley and Stringaris, 2018, p.206).

- Irritability: Hyperkinetic children can be quite temperamental and may react with intensity in some occasions. Irritability is a common feature of emotional liability and these children tend to have easily produced tantrums (Mulraney, Stringaris and Taylor, 2018, p. 201).

- Specific learning disorders: ADHD children are more likely to show neurodevelopmental delays. That is seen in the simple expressive language they possess, their poor handwriting, or in their poor reading skills, among others (Taylor et al., 2004, p. 10).

- Pervasive developmental disorders: Several studies show that individuals with autism spectrum disorder show hyperactive behaviour, and some ADHD meet criteria for autism (Taylor et al., 2004, p. 10).

- Tic disorder: Rothenberger and associates consider that comorbidities between ADHD and tic disorder are not related to tic severity, but with learning disabilities, disruptive behaviour and social dysfunction. Yet the tic disorder does not seem to increase the ADHD (Rothenberger, Roessner, Banaschewski and Leckman, 2007).

- Mania: Some studies show that severe non-episodic irritability is a feature from bipolar disorder. Although in DSM-V the term bipolar disorder is explicitly used for episodic presentations of bipolar symptoms (Barkley, 2015, p. 149). - Substance use disorder: It is believed that children with ADHD are at an elevated risk for developing a substance use disorder compared to non-ADHD infants (Wilens, Carrellas and Biederman, 2018, p. 215).

To conclude this section, we consider of importance to point out the differences between genders regarding ADHD. During many years the dysfunction was believed to be a male disorder. Consequently, many females have been undiagnosed. According to Nadeau and colleagues (1999, as cited in Rief, 2005, p. 10), girls with ADHD have less observable symptoms, are more likely to suffer anxiety and depression, experience selfesteem problems and are prone to be hyperverbal. Some studies show sex differences in the prediction of hyperactivity/impulsivity and conduct problems, being stronger 
predictors the externalising female behaviours than the male ones. That might be due to the bigger contrast between the normative female's behaviour and the one showed by females with ADHD (Mowlem et al., 2019, p. 486).

Diagnosing ADHD as soon as possible is greatly important, but is not as simple as it may look like. Many variables must be taken into account to avoid errors in the evaluations. A miscalculation may lead a child to be underdiagnosed or, on the other hand, to have a medicated infant when there is no need to use drugs to treat him or her. As personal issues affect children so much, such as parents' divorce, or the loss of a close relative, to mention some examples, it is very important to conduct the examination thoroughly and not to get confused with some other personal incidents or educational problems that might be interfering with the child's learning process.

\subsection{Treatment}

Apart from prenatal care, which is fundamental to prevent ADHD in noninherited cases, nothing else can be done to prevent the dysfunction or, shall we say, any other disorder.

There are different treatments for any mental disorder. Psychological interventions, educational changes, medication and diet are the existing treatments for ADHD.

Parenting children with ADHD can be challenging, but it can also present difficulties and generate stress to the families, making them feel overwhelmed in numerous times. As the European clinical guidelines suggest, education and advice should be the base of any treatment (Taylor et al., 2004, p.13). Families of ADHD children are usually affected. Parents' stress and conflicts between the family members are increasing problems that come in addition to the ones that the disorder brings. Those difficulties can lead to ODD (Oppositional Defiant Disorder) or CD (Conduct Disorder) if left untreated. Thus, teaching parents on management skills and making some educational changes can be very useful for the whole family, not just for the referred child. To prevent the disorder from getting worse, behavioural parenting training can help families to improve their relationship, overcome some child behaviours and reduce 
the stress. To do so, it is very important that parents express their situation to a clinician and their feelings about it in order to set feasible goals. That step can be hard, because some parents blame themselves for their child's diagnose and some other are reluctant to delegate decision making to a third party. Once the goals are set, development should be monitored to adjust the objective if needed and measure the progress (Barkley, 2015). Although there are several traded programs, the European clinical guidelines offer some wide clinical agreed suggestions. Some of them are presented below (Taylor et al., 2004, pp. 13, 14):

- Recognise difficult situations and specific behaviour problems. It is essential to analyse the parental style, the temperament of the infant and the different situations and problems that arise in different scenarios (home, school, etc.) to plan an effective psychoeducational program.

- Monitor the infant's progress regularly.

- Study positive and negative repercussions of different behaviours and note any inconsistency about it if that occurs. Praise when desired behaviours occur. Negative repercussions are applied when undesired conducts befall.

- Parents should learn effective methods of communication to give orders and establish the rules, such as making eye contact, give few commands at once or verbalise commands in a positive way.

- Use incentive systems, such as "token system” to strengthen appropriate behaviour. In the "token system” tokens (such as buttons, stickers, paper clips, or even happy faces) are the reinforcers and are exchanged for a bigger reinforcer, called "back-up reinforcer”, when the behaviour is the suitable or expected one. Back-up reinforcers should be preferably activities, namely doing some special activity together with parents and suchlike.

- Use "time-out" reinforcement. This technique should be used when other strategies and incentive systems failed and must be carefully executed in order to avoid the child to feel that he is being punished. Time-out method is meant to be a break or a rest from reinforcement.

- Include the child as an active member in the process whenever possible. - School-aged children can learn to assess their own behaviour and to use selfmanagement routines. 
Barkley also suggests the "problem solving” therapy (Barkley, 2015, p. 530). It is a cognitive-behavioural instrument where parents are normally asked to:

- Recognise a single problem and focus on it.

- Define the problem.

- Think of different solutions for the problem.

- Consider the advantages and disadvantages of the possible solutions.

- Discard those solutions with few advantages.

- Contemplate the possibility of blending solutions.

- Choose one solution to execute.

- Assess the results.

According to the author, that is a technique that allow parents to deal with some important issues that were not included in their initial behavioural parent training. Regardless of the technique used for the parenting behavioural coaching, it is proved that selecting parents as a main aim improves their child's behaviour. Anastopoulus and Farley (2003) suggest a parent training program that gives information to parents about the dysfunction, using cognitive therapy techniques to help parents to accept, understand and manage the disorder. They consider that clinicians should help parents through the following ten steps along their therapy sessions:

- Program orientation and overview of ADHD.

- Understanding parent-child relations.

- Increasing positive attending skills during special time.

- Extending positive attention to other situations. Giving commands more effectively.

- Establishing a home poker chip/point system.

- Adding response cost to the program.

- Using time-out from reinforcement.

- Managing behaviour in public places.

- School management issues and preparing for termination.

- Booster session.

Parent training can help when the children is not medicated, or in those cases where medication is reduced due to side effects, and there comes a time when difficult behavioural situations need special management. The same explanation applies for 
those cases of comorbidity, such as oppositional defiant disorder or conduct disorder (Anastopoulus and Farley, 2003, p.189). Most importantly, some studies show how multicomponent psychosocial treatments have better and more extended results than simple parent training. Haack and colleagues conveyed a study with ADHD predominantly inattentive using CLAS (Child Life and Attention Skills), a multicomponent psychosocial treatment developed by Pfiffner and associates (2007), reaffirming the positive outcomes produced by activating positive parenting changes. CLAS is a program that offers assistance to families of predominantly inattentive ADHD children through three ways: parent training, child skill training, and classroom dialogue (Haack et at., 2016, p.842). The original study endorses the efficiency of behaviourally based psychosocial programs to help ADHD predominantly inattentive type children. The CLAS program reduced the attention problems and led to an improvement in organizational and social skills of the referred children (Pfiffner et al., 2007, p. 1047).

According to the comorbidity, pervasiveness and the long-term duration of the dysfunction, clinicians usually apply combined multiple treatment strategies (Anastopoulos, Rhoads and Farley, 2006, p. 456). Therefore, behavioural interventions in school are widely used along with parent training. Two factors affect directly to the success of school programs, one is the knowledge teachers have about ADHD, and the other one is frequency. Teachers who receive training about ADHD are more likely to increase the probability to succeed when implementing behavioural contracts and adjusting lessons and materials for students with the hyperkinetic syndrome (Arcia et al., 2000). The problem arises when teachers are not trained to deal with the dysfunction, as it is the case, according to several investigations. Some studies show that most teachers barely receive any preservice instruction about how to work with students with ADHD (Pfiffner and DuPaul, 2015, p. 597), which affects directly to the academic achievement of these children. About the second factor, frequency, it is believed that behavioural techniques and curriculum modifications only work properly when applied continually within the school (ibid, p. 596).

DuPaul and Eckert bolstered the argument for the need of teachers to be aware of effective strategies to deal with ADHD students, and conveyed a meta-analysis about the effects of school-based interventions for ADHD, the results of which supported the 
effectiveness of the academic program, achieving a reduction of behaviours related to ADHD and an improvement of the academic output. They found out that contingency management (for example, token reinforcement) and academic interventions (for example, peer tutoring) were chosen over cognitive-behaviour modification strategies (DuPaul and Eckert, 1997, p. 21).

Therefore, several interventions are pervasively effective and, consequently, suggested to work with ADHD. Despite this topic will be discussed further in section 7, Teachers and ADHD, a summary of the behavioural interventions proposed by the European clinical guidelines for hyperkinetic disorder for kindergarten, preschool and school are featured below (Taylor et al., 2004, p. 14):

- Analyse classroom structure and task requirements.

- Recognise specific harsh situations and concrete behaviour problems.

- Discuss positive and negative outcomes of proper and unsuited behaviours or problems.

- Use token systems to reinforce positive behaviour.

- Use response cost systems to remove reinforcement with recurrent problem behaviours.

- Use brief time-out when other procedures are not effective with problem behaviours.

- Integrate ADHD children as an active member in the therapeutic process.

Combined treatment is the most effective therapy with ADHD children. Some youths benefit from psychological and school-based interventions, but sometimes these therapies are insufficient. For that reason medication should be considered when the patient meets the DSM criteria for the dysfunction and psychological treatments are not sufficient alone (Taylor et al., 2004, p. 15). Despite the fact that stimulant medication is quite safe, there are side-effects, which result in discontinuation of the treatment in many cases, sometimes because of the doctor's advice and, some others, because parents decide to cease the medication to avoid side-effects. For that matter, some parents are reluctant to start any stimulant medication with their children. Nonstimulant medications are now available and are an alternative to the stimulants. 
Pharmacological treatment is therefore divided into stimulants and nonstimulants. Stimulants include both methylphenidate and amphetamine compounds (Connor, 2015, p. 669). There is abundant corroboration about the effectiveness of methylphenidate over treatment periods up for a year, what makes it the first choice in pharmacological treatments. It diminishes the excess of movement, inattentiveness and impulsiveness and, consequently, reduces risk-taking behaviours, increases obedience, facilitates verbal information retrieval, and improves self-esteem (Taylor et al., 2004, p. 15; Connor, 2015, p. 668). Although side-effects are regularly minimal and can be usually regulated by adjustments, some reactions may take place. Some stimulant medications’ after-effect are sleeplessness, declined appetite, weight loss, headache, stomach ache, and heart rate and blood pressure rise (Connor, 2015, p. 672). Growth can also be affected and chronic use or high doses of methylphenidate can lead to dependence (Taylor et al., 2004, p. 16). Dexamfetamine is another stimulant with similar effects to those of methylphenidate. Some patients who do not benefit from methylphenidate react positively to desamfetamine, and vice versa (ibid, p.17). Methylphenidate and Lisdexanfetamine are the two stimulant treatments allowed to use in Spain with children above six years old and adolescents (García and González, 2016, p. 9). Regarding nonstimulant treatments, atomoxetine was the first non-stimulation medicine approved for ADHD. In Spain is the only one authorized (García and González, 2016, p. 9), nonetheless in the U.S.A. a formulation of clonidine and a guanfacine preparation are also permitted. All of them have also adverse effects, such as headache, abdominal pain, decreased appetite, nausea, vomiting, and sleepiness, although they are less probable to occur than with stimulants intake (Connor, 2015, p. 675).

Apart from medical or combined treatments, there are other alternative therapies for ADHD. As social relationships are generally impaired, social skills training are believed to be beneficial too for those ADHD children with poor social skills. Sharing, making conversation, joining new groups of peers, following rules when playing games, turn taking, identification of emotions and relaxing techniques are topics of teaching in these therapy programs (Yee Mikami, 2015, p. 576). Dietary interventions are also available treatments. Feingold (1976) linked the ingestion of artificial food colours and flavours to hyperkinesis and learning difficulties. Elimination diets and removal of food (such as corn, processed foods and caffeine) were suggested. Nevertheless, this 
alternative option has confusing conclusions and further studies must be conveyed to evaluate its efficacy (Pelsser, Frankena, Toorman and Rodrigues Pereira, 2017). Other complementary interventions for the dysfunction are yoga, meditation, and exercise. Although they are not recommended to be used as an only treatment due to a lack of evidence, they can be beneficial for self-awareness and physical control. Yoga has a strong respiratory constituent, which is believed to reduce the activity of the sympathetic nervous system (Bader and Adesman, 2015, p. 729). Meditation can be difficult for ADHD individuals, especially children, but it is recommended for them to practice quieting their minds through yoga breathing, which will help them to relax and focus, resulting on a very positive impact on attention (ibid, p. 730). Exercise is strongly recommended for everybody, not just ADHD individuals, because it improves cardiovascular health, grapples with obesity, and improves mood among other positive benefits. It is also believed to affect brain function and structure, fostering neural growth and development (ibid, p.731).

It is important to bear in mind that every human being is different, hence what works for someone may not work for others. And most importantly, there are different training programs, medicines and therapies that help ADHD people and their families to cope with the dysfunction, but there is no treatment that can cure ADHD.

\subsection{Executive functions and ADHD}

Children with ADHD are more heedless and impetuous than other infants. The lack of control of their activity level is what origins most of their troubles. In other words, we could say that many of their difficulties reside in the deficiencies of their brain's executive functions. Some people use the term “executive dysfunction”, although it is not used to be referred as a disorder, but a difficulty (Cooper-Kahn and Foster, 2013). Different authors contemplate that the view of ADHD as an executive function deficit disorder is strongly compatible with clinical observations of the disorder, albeit diverse psychological deficits have been linked to ADHD discarding the idea that ADHD is fundamentally an attention and inhibition disorder (Barkley, 2015, p. 407). 
Executive functions can be defined as a set of cognitive procedures that help people to control, plan and organize our brain, our behaviour, language and our actions. These executive functions can manage both organization and regulation. As organization we understand the act of collecting information and assemble it for evaluation. And for regulation we mean the act of store facts and information to modify or adapt our response or behaviour.

According to Cooper-Kahn and Foster, executive functioning can be broken down into smaller pieces. They offer a list of core skills based on the Behavioural Rating Inventory of Executive Function (BRIEF), one of the most used rating scales to assess executive functions' behaviours. These authors analyse thoroughly the next eight executive skills: Planning and Organization, Working Memory, Initiation, Task Monitoring, Self-Monitoring, Inhibition, Emotional Control and Shifting. If we analyse and compare the characteristics listed before about Inattentive and Hyperactive/Impulsive Type and the eight executive skills examined by Cooper-Kahn and Foster, we can find the following correlative dysfunctions:

\section{Inattentive Type}

- Easily distracted by extraneous stimuli: Several skills could be affected when analysing this feature. First of all, we could speak about problems with the Working Memory skill, making children struggle with their ability to sustain their attention, a hassle that worsen with external stimuli. And secondly, we might be dealing with someone with poor Task Monitoring skills, making the work adjustment very difficult to happen. That means that refocusing on the activity after an extraneous stimuli may be difficult after the changing conditions or, as we have recalled it, the external stimuli.

- Does not seem to listen when spoken to directly: People with poor Emotional Control skills might have difficulties controlling their emotions or reactions. Meagre Self-Monitoring Control could also block the ability to follow the social rules or understanding hints of irony or even metaphors, making ADHD children susceptible to social segregation.

- Difficulty sustaining attention in tasks and play activities: There is a problem with the Working Memory skill, which affects to the process of information. 
Some ADHD children have problems going over new information, some others recovering it or manipulating their knowledge.

- Forgetful in daily activities: There is a disruption in the Working Memory skill, that causes problems holding on to some information for a long time, such as remembering a daily activity long enough to do it the next day or complete it as required. There may also be difficulties with the Initiation skill, seeming that children are dallying, when they could be just having problems to start an activity.

- Does not follow through on instructions and fails to finish schoolwork, chores, or duties in the workplace (not due to oppositional behaviour or failure to understand instructions): There is a disturbance in both Planning and Organization, and in Working Memory skills. That is because ADHD students may have difficulties to fragment a task, an activity or an aim into smaller ones, at the same time that they can have problems remembering the given information long enough to accomplish the given command.

- Avoids, dislikes, or is reluctant to engage in tasks requiring sustained mental effort (such as schoolwork or homework): There is a deviation in the Working Memory skill, as well as in the Inhibition one. As we have explained before, ADHD youngsters may have problems retaining information for long periods of time, likewise they can have trouble restraining thoughts or some behaviours. That makes very difficult to sustain concentration for a long period of time. - Fails to pay attention to details and makes many careless mistakes. Several executive skills may be affected here, such as Planning and Organization, Task Monitoring, and/or Inhibition. As well as ADHD children tend to organize their materials randomly, they use the same methodology to organize their ideas, what leaves the details in a remote position and allows mistakes to step to the foreground. It is not a deliberated action, is a consequence of the poor Organizing skills they have to endure. Something similar happens with Task Monitoring. Many people diagnosed with ADHD really struggles evaluating their own aptitudes, tasks or results, which generates a very unlikely chance to pay attention to details or to evaluate the consequences of their mistakes, as the Inhibition skills permits.

- Loses things necessary for tasks or activities (toys, school assignments, pencils, books, or tools): There is a poor Planning and Organization skill, due to the 
difficulty ADHD people have to establish an order with information, exercises, materials and spaces.

- Difficulty organising tasks and activities: There is a problem with the Planning and Organization skill, for the same reasons mentioned before, ADHD kids struggle placing order, they rather organize ideas and materials haphazardly.

\section{Hyperactive / Impulsive Type}

- "On the go” or acts as if “driven by a motor”: Subjects with weak Inhibition skills tend to have problems to slow down or stop, which brings them to be impulsive and, sometimes, inappropriate according to what it is expected in a determined situation. Emotional Control skills may also be diminished. Poor emotional control makes people prone to uncontrol their emotions, hence their actions may be affected too.

- Leaves seat in classroom or in other situations in which remaining seated is expected: For the same reasons mentioned before, this feature can also be related to low Inhibition and Emotional Control skills, what causes the lack of body control.

- Runs about or climbs excessively in situations in which it is inappropriate: As the previous features related to the Impulsive Type, poor Emotional Control and Inhibition skills lead into unexpected and undesired physical actions.

- Fidgets with hand or feet or squirms in seat: Once more, wriggling and moving constantly are expected with Hyperactive children, since Emotional Control and Inhibition skills are very often deficient or, at least, not as good as they should be.

- Difficulty playing or engaging in leisure activities quietly. Poor Emotional Control and Self-Monitoring skills. Individuals that struggle to control their emotions and are not good adjusting their behaviour, have a tendency to remain excited or being talkative.

- Talks excessively: Just as mentioned above, it is needed to dominate or to adjust properly Emotional Control and Self-Monitoring skills to be able to remain quiet or talk as much as it is expected.

- Interrupts or intrudes on others: We could say that three skills are poorly developed when talking about this trait. Great Self-Monitoring skills allow us to modify and adapt our behaviour to the different social moments and 
environments, when we are not able to do so, such it is the case, we could talk about a disfunction with this skill. Inhibition is also poor developed, due to the incapacity to control effectively his/her conduct, by interrupting others instead of respecting them. And finally, we can say that Emotional Control is not well developed too, considering that the interruption is caused by an inadequate control of his/her emotions.

- Blurts out answers before questions have been completed: Just as directed before, not good enough Self-Monitoring skills contribute to actions such as speaking unthinkingly. It is also very difficult to hold your reins with an impaired Inhibition skill, or not having a full functional Emotional Control. - Has difficulty waiting for his or her turn in games and activities: Task Monitoring and Self-Monitoring skills are flawed in this case. Adjusting ones’ actions and emotions to closed instructions among a group of classmates can be very difficult to some ADHD individuals, as well as to analyse their own conduct or response.

As we can appreciate after reading all the obstacles some ADHD students have to deal with and why they react in some particular ways, it seems pretty unfair to state that they are just rude or spoiled children. It is true that until adulthood executive development is not completed, but it has been proved that having damage or delays in the front part of the brain can lead to problems with the regulation of the executive functions. Nevertheless, we cannot forget that every ADHD person is exclusive and not all ADHD individuals have issues with executive functions. By the same token, not every person who has an executive dysfunction is on account of ADHD. Other developmental disorders, such as autism spectrum disorders and learning disabilities might generate executive function deficiencies. Believe it or not, chronic stress, depression and anxiety can also affect our executive functions (Cooper-Kahn and Foster, 2013). To complete the picture, we must say that not all those who need more time to execute an action have a special condition, some individuals just need more time to reach a specific maturity level or to fulfil a skill. All children develop at different rates, no dysfunction needed. Thence, we need to be very careful before stereotyping anyone, as well as we need to be patient and comprehensive, no matter who or their assumed impairment. And, as teachers, what we can do is work with anyone with poor executive skills to improve them and to diminish the possible troubles some people 
have to deal with. The mentioned book from Cooper-Kahn and Foster show a variety of examples, tips, references and templates to work with. We all have our issues and every day is a brand new possibility for everyone. We just need to believe it and work for it.

Another author who suggests how to work with executive functions is Barkley. He suggests seven basic principles to address the executive functions deficits in ADHD (Barkley, 2016):

- Externalise information: The regulation of information is diminished or slower than expected in some ADHD individuals due to executive function deficiencies. An aid for that weakness is to externalise information. The use of prompts or any physical reminder (e.g. notes, post-its, etc.) help them to remember the information they need to recall.

- Externally Represent or Remove Gaps in Time: Executive function deficits can create problems with time, timing and timeliness. Representing the time physically or with signs can help ADHD children, as well as eliminating those "opening time” activities. Instead of giving a due date to these children it is better to assign a daily program to complete a task.

- Externalise motivation: It is believed that ADHD people have a dysfunction with the internal motivation towards a target. External rewards, such as the token system, help these children to achieve their goals. Barkley contends that there are two main reasons to start a behaviour management. On the one side, some people acquire the skill to manage internal motivation later than their peers. In these cases behavioural techniques can be used to help motivate those children externally, and withdraw the incentives once they have developed the internal motivational management skills. On the other side, problems with executive functions due to a dysfunction, as it is the matter with ADHD children, need reinforcement, rewards or any other pedagogical method during long periods of time, because removing the external motivation may prompt a regression and worsen the ability to maintain their focus over a task (Barkley, 2016, p. 20).

- Executive function and self-regulation: The author states that there are five assets that can affect goal-directed activities through executive functions or selfregulation: situation selection, situation modification, attentional control/redirection, reappraisal, and response modification/suppression (ibid, p. 
21). He also supports other researchers' indications to foster self-regulation endurance, which is fundamental when working with ADHD children that have diminished their motivational skills. The following cues are suggested: practice physical exercise regularly, taking breaks of ten minutes during demanding selfregulation activities or situations, relaxing or meditating during three minutes after tough self-regulation tasks, picture the recompense or the results during self-regulation activities, map out small rewards during demanding selfregulation tasks, use positive statements to praise one self's work, enhance positive emotions, take glucose-rich drinks during the activity.

- Make problem-solving manual: Taking into account that many ADHD infants have problems sustaining information during long periods of time, it may be useful for them to manipulate the information as much as possible through manual work. For example, it can be beneficial for them to use the abacus or handle physical objects when doing their maths.

- Intervene at the point of performance in natural settings: Intervention should take place where the problem exists, not elsewhere.

- Approach ADHD and its executive function deficits as a chronic condition: Executive function deficits might be considered as if they were a chronic condition. The treatment must be sustained over long periods of time, knowing that sometimes it is going to be like taking two steps forward and one step back. Modifications or readjustments on the treatment may also be considered during such long periods.

Many hyperkinetic individuals have problems with inattentiveness, impulsivity, and other related obstacles, such as learning or social difficulties. Compensating the executive functions deficits can help ADHD people to normalise their lives. Given this circumstance, further research and upgrades on executive functions managing are required to improve the diverse behavioural and psychological techniques and interventions. 
${ }^{1}$ This review is based on a search of information related to the topic. Apart from the cited bibliography in the text, several articles related to ADHD were consulted and helped to shape this section. Although they are not mentioned, they were really interesting and helped to get a clearer picture and a proper perception on the subject. The referred consulted bibliography is: Araújo e Izábal, 2006; Barkley, 1997; Kaufman, 2014; and McCarthy, 2019. 


\section{Teachers and ADHD}

The manner an ADHD child acts is unpredictable. They can undermine parents' patience and leave unarmed the most skilled teachers. This statement may discourage some people. The way you face the disorder determines the possibility to achieve your goals. Every singular person is different, that includes ADHD children. There may be general patterns, but there are no general rules. Not everything works for everyone; that makes working with ADHD children challenging. Being opened to testing and trying different methods and techniques, having a positive thinking and involving yourself in the process will bring you constructive results.

A remarkable quote from Russell A. Barkley says, "the children who will need love the most, will always ask for it in the most unloving ways”. It is a good reference to keep in mind, especially during bewildering or challenging situations.

As we have argued above, behavioural techniques and curriculum adjustments improve the academic skills and results of ADHD children. To make this possible steadily readjustments are needed, as well as teachers' knowledge about the dysfunction. The main problem lies on the absence of preservice teachers' instruction on the topic and, consequently, a great number of misconceptions associated to the disorder. Arcia and colleagues conducted a study to see to what extent school teachers knew about ADHD, not only about general characteristics, but also about how to deal with difficult situations and how to work with these infants. The results of their study showed that lack of knowledge about the matter was quite generalised among teachers. Many of them could not even discern whether some children had ADHD or not. Most of them used different techniques to cope with undesired behaviours in class, but the majority of these techniques were applied under a trial-and-error approach, hence most of those procedures were more likely to be reactive rather than proactive, falling outside a plan of action or any other strategical method (Arcia, Frank, Sánchez-LaCay and Fernández, 2000). In fact, some other investigations show how a good knowledge about the disorder and a positive and comprehensive relation between the teacher and the student contribute to enhance ADHD students' results, as it is the case of Pfiffner and DuPaul's study. They consider that, in order to achieve an academic improvement being an ADHD student, teachers should be informed about the following considerations (Pfiffner and DuPaul, 2015, p. 597): 
- ADHD is a biological and educational dysfunction that can be treated. It cannot be cured by treatment, but interventions are very helpful because the symptoms and the comorbid conditions are susceptible to environmental variables.

- ADHD is a problem of sustaining attention, effort and motivation, and it is also a problem that interferes with behaviour inhibitions. Therefore, it is not a knowledge condition.

- ADHD students have more difficulties than non-referred children to do school work or show desirable behaviours. They normally need support and guidance and, sometimes, fragmentation of tasks. Positive and negative reinforcement systems will be needed and, in some cases, even classroom accommodations. - Parent training and individual treatment help to improve academic results, but the most efficient intervention to enhance academic achievements is to apply school intervention programs within the school setting.

- School-based interventions should include proactive and reactive tactics to boost behavioural modifications.

- Asking for help to co-workers, parents or other students, as well as the use of new technologies can help to achieve the desirable results in school-based interventions.

Both authors support the idea of providing education about ADHD to teachers during their preservice training, but acknowledge that teachers normally use in-service training or readings through educational websites, such as http://www.adhdlectures.com/ (Pfiffner and DuPaul, 2015, p. 597).

Apart from lack of teachers' instruction, another complication emerges when we face professionals' hindrances. It is presumably easier to apply behavioural techniques for special education teachers with small classes, rather than general education teachers with classes up to thirty students. Yet reality and the implementation of inclusive programmes in schools are far from having small classes with a special education instructor. Barkley claims that the help of a behavioural aide in the classroom is precious, despite the budget or fund limitations. He considers that instructors should also be provided with continuous consultation assistance and they should be supported in their efforts too, including verbal recognition or financial reward for special materials and books (Pfiffner and DuPaul, 2015, p. 599). 
Some reports show how ADHD children can achieve better academic results if the classroom environment, the teacher programme, and the behavioural approach is constructive and inclusive. These programmes are believed to ease children's symptoms, assist their learning difficulties, and lighten their social and emotional issues (Majko, 2017, p. 18).

This $\mathrm{PhD}$ project was elaborated considering the educational practice in an inclusive school. In "The Salamanca Statement and Framework for Action on Special Needs Education”, inclusive schools are described along these lines:

"Schools should accommodate all children regardless of their physical, intellectual, social, emotional, linguistic or other conditions. This should include disabled and gifted children, street and working children, children from remote or nomadic populations, children from linguistic, ethnic or cultural minorities and children from other disadvantaged or marginalized areas or groups. These conditions create a range of different challenges to school systems. In the context of this Framework, the term 'special educational needs' refers to all those children and youth whose needs arise from disabilities or learning difficulties. Many children experience learning difficulties and thus have special educational needs at some time during their schooling. Schools have to find ways of successfully educating all children, including those who have serious disadvantages and disabilities. There is an emerging consensus that children and youth with special educational needs should be included in the educational arrangements made for the majority of children. This has led to the concept of the inclusive school. The challenge confronting the inclusive school is that of developing a child-centred pedagogy capable of successfully educating all children, including those who have serious disadvantages and disabilities. The merit of such schools is not only that they are capable of providing quality education to all children; their establishment is a crucial step in helping to change discriminatory attitudes, in creating welcoming communities and in developing an inclusive society” (UNESCO, 1994, p. 6).

Therefore, providing meaningful education to all learners was the main goal of the experience. As aids in the classroom were scarce due to state budget concerns, intervention changes were required because of the rise of ADHD children in society and, consequently, in the classes. Training and research about ADHD characteristics, 
needs and behavioural approaches to deal with the difficulties were required to conduct the methodology changes to implement successfully the English lesson plans.

Being proactive is indispensable to avoid undesirable events, although reactive measures will probably be needed sometimes. In the first place it is important to consider some classroom and behaviour management practices that will help all students, including those with ADHD. Barkley (2016) suggests some recommendations regarding features of the classroom and teaching style. He distinguishes between proactive and reactive methods, being proactive most of his guidance features. He contends that proactive teaching enhances desired behaviours to occur, as well as academic achievements, reducing the chance of problems to emerge (Barkley, 2016, p. 33). Among the different suggestions, we bring out the following proposals:

- Have a school psychologist or school counsellor experienced in ADHD to assist other teachers in the school.

- Don't retain a child in a grade. It is considered to cause more harms than benefits.

- Establish behavioural measures to control the classroom at the beginning of the school year.

- Reduce the ADHD child's workload or assignments to what is essential.

- Divide the amount of work into intervals, allowing students to have pauses or breaks in between.

- Set the desks strategically, facing the teaching area and close to the teacher.

- Productivity should be aimed at first, and secondly accuracy.

- Allow movement to ADHD children whereas they are working (e.g. squeeze a stress ball).

- Use organizing systems to help students (the use of colours and labels can be helpful).

- Allow students to use highlighters to spotlight important information.

- Involve ADHD students in the teaching process, letting them help teachers.

- Allow students to use technology to practice the learning contents.

- Dissuade impulsive answers.

- Allot study partners inside the classroom and outside school if possible (classmates that live close by). 
- Be enthusiastic and theatrical when teaching.

- Touch children lightly when addressing them to get their attention.

- The most difficult subjects or activities should be programmed for the first periods of school day.

- Increase incentives for good behaviour.

These are some of the recommendations Barkley proposes, and we have implemented them in our teaching practice, as it will be subsequently shown in section 9, “a case intervention”. We agree that having guidance and support is certainly an aid. Some schools even have their own therapist, who can help teachers to cope with the dysfunction and to diagnose children too. The only drawback of the proposal is that sometimes specialists are collapsed with a great amount of children waiting to be diagnosed, delaying the diagnosis. Regarding not retaining a child in a grade, we could not agree more with the suggestion, as long as children have minimal knowledge concerning some matters. But sometimes the law establishes some specific requirements to have aides in schools. As it is the case of Spain, where teacher's aides depend upon the number of children categorised in the ATDI (that stands for the Spanish "Atención Temprana del Desarrollo Infantil”), and sometimes children need to have a curricular lag of two courses to be included in the ATDI, which means that they need to fail grades in some subjects to be categorised under the special needs term (Consejería de Educación de España. Orden EDU/1152/2010, de 3 de agosto). Therefore, sometimes the needs of the students and the legislative requirements do not match, which is tricky for teachers and unfair for children. Even though we have some discrepancies regarding some methods, as is the case of touching children slightly to get their attention, we consider that is certainly a good idea. But taking into account that some children are reluctant of being touched, and some cultures are also less prone to do so, we consider that tapping delicately on the desk may be a good suggestion instead.

Barkley also claims that external motivation is beneficial for AHDH children, as is the case of verbal commends or the use of token systems. From the different techniques he suggests, the use of "attention training system" is noteworthy. The attention training system is an electronic box with a digital display board that shows the points the student has achieved. The tool is turned on when the student starts working and gives the pupil a point per minute working. Learners use the gained points to buy or 
exchange them for privileges (Barkley, 2016, p. 43). Some variants of this system are widely used in classrooms, such as the use of timers or the establishment of short periods of working time (e.g. if you work and remain quiet for ten/fifteen minutes, you can play a vocabulary game on the computer as a reward). We have used the former variant to study and assess vocabulary and grammar, and the latter one to regulate working time with ADHD children or any other children that needed some timing regulation due to their personal characteristics.

Barkley’s proposals are consistent with Rief's contributions (2005). Rief agrees with Barkley in his suggestions and adds some other valuable practices. According to Rief, the clue to constructive and productive classroom management is working on positive relationships and rapport with students, connecting with them on a personal level. The author contends that classrooms environments should be inclusive, respectful and mutually supportive. Flexibility is also required, as well as emotional safety; in other words, students shall not be afraid of participating or making mistakes. She also considers that using clear, positive statements to express our requirements work much better than introducing a rule or a statement with “don’ts”. In addition, she prompts teachers to use "social reinforcers" to enhance desired student behaviours. Praising students' behaviours induce other students to follow or copy the acknowledged one. For example, if we want to have pupils seated while working quietly, we can recognise and acclaim someone that is following the desired conduct: "I see that Mary is already doing her assignment. Great job, Mary!”, “I really appreciate how quietly David and Simon are working. Thank you!”. She also recommends the use of visual and auditory signals to get students' attention (e.g. flashing the lights, rising one’s hands, whispering, ringing a bell or playing a musical instrument, such as chimes). We implemented this technique in our daily routines and it works really well, and we have witnessed its usefulness even in noisy moments in preschool. Rief points out the importance of being proximate as teachers as well, that is, moving around the classroom frequently, which works as a basic cue to remind students to pay attention and behave. This practice implies arranging furniture and desks appropriately to allow movement in between the clusters, which is sometimes difficult in small, crowded classes. Another proactive methodology is the use of contracts. Contracts are normally a two or three-party agreement in which children and adults select determined goals and agree to improve in certain areas to achieve them. Rewards and negative consequences are normally 
included and signed. To handle misbehaviour, Rief suggests to apply the corrective consequences of the undesired conduct in a calm, non-emotional way, without lecturing, and addressing only the undesired behaviour, not the children themselves. In her book “The ADHD Book of Lists”, Rief (2003) presents different group reinforcement methods to use in classes in accordance with the style of teaching and the characteristics of the students. Some examples are shown here below:

- Table/Team Competition: It is a class wide motivation system in which groups earn points when demonstrating the desired behaviour. The group with more points at the end of the day or at the end of the week earn a reward.

- Chart Moves: Charts are created for each class or group and every time they achieve a target, they move forward the chart. Once they reach the end of the chart, the group or the class earns a privilege.

- Token Economy System: Students are given the possibility to earn tokens that will be subsequently exchanged at the class store or raffle. Compensations have different price costs and tokens can also be withdrawn if students are fined for infractions.

- Probability Reinforcers: Teachers give raffle tickets for desired conducts or achievements. The tickets are placed in a container, and drawings are held daily or weekly. Drawn names get privileges. With this method children appreciate the principle of probability, as the more tickets they have, the more probability to get a privilege they have.

- Group Response Cost: In this method students are given a certain amount of tokens or points, and the whole class has to work to keep them and earn a reward.

There are more response cost systems and different variations to work with. We have implemented some of the suggested before and we have also used some variations, such as using table games as management systems, combining "chart moves" and "team competition" methods. Our experience with the different methods we have used is very positive, since using management systems helped controlling not only the ADHD behaviour, but also the whole classroom behaviour, as well as the achievement of goals. 
Some studies show that self-regulatory deficits in children with ADHD contribute to their educational adversities and are not supported by the techniques and measures described above, considering that self-regulation procedures should be implemented to support ADHD children in the classroom, in addition to the aforementioned techniques (Guderjahn, Gold, Stadler and Gawrilow, 2013, p. 398). Reid and colleagues (2005) consider that self-monitoring, self-reinforcement, and selfmanagement are the most recognised cognitive training methods. They contend that self-monitoring is a process that entails analysing one's behaviour by observing and self-recording oneself, and is divided in turn in self-monitoring of attention and selfmonitoring of performance. In self-reinforcement processes the students self-award themselves, normally with tokens or points that will be subsequently exchanged. Selfmanagement practices entail self-evaluation. Student's self-assessments are checked by an external person afterwards (Reid, Trout and Schartz, 2005). Some studies consider that self-monitoring techniques do not facilitate behaviour change in ADHD students. Guderjahn et al. support that idea, considering that ADHD children do not benefit from self-monitoring (Guderjahn, Gold, Stadler and Gawrilow, 2013, p. 394). Build on our experience, neither do we consider that children can benefit from self-monitoring methods, at least we find very difficult for children under 10 years old to be able to do so. Self-management techniques in the form of tokens or points in exchange of a positive reinforcement work quite well with many ADHD children, no matter their age. Little children can also be taught to self-evaluate their work, but we cannot expect them to be unbiased. We have used self-evaluation techniques and we found out that children either understate their knowledge or cheat to overestimate their assessment results. We have used self-evaluation procedures to teach them self-assessment techniques and to let them practice how to do it, showing them the desired correction afterwards, to help them figuring out how to do it properly. We also have implemented self-instructions techniques with a positive effect and have developed our own self-instructions programs from Orjales' contributions. These programs are further developed and explained in the next section.

Several investigations show the positive impact of training on self-instructions. Orjales is an experienced specialist that developed a cognitive-behavioural program for ADHD children in 1991. The program involved training in identifying feelings, problem solving, social reinforcers, modelling, turtle technique, relaxing training, self- 
instruction training (following Meichenbaum’s ideas), and a specific program to apply self-instruction in the classrooms (Orjales, 2007, p. 23). Based on Meichenbaum’s ideas and phases, Orjales designed a training program to automatize reflexive thinking in 1988. After several years of implementation of her initial program, she added another step on her program afterwards to improve the results of her self-instructions project, having as a result the seven steps shown in Image 3. Following the instructions in Image 3 , children will control cognitive impulsivity and become aware of the strategies he or she needs to apply in each situation (Orjales, 2005, p. 5).

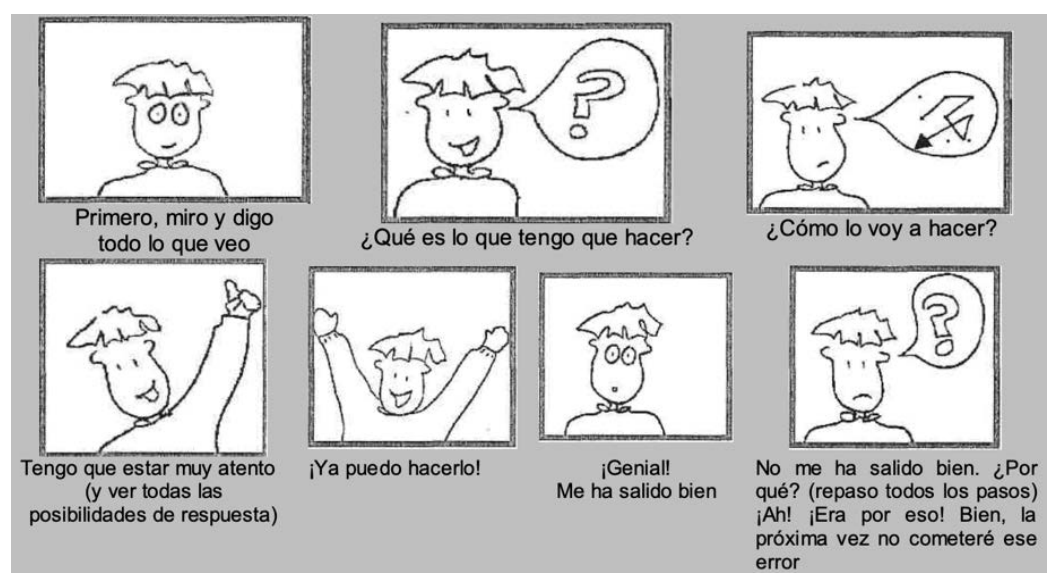

Image3. Diagram of self-instructions for cognitive training for ADHD students, modified by Orjales from Meinchenbaum’s proposal

For the implementation of Orjales’ program it is very important to place particular emphasis on the first step, “first I look and say everything I can see”. If ADHD children skip this step, they will lack in the preceding context analysis, reducing the comprehension of written instructions, which could be related to lack of motivation, an increased adult's demand, or the need of extra time to read the statement again (Orjales, 2007, p. 24). The effectiveness of training on self-instructions depends on the awareness of the cognitive, behavioural, emotional, and social profiles of children; when implementing the interventions; and the selection and sequencing of the activities. This program took place during a four level program that took into account the metacognitive development of the child. The first level relates to the training of the raising awareness of the child of the existence of thought processes and the use of problem solving strategies. The second level refers to the repeated implementation of 
the self-instructions. The third level is applicable to the training of the generalisation on the self-instructions implementation, putting them into practice on other contexts. Finally, the fourth level alludes to a more metacognitive training, intending that the ADHD child becomes aware of his/her weak spots and recognises when he/she has to control his/her impulsivity (ibid, p. 26). Although the effectiveness of her program is a fact, further research is needed to prove that ADHD children can develop a real reflexive thinking processing. Orjales contends that two or three years after her training self-instruction program, ADHD children still apply the steps they practiced, but those strategies are only applied when they have an important task to do or when they consider the task is difficult and they consider there is a risk of failure. Consequently, she believes that this kind of intervention is a very resourceful step to improve the cognitive performance of ADHD children between six and twelve years old, but selfinstruction training by itself is not enough to modify the impulsive nature of the hyperkinetic children (ibid, p. 27).

For all the aforementioned reasons, we can also help ADHD students to acquire knowledge and achieve their goals taking into account the different students' learning styles and using varied teaching methodologies, such as multiple intelligences teaching approach, teaching through movement, or multi-sensory instruction.

Berman asserts that by identifying someone’s preferred learning style and mirroring it, we can influence that person without his or her awareness (Berman, 1998, p. 1). He contends that there are different ways of identifying learning styles and he presents the following questionnaire designed for this intention (ibid, pp. 2, 3):

What Kind Of Learner Are You?

1. How can other people best interpret your emotions?

a. through your facial expressions

b. from the quality of your voice

c. through your general body language

2. How do you manage to keep up with current events?

a. by reading the newspaper thoroughly when you have the time 
b. by listening to the radio or watching the TV news

c. by quickly reading the paper or spending just a few minutes watching the TV news

3. What sort of driver (or passenger) are you?

a. you frequently check the rear view mirror and watch the road carefully

b. you turn on the radio as soon as you get into the car

c. you can't get comfortable in the seat and continually shift position

4. How do you prefer to conduct business?

a. by having face-to-face meetings or writing letters

b. over the phone because it saves time

c. by talking while you are walking, jogging or doing something else physical

5. How do you react when you're angry?

a. by clamming up and giving others the silent treatment

b. by quickly letting others know when you're angry

c. by clenching your fists, grasping something tightly or storming off

6. How would you describe the way you dress?

a. a neat and tidy dresser

b. a sensible dresser

c. a comfortable dresser

7. What do you think the best way is to discipline a child?

a. to isolate the child by separating him/her from the group

b. to reason with the child and discuss the situation

c. to use acceptable forms of corporal punishment

8. How do you behave at meetings?

a. you come prepared with notes and displays

b. you enjoy discussing issues and hearing other points of view

c. you would rather be somewhere else and so spend your time doodling 
9. What do you like doing in your free time?

a. watching TV or going to the cinema

b. listening to the radio, going to a concert or playing a musical instrument

c. engaging in a physical activity of some kind

\section{What Your Score Means}

If most of your answers are A, then your modality strength is visual. In other words, you learn through seeing things and you like everything to be written down on paper. In a classroom, having notes and the use of visual aids will help you.

If most of your answers are B, your modality strength is auditory. In other words, you learn through listening. In a classroom you will want to hear the new language, and listening to music could well be helpful.

If most of your answers are C, your modality strength is kinaesthetic. In other words, you learn on the move or through movement. Sitting passively in a classroom is unlikely to appeal to you but you'll probably respond well to the use of games and role-play.

Regardless of this test, there is no need to say that not everyone learns in the same way. There are three modality preferences: visual, auditory, kinaesthetic (Rief, 2005, p. 182). As stated before, visual apprentices learn best by seeing, watching and observing. Using written guidance, flashcards, graphic organizers, videos and any kind of visual prompts will help visual learners. Auditory apprentices learn best by listening and verbalizing, therefore using music or rhythms, drama, stories or cooperative learning can help auditory learners. Lastly, kinaesthetic apprentices learn through movement and physical activities. Consequently, learning games, experiential learning, crafts or technology will help kinaesthetic learners (Rief, 2005).

Concerning using different teaching methodologies, it is important to mention that learning through all the senses is believed to be helpful, as it is the strategy of learning through a multi-sensory approach. This thesis studies the teaching and learning 
of English as a second language, therefore the term "multisensory strategies" allude to the use of direct strategies entailing visual, auditory and kinaesthetic sensory systems to learn the phonological, morphemic, semantic and syntactic layers of language along with the articulatory-motor aspects of language, just as the strategies that Birsh suggests to acquire literacy skills (Birsh, 2018, p. 3). There is mounting evidence that many ADHD children have difficulties with spelling, multisensory activities such as writing words in the air sounding them out, writing words in sandboxes with fingers, or clapping the sounds or syllables in words, can help them assimilating the concepts properly (Rief, 2005). The basis of the different scopes and authors hitherto mentioned are applied to literacy and mathematics, but few research regarding teaching a foreign language has been found, apart from the several methodologies that have already been mentioned in section 4.1. to teach a non-native language. Interestingly we found some research that reveals the efficacy of learning English as a second language using multiple intelligences. Garner considers that a human intellectual competence must involve a set of abilities of problem solving, as well as it entails the potential for finding or creating problems (Garner, 1993, p. 64). He also gives consideration to the identification of diverse levels of expertise in the development of an intelligence and identifies initially seven types of intelligence: linguistic, logical-mathematical, spatial, bodily-kinaesthetic, musical, interpersonal, and intrapersonal (Garner, 1993). An eight intelligence, naturalistic, was added afterwards, and Gardner continues exploring further options. If we accept that different intelligences prevail in different people, it seems to suggest that the same learning task may not be suitable for all students. While people with a strong logical/mathematical intelligence might respond well to a complex grammar explanation, a different student might need the comfort of diagrams and physical demonstration because their strengths is in the visual/spatial area. Other students who have a strong interpersonal intelligence may require a more interactive climate if their learning is to be effective (Harmer, 2007, p. 90).

As we were saying, multiple intelligences have been applied in foreign language teaching. As a matter of fact, Michael Berman is the first one to apply the theory of multiple intelligences to the English language classroom. Another author who practises the MI (multiple Intelligences) approach to the English as a second language classes is Gökhan Bas. Bas gives us some prompts to put the theory of "multiple intelligences" into practice. He states that the ideology of the theory is based on cooperation, not on 
competition and considers that words are not enough and, the younger the learners, the most movement and senses’ involvement they need. Jokes and laughing not only are welcomed by children, but they can also encourage children to think. Bas suggests teachers to let children play with the language, either by saying chants, singing songs or telling stories. Another remarkable advice from the author is the use of drama, storybooks and games (Bas, 2008). Gökhan Bas also shows us an application of the multiple intelligences theory to teach weather forecasts and seasons in an English foreign language class (Bass, 2009) and conveys a study that demonstrates that there is a significant difference between the achievement levels of the students who have been educated by multiple intelligences supported project-based learning method and the students who have been educated by the traditional language teaching methods (Bas and Beyhan, 2010).

As to teaching through movement, the idea of incorporating exercise in classes is becoming an important asset. There are six purposes of movement:

1. Prepare de brain: Many researches consider that specific, directed physical movements help prepare the brain for learning or improve brain function (Lengel and Kuczala, 2010, p. 4).

2. Provide Brain Breaks.

3. Support exercise and fitness: Sixty seconds are enough to exercise and stretch the body, giving the brain a break.

4. Develop class cohesion: Developing a positive environment in class through short periods of movement helps students.

5. Review content: If students are moving during content review, they will awaken their bodies as well as their brains (ibid, p. 10)

6. Teach content: Teaching content through movement is a beneficial way to supplement traditional lectures, having as a result an increase of motivation, understanding and retention (ibid, p. 11).

Lengel and Kuczala contend that movement can play a direct role during the classroom (Lengel and Kuczala, 2010, p. 19), as it is detailed below:

- The brain is attracted to novelty: The six purposes of movement explained before prove this desired novelty. 
- The brain pays attention to movement: Movement with purpose helps keeping students focused.

- The brain needs to interact with people and things in its environment: Cohesive activities through movement induce interaction between peers.

- Learning is easier to store, remember, and retrieve if it has an emotional base:

Movement normally create positive emotional states, which makes students link positive emotions with learning.

- The brain operates from concrete experience, everything stems from that:

Nothing is more concrete than using movement to learn or review a concept.

Thereupon, using movement in classes is a suited teaching tool, as it gets along with the brain. However, two important aspects should be carefully considered. The first is safety, and the second is to ensure an effective transition from activity to seat. Applying the behavioural techniques for classroom management previously discussed should manage both aspects.

As Lengel and Kuczala say, there are many possible ways to move a body and it is hard to see someone frowning when someone is skipping, for instance. Therefore, asking students to skip or gallop to the board (blackboard or whiteboard) to solve a problem or do an exercise can make the activity more enjoyable (Lengel and Kuczala, 2010, p. 69). Thereupon we show some of the exercises the authors suggest. Some exercises that can be implemented in one to five minutes are:

a) Exercises to promote cardio-respiratory endurance: jumping jacks, squats.

b) Exercises to stretch and promote flexibility: sides of neck, shoulders and neck.

Transforming movement into a game will stimulate students. Some of this games can be used to generate or reinforce unity or cohesion between the whole class, as is the case of "rock-paper-scissors tag” and "shoulder tap wave” (ibid, pp. 100, 101):

a) Rock-paper-scissors tag: After splitting the class into two teams, we ask both groups to gather and think about a strategy. Then, both groups face one-toone along a designated area and they will start the game after the instructor signal to do so. The team that loses will walk as fast and safe as they can to a 
predetermined area by the teacher. The winning team will chase the other group, and anyone from the losing team that is tagged have to come over to their side for the next round.

b) Shoulder tap wave: Have students stand in a circle while placing their left hand on the shoulder of the person on their left, and their right hand on the shoulder on the person on their right. They must stay connected together thorough the activity. The coordination activity is like the "wave”, resulting in a ripple effect. The pattern would look like this: student 1 (left hand), student 2 (left hand), student 1 (right hand), student 2 (right hand), student 3 (left hand), student 4 (left hand), student 3 (right hand), student 4 (right hand), and so on, continuing the patterns until the ripple goes around the whole circle.

More group activities are shown in the book The Kinesthetic Classroom. Teaching and Learning Through Movement, and we have put some of them into practice or adapted and implemented them during our English lessons, as it is shown in section 8 .

There are also games that can be used to review or teach academic content. To review content we suggest the activity "red light-green light” from the mentioned book.

\section{Red light-green light}

Have students line up horizontally across the back of the room. Then, instruct them to take one step forward when they hear a true statement, while remaining still when they hear a false one. If any student steps forward when the answer is not correct, they must go back to the starting line (ibid, p. 117).

We have used this easy and quick game to review content. We really recommend it, as you just need some space, unless you opt for leaving the class and playing the game in the corridor or outside. We have practiced both options and the second one was a better choice. As going outside is something quite appealing to children, silence is required when going outside the class to play a game or rehearse a play in the corridor, meanwhile other children are in class. So, despite the fact that it was a whole-group 
moving activity, playing on the corridor was inconceivably quieter than playing inside the class. Regarding ADHD students, we consider it a very helpful activity, not only it permits them to move, but it also helps them acquiring the contents in those cases where students need more time or help to learn. Some ADHD students have problems understanding some grammar concepts and playing “red light-green light” helps them to comprehend the matter. Sometimes ADHD students copy their peers at the beginning of the game, because they do not understand the grammar, but end up making the right choices with the help of their classmates and the repetition of patterns during the game.

Another game we regularly use to review vocabulary is “toss the ball”, using a soft ball that can be caught with one hand. It is a tactile tool that comprises the benefits of kinaesthetic and sensory modes.

\section{Toss the ball}

The instructor picks a category, such as “animals”, and gives one student the ball. That student has to say a word from the category and toss the ball to a classmate as fast as he/she can, and so on. For example: student 1 says "lion” and tosses the ball to student 2, who says "cat", and tosses the ball to student three, who says "horse", and so on. Students have five seconds top to answer and cannot repeat a word. If they last more than five seconds to answer or repeat the word, they are out of the game. It is supposed to be a quick game and the winner is the student who stands all the round. If the instructor foresees that pupils do not know more words from that category, he/she can change the category.

There are diverse games to teach academic content too. From the proposed activities by Lengel and Kuczala, we have used in class an adaptation from the game "Editing on the move" (ibid, pp. 121, 122) to understand and practice phonics. We have called it "Rise your cup", and it is submitted in section 8. 
Students can work alone or with a partner. Each group or student is given a list of sentences that need to be edited. Students walk around the class while they edit one sentence at a time. To demonstrate the editing students should:

- Raise their hands in the air to demonstrate a capital letter.

- Pause for commas and slightly bend their knees.

- Period will be demonstrated by going into the tuck position (bend down and hug your knees).

- Exclamation mark will be shown by jumping up and down on both feet at the same time.

- Question mark will be demonstrated by standing on one leg and making a hook-like action with the opposite arm.

- Apostrophes will be added by lifting the right arm and making a hook-like action.

Teaching through movement definitely supports the idea of educating a child as a whole. Returning to the idea of engaging students in multisensory way, Irene Brouwer presents the methodology she uses to teach second languages in her book Foreign Languages for Everyone. How I Learned to Teach Second Languages to Students with Learning Disabilities. She believes that multisensory teaching is beneficial for all students (not just for at-risk students) because it engages the whole person (Brouwer, 2011, p. 15). And so do we, in fact we also have put into practice with our pupils several of the activities and routines of her methodology, as we will explain in the next section.

Brouwer uses the different sensory modes to convey her lessons and contends that they often overlap. Apropos the auditory mode, the author declares that, despite the auditory mode is the most used sensory mode in a typical foreign language classroom, she considers that visual or kinaesthetic modes are better for her students. This is because at-risk students have difficulties to break down the speech stream into recognizable sounds and words. To cope with that hitch, she uses music and singing. Brouwer believes that music embeds learning by bypassing rational cognition (Brouwer, 2011, p. 17). One of her methods is forming chants out of basic grammar rules. As a matter of fact, we use singing too. We consider that using songs and chants to teach 
phonics is a very amusing way to learn and practice sounds. The same applies to the learning of verbs. As many children really struggle learning English verbs, we have used songs to learn them. We have proposed several times a group activity in which $6^{\text {th }}$ grade students had to sing a song using at least ten verbs. The results have always been unbelievable. Students improved their verbs' acquisition, and what is more, those students with big difficulties to memorise even the easiest and most common ones, as is the case of many ADHD students, made progress. With respect to the performances and the programs used to edit the videos, it must be said that some of the works were really impressive. We like to show our pupils the following YouTube video to show them that there are many ways to teach and learn grammar or, in this case, the verbs:

\section{https://www.youtube.com/watch?v=gZzKe1BC2XU}

With this video $6^{\text {th }}$ grade students get excited, as they are teenagers and see the rap as a cool way to access knowledge. We let students use chants, rap or any other style. We also ask them to record it using an audio recorder or a video. It is important to keep in mind that not everyone is a nice singer and shyness plays an important role at their age too. We want to challenge them and make them have some fun while learning, not stress them or making them feel ashamed. The first time we asked them to record themselves we thought most of the works would be an audio file but, to our surprise, most of them were videos where students sang and danced. But the most extraordinary outcome was to confirm that those ADHD students with problems with the verbs really benefited from the activity.

Brouwer (2011) also gives us some indications to use the visual mode. She suggests making auditory foreign language more visual with the use of the following prompts:

- Overhead transparencies: Write on overhead transparencies the basic information for the lesson.

- Daily grey sheets: Students with visual-motor integration problems and written expression difficulties benefit from receiving copies of the material instead of having to copy it from the blackboard or whiteboard. 
- Colour-coded handouts: Brouwer uses colour-coded and paper-coded handouts. In this way when students see the colour of a handout they know where to place it in their notebooks.

- Seeing and repeating daily vocabulary: The author gives the students a daily vocabulary quiz and reviews previous vocabulary. To review vocabulary she uses some coloured-written sheets and asks students to repeat the words after her, which make students use three sensory modes to do so: seeing, hearing, and saying.

- Highlighting pens: Brouwer asks her students to use pink highlighters for feminine nouns and blue highlighters for masculine nouns to help students learn the correct gender of words and facilitate adjective and verb agreement.

There is no doubt that handling copies of the material is a big aid for some students, but sometimes schools' budgets do not allow to print as many copies as one would wish. For that matter, what we do instead is a "dictation-copy" activity, where students practice the dictation, but they can check the spelling at once, because the teacher is writing it on the board as he/she reads it. Once the dictation is finished we can also use the text to practice how to underline important information. The use of colours and drawings can also help, and concepts maps can also be added to help them highlight the important information and study. In relation to colour-coded handouts, what we do to help students organise their notebook to help them study is to divide the notebook into three sections to categorise: verbs, vocabulary and expressions, and activities. Every time they have to write a verb, we ask pupils to look for the proper form and meaning of the verb on their dictionaries and then we write it on the blackboard, so everybody is aware of it and has the proper form of the verb. Regarding vocabulary, there are some words that we know that are new for everyone or, at least, almost everyone, and we write them on the board too and ask students to write it down on their notebook. Activities, photocopies and games are set on the activities' section from the notebook. In this way children know where to write or place everything and it is a helpful method to categorise words and, at the same time, organise the different contents from the subject. When we read for the first time Foreign Languages for Everyone. How I Learned to Teach Second Languages to Students with Learning Disabilities, we loved the idea of making a vocabulary quiz with children every day, but unfortunately it was something we could not afford. Nevertheless, what we grant is 
repeating vocabulary daily and seeing the most important words or grammar. We like to make posters with the grammar or difficult words, so children can see them every day and use them when they are speaking or, for those children with difficulties, like many ADHD students, to use the visual aids to do written activities too. As Brouwer claimed, if we read the words loud and tell students to repeat them while they read them, we are using three sensory modes: seeing, hearing, and saying.

We learn our first language using all of our senses, we listen, we repeat the words we listen, but we also touch and learn the different textures and shapes of the multiple objects by touching them. We also see everything around and learn to name things, people, and even moods. We smell too and learn to name the different smells, and our brain is capable of bringing up memories from our infancy when we smell again some aromas. Why would we learn a foreign language differently? Students with disabilities, and ADHD children specifically, benefit from multisensory teaching, but they are not the only ones who profit from multisensory techniques, we all do.

Apart from the hyperkinetic state, some ADHD children often suffer from stress due to the constant difficulties and challenges they have to cope with every day. Having some fun and laughter can soothe them along the way, as well as movement. As we have previously pointed out, research demonstrates that physical exercise and mindfulness can lead to improvement in academic achievements and reduce inattention in ADHD children. Yoga entails movement, as it is a combination of physical poses, breathing practices and meditation, and several studies show the positive effects that a school based yoga intervention have over preschool children. Jarraya and colleagues conveyed a study with five year old kids. After twelve weeks with two 30-minutes yoga sessions per week, the results showed that some parameters of attention had improved, as well as visual-motor precision (Jarraya, Wagner, Jarraya \& Engel, 2019, p. 7). In the same way, Cohen and associates consider that yoga might be a promising treatment to ameliorate ADHD symptoms in ADHD pre-schoolers. After a six weeks home and school based children's yoga intervention, inattentive symptoms selectively decreased and the authors also found out that yoga improved reaction times and decreased omission errors on some tasks of attention (Cohen et al., 2018). Therefore, the practice of yoga seems to benefit ADHD students. But yoga is a helpful practice for everyone, as it entails meditation, which is a method used to calm and focus the mind. Portes (2018) 
presented an appealing yoga and meditation program for ADHD school students. She used an inclusive yoga program at a school as a pedagogic intervention, developed as part of a multimodal treatment, aiming at helping ADHD students in an inclusive school. During sixteen weeks a group of pupils from $3^{\text {rd }}$ grade practiced yoga for children and meditation for fifteen minutes twice a week. Through Hatha and Kundalini yoga, Portes focused on promoting silence and inner peace and, consequently, developed relaxation and self-control to students, with and without ADHD.

Although we do not usually have time to implement such an extensive program, we have practiced with our students some breathing exercises and yoga poses for relaxation during our English lessons, especially during the first minutes of the lesson after break time. We also have implemented some yoga sessions as a reward with response cost techniques. To put them into practice we used YouTube videos, like the following one:

- $\quad$ https://www.youtube.com/watch?v=CITc2AxYnPY

Yoga by itself cannot be used as a technique to reduce impulsiveness or achieve self-control, but it surely helps. Although practice and some time are required to start seeing positive results.

We have mentioned several times that there is not only one technique or way to help or teach children, with or without ADHD. The only way we have to help ADHD students as teachers is being patient and open-minded, try to understand them, rise their self-esteem, and try new ideas and different methodologies. It may seem hard or difficult, or it may seem a fantastic challenge and an exciting opportunity to improve ourselves as teachers and try new techniques and methodologies. Whichever way you look at it, just try to make it fun for everyone, included yourself. Teaching is a wonderful job, but is full of trials, yet it is worthwhile and is an opportunity for us to learn and grow with our students. Many people think that ADHD students are weak, lazy and brat kids. Maybe some people are too judgemental or uncompassionate, maybe sometimes it is hard to deal with some situations ADHD students bring along, but no one is perfect. Not anyone. So maybe we should be as perseverant and determined to teach as we ask them to learn. Learning a foreign language is really hard work for some 
people, even more complex and confusing for some ADHD children, but all of them can learn another language and deserve to have the chance and not to be dismayed.

In the next section we will present concrete examples and activities to teach English as a second language to ADHD students in inclusive classes. Some activities were outstanding, some were great fun, some others did not work as expected and some others ended up being more tedious than they looked like. Some days we practiced lots of games, some others none. Some days we all learned lots of things, apart from concepts, some other days just a few. But one of the many lessons we learned along the journey is that we all respond much better when someone believes in us and treats us kindly. Some days appear to be quite melancholic and a simple smile from someone can take sadness away. Kindness is a powerful weapon and smiles may help us overcome some of the obstacles we might find on our way. Sometimes children are upset for personal reasons or due to a problem they had with some peer or during the previous lesson. As teachers, we cannot pretend to have perfect lessons or believe that everything is going to be as we assumed it would be when we prepared the lesson plans. As teachers we can only expect the unexpected. Grown-ups are supposed to know how to deal with their feelings, but children are learning to process that information too. Sometimes it is as easy as give them a smile, or tell them a joke. From time to time that small, simple, kind gesture is enough. Other times it doesn't matter how many strategies you try, nothing works out. Pedagogical interventions may look easy in the books, but reality does not always conform with books. In any case, giving everyone a chance is fundamental and believing in your pupils is the first step to help them.

\footnotetext{
${ }^{2}$ Some of the websites we have visited during our research and find very useful are the following:

- https://chadd.org/

- $\quad$ https://www.adhdeurope.eu/

- https://www.adhdfoundation.org.uk/

- https://www.distractionpodcast.com/

- https://www.additudemag.com/

- https://www.fundacioncadah.org/web/

- $\quad$ http://www.feaadah.org/es/

- $\quad$ https://www.fundacionadana.org/

- http://www.tdahytu.es/

- http://www.asanhitdah.es/
} 


\section{Teaching second languages and ADHD}

The job of a teacher is not only the mere transmission of contents, but to help our students to become active members in our society. We also want to teach all of our students, taking into account their personal characteristics, their individual strengths and weaknesses and, at the same time, we want to attend to the whole class and address our teaching to all of them. Having ADHD students in class can lead to having complications if we do not follow some general guidelines and modify our teaching methodology. Considering the personal characteristics of each student, the different learning types, and the diverse teaching styles, it may seem that the job of a teacher is considerably complex, not to mention when learning a foreign language, which many of them struggle to acquire. Actually, ADHD impulsive symptoms may result in speaking without thinking or respecting turn in conversations, interrupting others and talking overmuch. These symptoms may reveal an association between ADHD and difficulties in pragmatic aspects of communication. Inattentive symptoms seem to be correlated with language comprehension difficulties as well (Bellani, Moretti, Perlini and Brambilla, 2011, p. 311).

Altogether, ADHD children show difficulties with phonological awareness (correspondence between phonemes and graphemes) and syntax (the placement of each word within a sentence). Some ADHD students show severe constraints in any activity that requires semantics perception, they appear to have poor auditory memory and, specially, they have narrative difficulties. The information ADHD children manage is scarce and disorganised, the stories they create are less cohesive and they make more mistakes when retrieving information than children without the dysfunction (VaquerizoMadrid, Estévez-Díaz, Pozo-García, 2005, p.84). And so, if these symptoms affect their mother tongue, the influence they can have over learning second languages is even greater, due to the additional difficulties they might encounter when listening to a foreign language and having to follow instructions they may not understand. In any case, every child is an individual and the extent of their symptoms and difficulties are different case to case. 


\subsection{General considerations}

Overall, ADHD children tend to be highly distracted, they get easily bored and have a preference for those exercises or activities in which the compensation is immediate. But we can work with them to postpone the gratification or to enliven some assignments. A way to do so could be adding arousing activities to the lessons plans, such as the TPR activities suggested in this chapter, or allowing movement to some tasks, as letting students highlight or underline information in a text. Now and again we have used a projector to do internet-based vocabulary activities, play vocabulary or grammar games, or sing a song or watch a video on YouTube, which are activities in which they use more than one sense to learn (multisensory learning). Children love playing games on computers and they also relish watching others play. The fact that they get an immediate response from someone apart from their teacher is likewise appealing. On the other hand, ADHD students also need to have a structured lesson with some routines to control their impulsivity, to help them focus on the activities, and to respond as expected.

Another beneficial classroom management tool is using positive behaviour reinforcements for some students or for the class. In the precedent section we have discussed the different behavioural management tools. We have used several resources to help ADHD children focus on the lessons. Classroom arrangements were done sometimes to place ADHD students next to the teacher and away from some classmates that distracted or disturbed them in some way. Sometimes sitting next to friends can be a distraction for anyone, even more so when we are talking about hyperkinetic infants, some other times seating next to a peer that annoy the referred children can detonate undesired situations. Therefore, controlling the class space accordingly to every student is essential. Modelling language and tone of voice are also very helpful, as well as the use of signals to communicate with children, such signalling a thumb up when they are doing a good job, winking or just smiling to them. The use of sense of humour is a basic and vital resource, not just to keep their attention, even to give a warning. According to our professional experience, we suggest to use funny signals to remind students to behave on the first place, such as a funny look or a "faked-funny" anger face. Sometimes one or to funny reminders are enough to address the situation, they know they have to stop the undesired behaviour but it makes them laugh. They really appreciate not being scold on the first place and enjoy the comical side of teachers, on 
the other hand, using just a gesture does not stop the rhythm of the class and it is also less stressful for teachers.

As for the whole class, sometimes there is a general whispering when they should be in silence, some others there is a more lively sound. We have used several techniques to address these situations. The most used one is to switch off the lights, children must quiet when the lights go off. Normally they would quieten as soon as the lights were turned off, but sometimes they need some time, although they always hush at the end. Clapping is useful too, especially if you involve children. That is to say, the teacher will begin clapping slowly and students must join the teacher as they go silent. Once the whole class is in silence the clapping stops and the lesson continues without saying a word about the disruption. The same procedure can be conducted by rising a hand, instead of clapping. A bell has also been used, but we prefer to avoid it to not bother the surrounding classes.

Activity rewards or privileges have also been used, such as: playing on the computer to vocabulary English games, having some free-English reading time, listening to students' selected music, choosing a game to play with the whole group to review vocabulary, playing with the teacher to some vocabulary games, five minutes of free drawing or picking classmates for school projects. Feedback is greatly important and, as ADHD children do not always pay attention to an oral observation, written notes can be used instead. Notwithstanding they may try to sabotage or destroy the negative or less positive written remarks, they might scribble on the comment or try to erase it or white it out. E-mails or personal letters to parents can be used instead. Although we prefer the use of diaries to contact families, because we like to make children participant of the school-home communication process. In fact, we read the annotation to the children and ask them if they agree with the description of the facts. Doing so, not only do we involve them on the communicative process, but we also use it as a way of making students think about their behaviour, and it is also a way to tell them that they are important and that what they think matters, even though we want their family to know about it. We want to stop the undesired behaviour, so we address the wrong conduct, not the children, and we tell them and expect them to think about what they have done in order to prevent it from happening again. We ask the families to sign the notes on the diaries to be sure that they got the message. If the note does not come back 
with a signature we e-mail the families. Most of the times children convey the message accordingly to the established rules. We do send positive notes too, of course, it is actually what we love doing the most. Positive remarks will not be sabotaged, although stickers or happy faces can be used instead as feedback as well, as children love them, even the older ones.

To be specific, material reinforcements have additionally been used, such as stickers, badges, or food treats (fruit or candies, always with parents’ consent). As class behaviour management system we have used the "group response cost". We gave four points to the class every day. Appropriate behaviour and work made them keep the points. At the end of the class they exchange each point for a "shooting” opportunity. Every year the sport selected was different: basketball, golf, playing hoops... Kindergarten sports toys were used to shoot and earn points and every class score was shown in the corridor, on the English corner, so every class could know their score and the rest of the classes' scores too. Accordingly, each class had four points each day, at the end of the class those four points became four shots (using the alphabetical class list to toss the ball, avoiding arguments or discrepancies about who shoots every day). Each scored shooting was exchanged for a real point. They got as many stickers as shooting scores. At the end of the term the class with more stickers had a special class as a prize. That "probability reinforcer" helps students to understand the principle of probability (the better they behave, the more points they have, the greater chance to "score" or "shoot" and, consequently, the more probability they have to win a reward). Sometimes the reward was a class in which we played physical games on the playground, yoga classes were well accepted too, and crafts' classes were very wanted. If we knew about anything appealing for them, we said it was a surprise class, but some other times we let the students vote for the recompense. The only drawback about that technique is that it requires a lot of time. Classes last an hour, which sometimes is a bit less, depending on the exchanges of the teachers between classes. Hence, if we need between five to ten minutes to shoot, at the end you really have forty-five minutes for every lesson. Children were always pretty fair with the scoring, and they were really challenged to win the "special class".

Down below we show an example of English corner we had and the scoring poster displayed for the different classes. The sport played was golf, as it can be seen on 
image 3. We profited the poster that year to promote ecological habits to preserve the planet. As mentioned above, the job of a teacher is not the mere transmission of contents.

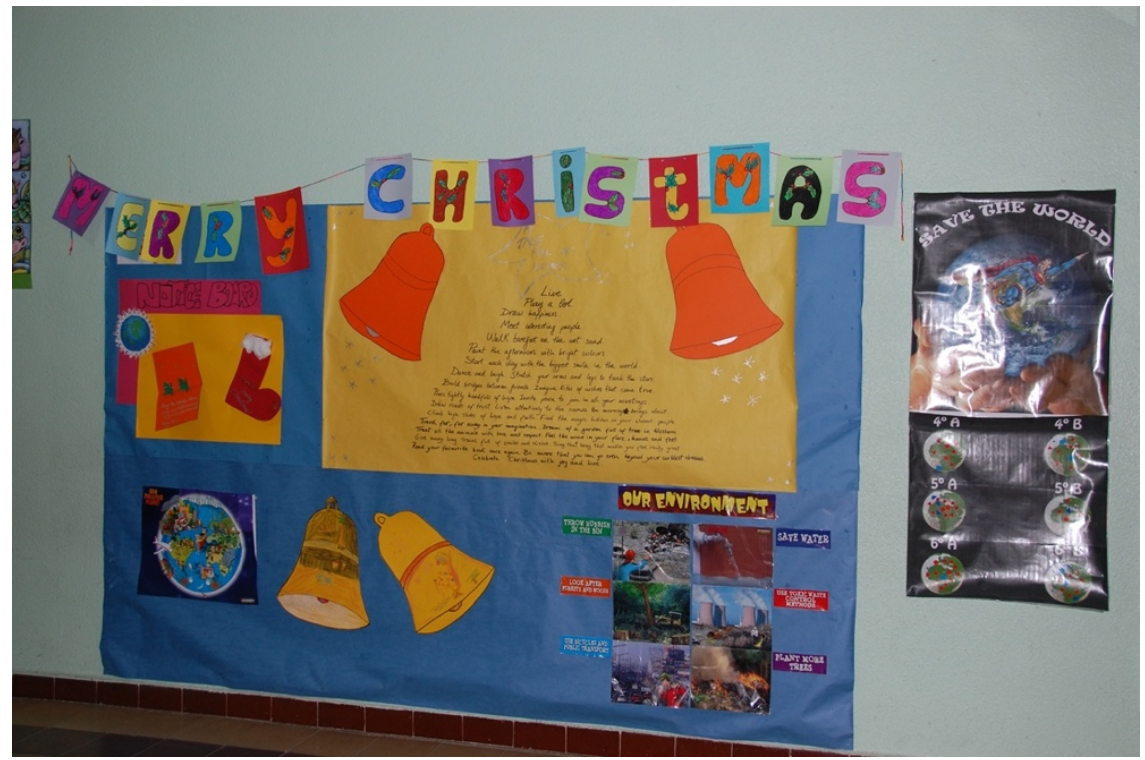

Image 3. English corner

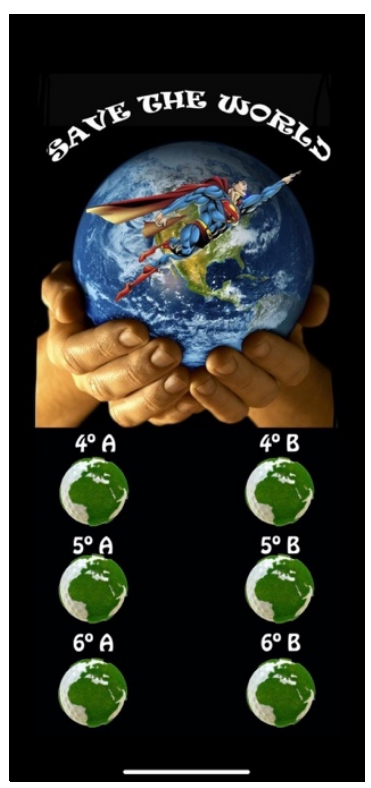

Image 4. Scoring poster

Other techniques were used during reading activities. Sometimes ADHD children get lost during a reading. There are different techniques to help keeping them focused, for example a way to enhance their attention may be letting them mark or colour the end of every sentence. Another useful resource we can use during writing or reading activities may be playing some music. Music can rise the dopamine levels of the 
brain, a stimuli that can help ADHD needs. It is very important to choose the right type of music. There is a study published by the journal of Neuroscience and Behavioral Physiology that states that listening to rock music could improve the Maths work done by ADHD children. The Institute of Higher Nervous Activity and Neurophysiology, from the Russian Academy of Sciences in Moscow published an article about human recognition of visual images, in which these images are supposed to be better recognised meanwhile listening to classical or rock music (Pavlygina, Frolov, Davydof, Milovanova, and Sulimov, 1999).

Additionally, we have tried to listen to different styles of music during the ESL lessons in this study, and live or loud music did not work during the practice of English language writing activities. Classical, instrumental or relaxation music were the best choices. Some soundtracks worked pretty well too, as well as the less quiet tracks were skipped, as it happened in the present project with "Proud and Prejudice" or "Black Hawk Down” soundtracks. In both cases there were lively instrumental tracks and some children stopped reading or writing and started to simulate they were playing the drums. Once there is one child doing something active or "funny", some others will follow. Accordingly it is very important to prepare the music previously or to be alert when using "Youtube" as a player, to be in time to skip the risky tracks and the advertisements. In the case that you use the selection of music as a privilege for some students, using it as a behaviour reinforcement, it is important to check on the lyrics before playing it. Sometimes children listen to music hits that have objectionable content, make sure you play age-appropriate songs in class.

Maintaining a word wall in the classroom with content words, irregular words and/or grammar is another instructional strategy we use to help students. In this way, the contents are continually exposed in class for children to see them, being part of their daily content exposure, and it is also an aid for them when they are doing activities or participating orally along the lessons. It is very helpful for everyone, especially for visual learners.

But none of these techniques can work if we do not have a previous knowledge about ADHD. Therefore, familiarity with the dysfunction and with the student's needs are essential requirements, as well as being proactive. Students' needs should be 
considered when planning the lessons, and continuous assessment shall be conveyed to evaluate the techniques and procedures that best meet those needs, considering the different features that comprise the teaching and learning process. Not every single day is the same, not every pupil has identical needs, not all of the students present the same difficulties, and not everybody learns best in the same way.

Normally, students with ADHD have difficulties with auditory learning and with learning from written texts. It is important to work with the learning styles that are best for ADHD students, in order to compensate for their weaknesses.

In the article "Language Disorders and Attention Deficit Hyperactivity Disorder”, Philippa Greathead (n.d.) suggests the following classification:

- Visual learning:

- They learn by seeing, watching and observing.

- They want to see how things are done.

- They enjoy posters, projections, colours ...

- $\quad$ They learn from videos.

- They draw and doodle.

- $\quad$ They work well with organization charts.

- They are good mental viewers.

- Auditory learning:

- They learn by listening and communicating with others.

- They learn from rhymes and rhythms.

- They learn from auditions.

- They have a good auditory discrimination of sounds.

- They learn languages easily.

- Kinaesthetic learning:

- $\quad$ They use their hands and body to learn.

- They create things, they make and undo things.

- $\quad$ They use their feelings. 
- Learning from written texts:

- $\quad$ They read for pleasure and to learn.

- They have good reading comprehension.

- $\quad$ They write well.

- Interactive learning:

- $\quad$ They learn well by interacting with other people.

- They learn from discussions and dialogues.

- They work well in a group and cooperatively.

- They have leadership skills and are socially flexible.

Determining the learning style of a child can help teachers selecting teaching methods and activities to maximise the child's learning. Hereafter we submit a series of activities and games that we have carried out during our teaching experience to practice discourse analysis with ADHD students in inclusive classrooms during the English as a second language lessons. We have included activities and games to enhance knowledge for the diverse types of learners, although many of the games are kinaesthetic, as ADHD students learn best when movement is involved in the teaching-learning process.

\subsection{ESL activities to work with students with ADHD}

"The limits of my language are the limits of my world" Ludwig Wittgenstein

Some ADHD children have difficulties on the grounds of language analysis, and that affects their communicative skills and their reading comprehension, written production and, consequently, their learning (García \& Ramos, 2012, p. 132). ADHD students may present disturbances on the different levels of language analysis or not, but research shows that all of them show significant disturbances when organising discourse, both on the pragmatic level, when adjustments to specific communicative contexts are required, and on the capacity of making inferences with figurative language (ibid, p. 133). 
We started this subsection quoting Ludwig Wittgenstein, who professed the sentence "the limits of my language are the limits of my world". For these limits to disappear, we propose a series of activities to work the four English skills with students with ADD/ADHD through the teaching of English as a second language.

We should keep in mind that we are working with children aged between nine and eleven, hence the hilarious or interesting examples for them may seem ludicrous to some adults. Examples involving children in the class, superheroes or famous people are normally appealing to them, as well as funny stories about teachers, notwithstanding they do not have to be true. Some children are still a little bit naïve when they are nine and ten years old, which makes them adorable and give teachers a broader scope to work. That innocence makes imagination flow per se. As The Little Prince would say, “Grown-ups never understand anything for themselves, and it is tiresome for children to be always and forever explaining things to them” (Saint-Exúpery, 2004, p. 13). Therefore we recall your inner child when reading some of the activities to not just analyse them, but to enjoy them as well.

\subsubsection{Activities related to written comprehension}

Apart from the tips and techniques tackled within the general considerations, we have implemented the following interventions when conducting written comprehension activities with ADHD students:

- Complete reading worksheets commensurate to their skills level.

- Get students into the habit of using the dictionary to search the unknown words.

- Use appealing texts for students.

- Follow the reading with a pencil, coloured pencils or markers to avoid getting lost. Making a check mark at the end of a sentence can also help.

- Practice “” skimming” and "scanning” activities.

- Ask questions to ensure that students understand the texts.

Regarding activities, we would like to start this section with a proposal that we have already addressed before, implementing some activities related to "skimming” and "scanning", following the recommendations from Lezberg and Hilferty (as cited in 
Ivanov, 2009). By the same token, it has also been shown how to work critical discourse analysis through an activity suggested by Cots (Cots, 2006). This activity analysed three levels, social practice, practical discourse and textual practice. Merging both schemes, we suggest the following activities to put into practice both ideas. We chose a text related to children from other countries, a reading from a book about "Children around the world”, part of a Portfolio program. There were several reasons to select that reading. In the first instance, it is a good reading to practice the social analysis. The second reason concerns to cultural awareness and last, but not least, has to do with the Portfolio program.

The program is called P.E.L. (European Language Portfolio). The P.E.L. is a project promoted by the Council of Europe. One of its main aims is to promote awareness of a European cultural identity and to develop understanding among people of different cultures (Council of Europe, 2004, p. 3). The Portfolio is made up of three parts:

- The passport: The passport contains information about the student.

- The language biography: Students register their language history and experiences. For example, they can write down about the English course they took during summer vacation, or about the exchanges they make with family from abroad when they are bilingual or have a relative living in another country.

- The dossier: Children keep projects, explanations for their expositions or items related to other countries. We try to challenge students and use the portfolio to learn about other cultures and practice oral presentations too. They can choose a city or country they are related to (family), or a place they have visited or want to visit in the future. Many children do not have the means or the possibility to travel, meanwhile others are experienced travellers. Some children have family in other countries and others do not have any relatives abroad. But we want all of them to have the same options and we want all of them to feel passionate about other places. We ask them to investigate about: location, time differences, main religion, gastronomy, main monuments, and some expressions in the language of the place they are presenting. Children love to prepare presentations, some of them prepare PowerPoint presentations and some other bring the information on paper. They all love bringing pictures from the different cities they choose and, if they happen to have visited the country, they also bring maps, brochures and leaflets from museums or other places they have visited, and 
any other related objects they have, such as sachets of sugar or souvenirs. For example, a student prepared a Power Point presentation about “The big apple”, and brought a baseball glove and a Statue of Liberty head ornament because she went to New York; another pupil, whose relatives are from Argentina, brought a guard with a straw where his family prepared mate, and gave a presentation about the main characteristics and traditions from his parents’ country.

The textbook we used in class had several readings related to the portfolio. As is the case of the following text, extracted from the school's textbook (Phillips and Redpath, 2010, p. 84):

\section{TEXT:}

Going to the theatre

My name is Kersen and I live in Indonesia. I love watching 'wayang kulit'. These are plays performed with shadow puppets. The plays always show traditional stories, and the good characters always win. When there is a 'wayang kulit' in my town, everyone watches it. Sometimes small children fall asleep because the plays are very long. Last year I saw one that was five hours long! Often the plays are very funny, and the puppets are stunning.

We propose two pre-reading activities for 6ht grade students. The first task aims to examine the reader's previous knowledge in the content area. It is considered that reader's previous knowledge -or as it is also known, background knowledge- connects with the text. It is also believed that activating vocabulary and previous knowledge helps to achieve a better understanding of the passage (Mohamed and Gumaa, 2013, p. 44). Some people, like Bailey (Bailey, 2019), claim that using previous knowledge can help some students, like learners with dyslexia. The same applies to some ADHD apprentices, those who have poor executive skills. Having difficulties with the working memory leads to problems retaining information for long periods of time. If we are teaching ESL to ADHD students we need to bear in mind that they, or at least some of them, may have problems remembering some vocabulary, that is why examining previous knowledge is so important, as well as helping them to remember some known words. To do so, we submit the following pre-reading activities: 
ACTIVITY 37: Write down as many words as you remember related to the topic (going to the theatre).

For a playful touch we could prompt them to do so in one minute and ask one of the students to use his or her chronometer to time the activity. It is quite common to have more than one student timing the exercise, ADHD students among them. That permits them to, in first place, lose some time, and in the second place, to play a little bit in between. As they really need to have some time between tasks, it is a way to control that "free" time and enrol them in the activity. The second pre-reading activity aims to reinforce the vocabulary, reviewing some known words and giving them some new ones that can help them understanding the text. First, we present the old and new vocabulary with some customized flashcards. The flashcards only contain pictures. The words for study are the following: theatre play, puppet, shadow, characters, stage, lights, costumes, audience, clap and seats. The flashcards are hung on the board and we name them at the same time that we touch them. Then, we ask the students to repeat the words. Instead of doing a writing activity, we suggest to play a memory game to reinforce the known vocabulary and to learn the new one in a funny and engaging way.

ACTIVITY 38: We are going to play a “memory game”. You will have one minute to memorize the words and the positions they have. Then, you will be asked to close your eyes.

Once the children close their eyes, the teacher removes some flashcards and prompts the students to open their eyes and say which vocabulary words are missing. You can play as many times as you want, until you see that most children know the vocabulary. A skimming activity is a good way to continue with the proposal. Therefore, students will be asked to read the text quickly and answer the next activity:

ACTIVITY 39: What is the text about? Where does it takes place?

To continue, we suggest to read the text aloud and ask some questions to the readers to verify that all pupils are understanding the text:

ACTIVITY 40: Throughout the reading questions: 
1. What does Kersen love?

2. What do they use to perform the plays?

3. Who wins in the plays?

4. Are the plays short?

A scanning activity fits perfectly right now. The purpose is to look for specific information. Even though the text is very short, we can appeal to vocabulary to elaborate the next activity:

ACTIVITY 41: Find these words in the text:

1. Performance.

2. Astonishing.

3. A dark image cast on a surface by a body that blocks light.

4. A fictional tale, shorter and less involved than a novel.

(Definitions by Wordreference Dictionary).

To complete the recommendation, we should suggest at least one post-reading activity. However, as previously said, apart from the guidance from Lezberg and Hilferty, we are going to submit some activities following Cots advice to work critical discourse analysis . Therefore, we are presenting three post-reading activities that are going to analyse social practice, practical discourse and textual practice.

The first post-reading activity focuses on social practice. We pretend that the children examine traditional facts from other countries and cultures and the emotions they arouse in them.

ACTIVITY 42: Answer the following questions:

1. Are shadow puppets typical in your country? Are there any typical theatre plays in your country?

2. Is there any activity in your town where "everybody" practices it?

3. Would you like to live in Indonesia? Would you like to live abroad?

The second post-reading activity focuses on the discursive practice. The focal point is now on discourse, a little bit more difficult task for the students due to the 
difficulties some of them have with the second language. Most of them could answer literally to the questions, but some of them are going to have troubles with the second question, in which they are asked to use their own words. Paraphrasing is a complicated job for some pupils yet. Children presenting disabilities or ADHD children are going to need help to rephrase the inquired definition.

ACTIVITY 43: Answer the following questions:

1. What are the main ideas of the text?

2. Describe `wayang kulit’ with your own words.

Finally, we submit the last post-reading activity and closing activity from the blended proposal. The following assignment focuses on textual practice. This is probably the most difficult task for those children with ADHD difficulties. Not only do they need to understand the activity, but they also are going to be asked to analyse English grammar. Having ADHD does not mean that you are not going to be able to succeed in grammar exercises, in fact some ADHD students are quite good with foreign grammar, but unfortunately it is by no means the rule. Many of them have poor executive skills, which affects this type of exercises. Poor Working Memory and Task Monitoring skills lead to having obstacles fracturing exercises into smaller tasks, in unison with problems with keeping in mind the given information during a period of time sufficient to accomplish the goal. Therefore, help will be offered, as well as the simplification of the activity if needed in special cases.

ACTIVITY 44: Answer the following questions:

1. How many adverbs of frequency are there in the text? Write as many sentences as you can from the text containing an adverb of frequency.

2. Is the story related in the present or in the past?

3. Write a sentence from the text containing:

- Present simple:

- Present continuous:

- Past simple:

Through the several activities that make up this first proposal of the section, we have used top-down strategies to interpret discourse and relate it to students' 
background knowledge. According to Nunan, top-down strategies that good readers employ, and that can be taught to young readers, include the following (Nunan, 1993, p. 82):

- Using background knowledge to help comprehending a text.

- Scanning the text for headings, sub-headings and non-text material such as pictures, graphs and diagrams to acquire a broad understanding previous detailed reading.

- Skimming the text and thinking about the content.

- Identifying the genre of the text.

- Discriminating between more and less important information.

We did not cover all the strategies Nunan cited, but we used some of them to work with the text "Going to the theatre".

Observations: Written activities are less appealing for children. The favourite activity from the blending proposal was, undoubtedly, the memory game. As for the written activities, some children had difficulties finding the synonyms from activity 41 , and a high percentage of the class had troubles with activity 44 due to the oblivion or unknowingness of the verbs, although they should know them. Studying the verbs is the most boring assignment they have, regardless of the fact that we play a lot of games to review and to help students to learn the verbs. Besides, ADHD learners tend to have problems with lexis and semantic levels, specifically with the understanding of verbs' tenses (Vaquerizo-Madrid, Estévez-Díaz, and Pozo-García, 2005, p. 86).

Many children, with and without ADHD, struggle when being asked to change the form of a sentence. The declarative sentence in English normally follows the SVO (subject, verb, object) form. The problem arises when they are asked to transform the affirmative sentence into a question. The Spanish language does not need to change the sentence structure, but this rule does not apply to English grammar, where sometimes there is an inversion of the verb and the subject. There are other instances of inversion in English, apart from questions, but they are out of the scope yet with the working groups. Instead of teaching children a big amount of English grammar rules, we can practice some examples and ask them to imagine or invent a context to make use of them. This proposition will help them in several ways. On the first place, they do not 
have to memorize grammar rules, a decision that will benefit all those pupils with poor working memory skills or other executive functions. On the second place, the fact that they invent or imagine the context will help them remember the example. And last, but not least, it is better to give pupils small, manageable chunks to remember than big lists. There is a bigger chance for them to retrieve that information when given it in small chunks, and the funnier or the most uncommon, the better. We tend to forget the ordinary examples. On account of that, the following activity may help children to practice how to make questions at the same time that allows us to give them some chunks to remember in the future. To introduce the activity, we remind the $5^{\text {th }}$ Grade children of the word order of an affirmative sentence using some humour, which will engage the class, even those ADHD children who tend to lose focus during explanations. Whenever possible, use humour, it always brings children round.

CLASSROOM DATA: First, we prompt the class to give an example. "Can anyone give us an example of an affirmative sentence?”, asks the teacher. Several pupils give an example. We write them all on the blackboard. Then, the teacher writes her example on the board, with the SVO explanation underneath:

"Rajoy is gorgeous".
S. V.
O.

Rajoy was the president of Spain at the time. All children knew him and thought he was not gorgeous, just because he was "old” to them (everyone older than 40 or 45 is too old for some kids) and politics was not appealing to them. It must be one of "those" basic children's rules, so in case we have forgotten it, we will remind you that boring and gorgeous hardly match. Therefore, for them the sentence was supposed to mean that the teacher thought Rajoy was gorgeous, which was amusing to them and, as every "love story”, had its ensuing gossiping among some pupils. Just a simple sentence was a funny statement to them, and that was exactly what we wanted. Everyone was paying attention to the sentence. We ask them to transform it into a question and write the answer on the blackboard:

“Is Rajoy gorgeous?”.
V. S
O. 
Then the teacher asks: "How can it be possible? Maybe "S. V. O." do not stand for "subject-verb-object”, maybe it stands for “Super Villain On duty”. We keep using discourse to engage pupils. Children will find it funny and we will have them focused again, moment that we will profit to explain it and, finally, suggest the following activity to practice it.

ACTIVITY 45: Transform this affirmative sentences into questions. Create a context in which they make sense:

1. Ana's Messi's cousin. (Ana or any other child's name in the classroom)

2. We are going to watch Star Wars, the movie.

3. He can eat twenty chocolates in five minutes.

4. They sing better than Ed Sheeran. (Ed Sheeran or any singer or famous music group at the moment).

5. Sandra kissed Mario Casas’ hand. (Sandra or any teacher's name. Mario Casas or any other famous artist children know).

Observations: Sometimes funny examples bring excited chattering to the class. It is important to ask students to be quiet and focus on the activity. On the first sentence “Ana's Messi's cousin” some children were lost, thinking that there was no verb. Some others did not remember the apostrophe rules for possessives. On the second and third sentences some children did not know what to do having two verbs in a row. And that is exactly what we expected. Sentences that bring difficulties to some pupils permit teachers to help students in class and are always a good chance to help them to remember the previous grammar. Moreover, using tricky chunks will help learners remember them in the future. At the end of the activity we listened to and sang a song by Ed Sheeran using YouTube. By this, not only we put into practice the multisensory teaching approach, but we use it as a positive reinforcement for the group. Positive feedback always is welcomed and helps them to focus again in the next task, along with the fact that we all need a break after difficult activities. But we must keep in mind that lessons can be longer than expected, because everyone needs to understand the activity at the end and, in inclusive classes with a high students' ratio and an absence of other teachers' help, that can take a while. Fortunately, not everyone had difficulties with the activity, some students ended up quite fast, so they were asked to help the students who were struggling the most, altogether with the teacher. 
Regarding the selection of material for reading, texts were drawn from different sources. Apart from the texts of the book, advertisements, travel leaflets, written signs, magazines' articles, internet texts, riddles, tales and fragments of books were used to enhance written comprehension. The use of different genres and social purposes of the texts contribute to improve reading skills and give students a broader sense of literature, not using just the conventional texts books, and offering all children the same opportunities by accessing the different texts within the school. Sometimes the use of some texts at home is culturally unattainable or implausible, therefore teachers should provide students with the same opportunities to foster language acquisition and, most importantly, teachers should give learners the tools they need to learn a foreign language. Following Wallace's ideas, we started with signs and advertisings. Catherine Wallace started using advertisements to enhance critical reading because she considers that advertising is noticeable and attractive for students, besides the linguistic content may be minimal (Wallace, 2003, p. 107). We suggested to our pupils $\left(4^{\text {th }}, 5^{\text {th }}\right.$ and $6^{\text {th }}$ Grade) the following activity:

ACTIVITY 46: Write down an English message, sign or advertisement you find around the city of Salamanca, and translate it into Spanish.

With this activity we wanted our students to be aware that communicative purposes are reflected on the basic building blocks of discourse, that is, the words and grammatical structures themselves (Nunan, 1993, p. 49). We also wanted children to perceive and appreciate that English surrounds us everywhere, despite the fact that we are living in Spain. Additionally, we intended to rise their awareness towards written English and to give them some tools to become a little bit independent when learning a language, and as the linguistic content may be minimal, it was an attractive activity students could do on their own with the help of a dictionary.

Observations: The results were very positive. Although the activity was not mandatory, almost all pupils participated and those ones that did not, eventually brought a message. They enjoyed walking around the city looking for English messages and they realized that, as we told them, English surrounds us. Not only they started to pay more attention to the written signs, but they also noticed sentences from TV 
advertisings or sentences from videogames. However, it is important to mention that this only happened during a short period after we did the activity, students were not that much alert about English messages around them after a while.

Making sense of a text is an act of interpretation that depends as much on what readers bring to a text as what the author puts into it. When we make cognitive links in the text we are not just noting the semantic links between the cohesive items, we are creating coherence (McCarthy, 1991, p.27).

ACTIVITY 47: Choose the right form to complete the text:

Rafa Nadal was/has been born in Manacor in 1986. He won/has won four French Open titles and an Olympic gold medal. In 2008, Nadal has become/became the second Spanish man to win Wimbledon.

Since 2004, Nadal has been/was a strong competitor to Roger Federer. They have played/played against each other in seven Grand Slam finals. Nadal has won/won five of them. Nadal ranked/has ranked World No. 2 behind Federer for a record 160 weeks. He was/has been the first in the rank for 46 weeks.

Rafa played/has played the Davis Cup with the Spanish team four times so far. They won/have won the trophy in 2004 and 2008, although he didn't play/hasn't played on the final due to a knee injury.

Some trivia about him:

- He has begun/began playing tennis when he has been/was five.

- In 2002, he has won/won his first ATP match at Majorca at the age of 15.

- He has always played/always played with his left hand although he is right-handed.

- He created/has created the Fundación Rafa Nadal, which promotes sport as an integration tool for those who need it the most, such as handicapped, immigrant and socially excluded people.

Activity 47 has been extracted from the following link: https://www.englishexercises.org/makeagame/viewgame.asp?id=1496. The text 
requires to know who Rafael Nadal is and to have some knowledge about tennis or, at least, tennis competitions. Those pupils with no knowledge at all about the topic were not able to make all the cognitive links required to make the right choices in the text, although they could have picked the right answers anyway, because dates and some cohesive items, like "so far", pointed out the right answer. The fact that they were unfamiliar with the topic made them use a lot of time and effort to try to understand the overall meaning, thus some of their answers were wrong. Hence an act of interpretation of a text not only depends on what the writer brings to a text, it also is determined by what readers bring to a text, as McCarthy contended.

Observations: As Nunan states, children comprehend best when the noun form appears instead of pronouns in written discourse (Nunan, 1993, p. 109). It can be appreciated in the following paragraph:

"Rafa has played the Davis Cup with the Spanish team four times so far. They won the trophy in 2004 and 2008, although he didn't play on the final due to a knee injury.”

"The Spanish team” and "They” form an anaphoric relationship, although it is hard to see for some children, ADHD students among them, and they do not understand that "they" refers to "the Spanish team". This must be considered when planning the activity. Peer help intervention can be used in this type of activities, at least with ADHD students.

Even in contemporary times, skill in reading is imperative, since a significant part of what one needs to know is communicated via written text: instructions on how to get out of an underground parking area, or instructions on how to operate the pump in a self-service gas station. We could not function in a modern society without reading (Celce-Murcia and Olshtain, 2000, p. 118). That is basically what children need to know to improve their reading skills, and that is what teachers can use to enhance and challenge their students to develop their reading skills. Broad literature and genres must be used in a foreign classroom, but sometimes certain students are reluctant to read, in general terms, so what we do in these situations is give whatever it is that gets their attention in written form. Sometimes it is a website about football, or about science, or 
animals. Now and again we copy texts on "Word" related to an appealing subject for a particular child. We also challenge them to read the labels from the products in the supermarket, and it is incredible how some funny requests engage them into reading, such as defying pupils to read the labels of their parents' facial/body creams. Such "provocations" tend to amuse some reluctant children. It may not be a large text, but is a way to start, and shorter or longer, they always find new words to add to their wealth of vocabulary. ADHD students in primary schools are far from being “effective readers”, but that does not mean they are not going to end up being good readers. When that is going to occur is conditioned by several aspects, such as whether or not there is a specific language impairment, whether there is or not a coexistent dysfunction, the implementations of teacher programs to develop reading skills, the behavioural techniques used during the interventions (if needed), the relation and collaboration between school/teachers-families, and the interest and effort of the students. The reader always plays an important role on the interpretation of texts, sometimes more than others, as is the case of hyperkinetic learners.

\subsubsection{Activities related to oral comprehension}

The things we know about the world assist us in the interpretation of discourse (Nunan, 1993, p. 67), as there is more to comprehending discourse than knowing the words on the page (ibid, p. 69), or in this case, the words we listen. Background knowledge is fundamental when we are learning a second language and when we are facing children as learners, that knowledge might be poor due to their age and the limited experiences they have had in comparison to adults learners. Therefore, the interpretations children, and specifically ADHD children, may have about the oral information they receive might be sometimes intermittent or wrong, ending up in dysfunctional communications. Here lies the importance of considering these facts when planning the oral comprehension activities and the techniques we are going to use to help ADHD students.

We have developed our own oral comprehension self-instruction cognitive training program from Orjales’ contributions (Orjales, 2005), and have implemented the self-instructions techniques to help students with and without ADHD, among the following intervention strategies: 
- Repeat oral productions when it is required.

- Use gestures and visual aids.

- Use simple and short instructions.

- Use gestures and shared complicity to make sure ADHD children, or any other children in the class, are comprehending the oral interaction.

- Vary pitch and intonation throughout the oral discourse.

- Use the "sandwich technique” (English-Spanish-English) when students do not understand the oral discourse.

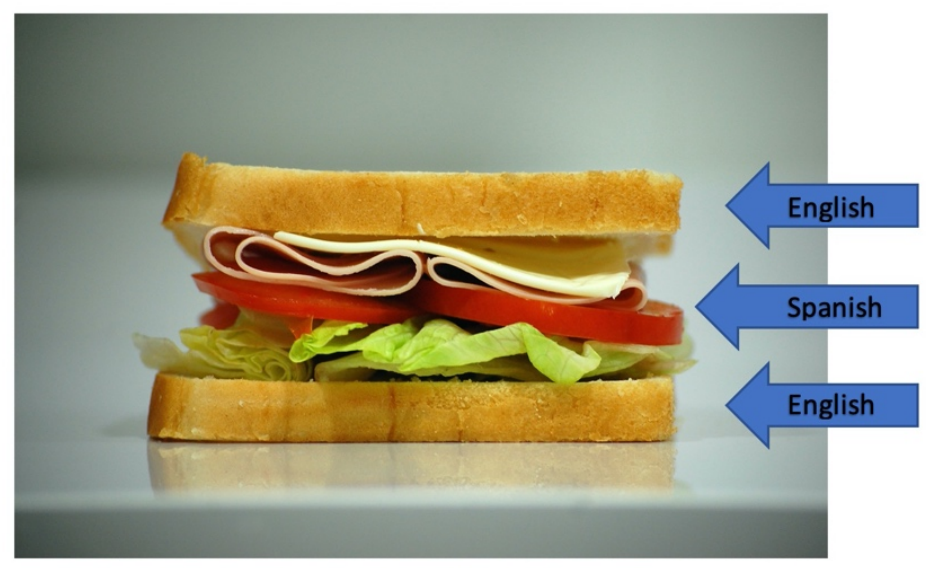

Image 5. “Sandwich-technique” diagram (English-Spanish-English).

- Use humour and jokes to keep students’ attention.

- Generate mental images.

- Implement the cognitive training self-instruction program for oral comprehension activities for children with or without ADHD.
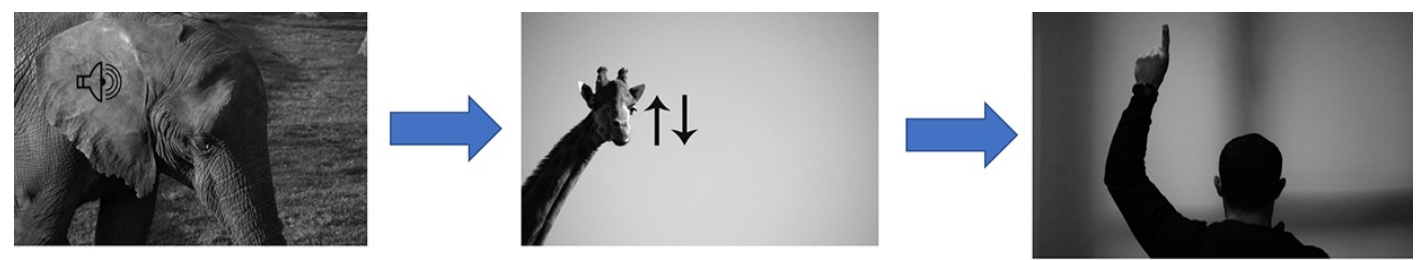

\section{Listen}

\section{Nod if you understand}

\section{Ask if you don't}

Image 6. Cognitive training self-instruction program for oral comprehension activities for children with or without ADHD (based on Orjales, 2005). 
As described previously, playing games is a ludic method to teach a foreign language, and it is very suited to work with ADHD students. We suggest the following games to practice discourse analysis within the English as a second language classes.

\section{GAME 1: Emperor, How far May I Travel?}

This game is designed by Monschein (2008, p. 23) to develop listening skills. One child is selected to be the "emperor". We ask the students to line up at one side of the room, with the emperor standing at the opposite side of the room. The children then ask “Emperor, emperor how far may I travel?”- The answer is given in the form of words, which can be first names, country names, and so on. The number of syllables in the given word determines the number of steps, jumps or hops the children are allowed to take. For example, if the answer is "A-fri-ca”, the students are allowed to take three steps or jumps forward, and this continues until someone reaches the Emperor.

This is the original activity, although variations in the answer of the "emperor" can be done, as we did. We practiced different categories: colours, verbs, adjectives, animals. It can also be used to review the content vocabulary of a lesson.

We decided that the first child reaching the "emperor" should switch places with his/her classmate, becoming himself/herself an "emperor/empress”.

Observations: This TPR activity can be used as a warm-up or as an end-of-session activity. Children really loved it and wanted to play it again and again, but that generated a stir due to its high physical component. Therefore, it is recommended to do it at the end of the session. Space is needed for the game, although playing at the corridor or at the playground could be considered in case space inside the classroom is limited.

GAME 2: Tap, Tap!

This activity is an adaptation of the game "Back to Back!" presented by Maria Monschein in her book The 50 best games for speech \& language development (2008, p. 22). 
To carry it out we will pair up the students and we will read a story or a short passage in English. We will ask them to pay attention and give the partner a pat on the shoulder each time they hear a verb (we can also ask that this action be done every time they hear an adjective or a specific sound). It will be read a second time and the students must say the number of times a verb appears (adjective, sound, etc.). We will tell them the exact number of repetitions and whoever gets it will receive a prize.

Observations: When making the pairs for the activity, we have put together the students taking into account their personal characteristics, in such a way that, if any student had more difficulties with the language or grammar activities, he/she has been paired with someone who could help and guide him/her. This activity has been done focusing on verbs and adjectives. When asked to look at the verbs, many students have not been able to locate many of them. With adjectives the test has been easier for students who had problems in the previous round. Specific grammar exercises are sometimes tedious for students with ADD/ADHD. With this game we intend to keep these students active and attentive, taking advantage of the playful component that this method of meaningful learning provides us. The fact that there is a prize is another motivating component for them, whether the reward is a social approval (for example: applause), a sticker or a candy. Given the capacity for concentration that the activity demands for students with attention deficit, I considered it appropriate to award these students with a candy at the end of the exercise, even if they had not been successful. All of the students could eat candies and were allowed to by their parents.

\section{GAME 3: Red light-green light}

Have students line up horizontally across the back of the room. Then, instruct them to take one step forward when they hear a true statement, while remaining still when they hear a false one. If any student steps forward when the answer is not correct, they must go back to the starting line.

We have used this game to review content. We recommend it, as the only requirement to play it is to have some free space, unless you opt for leaving the class and playing the game in the corridor or outside. From our experience we recommend to 
play it outside if there is not enough space inside the classroom. Although a variant can be played, instead of placing students horizontally, you can always profit the space between the desks' rows and make children line up, drawing a line on the floor with a chalk and asking them to move to their right if the statement you say is true.

Observations: It is a very helpful activity for ADHD students, not only because some ADHD students have problems understanding some grammar concepts and playing "red light-green light" helps them to comprehend the grammar structures and their uses. Although sometimes they start to play the game copying their peers, because they do not understand the grammar, they usually end up making the right choices with the help of their classmates.

\section{GAME 4: Simon says}

This action game will delight students, particularly ADHD learners. The teacher takes the role of "Simon" and commands students to do physical actions, such as "hop", “move your right arm back and forth”, or "stick out your tongue”. The students have to execute the actions only when preceded by the phrase "Simon says". Players are eliminated from the game by either executing directions that are not prefaced by the phrase "Simon says", or by executing an instruction which has not been commanded. The aim of the teacher is to get all the students out as fast as possible, and the winner of the game is the last pupil who has followed all of the given orders.

Observations: It is the ability to listen and understand the commands what matters in the game. It is a TPR game that can be played at any time, as there are no requirements needed. ADHD learners with poor listening skills or with limited vocabulary knowledge may fail at the very beginning of the game, or will try to cheat by imitating their peers. In those cases, letting ADHD students help the teacher to give commands can be a great strategy, and will definitely help them to acquire some new words and phrases to their consciousness.

\section{GAME 5: Chinese whispers}

This game is also known as “Telephone” or "Broken telephone”. Students form a line and the first pupil in the line whispers a message to the ear of the second student in the line, and so forth. Children repeat the message they hear from their previous 
partner, having as a result a sequence of deferred texts, which normally ends up with a piece of discourse that barely has a resemblance with the original message delivered.

Observations: Children relish playing this game, in particular ADHD students, as they do not feel they are being analysed and, consequently, no one is going to know if they conveyed the message properly or not, so they play at ease. But we found important to let everyone know that the aim of the game is to have the correct message at the end, otherwise you may have some rounds of intentional chaos and nonsense between the students, just pretending to have fun.

Fernández defines discourse analysis (DA) as a broad interdisciplinary field which studies how language is used within its social context. The author contends that discourse analysis can be applied to any text or situation, so that a song, a photo, an email or a video can become the subject of linguistic examination and social debate (Fernández, 2014, p. 71). In addition, Fernández believes in using ICTs in any discourse analysis course, where texts can be considered an instrument of social action, which may prompt students to use coherent reasoning (ibid, p. 72). She uses activities based on ICTs to approach the teaching of discourse analysis. She presents several activities in which the study of discourse as a tool for social construction is conveyed through ICTs. Based on these ideas, we submit two activities based on ICTs, the first one is grounded on a song and the second one is based on a movie. Through both activities we aim:

- To improve listening skills.

- To consider the text, that is, the video an instrument of social action.

- To encourage students to attempt critical assessments on texts.

- To rise antibullying awareness.

ACTIVITY 48: Before watching and listening to the video we ask:

1. What do you think about bullying? How would you think you would respond if someone bullied you or if you knew someone was being bullied? 
Watch the video and listen carefully to the lyrics of the song. Then answer the questions:

https://www.youtube.com/watch?v=g3Rf5qDuq7M

2. Do you think these kids are cool? Why?

3. Do you think Charlie and Leondre are polite? Give some examples to explain your answer.

4. Why did Leondre start to write the song?

5. How did he manage the bullying?

6. How do they define themselves?

7. Do you remember the chorus of the rap? Can you repeat it?

8. What do the audience shout after their audition?

9. Why did they really get the golden buzzer?

10. Do you still think the same as bullying and about how you would respond to it?

Observations: Students thought that Charlie and Leondre were cool and polite, so we told them that, therefore, it was possible to be very cool and polite at the same time. It may seem that we are straying from the focal point, but we aren't. Some children sometimes consider that if they are polite they are not going to become fashionable or that their classmates are not going to consider them great and trendy. As there is a correlation between behaviour and social consideration, they tend to misinterpret it. We are not here to blame them, in fact, they learn by a process of trial and error. And that misconception sometimes lead some kids to push other children or to end up bullying someone or covering the oppressors.

That was a very interesting activity that ended up taking all the lesson. Children were lighted up by the two kids. Rap really got through them, they were fascinated by the song, the rehearsal and the two artists, as every $6^{\text {th }}$ grade student would be. Although some children did not understand everything, so we told the students who understood it to explain it aloud with their own words. ADHD students barely understood anything, but enjoyed the song very much and, after their peers' explanation wanted to give their opinion, but in Spanish. We allowed them to speak "Spanglish" and helped them with 
the unknown words. It was an appropriate topic to use as discourse analysis is an instrument of social action, and it undoubtedly required children's critical reasoning and assessment.

Before doing the next activity, we watched "Wonder", the film. Children enjoyed greatly the movie and it reinforced the values we worked on the previous session about antibullying. We have submitted an activity with the very same video in the ESL activities section 5.3.2, in which discourse analysis is exercised. The questions are practically the same, they are just adapted for $6^{\text {th }}$ grade students.

ACTIVITY 49: Watch and listen carefully to the following sketch from "Wonder", the film. Then answer the following questions:

\section{https://www.youtube.com/watch?v=JBnh8BuUxHo\&feature=emb_logo}

1. How would you define the term "bullying"?

2. Describe some antibullying actions that are shown in the film.

3. Mr. Tushman cites a quote from Henry Ward Beecher. Part of the quote says: “Greatness lies, not in being strong, but in the right using of strength". What does it mean to you?

4. Today's society has evolved considerably in the last centuries. Technological inventions and developments have helped people considerably. But what about bullying? Do you think it is easier to bully someone using new technologies? What about preventing them?

5. Mr. Tushman gives the Henry Ward Beecher medal to "Auggie”, because he considers that "his quiet strength has carried up the most hearts". Can you name some of the moments he showed up that "quiet strength”?

Observations: Unfortunately bullying has become a very common problem among children. A way to prevent it from happening is working with children and deepening in some feelings and values, and letting them know that permitting and not reporting intimidating actions from others make yourself an accomplice. That is the major aim of this activity, leaving linguistic goals apart. Regarding discourse analysis critical thinking, we had some very interesting answers in response to questions four 
and five. Many $6^{\text {th }}$ grade children own a mobile phone and use WhatsApp, among other social networks to get in touch with their friends. Despite their youth, many of the students are using social media applications, and that is a dangerous item for them to use. Some of these pupils know the effect it can have, but some others ignore the magnitude and the implications the misuse of the social networks might have.

Consequently, some students argued the benefits they have from the use of nets such as WhatsApp, but they also shared their fears with the rest of the class. Despite the activity had a strong listening section, the speaking part was truly powerful too. The only disadvantage of it was the scarce participation of students. All of them wanted to say something in respect thereof, but most of them wanted to speak in Spanish, not in English, as they were missing words to complete their messages and that made them feel not confident enough to make their whole speech in the second language. Hence, we helped some of the children to participate in English and just a few of them expressed themselves in this regard. But all those who spoke, made a great contribution, not only to the English language, but to the topic. ADHD children were just seating, listening and muttering in Spanish with their group peers.

Another way to use songs is using cloze exercises. Cloze exercises help students to build their listening skills. When doing this fill in the blank exercises with listening passages, some people recommend to delete words systematically every nth word, despite its lexical category. Zúñiga considers that handing out activities to students to fill them while they listen to a recording is not enough. The author contends that the role of students in activities like this one is rather passive and limited integration of skills takes places. Zúñiga has developed some different ways to exploit listening materials, integrating several linguistic skills and fostering students’ autonomy and learning through peer assessment. He has created a hybrid exercise by blending a listening cloze activity with an info-gap speaking activity. By doing so students practice the four macro-skills of listening, speaking, reading, and writing, apart from micro-skills such as vocabulary, spelling and pronunciation (Zúñiga Vargas, 2015, p. 24). We did not use the author's hybrid activity, but we have our own scheme to use songs to improve listening skills, combined with other activities to make students active in the teachinglearning process. We always use festivities or cultural celebrations, such as Christmas, Saint Valentines’ Day or Peace Day to make listening cloze activities. Apart from the song, we ask students to investigate about the celebration, in such way students are 
reading, selecting information and writing. Then, they share their information in class with their classmates, so they are also speaking. Finally, students hang their information on the English corner for some days, so if anyone wants to check about the data later on, they can read about it again. In a different and simpler way we also practice the four macro-skills and micro-skills such as vocabulary, spelling and pronunciation. We always adapt the cloze activities to the English level and grade students are. The same song is adapted by leaving more or less blank spaces to fill during the listening. For the younger pupils illustrations can also be attached next to the blank spaces, and children can try to write the words before listening to the recording with a classmate. These worksheets can also be used with older children with special needs or accommodations in their curriculum. We submit hereafter an example of a song we used in a celebration of Saint Valentine’s Day. We used the song “Ain’t no mountain high enough” by Marvin Gaye.

First, we ask students to bring to school information about Saint Valentine’s Day. Children read their notes to their classmates and the teacher and leave their data on the English corner, so anyone can read it afterwards if they have some spare time between classes. In this sense children who brought information have practice reading, writing and speaking, and they also practice listening while they are listening to their peers' notes.

The next activity is aimed for $4^{\text {th }}$ grade students.

ACTIVITY 50: Fill in the blanks with a partner the words that are accompanied by an illustration. Leave the other spaces in blank. 


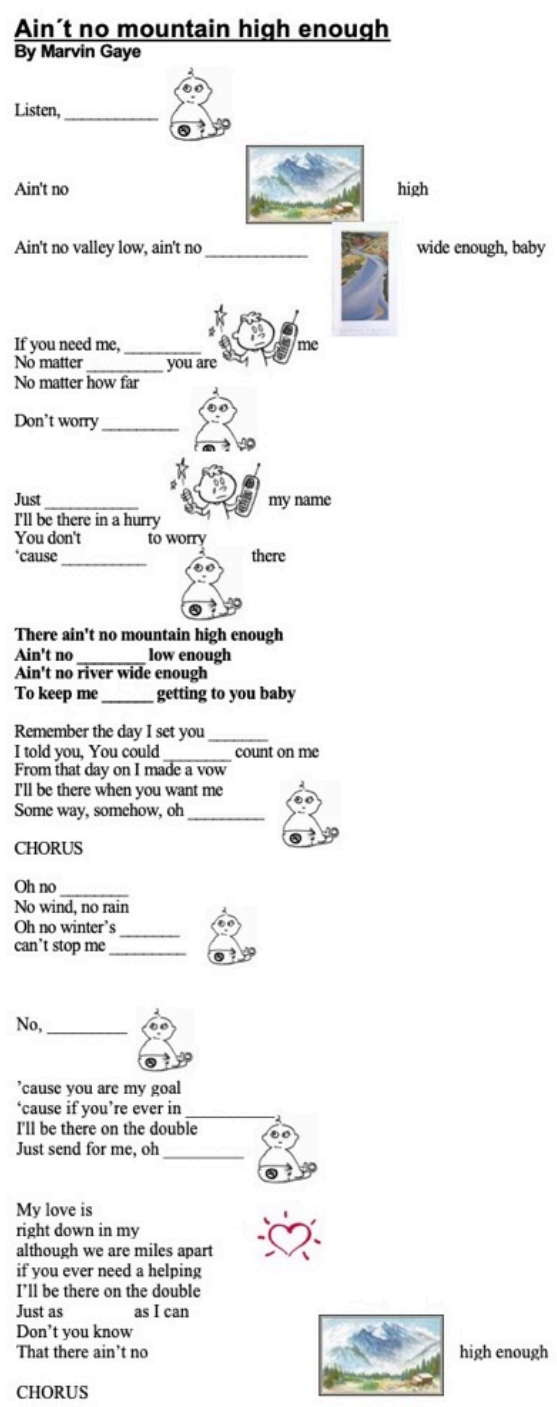

Image 7. Song activity

ACTIVITY 51: Listen to the song and fill in the blanks.

We listen to the song twice and then we check the answers. At the close of the correction we sing the song and stress on pronunciation.

Observations: With a simple song myriad activities can be done.

In section 5 we have already mentioned Richards (2008), an author who gives a lot of examples of activities to practice listening, combining bottom-up and top-down processes. As reported by Richards, exercises such as dictation, cloze listening, 
multiple-choice activities after a listening, and activities that require specific identification and processing of the data, develop bottom-up processes, helping students to keep data or identifying words (Richards, 2008, p. 5). Taking into account that many ADHD students have poor listening skills and have problems memorising and retrieving information, we barely practice cloze listening or multiple-choice activities after a listening. We play every listening track twice instead and try to improve their listening skills by giving them the possibility to listen to the activities while they answer. Even with the implementation of this technique many ADHD students, among other pupils without ADHD, encounter difficulties during the listening activities. We want them to answer the question, or at least try to answer them, improving their listening skills and their self-esteem. If we asked them to give their answers after the listening, instead of doing the exercises while listening to the tracks, we might have several children reluctant to do the activities, thinking that they are not able to do so. Notwithstanding, we sometimes do listening activities and ask them about specific identification of data, as is submitted in the next activity:

ACTIVITY 52: Listen and then answer the questions:

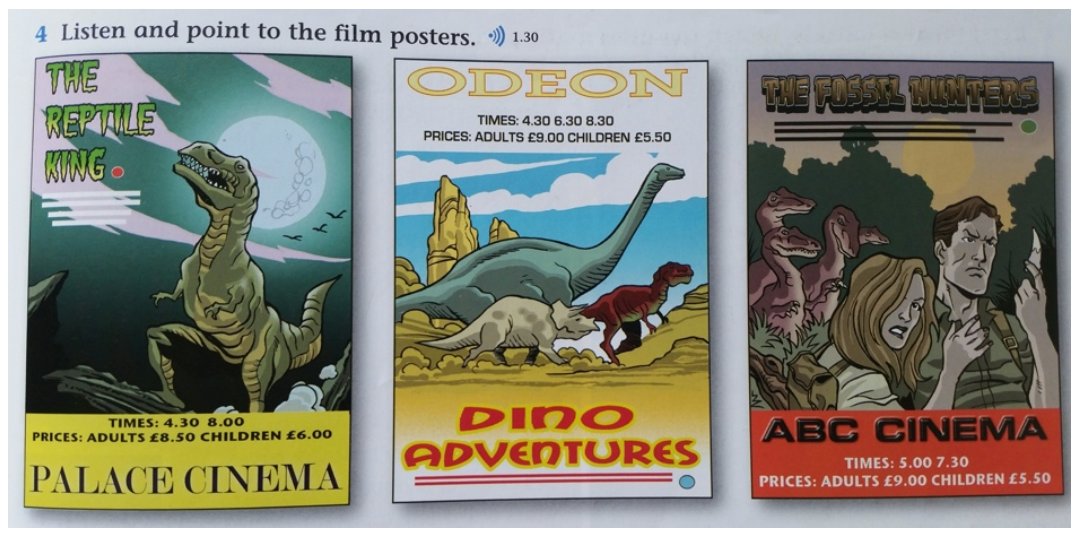

Image 8. Listening activity from Incredible English Kit. Class book 5 (Phillips and Redpath, 2010, p. 17)

1. Which film poster corresponds to the first film announced in the listening?

2. Which film poster corresponds to the second broadcasted film?

3. If you made any mistakes, what led you to an error? The ticket's prices? The time the films were on? Please explain your answers. 
We also practice bottom-up processes with listening exercises through bingos and dictations, as is shown thereupon.

\section{GAME 6: Bingo}

Bingo is a game in which each player has a card with numbers on. The host draws or calls out numbers at random and players mark the numbers form their card that match the called figures. The first person to have all of their numbers called out says "Bingo" and wins the game.

This is a versatile game that not only permits teachers to review numbers, but also vocabulary or even concepts. It depends on what teachers ask students to place on the cards or grids.

Bingo cards were originally made of $5 x 5$ grids. When playing with children the number of grids can be adapted to the children's age, needs or concepts being reviewed. We regularly play bingos with numbers with $4^{\text {th }}$ grade students at the beginning of the course, to review previous contents and we use 2x3 grids cards.

Observations: Instead of giving children bingo cards, teachers can ask students to draw a grid on their notebook. It is less time consuming for teachers, and asking children to have a template grid will enable teachers to play as many times as they want with different contents, as long as children use pencils to fill up their bingo cards. In case teachers want to give students printed bingo cards, there are several free bingo generators on the internet, such as "Bingo Baker".

ACTIVITY 53: Listen and type the numbers you hear:

The teacher calls out numbers: 748 / 23 / 13 / 30 / 12 / 1,849

Children have to write the numbers they hear: seven hundred and forty-eight / twenty-three / thirteen / thirty / twelve / one thousand eight hundred and forty-nine.

Observations: In this number's dictation we have used numbers that usually are problematic for some children, especially ADHD learners. Sometimes learners misspell number "forty" and its ten, because they write it as in number "four", they write 
“*fourty, *fourty-one, *fourty-two,...”. Besides, number “eight” brings recurrent errors in writing. At times children also write numbers "twenty" and "twelve" wrongly, writing an /u/ instead of /w/, as is pronounced, and probably due to the absence of concurrence of /t/ and /w/ together in Spanish. Moreover, students frequently have problems distinguishing orally between numbers "thirteen” and "thirty”. When it comes to start writing "thousand" and "hundred", multiple errors are done, being the most common ones the writing of $/ a /$ instead of $/ \mathrm{u} /$ in both instances.

We practice numbers and texts' dictations, although we only have submitted an example of a number dictation. But we also use dictations of vocabulary with ADHD learners, which are really helpful in those cases where ADHD children have difficulties to acquire the new words or when they omit or change the word order from the target vocabulary. Peers' collaborations are really helpful to convey the vocabulary dictation to practice or review vocabulary.

Listening activities are also part of multiple intelligences methodology. Bas contends that if children can draw or visualize and image, they may be able to more easily retrieve that information. On the basis of the theory of multiple intelligences in this regard, children can also draw a picture while listening to a description, for example (Bas, 2008, p. 1). Hence, colouring a drawing while following instructions from a listening is also an activity that integrates multiple intelligences in the ESL classroom. In the next activity we review content vocabulary with $4^{\text {th }}$ grade students through a listening activity. We ask them to colour the fish as indicated on the recording, practicing the next vocabulary: colours, surface, deep, shallow, bottom, sea, river.

ACTIVITY 54: Listen and colour.

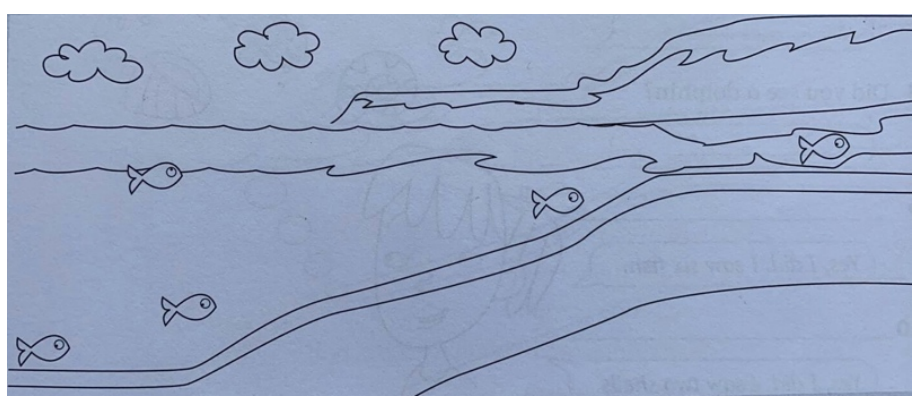

Image 9. Photocopiable material. Incredible English Kit 4 (Beare, 2010, p. 187) 
Another activity that integrates multiple intelligences in the ESL classroom using listening skills is the use of storybooks. Along with enriching vocabulary and showing grammar patterns, Bas declares that storybooks develop children's listening for general meaning, predicting, guessing meaning and hypothesising, added to the fact that tales help children to link fantasy with real world (Bas, 2008, p. 3) On the grounds of these ideas, we suggest a set of activities, based on a tale that the teacher or a student read aloud. The text that the teacher read out is shown hereunder:

\section{The Three Little Pigs}

There once was a mother pig who was very poor and had to send her three little pigs out to seek their fortunes.

The first little pig met a man who gave him some straw to build himself a house. He lived happily in the house until a wolf came along and knocked at his door.

“Little pig, little pig, let come in!” demanded the wolf.

"Not by the hair of my chinny-chin-chin” replied the pig.

“Then I'll huff and I'll puff and I'll blow your house in”, said the wolf. So he huffed and he puffed and he blew the house in, and chased away the first little pig.

The second little pig met a man who gave him a bundle of sticks to build himself a house. He lived in the house until the wolf came along and knocked at his door.

“Little pig, little pig, let come in!” demanded the wolf. The pig refused, just as his brother had done. The wolf proceeded to huff and puff and to blow his house in, and then chased away the second pig, too.

The third little pig met a man who gave him a load of bricks to build himself a house. This little pig built a fine house and lived in it, just as his brothers had lived in theirs. Eventually, the wolf came along and knocked on his door, demanding to be let in. Of course, the little pig refused. The wolf said he would huff and puff and he would blow the house in, but as much as he huffed and puffed, nothing happened.

The wolf rested for a few moments and then asked the little pig if he would just let the tip of his nose in.

The pig, who was no fool, refused. The wolf asked if he would just let the wolf's paw in, or the tip of his tail. 
Again, the pig refused.

"Then I will climb on your roof and come down your chimney", the wolf threatened.

The pig immediately made a fire so hot that the wolf could not possibly come down the chimney. Finally the wolf retreated.

The third little pig, being perfect in almost every way, invited his mother to join him, and they both lived happily in the little brick house for many years (Allison, 1998, pp. 53, 54).

ACTIVITY 55: Listen to “The Three Little Pigs” tale and then answer the questions:

1. What was the house of the first pig made of?

2. What did the wolf do to his house?

3. What was the house of the second pig made of?

4. What did the wolf say to the second pig?

5. What was the third little pig's house made of?

6. Could the wolf blow his house in? Why?

With this activity we are practicing listening abilities, trying to improve students' listening skills through an activity that requires retrieving information after listening to the story. Along with the listening practice, we submit a writing activity in which students have to give detailed answers based on a previous audition, in addition to working with linguistic elements in discourse, such as personal reference. In question 2 "his" refers to "the first pig" in question 1, and in question 6 "his" refers to "the third little pig” in question 5.

Observations: ADHD students faced great difficulties with this activity. In the first place, they were asked to answer the questions after listening to the story. An accommodation could have been letting ADHD students answer the questions while listening to the story, which we didn't. Indeed even if we had done it, they probably would have had problems with personal references. We decided to let ADHD students write their answers with a classmate, using peers' help implementation. It was a good idea, but we should have carried it out after letting them answer the questions while 
listening to the story, because they barely collaborated in the elaboration of the answers with their classmates.

Phonology, the linguistic study of sound systems, gives us different types of information that is helpful for better understanding what spoken discourse sounds like (Celce-Murcia and Olshtain, 2000, p. 30). Intonation and rhythm are fundamental components of phonology that must be taught and learned, and so are phonics. Teaching phonology using bottom-up processes entails teaching isolated sounds. Listening and repeating sounds, discriminating sounds, categorising words that comprise those sounds and thinking of some other words containing them are part of the methodology we use to teach phonology.

The next activity is extracted from the Activity Book of $6^{\text {th }}$ grade students (Phillips and Redpath, 2010, p. 64).

ACTIVITY 56: Listen. Which sound do you hear? Hold up your left hand or your right hand. (Children listen to some words from a track on a CD while they raise their hands).

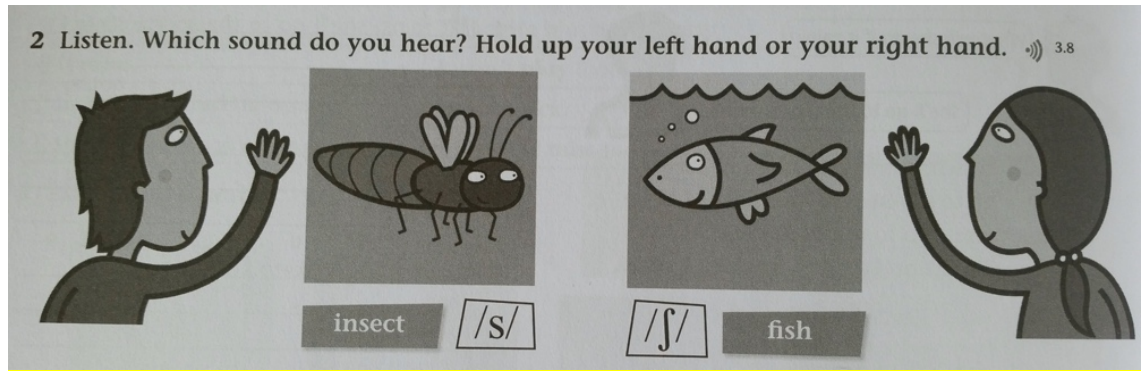

Image 10. Listening activity from Incredible English Kit. Activity Book 6 (Phillips and Redpath, 2010, p. 64).

Observations: We ask students to close their eyes while doing this activity for two reasons, the first one is to improve auditory perception by eliminating distractions, and the second reason is to avoid children from playing or copying, and not precisely to dodge imitating right answers, but wrong ones. ADHD students are prone to try to get others attention the first time they do this type of activities, but they end up doing it right with some behavioural management. 
ACTIVITY 57: Listen. Raise the cup.

Instead of following the methodology from activity 56, we sometimes practice the phonics awareness by asking students to rise cups. This activity is a modification from the original "Editing on the move" game, from Lengel and Kuczala (2010, pp. $121,122)$. We have used it to present or review phonics. Students work in groups. Each group is given some cups, as many as phonics are presented or reviewed. Each cup has a phonic written on it. The instructor says a word and students have to rise the cup which contains the phonic that represents the word. Students walk around their desks while they pick the proper cup. To avoid fights regarding who picks the cup, and to prevent anyone from eluding picking the cup up, all the members of the team must participate. We always stablish the clockwise direction pattern to save time from group discussions regarding the order of participation in games or activities.

Observations: Children love this TPR activity, especially ADHD children. The problem is that sometimes they use it just as a way to play or disturb their classmates. If annoyances occur during the game, children can do the same activity by remaining seated. It will be less ludic, but at least pupils will be able to practice with phonics.

Apart from the listening uses and benefits of phonics, some studies show that teaching phonics, among other components, help children learn to read. The National Reading Panel identified the following five critical components that are essential to teach children to read: phonemic awareness, phonics, vocabulary development, reading fluency, and reading comprehension strategies (Birsh, 2018, p. 6).

When practicing listening activities, we must consider that many children have difficulties with auditory perception, which is exacerbated in noisy classrooms with poor acoustics and makes learning difficult (Martin, 2009, p. 189). Some ADHD learners may also have problems understanding oral discourses, so teachers should seat ADHD students near them and use gestures to help them follow the discourse and to prevent them to get distracted during the listening. Students with ADHD often have problems with executive functions. We should notice that executive functions are cognitive processes necessary for complex goal-directed behaviour, including 
metacognitive knowledge regarding strategies and tasks, attention and memory systems that support these processes (e.g. working memory), and self-regulatory processes (Johnson and Reid, 2011, p. 62). Therefore, some ADHD learners may find complications with multiple-choice activities after a listening, and activities that require specific identification and processing of the data, activities recommended by Richards (2008), which are excellent for certain students, but quite arduous for others.

Regarding practice, listening activities sometimes are part of a multiple set of exercises in which several macro-structures are practiced, which oftentimes result in a more enriched experience for students, if that means that they are getting an active role in activities.

\subsubsection{Activities related to written expression}

Many deficiencies on ADHD individuals are manifested on the written expression. Casajús considers that a disorder of written expression is present when a student is having difficulties with written skills, such as grammar comprehension and punctuation, spelling, paragraph organization, or composing writing information (Casajús Lacosta, 2011, p. 99).

With regard to writing, two different activities can be distinguished: learning to write, and writing to learn. According to productive skills, writing activities can also be categorized into: choosing the right language; and having ideas, such as remembering, choosing, selecting, ordering, prioritizing and interpreting visual clues (Brewster, Ellis and Girard, 2002, p. 117). The authors also consider that writing practice helps to widen and reinforce the range of vocabulary, grammatical structures and sentence patterns students produce (ibid, p. 119). We aim to use writing activities to learn during our ESL lessons in inclusive classes with our primary students. And to do so we have consulted some authors' works and implemented several schemes.

According to Irene Brouwer, a good educational practice activates students' prior knowledge before building on that knowledge (Brouwer, 2011, p. 46). Routines are also helpful and beneficial techniques to use with ADHD students. That is why we use KWL charts at the beginning of every unit. With this graphic organiser as an initial 
written activity for every unit, we activate students' prior knowledge about the topic by making them write the words they know in the "K" column (that stands for "what I know”). We also engage them and make them participate in the teaching-learning process by filling the second column, "W" (that stands for "what I want to learn”). We let children write in Spanish the words or expressions they want to learn related to the topic. The last column is filled at the end of the lesson and it is used as a self-evaluation method to introduce children to self-assessment. We give them a few minutes to fill the two first columns on their notebooks, and then we write the students' contributions on the blackboard.

ACTIVITY 58: Complete the following KWL chart:

K-W-L Chart

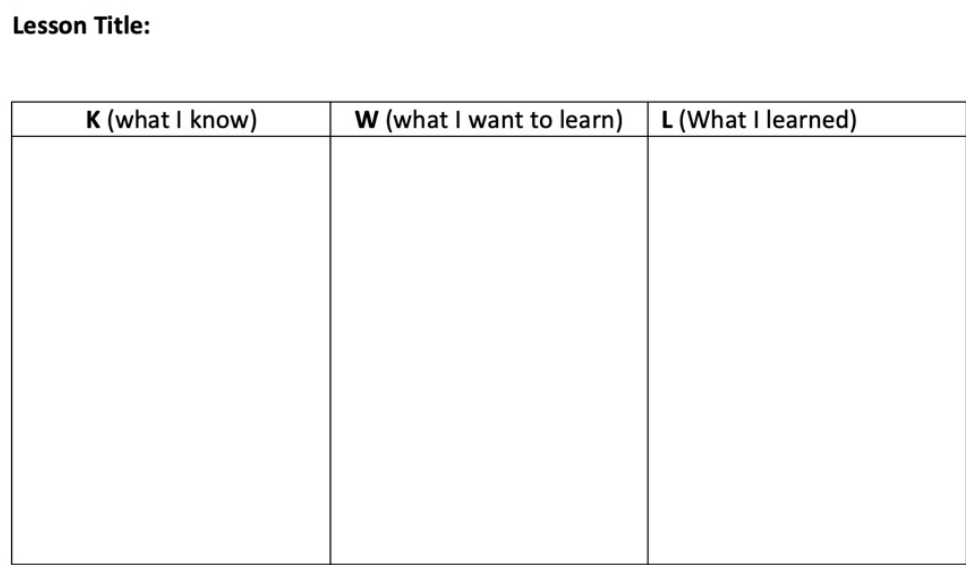

Image 11. K-W-L Chart

Observations: Many ADHD children barely remember a few words related to the topics, but as they can write the words they want to learn in Spanish in the second column, that permits them to participate and feel valuable when brainstorming the students' contributions. You can also let ADHD students help you write the words on the blackboard or erase the blackboard to release their hyperkinetic syndrome.

This is one of the diverse intervention strategies we use with our students for written expression activities. We have also developed our own written expression selfinstruction cognitive training program from Orjales' contributions, and we have implemented the developed self-instructions techniques to help students with and 
without ADHD. The intervention strategies we implement until present are the following:

- Improve and consolidate vocabulary with activities and games, such as word search, crosswords, “unscramble”, “hangman”, “stairs”, and similar word activities.

- Name pictures.

- Review grammar and vocabulary frequently.

- Give extra time to do activities that entail extra effort to those students who need it.

- Praise students’ effort.

- Respect ADHD students’ learning pace.

- Let ADHD students use computers or word processors to do written activities.

- Implement the cognitive training self-instruction program for written

expression activities for children with or without ADHD (based on Orjales, 2005).
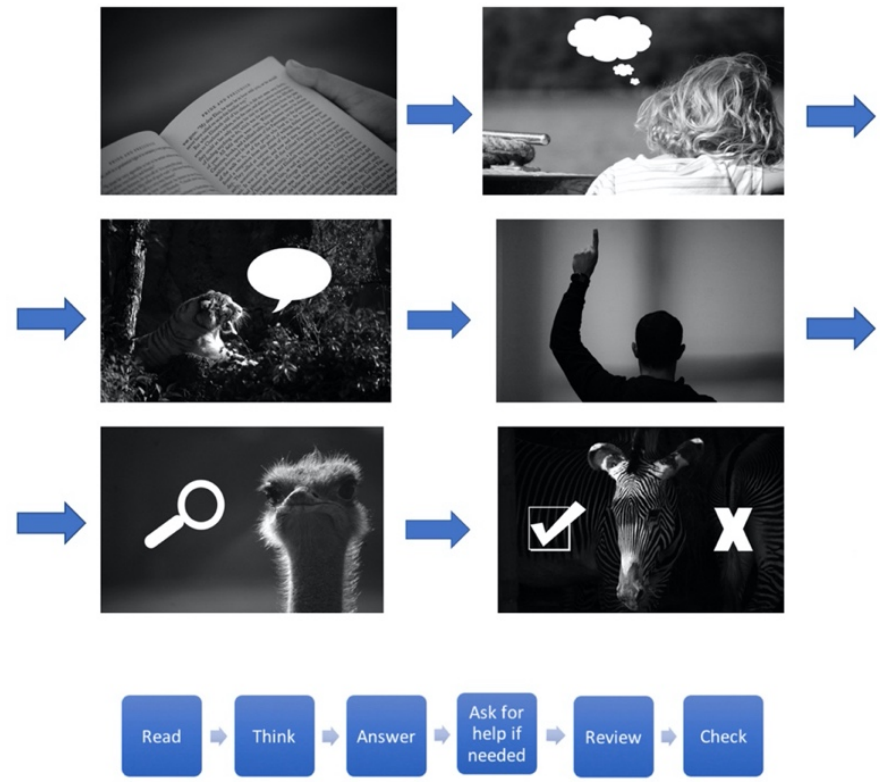

Image 12. Cognitive training self-instruction program for written expression activities for children with or without ADHD (based on Orjales, 2005).

Coming back to the matter, written language is also used to communicate with people that is not present at the time, or when a record of the communication is required. Besides, some types of messages are more appropriate in written form (Nunan, 
1993, pp. 8, 9), as is the case of postcards, letters or at present time, e-mails or other sorts of social media communication.

ACTIVITY 59: Write a letter and a postcard.

ACTIVITY 60: Note the differences between letters and postcards:

- Do you use the same register to write them?

- Are they the same length?

- Is there anything that you can write or add in a letter that cannot be included in a postcard? Give some examples.

We did activities 59 and 60 with $6^{\text {th }}$ graders. We showed them an example of a letter and a postcard, so they knew what we were expecting them to do, because many children had never written a postcard or a letter, since mobile phones and WhatsApp were the means most of them used to get in touch with their friends and relatives. Some children needed help to write the letter, as ADHD children and other students with different difficulties.

We also examined in greater depth how to write a postcard by working in greater detail the interconnections between the sentences in a piece of discourse. To do so we used and activity from the students’ Activity Book (Phillips and Redpath, 2010, p. 17).

ACTIVITY 61: Number the phrases:

See you soon.

things in London $\square$

It was $\square$

We've been on $\square$

Love from, $\mathrm{Al}$

We're in London and 3

Dear 1 
After the boat trip we're going to eat $\square$

Aunt Flo,

The London Eye.

we are on this amazing boat now.

fish and chips.

fantastic.

We've seen lots of interesting 7

In activity 61 we ask pupils to write a coherent postcard out of a jumbled up discourse. When correcting the activity, we ask students about the strategies they used to give coherence to the scattered text. Several devices helped students to assemble the passage, as the sentences starting in lower case letters or capital letters. As it was a postcard, the opening and closing of the card were easy connectors for the students, and it was not very lengthy.

Observation: Despite being a short text, ADHD students had problems to unscramble the postcard.

ACTIVITY 62: Write an email. Then answer the following questions about the email:

- Who sends the email?

- To whom is the e-mail addressed?

- What did you write in the "subject" section?

- What did you write in the opening section?

- What did you write in the closing section?

- Did you add a signature on the email?

We did activity 62 instead with $4^{\text {th }}$ graders. First, we wrote an email on the blackboard with the whole class and then we asked them to write an email on their notebook. We wrote a fictional email to Donald Trump, inviting him to visit our school 
and recommending him to visit some historical buildings and monuments in Salamanca. We showed them how to write a formal email and gave them some suggestions to open and close the email in case we were writing an informal or friendly text. We showed them how to use some conjunctions as well to create coherence, such as "and”, "first”, “then”, or "because”. We used this activity to learn how to write an email and to learn vocabulary related to ICT (Information, Communication and Technology) and pointing out some cultural information they may find useful if they travel or study abroad, like the fact that in other countries keyboards are different, as they do not have the "ñ" letter, or learning that the “@” symbol is said in a different way in English. It may seem absurd to talk about these facts, but not only these bits of advice can help some children to retrieve information about the activity later on, but they also show that we consider they can be fluent with the English language, as we are giving them tips in case they visit, study or end up living in another country. Believing in our students is the first step to make learners believe in themselves.

Observations: Children loved the activity, despite the fact that some students did not like writing. Using new technologies, and learning cultural facts about other countries is also appealing for children, and for ADHD students particularly too. We also showed them how to use the online dictionary www.wordreference.com, and let them use it to write their email. We had to stablish some rules about using the computer, because all of them wanted to use it all the time, so we stablished that only two students could be on the computer at the same time.

Writing to communicate develops skills in producing different kinds of text, for example, posters, advertisements, poems, plays, letters, menus, stories, instructions for making things, and so on (Brewster, Ellis, and Girard, 2002, p. 126). Children love creating texts in which they can use their personal's life information. They also enjoy using their imagination. The following activity blends both features, as children are asked to invent a menu, hence they can recall the menus they have seen at restaurants, or use their families menus, as well as their imagination.

ACTIVITY 63: Invent a menu. Write different main courses, desserts and drinks. 
Observations: $5^{\text {th }}$ grade children loved this activity, some of them wrote menus with great delicacy, using dishes of haute cuisine. ADHD children did the activity with pleasure, as they did not elaborate the menus very much, and consequently they did not have to write too much.

Producing different texts types needs to be guided and practiced. Brewster and colleagues classify writing activities as follows (ibid, p. 126):

- Personal writing: e.g. diaries, shopping lists, reminders, recipes.

- Social writing: e.g. thank you letters, invitations, congratulations, text messages, instructions.

- Public writing: e.g. letters to other classes, forms, posters, menus, class magazines.

- Creative writing: e.g. poetry, riddles, stories, plays, songs.

Activity 63 is a clear example of public writing. An instance of creative writing is submitted further on in the text, in activity 67. Although examples of social writing are shown in activities 59 and 61, another social writing activity is presented hereunder, in addition to a personal writing one.

ACTIVITY 64: Write a family recipe. Ask any member of your family to tell you about the ingredients and the directions to cook the meal.

Observations: As in activity 63, children fancied this personal writing activity, and cherished asking their parents and grandparents about recipes. Once again, ADHD students wrote simple recipes and they admitted that their families helped them with the recipe and the English writing too.

Before asking students to do the next activity, we gave a lesson about chat acronyms. By showing children some texting abbreviations in English, we employed a way of communication that $6^{\text {th }}$ grade children really used and loved, to show them how social writing really worked out in English. As English writing is different from spoken English, by this means we also got them into thinking about spelling and pronunciation and possible ways to convey their messages using as many abbreviations as they could. We showed them some basic abbreviations, such as: ASAP (as soon as possible), BFF 
(best friends), HRY (how are you), BTW (by the way), B4 (before), UR (your), PLS (please), or TTYL (talk to you later). Then we asked them to add some more words or expressions they could find useful. They added some words they already were using, such as: OMG (oh my God) and LOL (laughing out loud). After that we asked them to do the following activity, requesting them to be creative while they wrote a real message for someone in the class.

ACTIVITY 65: Write a text message to a classmate.

Observations: Children went crazy with this activity. The fact that they were sending messages to each other fascinated them, even though they were sending messages on paper. Some children were really creative, some others presented doubts, like a girl who said that why LOL had to mean "laughing out loud" instead of "lots of love”, and a few of students, ADHD learners among this group, had problems trying to use some of the abbreviations to send a message.

ADHD students do not use the language tools properly, the problems with their executive functions lead them to a poor information management, entailing both reception and incorporation of language. Vaquerizo-Madrid and associates consider than retelling and creation of stories can help children to develop narrative capacity and discourse (Vaquerizo-Madrid, Estévez-Díaz, Pozo-García, 2005, p. 87). For that reason we suggest the following activities: "Retelling" and "Create a story". Besides this activities bring children the opportunity to learn how to use cohesive devices, such as the following conjunctions:

- Additive: "and”

- Temporal: “first”, “second”, “then”

- Causal: "because”

- Adversative: "however”, "on the other hand"

It is important to bear in mind that in the area of writing, as it also happens in the area of reading, children need explicit instruction in comprehending and producing relationships in discourse (Nunan, 1993, p. 113).

ACTIVITY 66: Retelling. 
Retelling stories imply making a report of a story, sequencing the main ideas. This activity helps children to describe events, and enhances the acquisition of vocabulary and grammar rules.

Observations: Standardly ADHD students are not very good with retelling stories. A variation of this activity may help them, as they tend to be very creative. Instead of retelling a story, we can ask them to change the original version of a traditional tale. That will help them, because if they forget any key point of the story, no one is going to know if they did it on purpose or if they just forgot about it. Besides they can really create fantastic versions of known tales.

\section{ACTIVITY 67: Create a story.}

Creating stories are written activities in which students have to invent a story. Several options are possible here, from giving them freedom to write, to give students a topic, a worksheet with some steps to follow, or even using a story die.

Observations: ADHD students are normally not very good at writing, so we helped them organizing their ideas and using the proper verb tenses, which is very difficult for them.

When planning the vocabulary students want to use, it can be helpful to do word maps or diagrams to outline the stories. Either way the two activities can vary slightly depending on the age of children or their English level. For beginners we can consider giving them a template with speech bubbles to create a plot. Through the realization of both activities, "retelling" and "create a story", we found out that comics tend to be very appealing to all children. As a matter of fact, creating a comic without any template occurred to be very exciting with $5^{\text {th }}$ and $6^{\text {th }}$ graders, while writing a story with the only purpose of practicing writing was dull and some ADHD students did not finish the activity. We suggested $6^{\text {th }}$ grade students to retell or create a story for storytelling to pre-schoolers afterwards. We created the groups and let them choose how to do it and just facilitated them the materials and helped them writing the story, giving them some tips to do so and some examples of connectors and idiomatic expressions. When arranging the groups we gathered ADHD students with classmates that could help them, 
excluding combinations that could cause behavioural inconveniencies. The rules were that all of them had to participate in the creation of the story, as well as during the storytelling. The results of this task-based instruction activity were extraordinary. Some groups just retold a fairy tale by creating a big and colourful leaflet, others invented a tale, and other children even created a puppet theatre to play the script they wrote. They were very excited to visit the small children and loved the idea of storytelling. Preschoolers were dazzled at the beginning, but as there were many groups and they have short periods of attention, after a while they started moving and chattering around. The difficulties some children had with the English language pronunciation, the shyness from some students and the disturbances coming from the little kids, made the storytelling less brilliant as it should have been, but that was just our impression as teachers, because children loved it and wanted to do it more often. The only inconvenience of this type of activities is that several sessions are needed to create the stories and to do the storytelling; apart from that, we highly recommend them. An easier way to create a story collaboratively is with the following game:

\section{GAME 7: Story consequences}

This game belongs to "50 Things to do on a car journey. Usborne Activity Cards” (Gilpin, 2006). It is designed to be played with two or more people. We played it with the whole class, dividing the classes in rows of four to six people.

The first students in each row write a word that can describe a man, such as "happy” at the top of a strip of paper. Then they must fold back the top of the paper to hide the word, and pass it to the next player, in this case, the student seating behind them. Students seating on second position are asked to write a man's name (it can be someone famous, or someone everyone knows) before folding the paper and passing it on. The following requests are asked one at a time following the same methodology: a word to describe a woman, a woman's name, a place, what the man says to the woman, what she says to him and what happens at the end. Finally, the students who get the strip on last place unfold the paper and make a story out of the words on the strip, like this:

"Happy Dr. Dolittle met pretty Cinderella at the Eiffel Tower. He said to her “These cakes are good”. She said to him "I prefer cats”. Then a cow fell out the sky.” 
Observations: Despite the game is amusing and children enjoyed it, we experienced some shortcomings on the way. During the elaboration of the writing strip students were having lots of fun because they could foresee what we were up to with our writing requests. The problem emerged when we asked students to come up with a story. Most of them did not know what to say and just read out loud the words they had written. They were expecting a script or a model where to fit their words. We took some of their papers and showed them different examples of how to shape a story with their answers. Then, we tried it again and the results were better, although ADHD students needed the help of a classmate.

Concerning activities, Brewster and associates suggest that guided activities at sentence level may include putting words in the correct order, matching sentence halves, gap-filling using visuals or words, writing speech bubbles, or sequencing sentences, among other ideas. According to the authors such activities provide practice in handwriting, spelling, identifying lexical sets, learning or reinforcing meaning, grammar patterns, organization of ideas and integrating writing with other skills (Brewster, Ellis, and Girard, 2002, p. 125).

One of the activities presented in the oral comprehension section of this thesis integrated listening and writing abilities, that is activity 51, where children had to fill in the blanks the lyrics of a song. Some of the blanks had to be filled using images, while some others had to be completed while listening to the song. We tender some other guided activities at sentence level thereupon.

A useful way to practice and testing syntax is to give students sentences with the wrong order (Harmer, 2007, p. 223), as is shown in activity 68. This activity is submitted in the Activity Book of $6^{\text {th }}$ grade students (Phillips and Redpath, 2010, p. 62).

ACTIVITY 68: Make sentences:

1. have breakfast - you - If - be hungry - later - , - you won't - .

2. , - I'll - late - for school - I - miss the bus - be - . - If 
3. . - you won't - you - If - run quickly - , - miss it

4. now - have time - If - get up - you - , - you'll - . - for breakfast

Another way to practice guided activities at sentence level is by matching sentences halves. The following activity is extracted from the Activity Book of $6^{\text {th }}$ grade students (Phillips and Redpath, 2010, p. 63).

ACTIVITY 69: Match:

1. The teams had to stay on a. they were hungry.

2. The clouds were dark and

b. to cook the fish.

3. They needed to build

4. Rav cut down leaves and

5. When they finished the shelter

c. they were worried about rain.

6. They went fishing and

d. caught some fish for dinner.

7. They started to build a fire

e. a desert island for the night.

8. When they were building the fire, Oli

f. Meg and Oli built the shelter.

g. suddenly got the answer.

h. a shelter to sleep in.

Observations: The activity is based on a previous reading. As children had already read the story, they barely needed help, neither read the story again, except for ADHD students, who needed to check the reading several times. It is important to highlight the propensity for students to pronounce the word "island” as "Iceland". Instead of saying /' arlənd/, they are prone to say /'arslənd/. It is by far the word with the most problems of pronunciation after correcting it several times. Students forget that they do not have to pronounce the "s". We always use humour to deal with it, saying that it would be a real pleasure to go to "Iceland" on a trip all together. By doing so we try to generate the idea of "Iceland", a land with lots of ice, on their minds to link it with the pronunciation of the letter "c"; and the idea of an "island", with no ice, therefore no / s / sound is needed. We also use this short mnemotechnic verbal device to remind students when to pronounce the letter "c" as / s / or / k /. 
To reinforce grammar patterns we submit the following activity, in which students are asked to write conditional sentences. After learning and practicing second conditionals’ grammar, we invited children to do the next activity.

ACTIVITY 70: Write a clause using the second conditional. Use the given template to write a clause.

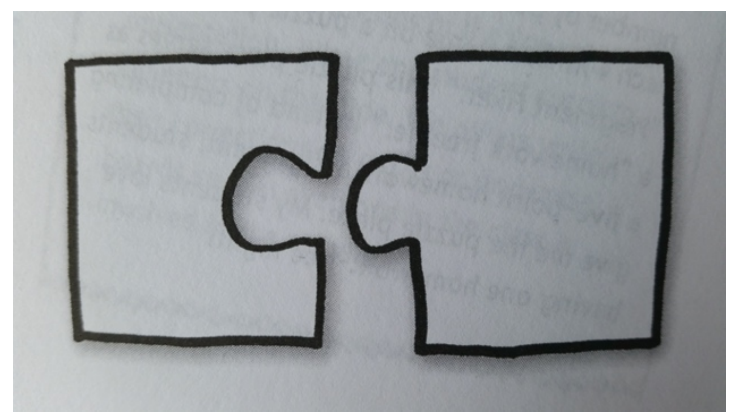

Image 13: Forget Fragments puzzle (Van Zile, 2003, p. 68)

We gave half of the class the puzzle piece from the left of the image, and the other half the right piece (A4 paper size). We did not ask them to write the "if clause" on the left or the right piece, we gave them freedom to convey their ideas. When students finished, we hung all the pieces on the board and asked students to match halves in order to have grammatically correct second conditional sentences. As they were matching the pieces of the puzzle, we displayed on the class the finished “conditional statement puzzles”. Some of the puzzle pieces were grammatically inaccurate, and we asked students to correct them and find them a match. Some other pieces were unconnected and did not fit with any of the remaining clauses, so we just gave them back to their owners.

We made up this idea based on the activity "Forget Fragments” from “Awesome Hands-on Activities for Teaching Grammar” (Van Zile, 2003, p. 68). The original game has nothing to do with conditionals sentences, the aim of the activity is to identify and correct fragments in students’ writing. In “Forget Fragments” students are asked to write a fragment to correct on the left side of the puzzle and to write the right sentence on the right side of the puzzle, which is also a great idea we love and helps children to learn to self-assess their works. 
Observations: Many children understood the first conditional, but had difficulties with the second conditional and the use of the past tense and "would". The problem in most of the cases was the poor command of the past of the verbs and the lack of usage of "would”. After this activity most of the children solved their problems and built grammatically correct sentences using the first and second conditionals. But that was not the case of ADHD children, who were able to write grammatically correct sentences, but needed a list of verbs to do so, as they did not know all the past tense forms of the verbs.

Language teaching under a discourse dimension does not mean leaving vocabulary aside. Vocabulary is the largest single element in tackling a new language for a learner. Vocabulary should, wherever possible, be taught in context (McCarthy, 1991, p. 64).

ACTIVITY 71: Design a poster and write rules.

In this activity children have to select a place (school, swimming pool, library, etc.), discuss what rules they would find in that place, and design a poster with obligation rules. After reading the grammar structure from the unit (must / mustn't), $4^{\text {th }}$ grade students are supposed to practice and think about how language works with this activity. Children work in groups of four to five people. With this cooperative language learning activity students are supposed to create meaningful rules’ posters using a grammar rule, and using writing and speaking to fulfill it. Background knowledge has to be shared to come to an agreement on the creation of the regulations and vocabulary is enriched with this activity. An example of children's work is given here:

\section{PARK RULES}

You mustn't drive a car in the park.

You mustn’t feed the animals.

You mustn't be rude to other people. You must share swings, see-saws and slides.

You must play at the park.

You must put litter in the bin. 
Observations: This writing activity is very appealing for children for several reasons. First, they are allowed to work in groups. Second, it is a creative activity. Lastly, they are asked to give rules, and they are very good at it, which also gives them the opportunity to draw on their sense of responsibility. This is also a good activity to work on behavioural rules with ADHD children, as there is always a group who wants to write the school or classroom rules.

ACTIVITY 72: Complete the dialogue. Use no more than two words to fill the blanks.

Ben: Hi, Ann.

Ann: Hello, Ben.

Ben: How going to the park?

Ann: Wow, I love to.

Ben: we go tomorrow?

Ann: I not. I plans for tomorrow. What going next Friday?

Ben: It perfect to me, as as we get back on to watch the football match.

Ann: Well, Friday it then! we bring anything special?

Benn: Mmm... I don’t think think about it. If anything comes to my mind I give you a

Observations: The following activity gets students to make suggestions, focusing in functional language, and concentrating on lexical phrases or chunks. Anticipating that some ADHD may have problems filling in the spaces, we let them check their answers with a classmate before checking the activity. As long as their responses are grammatically correct and make sense, we accept as many suggestions as they have.

Speakers and writers use synonyms, hyponyms and antonyms to communicate. To have such fluency in a foreign language a lot of practice and vocabulary is needed (McCarthy, 1991, p. 71). The following activity blends phonics and vocabulary building through writing expression. 
ACTIVITY 73: Write ten words containing the following letters:

- I P: (picnic, important, trip, etc.).

- FAC: (falcon, fascinating, caffeine, etc.).

- HS: (fish, ship, sunshine, etc.).

- MTE: (meat, time, meet, etc.).

But rather than teaching vocabulary in an isolated manner, we can use a game, which not only is funnier, but it also will help visual and auditory learners to retrieve the information.

\section{GAME 8: Tutti Frutti}

This "scattergories" version game allows us to review and build vocabulary. We can adjust the categories to whatever we want to practice. We regularly play using the following categories:

\begin{tabular}{|c|c|c|c|c|c|c|c|}
\hline Letter & $\begin{array}{c}\text { Proper } \\
\text { Noun }\end{array}$ & Noun & Colour & Adjective & Verb & Animal & Food \\
\hline $\mathrm{M}$ & & & & & & & \\
\hline $\mathrm{A}$ & & & & & & & \\
\hline$\ldots$ & & & & & & & \\
\hline
\end{tabular}

Observations: We give children one or two minutes to fill the categories with each letter, and then the student who fills all the columns on the first place, or the greater number of columns, gets to have his/her answers on the board. This game not only builds vocabulary, but also allows to work synonyms, antonyms or hyponyms, and that is as easy as asking children for the synonyms, antonyms or hyponyms of a noun or adjective once we had it written on the board. 
Between 8 and 39\% of diagnosed ADHD children have a dyslexic clinical profile, which occurs mainly when language delay has been observed during the first year of the child's life. The correlation between the dysfunctions resides in the working memory. Dyslexic children struggle with reading or decoding isolated words, they are slow readers as well, and commit a lot of mistakes when reading or spelling. They also underscore in phonologic tests (Vaquerizo-Madrid, Estévez-Díaz, Pozo-García, 2005, p. 86). To help ADHD children with a dyslexic profile or to help all those students struggling with reading or memorizing vocabulary, we submit hereafter a series of games and activities that can help them achieve their goal. We also encourage them to play those games at home with their families or friends, because the more they practice, the better the results, and it is also a way to involve their family and convey a schoolhome intervention.

\section{GAME 9: Hangman}

This letter guessing game requires no material or technology, therefore it can be slotted into lessons at any time.

Observations: This game is very appropriate for those ADHD students, or any other student with problems in the phonologic organization (relation between phonemegrapheme). It is also suitable for dyslexic students or learners who change, confuse or omit letters within words.

ACTIVITY 74: Unscramble the following words:

1. IWSM:

2. WOR:

3. SHIF:

4. ISAL:

5. RELOLRBADLE:

6. TYEANLNIPS:

7. TABEKISORAD:

8. HYELEAPADINEDKS:

9. MIBLC:

10. OFYOLAPTLALB: 
Observations: Just as we have noted in game 8, this activity will be very helpful for all those students that are struggling with phonologic organization or show signs of dyslexia. It is a very difficult activity for certain ADHD children, who need to use the class book or see the words written in the right order while they are doing the activity.

\section{GAME 10: Stairs}

We begin this game by choosing a word, "pencil” for instance. We write as many steps on the stair as letters has the word. Then students have to write a different word with each letter in every step, for example: "Picture”, "Envelope”, "Nurse”, "Centipede", "Ivory", and "Lemonade". The student who completes the stair in the first place gets to write his/her answers on the board.

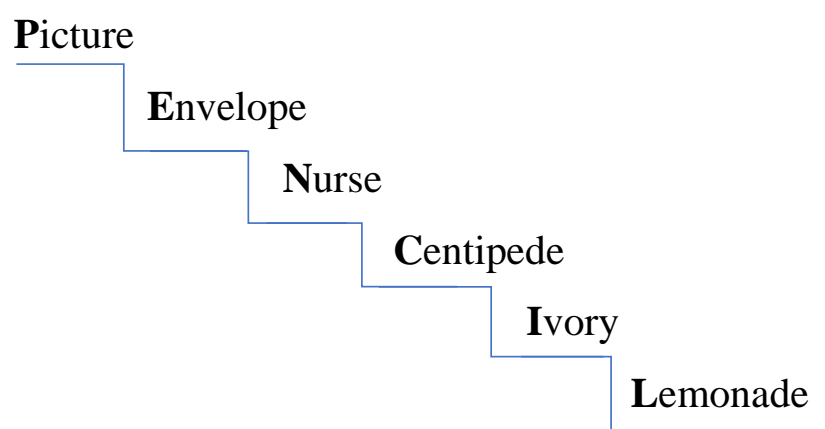

We can also ask them to write words from a specific category, such as verbs or adjectives, as it is shown down below with the verb “climb”. Students are asked to use only verbs to complete the stair, using the infinitive form and without repeating any word.

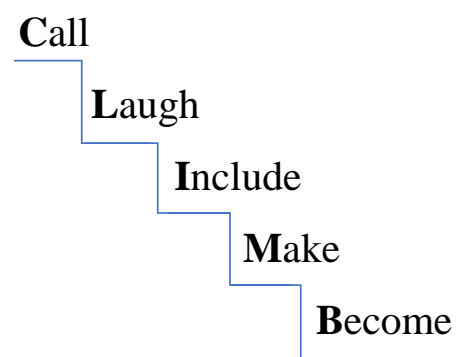

Observations: Children love this game and they build vocabulary in an easy and ludic way. The simplicity of the game permits to play it at any time during the lesson. Using the categorized version also permits students to be aware of the language, as they 
cannot write the first word that comes to their minds, which is how ADHD students will naturally respond. Therefore, having to think of a verb or an adjective entails extra effort for them, having to deal with language, knowledge and their impetuous condition.

\section{GAME 11: Find the words}

This game, which is submitted in "50 Things to do on a car journey. Usborne Activity Cards" (Gilpin, 2006), has the same core idea than "Stairs". One person thinks of a long word, such as "celebration" and everybody writes it down. Everyone has then three minutes to write down as many words as they can, just using the letters in the long word. Each word must be more than two letters long and letters can only be used once, unless that letter appears more than once in the word. For example the word “celebration” could give you the words “bee”, “car”, “lion”, “train”, and lots more. After the three minutes everyone checks their words and counts the points they have. Three-letter words are worth three points, four-letter words four points, and so on. The person who has the most points is the winner.

Observations: The original game suggests three minutes per round, but we gave students two minutes instead, as it was enough for learners to think of the words. We also considered that the winner of each game should think of the word of the next round. This is an entertaining and engaging game, and it helps children to learn and consolidate vocabulary, ADHD individuals too. As in the previous game, we can ask students to say and write only nouns, verbs, adjectives, adverbs or anything we want to practice, for example "words related to food chains", or "endangered animals vocabulary".

ACTIVITY 75: Name the following pictures and draw:

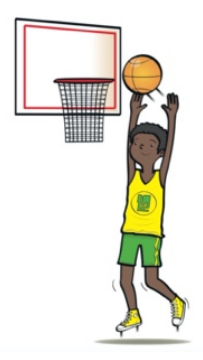

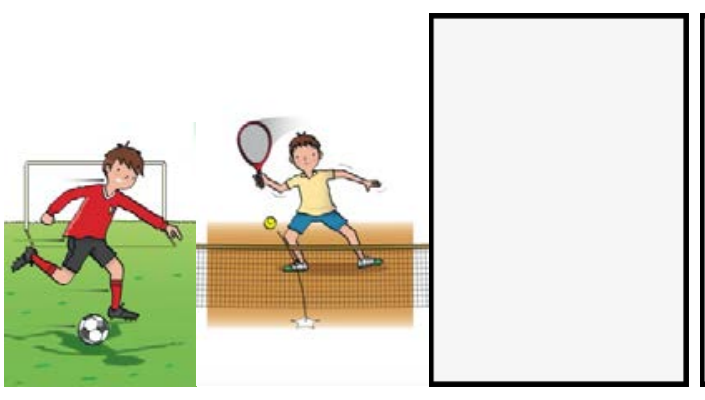

Climb

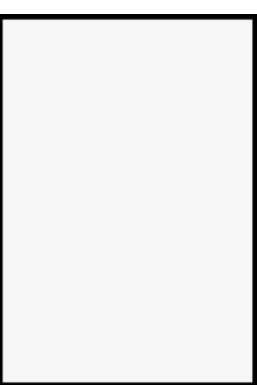

Row

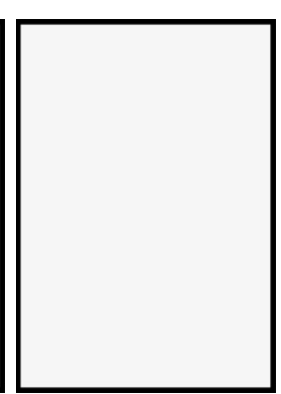

Fish 
Observations: Activities in which the images of the core vocabulary of a unit are presented for children to recognise and name or draw are very helpful for ADHD students. It may look like this kind of activities are childish, but it helps visual learners to acquire vocabulary. The images belong to the set of Flashcards of the method Incredible English Kit (Oxford ed.).

Activities like word search, anagrams or crosswords are very practical to do at any time and are highly effective to help children to learn vocabulary. ADHD children get bored making word search activities if the hidden words are difficult to find. When making crosswords, they like making them if there are images instead of text. If descriptions are used to solve the crosswords, they give up easily if they do not understand the clues and need to use the dictionary a lot. Anagrams are very welcome among students, with or without ADHD, as they just need to use their background knowledge.

Through the games and activities we have suggested to practice vocabulary, we are using bottom-up processing to acquire a new language. We prompt students to learn the smallest units of language first, to be "chained together" to form the next highest unit; these units in turn are then chained together to form the next highest unit and so on (Nunan, 1993, pp. 78, 79).

Concerning materials, dictionaries are perhaps the greatest single resource students can have at their disposal. Yet they are sometimes not very used. And this is sad, because dictionaries are full of information about words, not only their meaning (ibid, p. 39). Dictionaries offer us the meaning of words, but they show us how to pronounce them and how words operate too.

If children consult dictionaries as a way of unravelling some mistakes we have pointed them out, they are involved in the teaching-learning process. The same applies to the process of looking for a word. Some children just ask for the meaning of a word to teachers, as if they were online dictionaries, instead of looking for the definition or translation by themselves. If we do so, the word can continue being meaningless for them, as they got what they wanted in the precise moment they needed it without an 
effort. Asking them to use a dictionary is a way of giving students feedback, at the same time that we are giving them the opportunity to learn something new. From our experience, we consider that it is advisable to create picture dictionaries with younger learners, and with ADHD students too. We ask children to elaborate their own vocabulary list. Every person has their own background knowledge, despite they may all be the same age and may have attended the same classes. We all are unique individuals with unique strategies, skills and abilities, which help us conforming our own cultural and academic background. Children can build their own picture dictionary, which in turn can be used to build a card game or a memory game. We usually ask children to create cards with the images on one side, and the written word on the back of the cards. In this way, they can also use the cards as vocabulary self-assessment or they can give the cards to someone to help them study the vocabulary or being asked, as in a quiz. To play a memory game with other peers the written name must be omitted or covered. In this regard, children are using different senses, they are using the multiple intelligences method to learn and/or review vocabulary, because they are drawing, writing, saying the word orally and, if they play a memory game with someone else, they are also listening to the words. Therefore they would be using the four channels with this simple game. We also create our personal dictionaries during the English lessons. Every student elaborates a list of the new words on their notebooks.

About $50 \%$ of pupils with ADHD also have developmental coordination disorder (DCD), which is generally seen in the classroom as illegible or slow handwriting (dysgraphia). Although sometimes the difficulty in writing is due to oppositional behaviour or boredom (Kewley and Latham, 2008, pp. 90, 92). We sometimes ask students to use computers to write stories or essays, as they find it more amusing to write on computers than to do it by hand. But just sometimes, because as computers are appealing and can be very helpful sometimes, they can also be a great distraction for hyperkinetic children.

Regarding discourse and ADHD in the English as a second language context it is important to mention that, even though it is very difficult for many children in primary schools to write coherent texts in a second language, it is even tougher and challenging to do so for ADHD students. While some learners are trying to give coherence and textuality to their written assignments, most ADHD students are struggling to hand in 
some grammatically correct sentences, and they are more than pleased if they have those sentences right, although they know that an essay or a composition are supposed to have more than three or four sentences. It is very important to praise their work, as writing requires a tremendous effort for ADHD learners.

\subsubsection{Activities related to oral expression}

Before addressing the matter of this subsection, we would like to reveal the intervention strategies we use with our students for oral expression activities. We implement the following approaches:

- Encourage children to speak English.

- Permit children to speak "Spanglish” when they do not know how to say something in English, giving them the unknown words and expressions when they have finished their contribution.

- Give students enough time to answer without rushing them. Give ADHD students extra time to prepare their discourse if needed.

- Help ADHD students to comprehend the pragmatic elements of the language and assist them to grasp the linguistic context of the discourse.

- Praise proper behaviour, such as listening to others or respecting turn taking turns.

- Give feedback to students, praising their progress and correcting their mistakes using positive messages.

Considering interaction, some activities related to oral expression could also be categorised as listening comprehension activities, as communicative processes take place when at least one speaker and a hearer respond to one another. As is the case of role-plays, for example.

Some studies show how drama can be used as the basis in language classrooms with ADHD students, using the performances as a technique for strengthening social interactions when teaching a foreign language. Hvozdíková suggests using the characteristic impulsivity of hyperkinetic students in the context of creative drama (Hvozdíková, 2011, p. 466). The author highlights the importance of working in a 
friendly atmosphere and to emphasise cooperation when using this dynamic technique to teach foreign languages.

GAME 12: Role-play:

Role-playing is a game where participants play a character in a fictional situation. Role-plays may be just oral representations or short drama performances, but they are part of the audio-lingual method. When rehearsing role-playings it is important to start with students that are likely to have a fluent conversation. Sometimes we practice role-plays following a script, so when pupils listen to the rehearsal of two fluent peers, it is easier to participate for those students with less fluency skills or self-esteem issues, as they can imitate their classmates.

It is more difficult when improvising the lines during the role-plays. Meaning shall be negotiated in this free version. The fluency, the appropriateness of the linguistic choices each participant makes, and the efforts of each party will come together and create a conversation. The understanding will depend on the negotiation and the effort of each participant to make sense to each other (Nunan, 1993, p. 91)

Observations: ADHD students reluctant to participate on the first place change their minds and are longing to participate after one or two attempts from their classmates. Role-plays sometimes complement behavioural management techniques, because during the different stages there are diverse performances and outcomes. Children make mistakes, sometimes they pronounce some words erroneously, some others they get stuck in a line, or shyness controls the whole display. Although the roleplays' practices in class are short, it is very common to slip up, and that is really helpful, not only for those ADHD students with low self-esteem, who tend to think that they are the only ones stumbling through English presentations, but for everyone. Humans make mistakes, and that is what helps us to learn. We do not laugh at other's errors, we learn with everybody's lapses or blunders. One of our teaching premises is "perfection is not an option”. It may seem a shrinking goal. Far be it from this case, as we are just trying to avoid discouraging children. When we accept that mistakes are part of the learning process, we somewhat relax ourselves and focus on the lesson. If we are afraid of slipping up, instead of listening or paying attention to the class or the assignment we are doing, our mind is going to be thinking that our peers are going to laugh at us if we 
make an error, or that the teacher is going to scold us or even that we are going to fail the course, if we are extremely dramatic or nervous at some point.

Play is believed to provide children with opportunities to develop the prosocial and emotional regulation skills needed for social participation in home, school, and community settings. It is also the most natural context for learning language. Children with ADHD have difficulty with cooperative play, perspective taking, responding to social cues, and self-regulation. These difficulties combined with poor pragmatic language ability can contribute to negative social outcomes (Wilkes-Gillan, Munro, Cordier, Cantrill, and Pearce, 2017, p. 2). We can help developing the pragmatic language skills of children targeting language development and social interaction skills through group play, such the execution within the English lessons of some games like “Taboo” or "Head's up vocabulary”.

\section{GAME 13: Taboo}

We have simplified the original game "Taboo" to play it with $5^{\text {th }}$ and $6^{\text {th }}$ grade students. We form two big groups by splitting the class in two. Then, one member of each group comes to the front of the class and seats giving their back to the blackboard. After that, we write a word on the blackboard and the two students in the front must guess the written word. To do so, their partners have to explain to them the mystery word without using the word itself, sounds or gestures. The first player guessing the word wins and scores one point. If any student says the written word in the blackboard, they say the "taboo" word, and lose.

With this fantastic game not only do we review vocabulary, but we also practice oral expression and nominal substitution, as can be seen in the following example. Consider that we write on the blackboard the word "T-shirts". The word itself cannot be said, neither is shirt. Notice that we have a plural word, so it must be considered when referring to the written word.

- Student 1: It is a piece of cloth.

- Student 2: It is plural.

- Guesser 1: Trousers.

- Student 1: No, it is not. 
- Guesser 2: Shoes.

- Student 3: Nooooo!

- Student 4: You are wearing it.

- Guesser 1: Trousers.

- Teacher: Again... Still incorrect answer.

- Guesser 1: But he (pointing to a peer) said plural.

- Teacher: True. You both are wearing them (emphasizing the pronunciation of "them”).

- Guesser 2: I know! T-shirts!

- Teacher: Correct! Congratulations to the both of you. Nicely played!

- Guesser 1: That is not fair (angry tone and mood).

In this example the word "them" substitutes the taboo word "T-shirts". Using a plural hinders the use of nominal substitutions by students, but when selecting a singular word, $6^{\text {th }}$ grade students generally do it very well.

But it is not always that simple, actually that was a very good performance from students. Not always does it go the same way. Sometimes children do not listen and just start saying words from the unit we are studying. Some other times pupils do not understand their classmates and just say random words or even make up words. Having played several times also helps, the more they play, the more fluency and confidence they have when playing. That is why $6^{\text {th }}$ graders always speak much more and better than $5^{\text {th }}$ graders. And we take that fact into account when selecting the words and the guessers. We normally select children with a similar language level or development, but sometimes it is not possible in order to make every pupil participate, so we regulate the situation by choosing an easy word, so anyone can win when participating as a guesser. We also try to not participate much during the game. It might not be considered a proper Silent Way methodology, but it would be closer to the Silent Way method than to other traditional methodologies.

Observations: This game is, by far, one of our favourite games, and for children too. From our experience, not only is it one of the best activities to get students to speak English, but it can also be helpful to review vocabulary and grammar. With students with a higher competence of language we sometimes write simple sentences instead of 
words, for example "She likes cheese", or sentences containing the grammar structure from the unit we are studying. But we never tell them that we did so, students are the ones that must tell them without saying the "taboo" word. And all children must play. If someone has a tough or difficult day, we let them play another day, but all of them have the same opportunities to speak and to guess. And as it does not need any special requirement to be played, you can play it when you finish the lesson or as a reward if you have some spare minutes.

\section{GAME 14: Head's up vocabulary}

This game has a headband holder in which vocabulary cards are placed. One player holds the headband with a vocabulary card, and the other players give clues and explanations to the holder to guess the word he/she is holding on the headband. The word in the card cannot be said.

Observations: Although it is similar to "Taboo" and has a device, which sometimes is appealing for children, because it brings some novelty to the room, students prefer to play "Taboo". The fact that there is a contest between two pupils in “Taboo" is preferred over the use of a new item. Maybe it can be more appealing with younger students or small groups, where learners can switch and be the holders several times, instead of just watching how four or five classmates guess a word. ADHD students liked the headband and wanted to wear it. Therefore, we consider that it can be a wonderful game to play with ADHD children in small groups, maybe as a reward activity, or it can also be used to help ADHD students memorise vocabulary, letting them play with a peer to reinforce the basic contents and practice oral expression.

Assuming that play is the natural context within which a child's physical, cognitive, social, emotional, and language skills develop (Wilkes-Gillan, Munro, Cordier, Cantrill, and Pearce, 2017, p. 2), we suggest using the following games to review vocabulary and speak in the foreign language while they are playing.

\section{GAME 15: Find me!}

We use this game to review vocabulary. It is a TPR (Total Physical Response) game in which students have to find a flashcard. The instructor splits the class into two 
big groups and selects one student from each group to come to the front of the class, and asks them to wait giving their back to the class and closing their eyes, while she/he places or hides the vocabulary flashcards around the class. The rest of the students must remain silent meanwhile, and are not allowed to point or look at the flashcards during the game to avoid cheating. Once the flashcards are placed, the teacher says the name of a flashcard out loud and the two students who were waiting in the front of the class must find it. The first pupils finding the flashcard gets a point for his/her group.

Observations: Although we ask the seated students to remain quiet, they really love this game and get so excited, that it is very difficult to have silence while playing. The best strategy we have found to let them externalise their joy and give free rein to their excitement is to let them use the "deaf applause”, in which hands are raised in the air and are twisted back and forth. This is the children's favourite game by far, and maybe one of our favourites too, because we interact with them and use our better comedian facet. We use humour and play tricks on children to make them laugh at the same time they are looking around for the hidden flashcard. It takes a lot of time from the lesson, but it is worthwhile, as we just play it once or twice every lesson. We normally use this game with $4^{\text {th }}$ grade students and, even though it may look hard to believe, we also use this game as a behaviour control of the group sometimes. It has already been said that positive reinforcement works better than consequences most of the times. We sometimes use this game when we need to gain control of the behaviour of the class after a disruptive episode. We do not play it immediately after the undesired event, what we do instead is to tell the class that if they behave correctly again they will play “Find me!” on the next English session.

\section{GAME 16: Matching game}

Students are given two pairs of identical vocabulary cards. The cards are faced down in random order over the table. Each pupil turns over two cards at a time meanwhile they pronounce the vocabulary word illustrated in both cards. The goal is to turn over matching cards using their memory. The winner is the student who turns over the most matching pairs of cards.

Observations: This is a fabulous game to help ADHD students improve their visual skills at the same time they are acquiring vocabulary. If teachers do not have a 
specific card game, they can easily build it with images from google. But we sometimes ask ADHD students to build their own cards. By this means we are working three language skills: first, they have to make the cards, which implies reading the vocabulary we are asking to prepare. Then, they have to draw the vocabulary picture, which is really helpful for visual learners. Once the card game is complete, they play with a classmate, developing oral comprehension and oral expression skills. Therefore, visual and auditory skills are enhanced.

\section{GAME 17: What's missing?}

Flashcards are placed on the blackboard in a certain order. Teachers ask students to memorise the order for a certain period of time. Then, pupils must close their eyes while the instructors take some of the flashcards and ask students to open up their eyes again and are prompted to say the words that are missing.

Observations: This is a good memory game that we use when presenting vocabulary, as it helps students to memorise it. And it is also an excellent game to play with ADHD learners who have difficulties acquiring some words. Sometimes in addition to taking flashcards from the board we also alter the order of the flashcards, so pupils have to recall the missing words and the correct order of the altered ones.

\section{GAME 18: Jenga}

We use this game to review content. It is the game we play at the end of each unit and at the end of the term. Students are separated in two groups, and we stack the wooden blocks to build a tower with the Jenga's pieces. We ask pupils questions about vocabulary, verbs and grammar and they have to answer the questions as a group. If a team answers correctly, they have the chance to move a piece. If the team does not give the right answer, the other team has the choice to answer as a rebound. The two groups take turns answering questions and moving pieces until the tower falls over.

Observations: This skill and strategy game is used as a task-based and multisensory instruction activity to review content. It is a game that everyone loves, as they play in big groups, which means that they can receive their peers' help if they need it, so they are not going to be sitting watching others play, everyone plays. And 
everyone has a chance to move a block. ADHD students enjoy this game, particularly when they get the chance to move a piece.

\section{GAME 19: Ring the bell}

This is a simple quiz game in which children must ring the bell before answering a question. Two children start the game and the winner keeps moving along the class playing against his/her peers. Its simplicity and the fact that there is no need to move furniture or make children do anything special, allows you to play it if you have some spare time between activities or at the end of the classroom.

Observations: Many ADHD students are often at a disadvantage when playing this game, because sometimes they need more time than their classmates to answer the questions. But as they love helping teachers, we sometimes let them make the questions (we choose the question and they ask it to the contestants). After all, what we want is for them to enjoy and learn or review the content we are using with this auditory and TPR activity. Auditory learners acquire content by listening to it, and this is a good way to help them while they are having fun.

\section{GAME 20: Buzz}

It is the same game as the previous one, "Ring the bell”, but instead of using a bell we use a buzzer or a light. Children have to ring the buzzer or push the light to answer a question.

Observations: Sometimes we give the buzzer or the light to a student who needs help and let him/her choose a peer to play with them. In this way we are allowing peer aides and it is a very helpful technique for ADHD students. And it is also a very handy method to use when several students need help and there is no aide teacher to help the instructor.

\section{GAME 21: Noughts and crosses}

With this easy game not only can we encourage logical thinking, but we can also use it to review vocabulary or any other English content. We built a big grid with nine squares on cardboard, we made the "X"s and "O" counters out of card, and laminated all them to avoid the game being ruined after a few games. 
To play the game we split the class in two big teams, the " $\mathrm{X}$ "s team and the "O" team. Then we review content by asking questions to each team. If the team answers correctly, they can place one of their counters on the board, otherwise, they miss the chance.

Observations: It is a strategy game that children know and enjoy, and as ADHD students are familiar with it, they are eager to participate and they normally are very good strategists, so the group value their suggestions, although they sometimes are not that good with their content contributions.

GAME 22: Noughts and crosses. Variation

Rinvolucri (2011, p. 13) offers a variation of the classical noughts and crosses to highlight and review the English determiners. We adapted the original idea to the characteristics of the $4^{\text {th }}$ grade students.

First, divide the class into two teams, team A and team B. Then, display the following grid on the board:

\begin{tabular}{|c|c|c|}
\hline SOME & A FEW & ANY \\
\hline MUCH & A LOT OF & TOO MUCH \\
\hline MANY & SEVERAL & A PAIR OF \\
\hline
\end{tabular}

Team A has one minute to choose a particular square and produce a correct sentence using the word in that square. If the sentence is correct they get a cross in the corresponding square.

Then team B plays in the same way, getting an "O" in the corresponding square after a right answer. 
Observations: It is an excellent game and children are very enthusiastic about it. It is a fabulous way of reviewing and reinforcing determiners, and even ADHD learners with difficulties in the use of some of them, improved substantially. We just varied the recommended time from the original game, as $4^{\text {th }}$ grade children needed more time to form their sentences. As a matter of fact, on the first round there was no time limit, we just let them think of a sentence.

\section{GAME 23: Word Chain:}

This game is also known as "grab on behind", "last and first” or "alpha and omega”. It is a memory game that fits perfectly as an icebreaker, but it can also be played at any moment as no materials or special requirements are needed. We have used it sometimes to give students a break or as a reward at the end of the class.

Students have to say a word starting by the last letter from the previous one, for example: student 1 says "school”, student 2 has to say a word starting with letter "l”, such as "lion”, student 3 has to say a word starting with letter "n”, for instance "nurse”, and so forth. Repetition of words is not allowed.

Observations: It is a good game to play at any ages and it enhances auditory memory. It is a funny game that ADHD students love, despite the fact that they sometimes make mistakes, as they tend to repeat words after a while playing. Some children struggle with words in which the last letter is not pronounced, as in Spanish all letters are pronounced.

\section{GAME 24: Toss the ball}

The instructor picks a category, such as "animals”, and gives one student the ball. That student has to say a word from the category and toss the ball to a classmate as fast as he/she can, and so on. For example: student 1 says "lion" and tosses the ball to student 2, who says “cat”, and tosses the ball to student three, who says "horse”, and so on. Students have ten seconds top to answer and cannot repeat a word. If they last more than ten seconds to answer or repeat the word, they are out of the game. It is supposed to be a quick game and the winner is the student who stands all the round. If the instructor foresees that pupils do not know more words from that category, the 
category can be changed. Sometimes we also blend "word chain" and "toss the ball" and ask students to say words that begin with the letter or letters that the previous word ended with. For example: student 1 says "house” and tosses the ball to student 2, who says "elephant”, and tosses the ball to student three, who says "table”, and so on. As children love challenges, we sometimes play "toss the ball” and ask them to say words with two syllables, three syllables, adjectives or verbs. It is a quick and very funny game to review vocabulary and grammar. Children love it, and so do we, that is why we love playing with them, an idea they love and enjoy greatly, but be prepared to have all the class playing against you.

Observations: It is a game we use to review material and improve auditory skills, using movement and making learning fun and engaging. According to Lengel and Kuczala, when cognitive information is linked with movement, retaining and recalling de data become easier (Lengel and Kuczala, 2010, p. 10).

\section{GAME 25: Thumbs up}

We use this game to review vocabulary and help auditory students that struggle with some words in $4^{\text {th }}$ grade. If we are just reviewing vocabulary, we ask seven children to come to the front. If we are helping students to memorise some tricky words, we ask for four or five children to come to the front, according to the students' needs. We give each student on the front a flashcard, which they must hold and say out loud when receiving it. The rest of the students put their heads down or close their eyes and put their thumbs up. Then the pupils with the flashcards walk around the class, choose one student each by touching their thumb, and come back to the front of the class. Those who have been touched have to lower their thumbs. After that, all students can sit up and open their eyes, and the pupils that were touched try to guess who chose them by saying the name of the flashcard they are holding. If they guess correctly they switch places with the student who touched them at the front.

Observations: This is a TPR activity that help auditory learners drilling with this game. ADHD students love it, especially when they get to hold a flashcard, which helps them remembering that word afterwards, so if any of them have a specific difficulty with any word, it is advisable to play this game with the class and let that student hold the flashcard with the problematic word. 


\section{GAME 26: I spy}

One pupil looks for an object that everyone else can see, but doesn’t tell them what the object is. Then the student who chose the object says "I spy with my little eye something beginning with...” followed by the first letter of the object. The rest of the students take turns to guess things that they can see that start with that letter. The pupil who guesses the word thinks of the next one.

Another variation is instead of giving the first letter as a clue, a description can be given, such as "I spy with my little eye something green”.

This game belongs to " 50 Things to do on a car journey. Usborne Activity Cards” (Gilpin, 2006), a box of fifty cards, each displaying a funny game to play during a journey, but also very practical for ESL classes.

Observations: This game is a nice ice-breaker. It is also a good game to play when learning or reviewing the alphabet. We have used it with $4^{\text {th }}$ grade students and they enjoyed it, although the rhythm of the game was a bit slow, and some students got bored, as was the case of ADHD learners.

\section{GAME 27: Hungry alphabet}

One pupil says “I am so hungry, I could eat an apple” (an apple, or some other kind of food that has "a” as the first letter). The next student says "I am so hungry, I could eat an apple and a banana". The following learner says "I am so hungry, I could eat an apple, a banana and a cake”. And so forth. Each student takes turns to add a kind of food beginning with the next letter in the alphabet. The game ends when someone forgets to say something that is already on the list, or they cannot think of a kind of food that begins with the next letter.

As the previous activity, this game belongs to " 50 Things to do on a car journey. Usborne Activity Cards” (Gilpin, 2006).

Observations: This is a good game to play when learning or reviewing the alphabet or vocabulary related to food. We have used it with $4^{\text {th }}$ grade students when 
learning the alphabet, but they did not enjoy it very much, as they did not have the sufficient knowledge about food to name a word with each letter of the alphabet. But it is a fantastic game to use in $5^{\text {th }}$ and $6^{\text {th }}$ grade as an ice-breaker.

Some speaking activities follow a set pattern where the speaker takes the listener on a "guided tour", as is the case of apartment descriptions or giving route directions. This patterns can be taught and practised (McCarthy, 1991, p. 142). Discourse analysts have found that the organisation of talk in direction giving situations and alike follow the next structure (ibid, pp. 142, 143):

- Situation: Starting point, goal and means of transport must be specified during this phase.

- Information: Main routes are given during this phase.

- Ending phase: Confirmation that the route has been comprehended and closure of the interaction take place during this phase.

We usually practice a giving directions activity with $5^{\text {th }}$ grade pupils. We review the vocabulary of the city, we increase our knowledge with new, brand words, and we learn to give and understand directions. To do so, we draw a map on the blackboard or project a map on the screen, and pair up the students. Both members of the pair will be speaker and listener. We also ask them to practice several times the activity, as the first one normally is used to learn how to do it or to try to understand the "set pattern".

ACTIVITY 76: Give directions to your partner to get to school on foot:

- Select a starting point.

- Give clear directions.

- Make sure that your partner is understanding your directions.

Observations: Children love this activity, ADHD students included. But many children have problems to give or receive orders using a map. We give some examples first on the blackboard and explain them that they must pretend they are walking through the map to get it right. But some of them still have orientation difficulties when using a map to give or receive directions. Therefore, some of the mistakes on the route are not due to a language misunderstanding, but on account of orientation difficulties. The best way to help those with orientation difficulties is to ask them to come forward 
to the blackboard with an object, such as a rubber or a sharpener, and make them place the object on the map and make them move it as if it was them around the map while we give them some instructions. This activity requires a lot of time because of the difficulties using the map, but is a good activity to practice speaking and as they are involved in the process and rehearse it several times, they learn the "set pattern" quite well.

According to Vaquerizo-Madrid and colleagues, language has a phonologicsyntactic level in which we frame the verbal code of a language, a cognitive level regarding lexis and semantics, and a pragmatic level which confers language its communicative and social function. Generally speaking, ADHD children are likely to encounter more problems with the comprehension of the past, fluent conversation, verb tenses control, and phonetic differences (Vaquerizo-Madrid, Estévez-Díaz, PozoGarcía, 2005, p. 86). Hereafter you will find three games to practice and help learners to acquire the verbs. They can also be used as assessment games.

\section{GAME 28: World tour}

This game consists in asking the verbs by way of a contest. The students challenge each other in pairs, following the order in which they are seated, having to first ring a bell placed before them to be able to respond. The teacher gives them the meaning of a verb and the students must say the present, past and participle of the required verb. The student who rings the bell in the first place and answers correctly competes with the next partner. That student able to overcome all others and complete the round (in English "tour"), wins the game, because he has been able to turn the class around (hence the name of the game, "World Tour"). This game helps to assimilate the verbs to those students who have auditory learning or are kinaesthetic, as is the case of most students who have ADD/ADHD.

Observations: Some ADHD students may feel in disadvantage as they need more time to answer than the rest of their classmates. That can be easily tackled by asking them an easy verb or a verb we know they acknowledge. 


\section{GAME 29: Jumping Verbs}

We adapted this game from the "word chain” original game. A student says a verb and the next student has to say a verb that starts with the last letter from the previous verb. Example: Student 1 says “jump”, then student 2 has to say a verb that starts with letter "p”, such as "play”, the student 3 has to say a verb that starts with letter “y”, such as "yawn”, and so forth. Verbs cannot be repeated and the time limit to answer is ten seconds (for students with ADHD or any other difficulty that entails a delay in answering, there will be extra time).

Observations: This game may be tricky for ADHD students, so maybe we could let those pupils with difficulties start the game or being the "instructors" of the game. In this way we make sure they are paying attention and give them the possibility to gain knowledge by doing so.

\section{GAME 30: The shout in the circle}

This game is a Rinvolucri’s proposal from his book “Grammar Games. Cognitive, affective and drama activities for EFL students” (Rinvolucri, 2011, p. 117).

Students have to stand in a circle, with one pupil in the middle of the circle. Ask the student to tell the others the daily routine of someone. We told them that they could also invent a routine, for example "She gets up at 8.00 ”.

Every time the teller uses a verb the whole group must shout out the verb, e.g. “GETS UP”. If the teller says the verb incorrectly the circle must try to chorus the right form.

This exercise can be used with any area of grammar.

Observations: This fantastic game happened to be a disaster. We loved the idea of the author, and so did the students when we explained how to play the game, but it ended up being an unsuccessful attempt. A few children went in the middle, but the rest of the class was more excited about shouting than in highlighting the grammar by themselves, so we had to stop the game, as there were some pupils murmuring and shouting random words whenever they pleased. We should have used another way to point out to the verbs, as moving a step forward, or raising their hands instead of 
shouting. Hence, the problem of the unprosperous result was an inappropriate management during the implementation.

Turning to another issue, phonology, we could define it as the correspondence between sounds (phonemes) and symbols (graphemes). This is an area that is often difficult for at-risk students, and the level of difficulty vary depending on how "transparent" the pronunciation of a language is (Brouwer, 2011, p. 94). Spanish has simpler sound-symbol patterns than English, because it is highly grapho-phonetic (ibid, p. 94), that makes English phonology rather difficult for a large number of ADHD students. Therefore, children have problems pronouncing some words and, hence, counting the syllables of a word. Knowing how to divide words into syllables can help to pronounce new words and to spell words properly. An activity to practice counting syllables is featured below.

ACTIVITY 77: How many syllables do these words have? Clap your hands while you say them and find out. Classify them on the chart below and add two more words in each column:

House, supermarket, sun, cauliflower, bruise, sunflower, see-saw, lovely, hop, skin, Monday, Japanese, tape, motorbike, apple, children.

\begin{tabular}{|l|l|l|l|}
\hline 1 syllable words & 2 syllables words & 3 syllables words & $\begin{array}{c}\text { Words with more } \\
\text { than } 3 \text { syllables }\end{array}$ \\
\hline & & & \\
& & & \\
& & & \\
\hline
\end{tabular}

Observations: A few students have problems when counting syllables in English for the first time, ADHD students among them. The fact that two close vowels can merge together within the same syllable, as is the case of Spanish diphthongs, such as "ruido", is misleading for some children, which consider that "bruise" is a two syllables 
word. Other errors come from mistakes in pronunciation, like "lovely", because some children do not pronounce it properly, instead of saying / lıvli/, they say /lovely/, considering that is a three syllables word.

It is important to provide systematic phonetic training to students to become good spellers, teaching letter/sound correspondence (Rief, 2005, p. 177). One way we use to enhance systematic phonetic training is to play "spelling contests" in class with the following game.

\section{GAME 31: Bowling Alley}

This spelling game has delighted $4^{\text {th }}$ grade students year after year. It is obtained from a wonderful book to work Discourse Analysis in class within the English as a Second Language lesson, "ESL Vocabulary and Word Usage. Games, Puzzles, and Inventive Exercises” (Forte and Pangle, 2001, pp. 61, 62).

We split the class into two big groups. We make ten bowling pins out of cardboard for each group, red team and blue team, and set up the two sets of pins in a bowling alley way. On the back of each pin we have written a spelling word, the higher the number of the pin, the more difficult the word. One player from the blue team calls the number of a pin and the teacher reads it. If the player spells it correctly, he/she has knocked over a pin. Groups and players take turns choosing pins and spelling. The first group to knock over all the pins wins the game.

Observations: ADHD students may struggle spelling words out of a term they listen, so we make exceptions for them or other children with other disabilities and apart from telling them the word on the back of a pin, we also write it on the blackboard. We want them to succeed in spelling, not making an accommodation to some children would be unfair, and all of their efforts would have been in vain.

McCarthy avers that the faculty of linguists to segment the sounds of language into phonemes is incredibly helpful when used in the construction of words, generating contrasts between the words of a language. In the specific case of English, we can see such contrasts, for example, in the phonemes /p/ and /b/, as in "pat” and "bat”. The position and manner of articulation can be presented and exercised in language classes 
either as isolated sounds, in words, in contrasting pairs of words or in minimal contexts (McCarthy, 1991, p. 88). Such features will help for sure learners with difficulties, as is the case of a good few of ADHD students. To practice some isolated phonemes we have used the following phonological awareness exercises and games.

\section{GAME 32: Mirror, mirror...}

With this speech exercise we can help children to pronounce the phoneme /h/. They will need a mirror to practice the exercise.

We asked students to pronounce some words starting with the phoneme /h/ in front of the mirror. For example: “he”, "house”, “horn”, “Harry”, “have”, “happy”, "Halloween”, "hear”, "healthy”. To know that they are pronouncing the /h/ phoneme correctly there must be some fog on the mirror.

Observations: Many Spanish children pronounce the English phoneme /h/ as the Spanish grapheme “ $\mathrm{j}$ ”, which phoneme is / $\mathrm{x} /$. This exercise is one of the best ways to help them pay attention to the correct execution of the English phoneme /h/.

\section{GAME 33: Drawings in the air}

This exercise is a variation of the game "Tight-lipped Drawing” (Monschein, 2008, p. 3) and is designed to develop oral skills. This activity can be used as a warmup, to work a specific need, to introduce some "phonics" or, simply, as a game that serves as a break between activities that involve greater mental effort.

The exercise consists of making drawings in the air with a spoon or wooden spatula that the children will hold with their lips while they inspire through the nose and exhale through the mouth. We will ask them to draw pictures, for example, a circle, asking them to concentrate on their mouths and breathing. Later we will ask them to put the spatula or wooden spoon on their lower lip, then close their lips and hold the spatula. We urge them to perform various activities with closed lips, for example, doing squats without using their hand and without falling the wooden spatula. Finally, we will ask them to hold the spatula between their lips and make inspirations through their nose and exhalations through their mouth. Once these exercises are done, we will practice the 
English phonemes / ð / and / f / and we will pronounce some words that contain them, such as: "feather”, “that”, “this”, “photograph”, "phone”, “physical”.

Observations: It is a very attractive activity for all students, especially for those students with ADD/ADHD or for kinaesthetic learners. It is also very useful, since several speech therapy exercises are performed, which are not only fun, but also help them to pronounce phonemes with more precision.

\section{GAME 34: Speedy Lips!}

Making faces or facial movements help to stimulate the lips and the tongue, favouring the correct pronunciation of the phonemes. This game proposed by Maria Monschein (2008, p. 4) aims to add a playful component to the development of oral skills. To carry out this activity we will ask the children to bring a piece of fruit. We will place the fruit pieces in the centre of the table and we will ask the students to move as many fruit pieces as they can with their mouths. We will give them 30 seconds.

Observations: It is a highly ludic activity, which makes it difficult to practice in classes with a very high ratio. It was attempted in a classroom with all the students at once, dividing it into small groups, but the result was a great hubbub and lack of control. After testing it in different classrooms, the best way to do it is to divide the class into small groups and put it into practice only with one group, while the others perform another activity or wait. The only downside of doing it in turns is that students who show attention deficit (with or without hyperactivity) are not able to perform another task while waiting, they cannot avoid being aware of the group that is playing. All the students wanted to repeat the activity once it had finished.

\section{GAME 35: As Light as a Feather}

This simple game presented by María Monschein in the book The 50 best games for speech \& language development (2008, p. 7) is a simple activity that can be raised at the beginning of the class as a warm-up activity, at the end of the class as a relaxation activity or it can be done by working the phonemes / $v$ / and / u: /. 
In order to carry out this activity, children will need a feather, the lighter the better. The game consists of keeping the feather in the air blowing. The winner will be the one who is able to keep the feather in the air for longer.

Once the game is done, we will practice the phonemes / $v$ / and / $\mathrm{u}$ / and pronounce some words that contain this sound, for example: "book", "cook", "look", "soon", "spoon".

Observations: It is a very fun game that allows us to practice various vowel sounds and distinguish between short and long sounds. For Spanish-speaking learners, it is difficult to differentiate between short and long vowel sounds, since Spanish does not have that dichotomy. It is a great practice to perform in classrooms where there are students with attention deficit, since the most visible symptoms that characterize them (i.e. excess movements, difficulty concentrating, lack of constancy) go unnoticed and can learn phonetics at the same time as their companions.

Some activities focused on grammar or vocabulary can also be conducted either by writing or speaking, the next activity is a case in point. We wanted to practice modal verbs and we used the grammar game “Umbrella” (Rinvolucri and Davis, 2002, p. 140) to highlight modal verbs orally. We did not play the game as it is shown in the book, we just did the first part of the game.

ACTIVITY 78: We ask a student to draw on the blackboard a person holding an umbrella like this one:

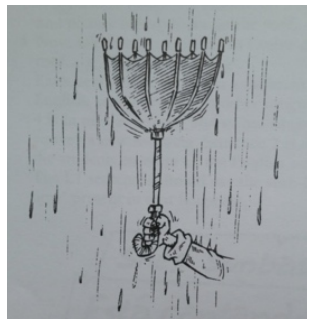

Image 14: Umbrella (Rinvolucri and Davis, 2002, p. 140).

We explain the class that this umbrella design is new, asking the students to work on small groups and brainstorm the advantages and disadvantages of the design they can see. To do so they have to use the following sentence stems: 
It/You can/can't...

It/You could/couldn't...

It/you will/won't...

For example: You can see where you are going with this umbrella.

Observations: Children came up with very few ideas, and ADHD students were completely mute, so we did not fulfil our target. We should have used a different object instead.

Some other oral expression activities have been practiced with students during the preparation of this thesis. As we mentioned on the writing expression section, students wrote stories that they subsequently told to kindergarten children. So, storytelling activities have also been done. The same happens with picture's descriptions, they are the perfect complementary activity for a reading comprehension session. We usually ask learners to describe the pictures that accompany the readings as a pre-reading activity, and we also use it to let pupils infer what texts are about.

Martin points out that it is important to consider that some learners have difficulties with auditory perception, which is aggravated in noisy classrooms with poor acoustics and makes learning difficult. The author also indicates that some studies with bilingual Spanish/English children show that they have difficulties distinguishing words that are minimally phonologically different, such as "pin/pen”, or "boat/vote” (Martin, 2009, p. 189). Hence, we need to contemplate these statements when practicing speaking and listening activities, as there will be a speaker and several listeners, who may be affected by auditory perception problems.

The main point in this section is the interaction between oral expression and oral discourse. According to Celce-Murcia and Olshtain, phonology provides us with the possible rhythm and intonation combinations, being the discourse and the situation, that is, the message and the context, what determines the most appropriate choice of prosody in any given situated utterance (Celce-Murcia and Olshtain, 2000, p. 47). It is important to work prosody with children, but also to deal with individual phonetic segments. We also have included some speech therapy exercises to help children pronounce some 
sounds, as English has 26 letters that graphically represent 44 sounds in spoken English, some of them completely new for young Spanish students of ESL.

There are also social functions of intonation. When practicing dialogs or doing role plays social functions of intonation can be taught, revealing for example assertiveness, but some expressions, such as sarcasm are yet out of reach for most children. ADHD students may need help to participate and their contributions must be praised, as well as their achievements, however small they may seem.

Regarding ADHD children's contributions during oral expression activities, we consider important to contend that some studies show that ADHD students display an excessive verbal intervention during spontaneous conversations but, on the contrary, there is a decrease intervention when planning and organizing answers are required (Miranda-Casas, Ygual-Fernández and Josel-Ramírez, 2004, p. 111). But those are results tested and obtained in the L1. Reality with ADHD students when learning a second language differs significantly. During the speaking activities conveyed throughout this study, ADHD learners barely participated neither during spontaneous conversations nor more elaborated activities. In fact, they made more and better contributions when asked for specific answers, as long as they had help and time to prepare their response (either peers' help or teacher's help). Further studies are needed to see to what extent speaking skills are impaired in ADHD students when learning a foreign language. Meanwhile, we teachers will continue working with activities trying to make ADHD learners' executive skills better and attempting to improve their verbal abilities, although we are working under the L1 research basis.

All the same, the most important feature of a classroom speaking activity is to provide an authentic opportunity for the learners to use their general knowledge in the second or foreign language (Celce-Murcia and Olshtain, 2000, p. 177). Besides we give our students the opportunity to express themselves freely in the second language, and prompt them to use English, their second language, outside the classroom. Most of our pupils are reluctant to do so because they are shy or they are afraid that someone could make fun of them when they make mistakes. But some of them used English to speak during recess time some days and others came to school and shared with the class that they found on the street some tourists and they tried to have a conversation with them. 
This is quite a bold attitude for a primary school child and, believe it or not, sometimes the most intrepid students are ADHD children, who may have problems speaking in class, but then they find talking to someone outside the school funny. Teaching ADHD students may not be easy, but not everything is as bad as it might seem at the beginning.

\subsection{Further activities and considerations}

Some activities that have been conveyed during this study are not categorised in the previous section, as is the case of silent activities. Likewise, further considerations regarding teaching are added in this subsection, as a final contemplation about teaching second languages and ADHD.

\subsubsection{Silent activities}

\subsubsection{Miming games}

\section{GAME 36: Act it out!}

This is a miming game to review vocabulary. We divide the class into groups of four or five people. Then, one person from each group gathers together and the instructor shows them one vocabulary word. After this, these students come to the front of the class and have to mime the given word. The first group to guess the word scores a point.

Observations: All children must act out a word. Sometimes certain children are too shy or afraid to participate because they do not want others to laugh at them or to blame them if their group does not score a point. Sometimes ADHD children with low self-esteem refuse to play for that very reason. Highlighting that we are just playing to have fun, that no one is perfect and that mistakes are part of the game can help them to overcome their fears and to increase their self-esteem.

GAME 37: Verb mimics

The same methodology as “Act it out!" can be used here. Although we normally split the class into two big groups to play this game. Two students come to the front of 
the class, and the teacher will show them a verb, which they have to exemplify. The first group to say the verb gets a point.

Observations: Apart from the foregoing observations, we should add a noteworthy remark, this game provides invaluable aid to ADHD pupils to learn English verbs. Many ADHD students are kinaesthetic or visual learners, which makes this game a great help to their verbs acquisition, particularly if they are the ones acting out.

\subsubsection{Activities with Cuisenaire rods}

Turketi (2010) offers a very nice and accurate variety of activities to teach English to ADHD students as a foreign language. She shows a very interesting activity to teach grammar and vocabulary (family members + this is / I am, you are, he/she is, we are) using rods and the Silent Way method.

At the beginning of this thesis we explained that the basis of the Silent Way method is that the teacher should remain as silent as possible, prompting students in this manner to intervene. Students learn by using materials.

The material we have used is the Cuisenaire rods. Cuisenaire rods are small pieces of coloured wood of different lengths. They were originally used to teach Maths, each length and colour was associated to a number, from 1 to 10 , as it is shown in the next image:

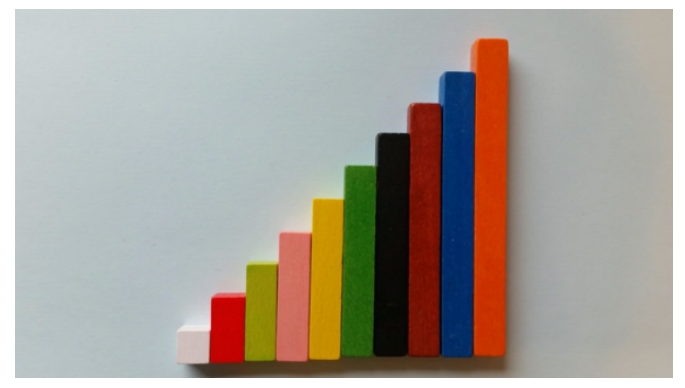

Image 15. Cuisenaire rods

But Cuisenaire rods are also used in languages, they can be used to symbolize elements in a story, to review vocabulary, grammar, to make sentences or to show word 
and sentence stress. Akarcay contends that Cuisenaire rods encourage individuals to become independent and responsible learners, permitting teachers at the same time to create simple linguistic situations. As learners manipulate and play with the rods, learning becomes multisensorial, as well as inclusive, interesting, easy, memorable, and imaginative. These linguistic situations automatically help learners to concentrate on the task (Akarcay, 2012, p. 17).

The simplest activity is to teach students numbers or colours with them. But we can also work on the parts of speech. By choosing a different rod to represent each part of speech students can build different sentences.

ACTIVITY 79: Make sentences:

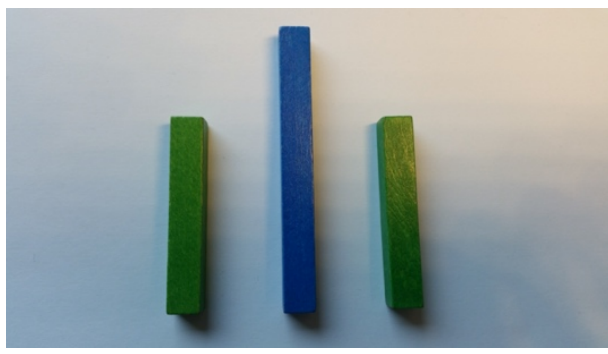

Image 16: Sentence pattern

noun - verb - noun

Example: Olivia loves horses.

ACTIVITY 80: Make sentences using the following rods as you please. Use as many rods as you want:

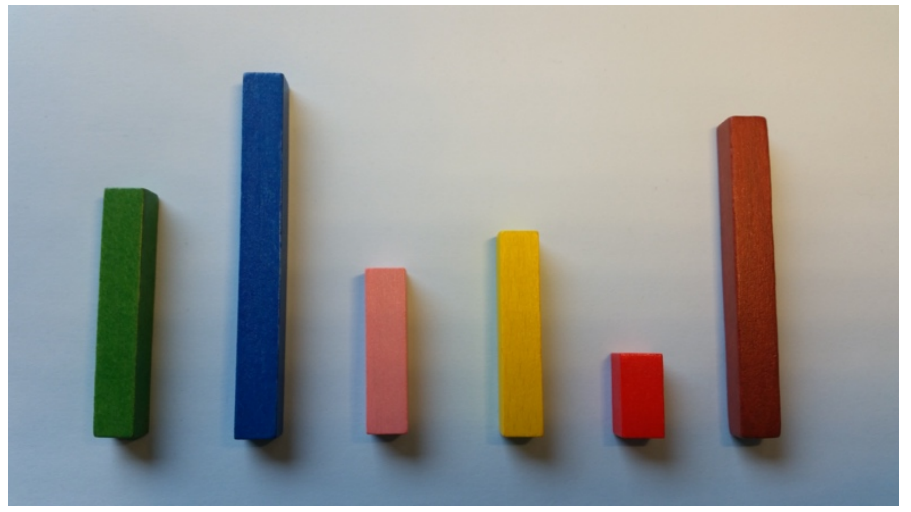

Image 17: Parts of speech rods.

noun - verb - article - auxiliary verb - negation - punctuation mark 
Examples: Does Bob like chocolate?

Mary needs a pencil.

Another way to use rods is to help students to expand their vocabulary with word families. To do so, we first give each colour rod a family category:

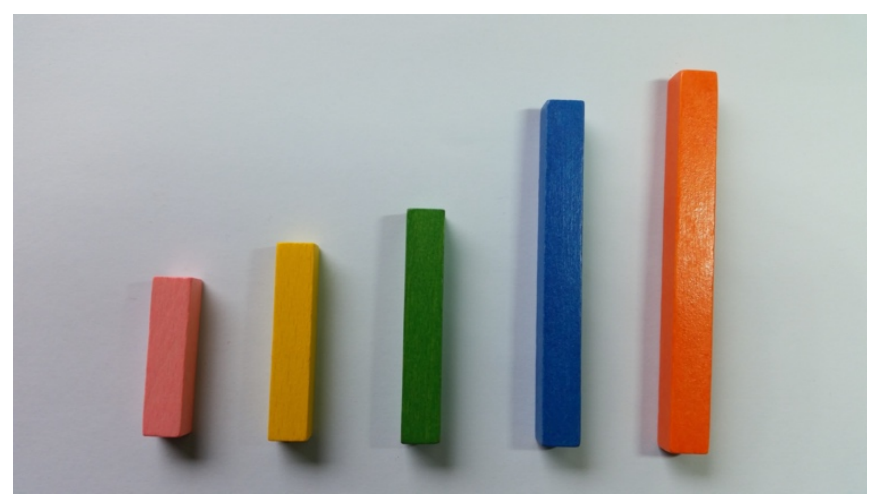

Image 18. Word families

days of the week - months of the year - animals - clothes - weather

ACTIVITY 81: Write as many words as you can (we show the blue rod, or any other colour rod).

Example: : scarf, coat, jeans, socks, T-shirt, shirt, jumper.

ACTIVITY 82: Write sentences using the given word families:

Examples: A lion wears a cap in

Two cows went for a walk on a sunny February morning.

Rods are the perfect material to give a CLIL Maths lesson or to review the numbers using maths calculations.

ACTIVITY 83: Represent number 7 in different ways and write the productions:

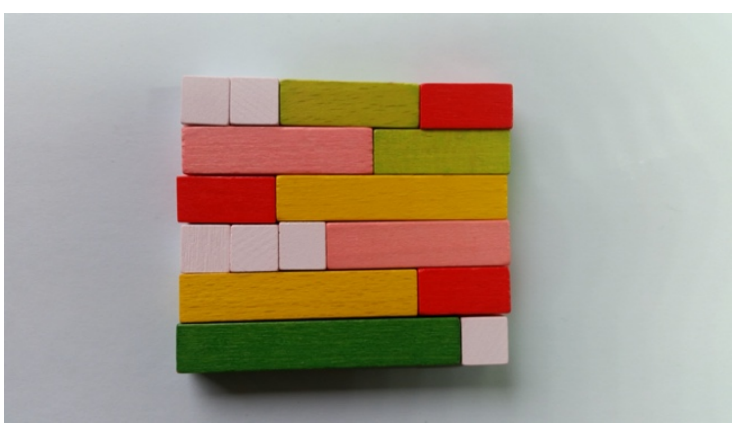

Image 19. Representations of number 7 
ACTIVITY 84: Work with a partner. Practice addition and subtraction.

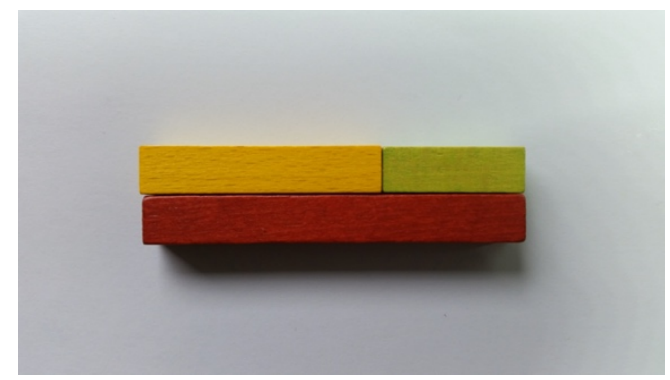

Image 20: Addition example

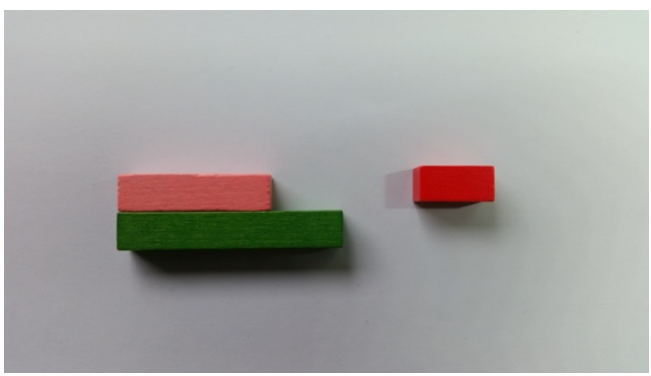

Image 21: Subtraction example

With this simple activity students practice numbers while they manipulate and speak with a partner.

Verb tenses can also be practiced with rods. We can assign a rod to a verb tense. We submit hereafter two possible activities to practice verb tenses.

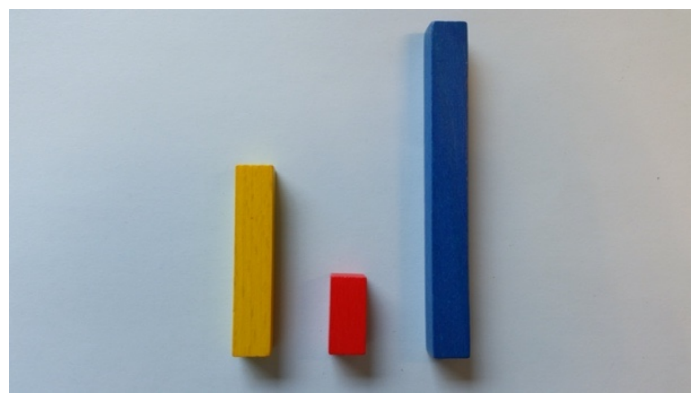

Image 22. Verb tenses with rods

- Past Simple - Future (will)

ACTIVITY 85: Underline the verb. Replace with the correct form of the verb.

1. *I go to London last summer. WENT

2. *She visit her grandmother next week. WILL VISIT

3. *They be going to the theatre. 
ACTIVITY 86: Write sentences using the proper verb tense:

1.

2.

3.

Another activity with rods with a TPR methodology that is great fun for children is submitted thereupon. Not only is entertaining, but it also is memorable for children, because it helps students to identify and recall the information easily, as physical actions illustrate the meaning without trouble. It covers vocabulary (parts of the body and colours) and grammar (prepositions). It is also a good activity to assess both contents with primary students.

ACTIVITY 87: Follow the instructions:

1. Put the pink rod over your right foot.

2. Put the yellow rod between your knees.

3. Put the red rod on your left arm.

4. Put the blue rod inside your mouth.

5. Put the brown rod behind your ear.

6. Put the orange rod under your big toe.

7. Put the white rod in front of your belly.

8. Put the green rod next to your hips.

Rods or Lego pieces can also be used to build houses and describe them, or to build cities and give directions to go from one place to another. Actually children can be asked to build whatever they like with these wooden pieces and then describe their constructions. These are great activities to do with the younger students, to enhance language development through play and experimentation.

Cuisenaire rods are visual and manipulative, and as children like touching and handling materials, these wooden materials are appealing for them. Many schools use them to teach Maths, but kids also play with them in nurseries, as is the case of our students. Therefore, our pupils were familiar with the materials, although they were very surprised that rods could be used in a language class. 
Rods are very useful with ADHD students and with all those visual and kinaesthetic learners. As many of ADHD children need to have something on their hands or to express movement in a certain way, being able to manipulate rods as they were learning helped them focus too. Additionally, having the materials in front of them helped ADHD learners to remember the instructions. And last, but not least, working with rods in the English class looked like having fun not just working, for most of students, with or without ADHD, which is really helpful to learn and to engage those students who are reluctant to practice grammar in a written manner.

\subsubsection{Further deliberation}

First and foremost, it may be noted again the importance of the earliest possible detection of the dysfunction, as one of the most important obstacles we may find in our way is the absence of diagnosis in some hyperkinetic individuals. Some studies implemented in our country come up to an early finding of ADHD, as the ADHD-3P, a new screening tool developed with Spanish population for preschool children. The authors consider that targeting the "three Ps": "padres, profesores y pediatras" (parents, teachers and pediatricians) involved in the process of assessment and intervention, effective interventions will contribute to support not only the child, but also their parents and teachers (Rodríguez-Becerra, Fernández-Mateos and Jenaro, 2019, p. 36). Although the predictive ability of the instrument is currently unknown, it is promising and supportive for ADHD children and for the educational community too.

Apart from the early detection, a good knowledge of the syndrome and an effective management of the ADHD child, families and classes are primal. Kewley and Latham offer us some extra advice to support ADHD individuals. The authors remark that occasionally some parents will refuse to accept that their child has a problem, and some of them may even blame the teacher for the child's problems. Misleading media reports and the possibility of having their child medicated may affect the parent's decision (Kewley and Latham, 2008, p.122). The authors also highlight the importance of being aware that some ADHD students are not ready for the same level of independence and responsibility as their peers, they will need support from their parents and teachers for much longer (ibid, p. 49). Likewise, they state that "being fair" might 
not entail that all children are treated identically. Rules and expectations may need to be individualized, but should be applied fairly and consistently (ibid, p. 39). This is a very delicate aspect to consider, but yet necessary. We are all different human beings with nonidentical needs, with or without ADHD syndrome, it may appear to be logical to implement diverse and customized considerations, especially with those children who really need them, such as some ADHD students. In any case, sometimes teachers have tried their best and attempted different implementations and strategies with a pupil, and yet the child is still having problems. It is important to check with other teachers to inform families and specialists, to be sure that there are no other issues interfering in the academic matters, such as being bullied, family afflictions, sibling problems, illnesses or other coexisting difficulties. About a third of children with hyperkinetic disorder have coexisting specific learning difficulties over and above their problems with concentration. For this reason it is decisive to inform the student's family when there is a matter of concern regarding the child (ibid, p. 54).

We have also commented along this thesis some problems ADHD students face regarding discourse production and reception. The complications hyperkinetic children have with their executive functions, together with the low self-esteem and, in many cases, coexisting dysfunctions, affect to a great extent their language skills and, therefore, discourse. Nunan revises the term “schema” and recalls Widdowson's interpretation of schema theory from the perspective of discourse comprehension, considering that there are two levels or dimensions to any given discourse: a systemic level and a schematic level. The systemic level includes the reader or listener's linguistic knowledge, while the schematic level relates to background content knowledge. In making sense of a piece of discourse we link our own schematic knowledge with that of the writer or the speaker by interpreting what we read or hear (Nunan, 1993, p. 71). What happens with ADHD individuals if they have impaired executive skills? From our experience with ADHD children while working discourse units in ESL lessons, we argue that when starting to learn a foreign language in primary school, ADHD students may have a scarce systemic level in the non-native language, that added to the difficulties many of these students have with the working memory and planning and problem solving executive skills, results in complications, disruptions and misunderstandings when trying to make sense of a piece of discourse. How are they going to keep track properly of the piece of discourse they are reading or hearing? Well, 
at the very beginning they don't. And that is why many ADHD primary pupils reject English lessons. They do not understand what they are listening to, they get lost, and they don't remember what they have heard. Besides, they do not know how to say words in English, they are ashamed of making mistakes and they are tired of being pointed out and lectured for actions they cannot control, even though they want to. Although every single person may feel something similar when starting learning a second language, ADHD students live it in a magnifying way due to their personal characteristics.

As mentioned in the previous section, ESL teachers are working with ADHD students taking into account the results obtained when studying ADHD individuals using their mother tongue. ADHD affects language and, consequently, general education, as reading, writing, listening and speaking are basic skills used to acquire knowledge. Some studies show to what extent language is affected in ADHD students. By studying the syntactic structures used by pupils, Crespo Allende and colleagues find evidence that as children increase the school level, the difference between ADHD and non ADHD students' syntactic structures rise. Thus, under this circumstances it could be postulated that the more complex the level and the complexity of the learnings, the more hampered the processes of learning of ADHD students are, as the use of language is required (Crespo Allende, Elías Lillo and Góngora Costa, 2012, p. 113). Consequently, we highlight once again the importance of conveying further studies within the Didactics field, regarding the difficulties ADHD students find when learning a second language, so that teachers can adequate their teaching methodologies and interventions to minimize the hyperkinetic students' difficulties when learning a foreign language.

But apart from the linguistics challenges ADHD students bring to ESL instructors, other complications may emerge when teaching. What to do when reaching an impasse? Although there are tons of activities, games and possible pedagogical tasks to teach ESL, sometimes we are stuck. The class, the difficulties some pupils may have, the problems understanding a specific matter, are some of the reasons that can undermine the lessons plans and make teachers feel stranded sometimes. Thomas Edison once quoted "The greatest invention in the world is the mind of a child”. We couldn't agree more. The first thing to do when reaching an impasse, apart from reading 
and investigating about the topic, is to think like a child. Putting ourselves in their shoes might give us a different perspective and understanding of the issue, and we will probably have a new approach to the matter. At the end of every school course we conduct anonymous surveys to fifth and sixth primary school graders. We always ask them to tell us what they do not like about the classes and why. We also ask them to tell us what they would change and why and what they would not change, giving us a reason too. It is important to tell them that we already know how to do different classes if we had different resources in class, so it is very important to keep in mind the school we are, the space we have, the resources we have, the pupils there are in the class and that there is only one teacher to help them all. We let them write it in English or Spanish, because we really want them to participate anonymously and be honest, and writing in English would impede it to some of them. It is unbelievable the great ideas they can give you. We always read the papers aloud and explain them why we can or cannot do some of their ideas, always in a pleasant way and giving them the very reasons. Being sincere and transparent to them is very important, not only to make them feel valued and not rejected, but if we ask them for judgement, it is consequential to explain them why we accept or dismiss an opinion or idea. They do have amazing proposals, and in several occasions we have used their ideas in the next school course. In fact, the game "stairs" submitted on the writing expression activities' section was a request of a student, and we have been playing it ever since. Sometimes children say that they do not want anything to change, that they love the classes as they are. Some other times they ask us to play a specific game and, if it is possible, we really try it to practice vocabulary or some grammar structures. We also tell them if we want to change some routines or stop doing something and ask them for their opinion. From our point of view it is crucial to make your students feel a part of your program, for your main purpose as a teacher is to teach them and make them feel happy in the process. And it is fascinating how many sixth graders, who have taken the survey the previous course, write their name at the end of the note, because they feel comfortable with the activity and do not mind us to know who they are, even if they are asking us to stop doing something. 


\section{A case intervention}

Despite the fact that ADHD represents a challenge to language instructors, the disorder itself can be effectively treated, as Bula Villalobos contends. More than that, he considers that the attitude and knowledge exhibited by both, the student and the English teacher are determinant to the success of an implementation plan (Bula Villalobos, 2011, p. 31).

In this section we will describe the activities, and the classroom and behavioural classroom practices that we implemented during the English lessons to a whole group/class with an ADHD student, as well as the individual techniques we used to assess that student, as a case intervention example. The name and other identifying information will be changed or omitted to protect his/her privacy, hence we will refer to him/her as David.

The classes in the school were this case studio took place are always arranged in clusters of four to six children, to promote cooperative learning. However, he was sitting alone sometimes to avoid him from talking or disturbing his group peers. We decided to seat him in a group next to the blackboard, so we could be next to him to help him during the explanations and to avoid distractions or undesired behavioural interventions, and strategically placing some children who could help him or ignore him when he tried to talk to them or be funny. Group arrangements had to be done sometimes to avoid excessive talkativeness. We also assigned a group leader to make them responsible for the group, which really works well, because apart from the teacher, they regulate their own behaviour and distractions. Sometimes the leader was not respected and classes had to be stopped to deal with that issue, but it really happened a few times. In David's group the best choice was to allow David to be the leader, his behaviour was completely different. Sometimes giving ADHD children some responsibilities can mean a big deal to them. But of course it was not fair for the rest of the group to have him always as a leader, so a little bit of deaf touch was needed.

At the beginning of the lessons we reviewed with the pupils the vocabulary and grammar from the previous lesson. We normally used a brainstorming technique or a game to do so, such as "toss the ball”. It helped every single student, not just David, to review the contents and to focus on the class. We also set learning expectations at the 
beginning and at the end of every lesson. It is very difficult to achieve a goal if you do not know what you are expected to do. We also tried to be predictable, although it is very difficult to plan a class and pretend everything is going to work as expected, but having routines can be considered as predictable acts, which really help ADHD students.

Regarding activities, when the class read a passage aloud, he was allowed to follow the readings with a pen or a marker, whatever he wanted, or to checkmark every ending sentence, to keep up the reading pace of the class and to permit him some activity meanwhile he was working. We sometimes reduced the length of the assignments or gave him the possibility to choose among two or several options. Interestingly, when he was provided the choice-making intervention, he normally accepted it, but then finished the rest of the class assignments at home with his mother's help, although we never asked him to do so. Maybe it was his own way to say thank you for caring about him. His mother was a wonderful, loving, caring mum, which always was thankful for our help and contributed to keep pace with the English contents. She was very aware of his son's difficulties and instead of pushing him out of his limits or trying to avoid the problem, she was always delighted to help and accepted the good and the bad news regarding his son's behaviours, and the teachers' management considerations. It must be very difficult to accept some issues regarding your own children, but objectivity and patience are really needed to help our children instead of interfering in their learning or trying to rush them. We all have our own learning pace and we must respect it. There are behavioural and learning techniques that can help us, but we must always respect the cognitive and learning pace of every single individual.

We also implemented the self-instructions' scheme for cognitive training for children with or without ADHD for written activities in section 8.2.3, and the selfinstructions' scheme for cognitive training for children with or without ADHD for spoken activities in section 8.2.4.

David was periodically assigned a partner to assist him with the grammar activities, which worked pretty well, always with the teachers' supervision. Sometimes that partner was assigned to play vocabulary games with him too, as a reward. Some other times we, the teachers, played some vocabulary or grammar games with him to 
help him acquiring the contents and to know if he had difficulties, and how to help him. It was also a good way to assess him in a less formal manner, which is also helpful with ADHD students, for they sometimes underscore in formal tests due to insecurities, nervousness, lack of time or as a result of reading errors when they are reading the assignment's statements. As tutors of students doing work experience in Primary Education (English mention), we had an intern university student in class during a few weeks, which also was an aid sometimes. ADHD children accepted their help very well, although sometimes they tried to talk or play with them instead of working. Either the university student or the teacher played games and worked with all the class, but enabled ADHD children to practice and play more often during their working experience, which was really helpful for everyone.

Johnson and Reid (2011) offer teachers some effective methods to overcome executive functions deficits with students with ADHD. Among other recommendations, they suggest teaching students self-monitoring strategies to promote persistence when doing a task, and they mention an example of Reid and Lienemann, who helped students increase the length of their stories by asking learners to count up the written words and graphing the results. We tried something similar with David, we told him to count the lines he wrote on his notebook, challenging him to outdo himself by means of writing one more line each time, but it did not work. He wrote more lines, but meaningless or using Spanish instead of English. The only way he really improved his writing essays was sitting next to him and helping him think of what he already knew, but was insecure to use. Sometimes ADHD students work so hard to avoid demonstrating lack of ability that they do not have time to demonstrate what they actually know.

Some behavioural techniques were applied regarding impulsive answers. David was really eager to participate during the English lessons, which made him rise his hand up every time the teachers asked any questions, even before the question was finished. That conduct could turn against him, because if we asked him after finishing the question and he did not know the answer, he was bringing out himself his lack of knowledge about the matter. We decided that no one could rise his or her hand up until we finished making the question or the intervention. We sometimes tried to cheat on them theatrically to make them laugh and, at the same time, understand how important 
it is to be patient, listen up and let people finish their question or speech. We also agreed in private with David some face signals to know if he really knew the answer or if he was just trying to participate, to avoid their classmates thinking he did not know the answer. We always let pupils know that making mistakes is part of the learning process, but David was sensitive and we did not want to harm his self-esteem or discourage him from participating or keep working on the subject. The signals worked pretty well and he, among other non ADHD children, managed to moderate his interventions.

As a self-regulation intervention we told him to press tight his toes against the floor every time he was nervous or when he had to speak in front of the class, to control physically his nervousness by locating the energy on his feet and, unconsciously, controlling his mind too focusing it on the physical activity. It did not always work, but it was useful and benefited him.

Theatrical classes, kind gestures and big sincere smiles helped out along the process. Games and sporadic prizes in form of candy also pitched in. Home-school communication was practical and effective, using report cards when an undesired behaviour or a desired result was achieved.

David, the ADHD pupil in this case study, presented problems with language in several areas:

\section{Syntax}

The student presented problems when differentiating the components of the sentence. His poverty of vocabulary meant that he did not know how to differentiate the verb from the rest of the sentence constituents. He presented great difficulties to memorize verbs, and that was the reason he was not even able to differentiate between subject and predicate.

Accommodations: We helped the student to memorize verbs and guided him individually to locate the verb in the sentence. To do so, we suggested that he studied the verbs in a three stepped program: first he had to write a verb, then he had to draw a picture representing the mental image that the verb evoked to him, and finally, recite it to someone and, in turn, have someone read it to him. In this way, he was working with 
the four linguistic skills and, regardless of the type of apprentice he was, the information should reach him through one of the four channels. To reinforce the procedure and to add a playful component, we played the game "World Tour" in class, which consists in asking the verbs by way of a contest. This game helps to assimilate the verbs to those students who have auditory learning or are kinaesthetic, as is the case of this ADHD pupil.

\section{Semantics}

The learner also presented poverty of vocabulary, which affected his participations during the English lessons because of his limited language when he wanted to express himself. He had trouble even memorizing ten words. Sometimes he managed to memorize how they were pronounced but he wrote them as they sounded. He also had difficulties following spoken instructions and was completely lost when figurative language was used.

Accommodations: We did not count off for spelling in tests. We encouraged him to use non-verbal communication to help him express his ideas when speaking. We also played vocabulary games with the whole class or just with him, such as the "memory game”, “the hangman”, “act it out!”, “find me!”, “thumbs up”, “buzz”, “ring the bell”, “pass the ball”, "head’s up vocabulary”, “simon says”, “stairs”, “tutti frutti”, or “jenga” to help him acquiring the vocabulary. As we have already explained the games in the previous section, we are only mentioning them here as intervention activities. He was sometimes given some specific activities to name pictures, solving crosswords, word searches or creating anagrams, which are amusing and very useful activities to improve semantics skills too. Playing online vocabulary games was also very helpful, we used them as a reinforcement. The next websites were good resources for practicing vocabulary online:

- https://www.mindgames.com/Word+Games

- https://learnenglishkids.britishcouncil.org/games

- https://learnenglishkids.britishcouncil.org/word-games

- https://www.gamestolearnenglish.com/

- http://www.eslgamesworld.com 


\section{Pragmatic-discursive}

The student was not capable of producing a coherent discursive production. Words were missing and sentences lacked order and meaning. He was aware of it and sometimes he decided to stop talking, claiming that he had forgotten what he was going to say.

Accommodations: We reinforced positively the student's contributions and strengthened his self-esteem. We also encouraged him to participate, helping him through questions or inferences. We prompted him to use non-verbal communication signals and to use the self-regulation technique we taught him (pressing tight his toes against the floor every time he had to speak in front of the class) too. Praising him for his achievements was basic and essential. We also reviewed the previous lesson at the beginning of the class to help him remember the contents. We helped him to improve his vocabulary and prompted him to use it. And we also allowed him to speak "Spanglish” instead of remaining silent, and gave him the "missing” English words when he finished his intervention.

\section{Metalinguistics}

The student had difficulties understanding metaphors. He also did not manage to memorize the vocabulary referring to "false friends" ("false friends" or "false cognates" in English), such as "library/bookshop". The child considered that "library" was a "bookcase", and when he was asked about the meaning of "bookshop" he was blocked. David was not able to detect grammatical infractions in meaningful sentences, neither distinguish between meaningful or meaningless phrases. Bialystok and Bouchard (1985, p. 229) define metalinguistic ability as the improvement on two skills of language processing: control over cognitive processes and development in analysis of knowledge of language. Having problems focusing the attention on misleading information are part of an executive function matter (Byalistok, Peets \& Moreno, 2014). Therefore, as cognitive control is connected to executive functions, we could say that the metalinguistic ability can be undermined when an ADHD individual has poor executive skills, as this seems to be the case.

Accommodations: We continued working on improving David's vocabulary grounding, and differentiating between verbs and other components in the sentence. 
This last accommodation can also be considered as an executive function activity, as it pretends to focus on the location of verbs within the sentence.

As a result of the different activities, classroom management techniques and behavioural practices we applied to the ADHD pupil and his class, David improved his condition and his performance in the English classroom and, most importantly, he started to like learning English as a second language. He also improved his self-esteem, which is vital in life, not just to learn a subject. He realised that he could learn a second language and, despite the fact that everyone makes mistakes, he became conscious that he needed some techniques and practices to achieve his goals and accepted it. Actually, we all have our way of learning, certain individuals just need some clues to find his/her own path. Some people define having ADHD as if they were listening to a radio which is not tuned in properly continually. So... what would happen if that detuned radio station that surrounds you is in a foreign language and you do not understand a word? That is what many ADHD students face when they are learning a foreign language. 


\section{Conclusion}

Over several years, various types of activities have been carried out and several methodologies have been put into practice in Primary Education classrooms to try to meet the needs that students with ADD/ADHD have when learning English as a second language in inclusive classes. While it is true that it is essential that teachers work on and retrain themselves, being able to vary their methodology according to the needs of each classroom, each individual or each moment, it is also considered appropriate that the various institutions of higher education and the current legislation address and cover the real needs of classrooms and students. Each apprentice, regardless of having $\mathrm{ADD} / \mathrm{ADHD}$ or suffering from another type of special or specific need, has the right to be treated as they deserve.

The needs of the classrooms and the ratio of the same prevent that, in many occasions. Certain activities cannot be carried out properly in the educational centres, since the group-class is usually too numerous to execute some of the language games and activities that have been submitted in this thesis. Working with groups of 25-30 students does not allow controlling the correct execution of certain actions by all students, such as the correct positioning of the lips when performing language development games. It is fundamental to be aware of the need of two professionals to co-work and be responsible for executing activities and/or games, in order to be able to work correctly with a large group. The more ADHD children or students with other needs per class, the more help is needed. Some children with special needs require a person to work only with them all the time, what do we do with the rest of the children that need help? And what about the rest of the class? Everyone deserves help and attention. As a matter of fact, several ADHD organisations from Castilla y León demanded the regional education authority for excluding ADHD students from the ATDI (the Spanish abbreviation for “Atención Temprana del Desarrollo Infantil”), acronym that stands for "Early Child Development Care”, a computer programme where the Department of Education register those children that need a special educational attention (Asanhi, 2017).

Real inclusive classrooms are an extraordinary place to learn, not just to acquire knowledge, but to develop and cultivate moral ethos, such as respect, empathy, compassion, integrity, honesty or humbleness. But one teacher per class to work with 
almost thirty children, with several students with special needs among them, is not enough. It is not a problem with the characteristics or upbringing of children, is a difficulty that arises when the needs of the students exceeds what one person can solve at a time. The result is that sometimes children do not get all the help they need, no matter how hard the teacher tries to help all of them, and many teachers end up stressed or even frustrated, because they cannot help all of their students and parents do not always understand it and blame the teachers for many of the system's shortages and deficiencies. Investing in personal resources may be expensive for the system, but what is the cost of not investing in children's education? Nelson Mandela once said that "our children are our greatest treasure, because they are our future”. Yet, in the same way, it is an indispensable requirement that accommodations and adjustments are conducted by the different stakeholders.

Along with the advocacy of inclusive classrooms, it is advised to use one and the same classroom for English lessons. This enables teachers to vary activities according to the students' moods, and to have different thematic corners. Each corner could be used for a macro-structure, which may facilitate work for teachers and minimize waiting times between activities. It also gives teachers the resources to work with smaller groups of children if needed, that is to say, while some children are writing, teachers can provide some other children with individualized help, or monitor speaking activities. This is also beyond productive because teachers can easily access materials and games, and is cheaper than having to prepare materials for every single classroom they attend. Not to mention the fact that having the same classroom for English lessons permits having many examples of English writing and functional print, which reinforces awareness of the English language.

ADHD students are known for being inconsistent and careless, and for having difficulties to turn assignments on time, besides they generally have problems with organization. But they also have problems with their working memory, and it is hard for them to maintain their effort and to do activities that require planning, as is the case of many writing activities. To top it all, as a rule ADHD individuals have poor linguistic skills, which affects not only writing, but also listening, reading, and speaking. Teachers should be condescending and empathetic with ADHD students, because not only are 
they facing internal problems, but they also have to deal with lots of triggering facts that come with their dysfunction, like academic and social matters.

During our experience as teachers and throughout the development of this thesis we have found that most hyperkinetic students have problems following the readings or keeping in track during the lessons, as we almost always had to implement a strategy to help them to some extent. On the basis of that postulate, teaching English as a second language with ADHD students must be treated carefully. If children are distracted or miss some explanations, mistakes and difficulties are about to be encountered. Apart from the distraction during readings, ADHD students make mistakes when reading some words and interestingly mix up the pronunciation of words such as "how" and "why”. They have also issues understanding oral expressions, as they lack confidence and enough vocabulary to comprehend the entire message, plus they tend to get distracted during the communicative interaction, which does not help them to follow the entire process. In fact, instead of trying to get the idea of the discourse, the more difficulties they have to understand oral messages, the sooner they get distracted. It appears that those ADHD students with good music abilities possess good phonological awareness skills (sound level). Regarding writing expression, multiple difficulties can be encountered among hyperkinetic learners. They have organizing issues, with negative effects when it comes to planning an essay or organizing a writing activity. They tend to misspell words and letters and get confused with false friends (e.g. "library” and "book shop”). Many of them have also problems with grammar, which makes some writing activities quite defiant. Several hyperkinetic children have also poor vocabulary that not only affects the oral discourse, but the written one too. As for speaking, several factors affect their production. As a starter, their disorders in syntax and semantics have a direct effect over their speech. As if this were not enough, many ADHD individuals present pragmatic deficiencies, as it is frequent that they have problems to interact with others; in addition to metalinguistic issues, given that ADHD children normally do not understand figurative language, metaphors, ambiguity and many humorous or ironic statements. All of this make that hyperkinetic students have a hard time trying to communicate themselves orally, although they strive to chat.

Another noteworthy observation during our teaching experience is comorbidity in ADHD. Several students with whom we have worked present this, along with other 
disorders (i.e., learning disorder or problems with language). This must be taken into account when planning and carrying out activities, since many of them are not able to understand all the indications in a second language or do not yet possess the skills and abilities that are required to participate in games in which aspects of specific grammar are worked on. If it is not organized properly, instead of favouring these students, we can increase their frustration. One way to prevent this from happening may be working in small groups or in pairs. In such a way a child with ADD/ADHD would be grouped with a partner who does not have the dysfunction, thus avoiding having to expose himself/herself to the great group in activities or games that they do not dominate or that show the lack of skills that he/she has due to the disorder.

The planned sessions during this study focused on using successful strategies and practices, considering the ADHD children needs, and benefiting every single student, with or without ADHD, with the implementation. Instruction and modelling were used to teach English, demonstrate appropriate social behaviour, and to adjust disruptive conducts and bad habits during the lessons. Praising proper actions from students, working on texts or tales with a high moral content, talking about a problematic issue (making children respect themselves and turn taking), practicing relaxing exercises (doing yoga poses or stretches and breathing exercises to calm down) and using roleplaying to demonstrate proper language patterns and right conduct, were some of the applied techniques during the ESL lessons.

Throughout the first year, the simplifications of activities were worked on, and the TPR methodology activities were increased. Students with ADHD responded very well to the new procedures. Some cases also required contracts or positive reinforcements (candy, stickers, smile faces in the notebook ...). With some students it was enough to obtain a positive reinforcement only during a small period (adaptation period), to later consider their own learning as reinforcement or reward. As the students gained confidence and their self-esteem improved, the reinforcements were gradually retreated. On the other hand, there were students with whom at certain times (change of medication, readjustment of medications, times of growth, entry into adolescence, discussions at home ...), in which positive reinforcement was not enough. 
It is paramount that students who suffer from this disorder feel that we truly believe in them. Many of these children have self-esteem problems or low selfconfidence, which means that they do not believe they can acquire the achievements and knowledge of their classmates. It is our role as teachers to make them see that this is not the case. Being a teacher goes beyond the mere transmission of knowledge. We must work on concrete short-term objectives, so that ADHD learners are aware that achieving the goals is feasible. Giving them confidence and time is the key to students with ADHD to believe in themselves and re-hook in the classes.

The work on self-confidence made a big difference in the learning process and in the results obtained by students with ADD/ADHD in the English area, since some of these children have their self-esteem affected for the negative comments received, or for the sense of failure that some had for making more mistakes or needing more response time. The same happened when including relaxation techniques in the sessions. Sometimes, dedicating three to five minutes of relaxation at the beginning of the class or at the time when a conflict arises, makes the difference between being able to give a class or spending an hour trying to resolve the interruptions along the lesson. And, above all, it is very important to be aware that teachers are transmitters, not only of knowledge, but also of sensations, values, routines... If we go nervous to class, students will be nervous. If we enter calmed in a classroom and work on breathing and relaxation, we will generate a climate of calm.

At this point and as a final reflection, we must be aware that the educational practice is diverse. There are no absolute techniques. Each day is different and each student is different. Therefore, we must work with a wide variety of methodologies and we must be open to change. What has been found in the current study is the importance and enrichment offered by the practice of the strategies shown in this paper, not only for children who suffer from attention deficit (with or without hyperactivity), but for all the members that make up the groups with which we have worked. The realization of fun and motivating activities make all students enjoy the language classes, regardless of their individual level or the needs they present.

To conclude this thesis, we would like to remark that further investigations addressed to language acquisition and ADHD impairment are needed. The importance 
of discourse analysis in the language teaching context is increasingly gaining recognition between researchers. The analysis of classroom discourse, namely the interactions between teachers and students, can help teachers to enhance the communication between instructors and learners and, therefore, can help students to achieve their goals. So maybe a fruitful future investigation in the scope of discourse analysis and ADHD in the English as a second language class is the study of classroom discourse conversations between teachers and ADHD students in inclusive classrooms. It would be a brand new point of view in the English as a foreign language classrooms and it would definitely be favourable for ADHD learners. 


\section{Works cited}

The elaboration of the present project has been done by consulting several manuals, articles and on-line publications. The overall resources have been counselled to assay the researched areas.

The discussed references are the following:

Acevedo-Polakovich, I. D., Pugzles Lorch, E., and Milich, R. (2007): Comparing Television Use and Reading in Children With ADHD and Non-Referred Children Across Two Age Groups. MEDIA PSYCHOLOGY, 9, 447-472. Lawrence Erlbaum Associates, Inc. Retrieved from: https://www.researchgate.net/publication/239795932_Comparing_Television_U se and_Reading_in_Children_With_ADHD_and_Non-

Referred_Children_Across_Two_Age_Groups (Accessed 25 January, 2020)

Achenbach, T. M. (1991): Manual for the Child Behavior Checklist. Burlington: University of Vermont.

Achenbach, T. M. (2001): Child Behavior Checklist cross-informant version. Burlington: University of Vermont.

ADDitude Magazine (n.d.). [online]. Retrieved from: https://www.additudemag.com/ (Accessed 28 February, 2020)

ADHD Europe (n.d.). [online]. Retrieved from: https://www.adhdeurope.eu/ (Accessed 28 February, 2020)

ADHD Foundation (n.d.). [online]. Retrieved from: https://www.adhdfoundation.org.uk/ (Accessed 28 February, 2020)

Akarcay, S. (2012): Cuisenaire Rods: Pedagogical and Relational Instruments for Language Learning. SIT Digital Collections. Retrieved from: https://www.semanticscholar.org/paper/Cuisenaire-Rods\%3A-Pedagogical-andRelational-for-Akarcay/f18a1493bcbac121074fee01ff687c4243318b17 (Accessed 2 May, 2020)

Al-Azawi, R., Al-Faliti, F., and Al-Blushi, M. (2016): Educational Gamification Vs. Game Based Learning: Comparative Study. International Journal of Innovation, Management and Technology, Vol. 7, No. 4, pp. 132-136.

Allison. C. (1998): 365 Bedtime Stories. New York: Broadway Books. Alonso, P. (2014): A Multi-dimensional Approach to Discourse Coherence. From Standarness to Creativity. Bern: Peter Lang. 
Alves, F. (2015, October 3): T-Mobile Customer Service Call [Video]. Youtube.

Retrieved from: https://www.youtube.com/watch?v=h3XfI8rNGdE (Accessed 9 January, 2020)

American Academy of Pediatrics (2016). Media and Young Minds. Pediatrics, Volume 138 , number 5. Retrieved from:

https://pediatrics.aappublications.org/content/pediatrics/138/5/e20162591.full.pd f (Accessed 7 October, 2019)

American Psychiatric Association. (2013). Diagnostic and statistical manual of mental Disorders. Fifth edition. Arlington, VA: American Psychiatric Association Publishing.

Anastopoulos, A. D., and Farley, S. E. (2003): A Cognitive-Behavioral Training Program for Parents of Children with Attention-Deficit/Hyperactivity Disorder. In a Kazdin, A. \& Weisz, J. (Eds.) Evidence-based psychotherapies for children and adolescents. New York: Guilford Press.

Anastopoulos, A. D., Rhoads, L. H., and Farley, S. E. (2006): Counseling and Training Parents. In Barkley, R. A., Attention-Deficit Hyperactivity Disorder. A Handbook for Diagnosis and Treatment ( $3^{\text {rd }}$ ed.). New York: The Guilford Press.

APPUSERIES (2013, April 18): Yoga for Kids - Vol 1 (All Standing Postures)

[Video]. Retrieved from: https://www.youtube.com/watch?v=CITc2AxYnPY

(Accessed 19 February, 2015)

Araujo, E. e Izábal C. (2006): Trastorno por Déficit de Atención con Hiperactividad en la actualidad: Evaluación y Diagnóstico. Retrieved from: http://www.academia.edu/11395233/Trastorno_por_D\%C3\%A9ficit_de_Atenci \%C3\%B3n_con_Hiperactividad_en_la_actualidad_Evaluaci\%C3\%B3n_y_diagn \%C3\%B3stico (Accessed 9 January, 2017)

Arcia, E., Frank, R., Sánchez-LaCay, A., Fernández, M.C. (2000): Teacher understanding of ADHD as reflected in attributions and classroom strategies. Journal of Attention Disorders, Vol. 4, No. 2 (August 2000), 91-101.

ASANHI (n.d.). [online]. Retrieved from: http://www.asanhitdah.es/ (Accessed 28 February, 2020)

ASANHI (2017): Asanhi. [online]. Retrieved from: http://www.asanhitdah.es/2017/06/29/facyl-tdah-denuncia-que-alumnos-con- 
tdah-de-cyl-no-recibe-una-adecuada-atencion-educativa/ (Accessed 17 February, 2020)

Azadipour, S. (2019): Personality types and intercultural competence of foreign language learners in education context. Journal of Education and Health Promotion. Vol. 8, number 236. Retrieved from:

https://www.ncbi.nlm.nih.gov/pmc/articles/PMC6904958/ (Accessed 26 December, 2019)

Bader, A. and Adesman, A. (2015): Complementary and Alternative Medicine for ADHD. In Barkley, R. A. (ed.), Attention-Deficit Hyperactivity Disorder. A Handbook for Diagnosis \& Treatment. New York: The Guilford Press.

Bae, J. (2001): Cohesion and Coherence in Children's Written English: Immersion and English-only Classes. Issues in Applied Linguistics. Vol. 12. No. 1, pp. 51-88. Retrieved from: https://escholarship.org/uc/item/3hb2z0s4 (Accessed 20 November, 2019)

Bailey, E. (2019): Prior Knowledge Improves Reading Comprehension. ThoughtCo, Apr. 5, 2019. Retrieved from: https://www.thoughtco.com/prior-knowledgeimproves-reading-comprehension-3111202 (Accessed 6 December, 2019)

Barkley, R. A. (1991): Attention-deficit hyperactivity disorder. A clinical workbook. New York: Guilford Press.

Barkley, R. A. (1997): Behavioral Inhibition, Sustained Attention, and Executive Functions: Constructing a Unifying Theory of ADHD. Psychological Bulletin, 1997, Vol. 121, No 1, 65-94.

Barkley, R. A. (2013): Taking Charge of ADHD. The Complete, Authoritative Guide for Parents ( $3^{\text {rd }}$ ed.). New York: The Guilford Press.

Barkley, R. A. (2015): Attention-Deficit Hyperactivity Disorder. A Handbook for

Diagnosis \& Treatment. (4th ed.). New York: The Guilford Press.

Barkley, R. A. (2016): Managing ADHD in School: The Best Evidence-Based Methods for Teachers. Eau Claire: PESI Publishing \& Media.

Bas, G. (2008): Integrating Multiple Intelligences in ESL/EFL Classrooms. The Internet TESL Journal. Retrieved from: https://files.eric.ed.gov/fulltext/ED503869.pdf (Accessed 9 March, 2020)

Bas, G. (2009): Teaching of Weather Forecasts and Seasons by Multiple Intelligences in EFL/ESL Classrooms. Humanising Language Teaching, Issue 6. Retrieved from: https://old.hltmag.co.uk/dec09/less01.htm (Accessed 9 March, 2020) 
Bas, G. and Beyhan, O. (2010): Effects of Multiple Intelligences Supported ProjectBased Learning on Students’ Achievement Levels and Attitudes Towards English Lesson. International Electronic Journal of Elementary Education Vol. 2, Issue 3. Retrieved from: https://files.eric.ed.gov/fulltext/EJ1052017.pdf (Accessed 8 March, 2020)

Baxter, E. (2014): 50 Metaphor Examples for Kids. Retrieved from: https://blog.udemy.com/metaphor-examples-for-kids/ (Accessed 22 February, 2020)

Beare, N. (2010): Incredible English Kit 4. Teacher's Book. Oxford: Oxford University Press.

Bellani, M., Moretti A., Perlini C. and Brambilla P. (2011): Language disturbances in ADHD. Epidemiology and Psychiatric Sciences, $N^{\circ}$ 20, pp. 311.315.

Berman, M. (1998): A Multiple Intelligences Road to an ELT Classroom. Wales: Crown House Publishing Ltd.

Bhatia, V. (2002): Applied genre analysis: A multi-perspective model. Ibérica: Revista de la Asociación Europea de Lenguas para Fines Específicos (AELFE), ISSN 1139-7241, $N^{\circ}$. 4, 2002, pp. 3-19. Retrieved from: https://www.researchgate.net/publication/28185101_Applied_genre_analysis_A _multi-perspective_model (Accessed 19 February, 2020).

Bialystok, E., \& Ryan, E. (1985): Toward a Definition of Metalinguistic Skill. MerrillPalmer Quarterly, 31(3), 229-251. Retrieved from: www.jstor.org/stable/23086295 (Accessed 27 February, 2020)

Bialystok, E., Peets, K. F., \& Moreno, S. (2014). Producing bilinguals through immersion education: Development of metalinguistic awareness. Applied psycholinguistics, 35(1), 177-191. Retrieved from: https://www.ncbi.nlm.nih.gov/pmc/articles/PMC3987956/ (Accessed 27 February, 2020)

Birsh, J. R., (2018): Connecting Research and Practice. In Birsh, J. R. and Carreker, S. (Eds.) Multisensory Teaching of Basic Language Skills. $4^{\text {th }}$ Ed. Maryland: Paul H. Brookes Publishing Co.

Brewster, J., Ellis, G. and Girard, D. (2002): The Primary English Teacher's Guide. Harlow Essex: Pearson Education Limited in association with Penguin Books Ltd.

British Council Learn English Kids. Games (n.d.) [online]. Retrieved from: 
https://learnenglishkids.britishcouncil.org/games (Accessed 28 February, 2020)

British Council Learn English Kids. Word games. (n.d.) [online]. Retrieved from:

https://learnenglishkids.britishcouncil.org/word-games (Accessed 28 February, 2020)

Brouwer, I. (2011): Foreign Languages for Everyone. How I learned to teach Second Languages to Students with Learning Disabilities. Grand Rapids, Michigan: Edenridge Press.

Brown, G. and Yule, G. (1983): Discourse Analysis. Cambridge: Cambridge University Press.

Buenfil Burgos, R. N. (1991): Análisis de discurso y educación. Conferencia presentada en el Centro de Investigación Educativa de la Universidad de Guadalajara. DOC/DIE: 300:26 México, D.F., mayo de 1993. Retrieved from: https://www.researchgate.net/publication/315802040_Analisis_de_discurso_y_e ducacion (Accessed 6 November, 2019)

Bula Villalobos, O. (2011): Attention-Deficit Hyperactivity Disorder in the EFL Classroom: A Case Study. Innovaciones Educativas. Año XIII. $N^{\circ} 18$. Retrieved from: http://www.uned.ac.cr/ece/images/revista/numero\%2018\%202012/02Bula-Attention.pdf (Accessed 26 October 2014).

Cameron, D. (2001): Working with Spoken Discourse. London: SAGE Publications. Casajús Lacosta, A. M. (2011): Didáctica Escolar para Alumnos con Trastorno de Déficit de Atención con Hiperactividad (TDAH). $2^{a}$ ed. Barcelona: Horsori Editorial.

Chamot, A.U. (1995): Implementing the Cognitive Academic Language Learning Approach: CALLA in Arlington, Virginia. The Bilingual Research Journal, Vol. 19, Nos. 3 \& 4, pp. 379-394. Retrieved from: https://ncela.ed.gov/files/rcd/BE021100/Implementing_the_Cognitive.pdf (Accessed 31 October, 2019)

Celce-Murcia, M. and Olshtain, E. (2000): Discourse and content in language teaching: a guide for language teachers. Cambridge: Cambridge University Press.

Children and Adults with Attention-Deficit/Hyperactivity Disorder (n.d.). [online]. Retrieved from: https://chadd.org/ (Accessed 28 February, 2020)

Cohen, J. D. and Servan-Schreiber, D. (1992): The Stroop Revisited: A Meta-Analysis of Interference Control in AD/HD. Psychol. Rev. 99: 45-77.

Cohen, S., Harvey, D., Shields, R., Shields, G., Rashedi, R., Tancredi, D., Angkustsiri, 
K., Hansen, R., and Schweitzer, J. (2018): The Effects of Yoga on Attention; Impulsivity and Hyperactivity in Pre-School Age Children with ADHD Symptoms. J. Dev. Behav. Pediatr., 39(3): 200-209. Retrieved from: https://www.ncbi.nlm.nih.gov/pmc/articles/PMC5871620/pdf/nihms929231.pdf (Accessed 17 March, 2020)

Conners, C. K. (1989): Conners’ Rating Scales Manual. New York: Multi-Health Systems.

Conners, C. K. (1994): The Conners' Continuous Performance Test. Toronto: MultiHealth Systems.

Connor, D. F. (2015): Stimulant and Nonstimulant Medications for Childhood ADHD. In Barkley, R. A. (ed.), Attention-Deficit Hyperactivity Disorder. A Handbook for Diagnosis \& Treatment. New York: The Guilford Press.

Cook, B. G., Tankersley, M., and Landrum, T. J. (Eds.). (2012): Classroom Behavior, Contexts, and Interventions. Bingley: Emerald Group Publishing Limited.

Cook, G. (1989): Discourse. Oxford: Oxford University Press.

Cooper-Kahn J. and Foster M. (2013): Boosting Executive Skills in the Classroom. A Practical Guide for Educators. San Francisco, California: Jossey-Bass, a Wiley Imprint.

Cots, J. (2006): Teaching “with an attitude”: Critical discourse analysis in EFL teaching. ELT Journal, vol. 60:4, pp. 336-345.

Coulthard. M. (1985): An Introduction to Discourse Analysis. Second Edition. London and New York: Routledge.

Council of Europe (2004): My European English Portfolio. Spain: MECD (Ministry of Education, Culture and Sports. Retrieved from: http://redined.mecd.gob.es/xmlui/bitstream/handle/11162/143764/11557_19.pdf ?sequence $=1 \&$ isAllowed $=y$ (Accessed 30 March, 2020)

Crespo Allende, Nina, Jacqueline Elías Lillo y Begoña Góngora Costa (2012): El Desempeño Sintáctico en Niños con Trastorno de Déficit Atencional e Hiperactividad: Perspectiva Comparativa y Ontogenética. RLA. Revista de Lingüística Teórica y Aplicada. Concepción (Chile), 50 (1), I Sem. 2012, pp. 95 117.

Cruz, Jorge (2012, September 13): The Cranberries Zombie Official Video 720p HD 
[Video]. Youtube. Retrieved from:

https://www.youtube.com/watch?v=cWfZjV4i2Nk (Accessed on 10 January, 2020)

Davis, R. (2006): Utopia or Chaos? The impact of Technology on Language Teaching. The Internet TESL Journal, Vol. XII, No 11. Retrieved from: http://iteslj.org/Articles/Davis-ImpactOfTechnology.html (Accessed 28 July, 2020)

Deterding, S., Dixon, D., Khaled, R. and Nacke, L. (2011): From Game Design Elements to Gamefulness: Defining “Gamification”. Paper presented at the 15th International Academic MindTrek Conference, Tampere. Retrieved from: https://www.researchgate.net/publication/230854710_From_Game_Design_Ele ments_to_Gamefulness_Defining_Gamification (Accessed 28 July, 2020)

Distraction with Dr. Ned Hallowell (n.d.). [online]. Retrieved from: https://www.distractionpodcast.com/ (Accessed 28 February, 2020)

DuPaul, G. J. and Eckert, T. L. (1997): The Effects of School-based Interventions for Attention Deficit Hyperactivity Disorder: A Meta-Analysis. School Psychology Review, 1997, Vol. 26, No 1, pp. 5-27.

ESL: English as a Second Language. Free English Learning Resources (n.d.). [online]. Retrieved from: https://www.rong-chang.com/qa2/stories/story001.htm (Accessed 23 February, 2020)

ESL: English as a Second Language. Free English Learning Resources (n.d.). [online]. Retrieved from: https://www.rong-chang.com/qa2/stories/story011.htm (Accessed 23 February, 2020)

ESL Games (n.d.) [online]. Retrieved from: http://www.eslgamesworld.com/members/games/vocabulary/index.html (Accessed 28 February, 2020)

España. Consejería de Educación. Resolución de 17 de agosto de 2009, de la Dirección General de Planificación, Ordenación e Inspección Educativa, por la que se regula el artículo 72 de la Ley Orgánica de 2/2006, de 3 de Mayo. Boletín Oficial de Castilla y León, 26 de agosto de 2009, núm. 163, pp. 26108-26118. Retrieved from: http://bocyl.jcyl.es/boletines/2009/08/26/pdf/BOCYL-B26082009.pdf (Accessed 1 March, 2020)

España. Consejería de Educación. Orden EDU/1152/2010, de 3 de agosto, por la que se 
regula y desarrolla los aspectos relativos a la ordenación y a la organización de la respuesta educativa al alumnado con necesidad específica de apoyo educativo, bajo los principios de calidad y equidad educativa de la Ley Orgánica de 2/2006, de 3 de Mayo, de Educación. Boletín Oficial de Castilla y León, 13 de agosto de 2010, Núm. 156, pp. 64449-64469. Retrieved from:

http://bocyl.jcyl.es/boletines/2010/08/13/pdf/BOCYL-D-13082010-1.pdf

(Accessed 1 March, 2020)

Federación Española de Asociaciones de Ayuda al Déficit de Atención e

Hiperactividad (n.d.). [ONLINE]. Retrieved from: http://www.feaadah.org/es/

(Accessed 28 February, 2020)

Feingold, B. F. (1976): Hyperkinesis and Learning Disabilities Linked to the Ingestion of Artificial Food Colors and Flavors. Journal of Learning Disabilities, Volume 9, Number 9, November 1976, pp-551-559.

Fernández, D. (2014): Teaching and learning discourse analysis: some ideas on the use of ICTs. I Jornadas Iberoamericanas de Innovación educativa en el ámbito de las TIC. Las Palmas de Gran Canaria, 27-28 de Noviembre 2014. Retrieved from:

https://pdfs.semanticscholar.org/8c83/edfed352d94179fea1c7f6b36679a6085f72 .pdf (Accessed 27 December, 2019)

Forte, I. And Pangle, M. A., (2001): ESL Vocabulary and Word Usage. Games, Puzzles, and Inventive Exercises. Nashville, Tenessee: Incentive Publications, Inc.

Fundación Adana (n.d.). [online]. Retrieved from: https://www.fundacionadana.org/ (Accessed 28 February, 2020)

Fundación Cantabria Ayuda al Déficit de Atención e Hiperactividad (n.d.). [online] Retrieved from: https://www.fundacioncadah.org (Accessed 28 February, 2020) Games to Learn English (n.d.). [online]. Retrieved from: https://www.gamestolearnenglish.com/ (Accessed 28 February, 2020)

García Cruz, J. M. and González Lajas, J. J. (2016): Guía de Algoritmos en Pediatría de Atención Primaria. Trastorno por Déficit de Atención con Hiperactividad (TDAH). AEPap (online). Retrieved from: https://algoritmos.aepap.org/adjuntos/TDAH.pdf (Accessed 7 February, 2020)

García Escala, G. y Ramos Morales, C. (2012): Propuesta didáctica para niños con déficit atencional: estimulando el razonamiento analógico verbal para desarrollar la oralidad tardía. Estudios pedagógicos XXXVIII, $N^{\circ}$ 1: 131-148. 
García Peñas, J. J. y Domínguez Carral, J. (2012): ¿Existe un sobrediagnóstico del trastorno de déficit de atención e hiperactividad (TDAH)? Evid. Pediatr. 2012; 8:51.

Gardner, H. (1993): Frames of Mind: The Theory of Multiple Intelligencies ( $2^{\text {nd }}$ ed.). New York: Basic Books.

Gilpin, R. (2006): 50 Things to do on a journey. London: Usborne Publishing.

Glük, T. (1995): May you live in interesting times. Iowa: University of Iowa Press.

Gozal, D. and Molfese, D. (Eds.). (2005): Attention Deficit Hyperactivity Disorder: From Genes to Patients. Totowa, New Jersey: Humana Press Inc.

Grant, D. and Berg, E. (1948): The Wisconsin Card Sort Test: Directions for administration and scoring. Odessa: Psychological Assessment Resources.

Greathead, P. (n.d.): Language Disorders and Attention Deficit Hyperactivity Disorder. ADDISS. Retrieved from: http://www.addiss.co.uk/languagedisorders.htm (Accessed November 2016)

Greipl, S., Moeller, K. and Ninaus, M. (2020): Potential and Limits of Game-Based Learning. International Journal of Technology Enhanced Learning, Vol. 12, No. 4. Retrieved from: https://www.researchgate.net/publication/340478851_Potential_and_limits_of_g ame-based_learning (Accessed 5 August, 2020)

Groth-Marnat, G. (1990): Handbook of Psychological Assessment (2 ${ }^{\text {nd }}$ ed.). New York: Wiley.

Guaqueta, C. A. and Castro-Garces, A. Y. (2018): The Use of Language Learning Apps as a Didactic Tool for EFL Vocabulary Building. English Language Teaching, Vol. 11, No 2, pp. 61-71.

Guderjahn, L., Gold, A., Stadler, G., and Gawrilow, C. (2013): Self-Regulation Strategies Support Children with ADHD to Overcome Symptom-Related Behavior in the Classroom. ADHD Attention Deficit Hyperactivity Disorder, Vol. 5, No. 4, 397-407. Retrieved from: https://www.researchgate.net/publication/256985255_Selfregulation_strategies_support_children_with_ADHD_to_overcome_symptomrelated_behavior_in_the_classroom (Accessed on 20 February, 2020)

Haack, L. M., Villodas, M., McBurnett, K., Hinshaw, S. and Pfiffner, L. J. (2016): 
Parenting as a Mechanism of Change in Psychosocial Treatment for Youth with ADHD, Predominantly Inattentive Presentation. J. Abnorm. Child Psychol. 2017 Jul., 45(5), pp. 841-855.

Halliday, M. A. K. and Hasan, R. (1993): Cohesion in English. London and NY: Routledge.

Harmer, J. (2007): The Practice of English Teaching (4 ${ }^{\text {th }}$ ed.). Harlow: Longman.

Harris, Z. (1952): Discourse analysis. Language, vol. 28: 1, pp. 1-30.

Hernández, F.L. (2000): Los métodos de enseñanza de lenguas y las teorías de aprendizajes. Encuentro. Revista de investigación e innovación en la clase de idiomas, 11, pp. 141-153. Retrieved from:

https://ebuah.uah.es/dspace/bitstream/handle/10017/950/Los\%20M\%c3\%a9todo s\%20de\%20Ense\%c3\%b1anza\%20de\%20Lenguas\%20y\%20las\%20Teor\%c3\%a das\%20de\%20Aprendizaje.pdf?sequence=1\&isAllowed=y (Accessed 28 October, 2019)

Hobbs, J. R. (1982): Towards an Understanding of Coherence in Discourse. In Lehnert, W. G and Ringle, M. H. (eds.): Strategies for Natural Language Processing. New York and London: Psychology Press.

Howitt, S. (1810): The Fox and the Wild Boar [Image]. Retrieved from: http://www.ancestryimages.com/proddetail.php?prod=g3998 (Accessed 22 February, 2020)

Hvozdíková, S. (2011): Foreign Language Acquisition and ADHD Learners at Primary Level of Education. MVEK Prešov 2011. Katedra pedagogiky FHPV PU. Retrieved from: https://www.pulib.sk/web/kniznica/elpub/dokument/Istvan1/subor/Hvozdikova.p df (Accessed 23 March 2020)

Jarraya, S., Wagner, M., Jarraya, M., and Engel, F. (2019): 12 Weeks of KindergartenBased Yoga Practice Increases Visual Attention, Visual-Motor Precision and Decreases Behavior of Inattention and Hyperactivity in 5-Year-Old Children. Frontiers in Psychology, 10:796. Retrieved from: https://www.frontiersin.org/articles/10.3389/fpsyg.2019.00796/full?fbclid=IwA R32AeqnWbTgeT6USnr7tZvqVnPGq5J17YxYkJgguJMTnXuof6K6bLDjpHM (Accessed on 17 March, 2020) Johnson, A. (2019): As ice melts, the Inuit strive to keep their culture alive. National 
Geographic. Retrieved from:

https://www.nationalgeographic.com/culture/2019/07/inuit-share-traditionalknowledge-to-survive-melting-ice-feature/ (Accessed 2 December, 2019)

Johnson, J. and Reid, R. (2011): Overcoming Executive Function Deficits With Students With ADHD. Theory Into Practice, 50:61-67.

Kaufman, S. B. (2014): The Creative Gifts of ADHD. Retrieved from:

http://blogs.scientificamerican.com/beautiful-minds/2014/10/21/the-creativegifts-of-adhd/ (Accessed 17 February, 2018)

Kehler, A. (2001): Coherence, Reference, and the Theory of Grammar. Chicago: CSLI Publications.

Kewley, G. and Latham, P. (2008): 100 Ideas for Supporting Pupils with ADHD. London: Continuum International Publishing Group.

Lengel, T. and Kuczala, M. (2010): The Kinesthetic Classroom. Teaching and Learning Through Movement. U.S.A.: A joint publication with Corwin and RTC (Regional Training Center).

Lectures on ADHD by Russell A. Barkley, Ph.D. (n.d.). [online] Retrieved from: http://www.adhdlectures.com/ (Accessed 6 February, 2020)

Ley orgánica para la mejora de la calidad educativa (LOMCE) (Ley Orgánica 8/2013, 9 de diciembre). Boletín Oficial del Estado, $n^{\circ}$ 295, 2013, 10 diciembre. Retrieved from: https://www.boe.es/buscar/pdf/2013/BOE-A-2013-12886-consolidado.pdf (Accessed 23 March, 2017)

Liu, Z., Ahmed, Z. and Gazizova, F. (2020): Using the Concept of Game-Based Learning in Education. iJET, Vol. 15, No. 14. Retrieved from: https://www.researchgate.net/publication/343348919_Using the_Concept_of_G ame-Based_Learning_in_Education (Accessed 5 August, 2020)

Majko, A. (2017): Children with ADHD, Classroom Inclusive Programmes. European Journal of Social Sciences Studies. Vol. 2, Issue 1, pp. 10-26.

Mantis Libra (2018, February 11): Wonder - Ending Clip HD [Video]. Youtube. Retrieved from: https://www.youtube.com/watch?v=JBnh8BuUxHo\&feature=emb_logo (Accessed 9 January, 2020)

Martin, D. (2009): Language Disabilities in Cultural and Linguistic Diversity. Bristol: Multilingual Matters. 
McCarthy, L. F. (2019): How Does Behavior Therapy Work for Children? Retrieved from: http://www.additudemag.com/adhd/article/3577.html (Accessed 2 February, 2020)

McCarthy, M. (1991): Discourse Analysis for Language Teachers. Cambridge: Cambridge University Press.

Miller, A. (n.d.): 9 Factors that Influence Language Learning. Retrieved from: https://www.whitbyschool.org/passionforlearning/9-factors-that-influencelanguage-learning (Accessed 26 December, 2019)

Miller, C. J. (2007): Television Viewing and Risk for Attention Problems in Preschool Children. Journal of Pediatric Psychology 32(4) pp. 448-452, 2007.

Miranda-Casas, A., A. Ygual-Fernández y J. Rosel-Remirez. (2004): Complejidad Gramatical y Mecanismos de Cohesión en la Pragmática Comunicativa con Niños con Trastorno por Déficit de Atención con Hiperactividad. Revista de Neurología; 38 (Supl. 1), pp. 111-116.

Mohamed, I. and Gumaa, A. (2013): The Role of Background Knowledge in Enhancing Reading Comprehension. World Journal of English Language. Vol. 3, No. 4. Retrieved from: https://www.researchgate.net/publication/276417360_The_Role_of_Background _Knowledge_in_Enhancing_Reading_Comprehension (Accessed 6 December, 2019)

Monschein, M. (2008): The 50 best games for speech \& language development. Buckingham: Hinton House Publishers Ltd.

Mowlem, F. D., Rosenqvist, M., Martin, J., Lichtenstein, P., Asherson, P., and Larsson, H. (2019): Sex differences in predicting ADHD clinical diagnosis and pharmacological treatment. European Child and Adolescent Psychiatry. Vol. 28, Issue 4, pp. 481-489. Retrieved from: https://link.springer.com/article/10.1007\%2Fs00787-018-1211-3\#citeas (Accessed 29 January, 2020)

My Treasury of Nursery Rhymes (2008). Sywell: Igloo Books Ltd.

Mulraney, M., Stringaris, A., and Taylor, E. (2018): Irritability, disruptive mood, and ADHD. In a Banaschewski et al. (eds.), Oxford Textbook of Attention Deficit Hyperactivity Disorder. United Kingdom: Oxford University Press. Muñoz-Silva, A., Lago-Urbano, R., Sánchez-García, M., and Carmona-Márquez, J. 
(2017): Child/Adolescents' ADHD and Parenting Stress: The Mediating Role of Family Impact and Conduct Problems. Frontiers in Psychology 2017, vol. 8:2252. Retrieved from: https://www.ncbi.nlm.nih.gov/pmc/articles/PMC5744077/ (Accessed 29 January, 2020)

Nunan, D. (1993): Introducing Discourse Analysis. London: Penguin Group.

Olshtain, E. and Celce-Murcia, M. (2005): Discourse Analysis and Language Teaching. Oxford: Blackwell Publishers Ltd.

Orjales, I. (2005). Estrategias para la mejora de la conducta y el rendimiento escolar del niño con TDAH en el aula. Madrid: Esquema de Comunicación S.A. Retrieved from: https://www.fundacioncadah.org/web/doc/index.html?id_doc=92 (Accessed 10 April, 2017)

Orjales, I. (2007): El tratamiento cognitivo en niños con trastorno por déficit de atención con hiperactividad (DAH): revisión y nuevas aportaciones. Annuary of Clinical and Health Psychology, 3, pp. 19-30.

Oxley, C. and Stringaris, A. (2018): Comorbidity. Depression and anxiety. In Banaschewski et al. (eds.), Oxford Textbook of Attention Deficit Hyperactivity Disorder. United Kingdom: Oxford University Press.

Pavlygina, R. A., Frolov, M. V., Davydov, V. I., and Milovanova, G. (1999): Recognition of visual images in a rich sensory environment: Musical accompaniment. Neuroscience and Behavioral Physiology. 29(2): 197-204. Retrieved from: https://www.ncbi.nlm.nih.gov/pubmed/10432509 (Accessed 19 September, 2019)

Pelsser, L. M., Frankena, K., Toorman, J., and Rodrigues Pereira, R. (2017): Diet and ADHD, Reviewing the Evidence: A Systematic Review of Meta-Analyses of Double-Blind Placebo-Controlled Trials Evaluating the Efficacy of Diet Interventions on the Behavior of Children with ADHD. PLoS ONE, 12 (1): e0169277. Retrieved from: https://pdfs.semanticscholar.org/fef7/e24582f2a6594df89d1e81fac0e71c6a34ae. pdf?_ga=2.51554345.1245729296.1581262729-1724572912.1581262729

(Accessed 9 February, 2020)

Philipps, S. and Redpath, P. (2010): Incredible English Kit. Class Book 5 (2 ${ }^{\text {nd }}$ ed.). Oxford: Oxford University Press. 
Philipps, S. and Redpath, P. (2010): Incredible English Kit. Class Book 6 (2 ${ }^{\text {nd }}$ ed.). Oxford: Oxford University Press.

Philipps, S. and Redpath, P. (2010): Incredible English Kit. Activity Book 6 (2 ${ }^{\text {nd }}$ ed.). Oxford: Oxford University Press.

Pfiffner, L. J., Yee Mikami, A., Huang-Pollock, C., Easterlin, B., Zalecki, C., and McBurnett, K. (2007): A Randomized, Controlled Trial of Integrated HomeSchool Behavioral Treatment for ADHD, Predominantly Inattentive Type. Journal of American Academy of Child and Adolescent Psychiatry. 2007 Aug., 46 (8), pp. 1041-1050.

Pfiffner, L. J. And DuPaul, G. J. (2015): Treatment of ADHD in School Settings. In Barkley, R. A. (ed.), Attention-Deficit Hyperactivity Disorder. A Handbook for Diagnosis \& Treatment. New York: The Guilford Press.

Portes Barroso, C.C. (2018): La experiencia de un programa de yoga y meditación para estudiantes de primaria con TDAH (Doctoral dissertation). Retrieved from: https://tdx.cat/handle/10803/665927\# (Accessed 17 March, 2020)

Quintero Gutiérrez del Álamo F.J. y García Campos N. (2019). Actualización en el manejo del TDAH. En: AEPap (ed.). Congreso de Actualización Pediatría 2019. Madrid: Lúa Ediciones 3.0; 2019. p. 29-36. Retrieved from: https://www.aepap.org/sites/default/files/pags._2936_actualizacion_en_el_manejo_del_tdah.pdf (Accessed 10 October, 2019)

Richards, J. C. (2008): Teaching Listening and Speaking. From Theory to Practice. New York: Cambridge University Press.

Reid, R., Trout, A. L., and Schartz, M. (2005): Self-Regulation Interventions for Children With Attention Deficit/Hyperactivity Disorder. Exceptional Children, Vol. 71, No. 4, pp. 361-377. Retrieved from: https://www.miottawa.org/Health/CMH/pdf/brains/Attention\%20and\%20Execut ive\%20Function/ADHD\%20Resources/Self-Regulation\%20Interventions.pdf (Accessed 29 February, 2020)

Reynolds, C. and Kamphaus, R. (2004): Behavioral Assessment System for Children-2 ( $2^{\text {nd }}$ edition). Circle Pines, MN: American Guidance Service.

Richards, J. C. and Rodgers (2003): Enfoques y métodos en la enseñanza de idiomas. Segunda edición. Cambridge: Cambridge University Press.

Rief, S. F. (2005): How to Reach and Teach Children with ADD/ADHD. Practical 
Techniques, Strategies, and Interventions. Second Edition. San Francisco, California: Jossey-Bass, a Wiley Imprint.

Rinvolucri, M. (1984): Grammar Games: Cognitive, affective and drama activities for EFL students. Cambridge: Cambridge University Press.

Rinvolucri, M. and Davis, P. (1995): More Grammar Games: Cognitive, affective and movement activities for EFL students. Cambridge: Cambridge University Press.

Rothenberger, A., Roessner, V., Banaschewski, T. and Leckman, J. F. (2007): Coexistence of tic disorders and attention-deficit/hyperactivity disorder: Recent advances in understanding and treatment. European Child and Adolescent Psychiatry, 16 (Suppl. 1), 1-4.

Rowland, J. L. (2007): Closed-Captioned Video and the ESL Classroom: A MultiSensory Approach. MPAEA Journal of Adult Education Volume XXXVI, Number 2. Retrieved from: https://files.eric.ed.gov/fulltext/EJ891068.pdf (Accessed 4 November, 2019)

Rymes, B. (2016): Classroom Discourse Analysis. A tool for Critical Reflection. Second Edition. New York: Routledge.

R3n1.L (2013, September 27): Learn English ESL Irregular Verbs Grammar Rap Song! StickStuckStuck with Fluency MC! [Video]. YouTube. Retrieved from: https://www.youtube.com/watch?v=gZzKe1BC2XU (Accessed 14 March, 2020)

Saint-Exúpery, A. (2004): El Principito.10ª ed. México: Editores Mexicanos Unidos, S.A.

Schiffrin, D. , Tannen, D. and Hamilton, H. E. (eds.) (2001): The Handbook of Discourse Analysis. Oxford: Blackwell Publishers.

Serjev, I. (2009): Discourse Analysis in EFL Reading. Malmö högskola. Retrieved from: http://dspace.mah.se/bitstream/handle/2043/8453/Sergej\%20Ivanov\%20degree\% 20project.pdf?sequenc (Accessed 10 July, 2014)

Snow, M. A. (2017): Content-Based Language Teaching and Academic Language Development. In a Hinkel, E. (ed.): Handbook of Research in Second Language Teaching and Learning. Volume III. New York: Routledge.

Soutullo, C., Alda, J. A., Bobes, J., Bonet, T., Cardo, E., Casas, M., et al. (2013): El TDAH en España. Propuestas estratégicas. Plan de Acción en TDAH PANDAH. Spain: Adelphi.

Swanson, J. (1992): School-based assessments and interventions for ADD students. 
Irvine: K. C. Publishing

Tamana, S. K., Ezeugwu, V., Chikuma, J., Lefebvre, D. L., Azad, M. B., Moraes, T. J., et al. (2019): Screen-time is associated with inattention problems in preschoolers: Results from the CHILD birth cohort study. PLOS ONE 14(4): e0213995.

Taylor, E. et al. (2004): European clinical guidelines for hyperkinetic disorder- first Upgrade. European Child \& Adolescent Psychiatry, Vol. 13, Supplement 1: 1/7$1 / 30$.

TDAH y Tú (n.d.). [online]. Retrieved from: http://www.tdahytu.es/ (Accessed 28 February, 2020)

Turketi, N. (2010): Teaching English to Children With ADHD. MA TESOL Collection. 483. Retrieved from: http://digitalcollections.sit.edu/ipp_collection/483 (Accessed 25 October 2014)

UNESCO (1994): World Conference on Special Needs Education: Access and Quality. Salamanca: UNESCO. Retrieved from: https://unesdoc.unesco.org/ark:/48223/pf0000098427 (Accessed 18 February, 2020).

Van Dijk, T. (1997): Discourse as social interaction. London, Thousand Oaks, New Delhi: SAGE Publications.

Van Zile, S. (2003): Awesome Hands-on Activities for Teaching Grammar. New York: Scholastic.

Vaquerizo-Madrid, J., Estévez-Díaz, F. y Pozo-García, A. (2005): El Lenguaje en el Trastorno por Déficit de Atención con Hiperactividad: Competencias Narrativas. Rev. Neurol.; No 41 (Supl. 1): S83-S89.

Wallace, Catherine (1998): Critical language awareness in the foreign language classroom. Thesis for the degree of Doctor of Philosophy. Institute of Education. University of London. Retrieved from: https://discovery.ucl.ac.uk/id/eprint/10007455/8/Wallace,\%20Catherine_Redact ed.pdf (Accessed 25 October, 2019)

Wallace, Catherine (2003): Critical reading in language education. New York: Palgrave Macmillan.

Wehmeier, P. M., Schacht, A., and Barkley, R. A. (2010): Social and Emotional Impairment in Children and Adolescents with ADHD and the Impact on Quality of Life. Journal of Adolescent Health, 46 (2010), pp. 209-217. 
Wilens, T., Carrellas, N., and Biederman, J. (2018): ADHD and substance misuse. In Banaschewski et al. (eds.), Oxford Textbook of Attention Deficit Hyperactivity Disorder. United Kingdom: Oxford University Press.

Wilkes-Gillan, S., Munro, N., Cordier, R., Cantrill, A., and Pearce, W. (2017):

Pragmatic Language Outcomes of Children With Attention Deficit Hyperactivity Disorder After Therapist and Parent-Delivered Play-Based Interventions: Two One-Group Pretest-Posttest Studies With Longitudinal Component. The American Journal of Occupational Therapy, July/August 2017, Volume 71, Number 4. Retrieved from: http://www.terapeutasocupacionales.es/assets/files/COPTOA/Bibliotecavirtual/AJOT/JulioAgosto\%202017/7104220030p1.pdf (Accessed 26 March 2020)

Wood, L. A. and Kroger, R. O. (2000): Doing Discourse Analysis. Methods for Studying Action in Talk and Text. California: Sage Publications Inc.

Word Games - MindGames.com (n.d.). [online] Retrieved from: https://www.mindgames.com/Word+Games (Accessed 28 February, 2020) Wordreference (2020). [online]. Retrieved from: https://www.wordreference.com/ (Accessed 10 January, 2020)

Yee Mikami, A. (2015): Social Skills Training for Youth with ADHD. In a Barkley, R. A. (ed.), Attention-Deficit Hyperactivity Disorder. A Handbook for Diagnosis \& Treatment. New York: The Guilford Press.

Zúñiga Vargas, J. P. (2015): Listening Cloze Meets Info-Gap: A Hybrid Activity to Exploit Listening Materials. English Teaching Forum, V. 53, $N^{\circ}$ 4, pp. 24-32. Retrieved from: https://www.researchgate.net/publication/328875892_Listening_Cloze_Meets_I nfo-Gap_A_Hybrid_Activity_to_Exploit_Listening_Materials (Accessed 4 March, 2020) 